\title{
Cognition enhancing drugs : cholinergic function and age-related decline
}

Citation for published version (APA):

Riedel, W. J. (1995). Cognition enhancing drugs : cholinergic function and age-related decline. [Doctoral Thesis, Maastricht University]. NeuroPsych Publishers. https://doi.org/10.26481/dis.19951117wr

Document status and date:

Published: 01/01/1995

DOI:

10.26481/dis.19951117wr

Document Version:

Publisher's PDF, also known as Version of record

\section{Please check the document version of this publication:}

- A submitted manuscript is the version of the article upon submission and before peer-review. There can be important differences between the submitted version and the official published version of record.

People interested in the research are advised to contact the author for the final version of the publication, or visit the DOI to the publisher's website.

- The final author version and the galley proof are versions of the publication after peer review.

- The final published version features the final layout of the paper including the volume, issue and page numbers.

Link to publication

\footnotetext{
General rights rights.

- You may freely distribute the URL identifying the publication in the public portal. please follow below link for the End User Agreement:

www.umlib.nl/taverne-license

Take down policy

If you believe that this document breaches copyright please contact us at:

repository@maastrichtuniversity.nl

providing details and we will investigate your claim.
}

Copyright and moral rights for the publications made accessible in the public portal are retained by the authors and/or other copyright owners and it is a condition of accessing publications that users recognise and abide by the legal requirements associated with these

- Users may download and print one copy of any publication from the public portal for the purpose of private study or research.

- You may not further distribute the material or use it for any profit-making activity or commercial gain

If the publication is distributed under the terms of Article $25 \mathrm{fa}$ of the Dutch Copyright Act, indicated by the "Taverne" license above, 


\section{COGNITION ENHANCING DRUGS,}

Cholinergic Function and Age-Related Decline 
(1) W. Riedel, Matastricht 1995

Production: Datawyse | Universicy Press Maastriche

Riedel, Willem Jan

Cognicion Emhancing Drugs, Cholinergic Function and Age-Rclated Deeline / Willem Jan Riedel. - Maastricht Neuropsych Publishers Maastricht. - llil.

$15 B N \quad 90-75579-02-0$

NUGI 744,746

Neuropsych Publishers is a non-profit organizarion which aims at promoting the science of "Brain \& Bchaviour" and improving the application of the products of this scicnce in health care and education. Neturopsych Publishers accomplishes these ams by publisting books, disscrtations and other products of scientific activity, dissemination of educational matcrials and publication of tests, asscessment scalcs and other psychometric irstruments in the field of Neuropsychology, Neuropsychiatry and other areas within the domain of Brain \& Belaviour.

Postal address;

Neuropsych Publishers

Departmente of Psychiary \& Neuropsychology

Section Neuropsychology, Neuropsychiatryn and Psychobiology

Universiry of limburg

$\mathrm{PO}$ Box 616

NL-6200 MD Mastricht

"p"the Notherlands

The author wishes to thank the following companies for their financial support for the publication of this thesis: Servier R\&D Benelux, UCB Pharma, Lundbeck, Eli-Lilly, Astra Pharmaceutica, Janssen-Cilag, Bristol-Myers Squibb, Ciba-Geigy, Bayer, Searle Nederland, Hoechst Roussel 


\section{COGNITION ENHANCING DRUGS,}

\section{Cholinergic Function and Age-Related Decline}

\section{PROEFSCHRIFT}

ter verkrijging van de graad van doctor aan de

Rijksuniversiteit Limburg te Maastricht, op gezag van de Rector Magnificus, Prof. Mr. M. J. Cohen, volgens het besluit van het College van Dekanen, in het openbaar te verdedigen op vrijdag 17 november 1995 om 12.00 uur

door

Willem Jan Riedel

geboren op 22 maart 1956 te Groningen 
Promotor:

Prof. Dr. J. Jolles

Beoordelingscommissie: Prof. Dr. H.M. van Prag (Voortiter)

Prof. Dr. J.E. Hueting (Emeritus Hoogleraar Vrije Universiteit Brussel)

Dr. J.F. O'Hanlon

Prof. Dr. J.F. Orlebeke (Vrije Universiteit Amsterdam)

Prof. Dr. H.A.J. Strusylker-Boudier

The studies described in this thesis were carried out at the Maastricht Brain \& Behavior Institute, the Department of Psychiatry \& Neuropsychology and the Institute for Human Psychopharmacology of the University of Limburg and University Hospital Maastricht. 


\section{Table of Contents}

Prologue 7

Part I Cognitive Aging $/ I$

1. Cognitive Impairment in Elderly People: Predisposing Factors and Implications for Drug Therapy II

Abstract 11

1.1. Introduction 12

1.2. Cognitive Aging in Healthy Subjects 12

1.3. Pathological Cognitive Aging: Concepts and Diagnostic Criterion 16

1.4. Behavioral and Noncognitive Dysfunctions in Borderline States 21

1.5. Implications for Drug Therapy 23

1.6. Concluding Remarks 27

2. Memory Scanning, Automatic Processing and Focussed Attention in AAMI 35

$$
\text { Abstract } 35
$$

2.1. Introduction 36

2.2. Method 37

2.3. Results 38

2.4. Discussion 40

3. The Scopolamine Model of Cholinergic Depletion: Model of Memory Dysfunction? 43
Abstract 43
3.1. Introduction 44
3.2. Material and Methods 45
3.3. Results 50
3.4. Discussion 57

Part II Cognirion Enhancing Drugs 63

4. Cognition Enhancers in Age-Related Cognitive Decline 63
Abstract 63
4.1. Introduction 64
4.2. Subjects and Experimental Models 65
4.3. Dependent Variables in Experiments and Clinical Trials 67
4.4. An Overview of Cognition Enhancers in Acute and Repeared Dose Studies 69
4.5. Discussion 80
4.6. Concluding Remarks 85 


\section{CONTHNTS}

5. The Infuerce of Piracetam on Actual Driving Behawiour and Postural Stability of Elderly Subjects 95

$\begin{array}{ll} & \text { Abstract 95 } \\ \text { 5.1. Introduction } 96 \\ \text { 5.2. Method } 97 \\ \text { 5.3. Results 101 } \\ \text { 5.4. Discussion } 106\end{array}$

6. Caffeine Attenuates Scopolamine-Induced Memory Impairment in Humans 109 Abstract 109

6.1. Introduction 110

6.2. Material and Methods 110

6.3. Results 115

6.4. Discussion 121

Part III Antidepressants and Cognition 125

7. Avoiding and Managing Anticholinergic Effects of Antidepressants 125

$$
\text { Abstract } 125
$$

7.1. Pharmacological Effects of Antidepressants 126

7.2. Overview of Anticholinergic Effects 128

7.3. Peripheral Anticholinergic Effects 128

7.4. Central Anticholinergic Effects 129

7.5. Antidepressant Treatment Strategies with Particular Reference to Anticholinergic Effects 133

7.6. Discussion and Conclusion 135

8. The In Auence of Trazodone Treatment on Cognitiwe Funcrions in Outpacients with Major Depressive Disorder 141
Abstract 141
8.1. Introduction 142
8.2. Method 142
8.3. Results 145
8.4. Discussion 147

$$
\text { Epilogue } 151
$$

Samenvatring 155

Dankwoord 161

Curriculum Vitae 163 


\section{PROLOGUE}

\section{The prychopharmacological and the cognitive rewollation}

Attempts to improve the cognitive functions of the human brain, such as alertness, attention, comprehension and memory, by means of substances which acr according to pharmacological mechanisms, are as old as mankind [15]. Many natural subsrances derived from plants (e.g. caffeine, nicotine) and herbs (e.g. ginkgo biloba) have existed since centuries and are still investigated today to answer the question whether they improve cognitive functions in man. Only in the last 30 years, pharmaceutical compounds were synthesized with the specific aim to improve human cognitive functions. The first generation of these compounds were called nootropic drugs [9]. The meaning of the term referred to the trophic, or positive, action that these drugs would exert selectively on the so-called noetic functions of the brain (noös=mind): thinking, comprehending, remembering, etc. A more recent definition of nootropics was described as: "drugs intended to improve attention, cognition and memory in patients suffering from symptoms of dementia" [1]. Today, the term nootropics has been replaced by the term cognition enhancers or cognitive enhancers 18,12$]$. The meaning of this term is roughly the same, but is less pretentious as that of the nootropics, since they are not as sharply restricted to higher brain functions, but are defined in terms of their effect: they should enhance human performance in everyday tasks requiring efficient and speedy cognitive functioning [10, 14].

This recent psychopharmacological revolution [10] seems to parallel changes in the demands that modern society puts upon the human mental capacities and the way in which experimental psychology has contributed to these: the cognitive revolution [6]. Particularly in the latter 30 years a situation, in which few people drove a car and even less had ever operated a compurer, has evolved into one of world wide webs of concrete and electronic highways where most working. people are seated, relatively speaking, in a state of physical rest, either while operaring a car or a personal computer or while engaged in some form of communication. The common denominator of this development is that human (work) activities have become more and more abstract and symbolic, the pace has increased, and hence while pliysical work demands have declined, demands on intellectual, cognitive and psychomotor abilities have been raised. Successful survivors to these environmental changes must adapt to high mental workloads and be able to selectively attend and ignore multiple sources of information. Interesting field obserwations can everyday be made in traffic where car drivers can be observed who operate through heavy traffic while making a phone call [3]. Can these people adequately communicate and remember the information that is forwarded to them via the telephone while at the same time operating their vehicle safely through traffic? It is evident that the highest demands can not be met by all people. The most vulnerable subgroup to fall victim to the cognitive revolution are the elderly 151. Many of society's latest products, such as the remote control of audio and video equipment, can not be adequarely operated by an average person over 60 years of age. But also many young healthy people never manage to fully comprehend the operating manual of a personal computer or a video recorder.

The victims of the cognitive revolution, but perhaps also of a prolonged lifespan in combination with a declining cognitive capacity, are those who experience cognitive deficits [17]. Age-related cognitive decline, bur also depression and dysthymia are diagnoses that provide the two mainstreams of cognitive deficient patients in the neuropsychological (memory) dinic. Although 
these two both present with cognitive complaints, they reflect the expression of differently deficient pharmacological dimensions which may be restored therapeutically. The best known hyporhesi: explaining age-related cognitive decline is that of dysfunction of cholinergic neurotransmission [2], whereas the monoamine hypotheses of depression implies dysfunctions of dopaminergic, serotonergic, and/or noradrenergic neurotransmission $[7,11,13]$. Hence, two different hypothesis pertinent to two different diagnoses, both predict cognitive improvement as a result of the appropriate pharmacotherapy.

When patients present to a health care facility, a general practitioner, a neurologist, psychiarrist, or a specialized memory clinic, with cognirive complaints only, no established pharmacological treatment can be offered. Participation in clinical trials allowing the administration of investigational drugs, putative cognition enhancers, for which there is an overwhelming demand from patients, is the only possibility. Until now, the results obtained with investigational cognitive enhancing drugs have been disappointing, but at the same time, the amount of new investigational cognition enhancers is overwhelming and hence much research as to the testing of new cognition enhancers needs to be done [4]. When depression or dysthymia is accompanied with cognitive complaints, antidepressant treatment may provide relief of cognitive dysfunction and complaints, but may also present complications in terms of additional cognitive impairment frequently induced by antidepressant drugs [16].

\section{Aims and outline of this thesis}

The core theme of this thesis constitures the pharmacological treatment of cognitive dysfunction. Such a theme can not be addressed in isolation, however. Therefore, the next chapters are organized in three parts. Each part opens with a review of the literature (chapters 1, 4 and 7), whereas the other chapters present the results of empirical studies. The first part, COGNITTVE AGING, consists of three chapters in which the nature of age-related cognitive decline is the central theme. The second part, COGNI"ION ENHANCING DRUGS, consists of three chapters in which the putative cognition enhancing effects of psychoactive substances comprise the central theme. The third part, ANTIDEPRESSANTS AND COGNITION, consists of two chapters in which the cognitive impairing and improving effects of antidepressants play a major role. The main findings and the possible implications of the above-mentioned studies are discussed in the epilogue.

The main questions addressed in this thesis are:

\section{Is age-related agnitive dedine a dinical entity and can it be treated pharmacologically?}

In chapter 1, the nature of human age-related cognitive decline and the effect of age on cognitive function are reviewed and put into the perspecrive of normal and pathological cognitive aging, depression, and dementia. The chaprer concludes with recommendations for the drug treatment of cognitive dysfunctions.

\section{Do mewory complaints in elderly people contribute to cognitive dysfunction in aging?}

In chapter 2, the memory-specificity of age-2ssociated memory impairment is questioned by means of a study on the impact of memory complaints on the cognitive performance of elderly people as compared to non-complaining elderly.

\section{Does cholinergic blockade induced by scopolamine resemble age-related cognitive decline?}

In chapter 3, a study on the effecrs of scopolamine, a pharmacological model of aging, on cognitiwe function in young healthy volunteers, as compared to the effects of aging, is described. 
Changes in cognirive performance, experimentally induced by means of pharmacological blockade of acerylcholine neurotransmission in young healthy volunteers, are compared to changes in cognitive performance as a function of aging. The hypothesis that scopolamine mimics the effect of aging on cognition by reducing the general avalability of cognitive resources is discussed.

\section{Do cognition enhancers enhance cognition and how do they work?}

In chapter 4, a review is presented of the results of all experimental and dinical studies on the effects of many different cognition enhancers in non-demented humans, which were published in the last 5 years. Distinctions are made between cognition enhancers representing different pharmacological modes of action, results obtained in clinical trials versus experimental studies, studies employing acute doses versus repeated doses of cognition enhancers, and between studies in elderly people with cognitive decline versus studies employing experimental models of cognitive dysfunction in healthy volunteers.

\section{Does piracetam improve deficient car drining behaviour in elderly people?}

In chapter 5, a double-blind, placebo-controlled, cross-over study on the influence of piracetam, the first drug ever proposed as a cognition enhancer, on the performance of 38 deficient driving elderly on two tests of car driving in actual traffic, is described.

\section{Do caffeine and nicotine reverse the scopolamine-induced cognitive dysfuncrion?}

In chapter 6, a study is described in which the scopolamine model of cognitive dysfunction is applied to study, according to a double-blind, placebo-controlled, cross-over design, the effects of two of the worlds most widely used putative cognition enhancers, caffeine and nicotine, on memory and cognition.

\section{Can antichalinergic cognitwe impairing effects of antidepressants be awoided or managed?}

In chapter 7 , the impact of adverse anticholinergic effects of antidepressants are discussed and ways to avoid or control them. While depression is often accompanied by cognitive dysfunction, or may even be caused by it, the most frequently prescribed antidepressants are still those with anticholinergic side-effects. These anticholinergic antidepressants' most typical infuence on cognition is that of imparing cognition, particularly memory. This apparent paradox may lead to the situation that pharmacological treatment of one psychopathology, depression, is replaced by another, pseudo-dementia. Recommendations as to the prevention of this problem, which is particularly prevalent in elderly patients, are described.

\section{Does trazodone treatment impair or improve cognitive function in patients with major depression?}

In chapter 8, a study on the effects of a 5 -week single-blind treatment with trazodone, the first antidepressant without any anticholinergic effecrs, preceded and followed by placebo. on cognitive functions in patients with major depression is described.

The epilogue concludes this thesis with a general discussion of the various findings and concluding remarks. 


\section{REFERENCES}

1. Mrraducei $L_{\text {th }}$ Angat $J$, Bech $P$, ex al. Consensws Conference on the Methodology of Clinical Trials of

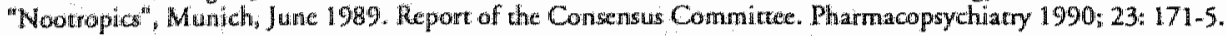

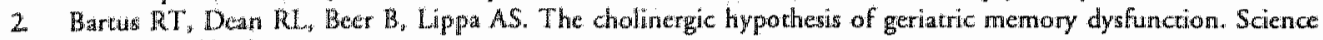
$1982 \times 217: 408-417$.

3. Brookhuis $K A, D e$ Vries $G$, De Ward D. The effects of mobile telephoning on driwing performance. Accident Analysis and Prevention $1991 ; 23: 309316$.

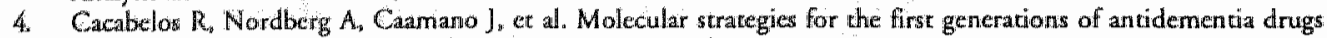
(1). Therine and related compounds. Drugs of Today 1994: 30: 295-337.

5. Cerella. J. Rybash J, Hoyer W, Commons MA. Adult Information Processinga Limits on Loss. San Diego: Academic Press Inc 1993.

6. Jistenga LKA, Wan Rappand JFH. Hoofdstromen en mensbeelden in de psychologic. Amsterdam: Boom, 1987.

7. Pritwe J. Deckert $M$, Lancik M. Strik W. Struck M, Wodar. N. Current status of the amine hypotheses on depression. Nervenarzt $1992 ; 63: 3-13$.

8. Jrost W. Matre L. The families of cognition enlancers. Phamacopsychiatry 1989; 2: 54-100.

9. Ciurgea Cl. Vers une pharmacologie de l'activite integracive du cerveau. Accual Pharmacologie 1972; 25: 115157 .

10. Hollister LE. Problems in the search for cognition enhancers. Pharmacopsychiatry 1990; 2: 33-6.

11. Mclecer H. Stroconergic dysfunction in depression. Br J Psychiatry Suppl 1989; 155 (Suppl 8): 25-31.

12. Porsolt RD. Strategics in Psychopharmacalogy: Cognition Enhancers - From Animals to Man: Preface. Pharmacoputhehitury 1990; $23: 29-30$.

13. Richelison E. Biological basis of depression and therapeutic relewance. J Clin Psychiatry 1991; 52 (Supp):4-10.

14. Sarter M. Taking stock of cognition enhancers. Trends Pharmacol Sai 1991; 12: 456-61.

15. Siegel $\mathbb{R K}$. In toxication: Life in pursuit of artificial paradise. New York: $\mathbb{E}$. P. Dutton, 1989.

16. Siegfried $K$, $O^{\prime}$ Connolly $M$. Cognitive and psychomotor effects of different antidepressancs in the treatment of old age depression. International Clinical Psychopharmacology 1986; 1:231-243.

17. Verhey IXJ. Dementua, depression and forgetfulmess. Maastricht: Datawyse, 1993. 


\title{
Chapter 1
}

\section{COGNITIVE IMPAIRMENT IN ELDERLY PEOPLE:}

\author{
Predisposing Factors And Implications For Experimental Drug \\ Studies*
}

Abstract. The consequences for cognitive functioning, of normal aging, depression and dementia are well known. The borderland berween normal and pathological cognitive aging is less well understood. Recentlly, it has been found that it is of importance to differentiate between successful cognitive aging, usual, and pathological cognitive aging. The present paper reviews existing views on this borderland. Recently, it has been found that health-related factors, or Biological Life-Events (BLE), may determine the rate of cognitive aging. Various different, but similar, diagnostic descriptions of age-related cognitive dysfunction do exist simultaneously. Benign Senescent Forgetfulness (BSF) and Malignant Senescent Forgerfulness (MSF), Age-Associated Memory Impairment (AAMI), Age-Consistent Memory Impailment (ACMI), Late-Life Forgetfulness (LLF) and Mild cognitive changes (subthreshold) and Cognitive impairment disorders (DSM IV) are some examples of different experimental diagnostic categories. There are also various different, but similar, diagnostic tools to obtain these experimental diagnoses, such as for example, the Global Deterioration Scale (GDS), the Clinical Dementia Rating scale (CDR) and the Cambridge Mental Disorders of the Elderly Examination (CAMDEX). A diagnosis is considered important for the early detection of dementia. Pharmacological treatments are still in the experimental stage. Improvement of cognitive function has particularly been studied in clinical trials with groups of parients with Alzheimer's Disease (AD) as well as patient groups with AAMI. Future strategies may orient more towards treating symptoms of cognitive dysfunction, probably also on the basis of diagnosis of health-related factors, in age-related cognitive decline as well as in depression. 


\subsection{INTRODUCTION.}

Decreages in cognitive functions are regarded as an inevitable consequence of advancing age. The majority of healthy diderly people complain about forgefulness and decreased concentration, and this compronises their quality of life [77]. These complaints are based upon objective changes in cognitive function, as it is well established that virtually all aspects of cognitive functioning deteriorate with age $111,16,22,144$. . However, not all individuals show the same rate of decline: the variability of the performance in cognirive tests increases with age.

Not only does the physiological aging process influence cognition in the elderly, but also various biological factors such as medical conditions. There is a bordetine between so-called "normal cognitive aging' and pathological conditions such as dementia, notably Alzheimer's disease (AD), in which there are pathological disorders of memory and other cognitive functions [94], Great progress has been made in our understanding of particular brain changes in elderly subjects with cognirive deficits or $\mathrm{AD}$, and in our understanding of the basal mechanisms of drug action in the brain. There has also been a rapid increase in the interest of clinicians, researchers, and the pharmaceutical industry in the development of new classes of drugs for -especially palliative treatment of age-related cognitive deficits and dementing conditions $16,99,106]$. However, a breakthrough in the pharmacological treatment of these conditions does not seem to be at hand. There are several reasons for the lack of progress in this respect. First, the clinical diagnosis of Alzhemer's disease and related conditions appears to be diffeult, especially in the early phases where the differentiation from the "normal" cognitive aging is at stake (see [161]. Second, there is a lack of information concerning possible prodromes of Alzheimer's Disease in a phase in which there is a memory problem but not yet a frank dementia, and longitudinal studies are sparse. Third, experimental drug research in subjects who are not demented and thus do not suffer from a clearly defined medical condition has up till now been less popular than drug research in patients with Alzheimer's disease. Yet, treatment of patients suffering from cognitive decline in a phase in which the severity of the cognitive deficit is not too profound may bear more promise than treatment of clearly demented patients.

The present paper rewiews existing knowledge with respect to this borderland between normal aging and dementia with the aim to describe the domain where future drug trials should be directed at. The paper therefore describes current knowledge about the so-called "normal' cognitive aging (secrion 2), and the borderline between normal aging and pathological aging, especially with respect to cognition in the elderly (section 3 and 4 ). Implications for future drug studies of cognitive aging are described in section 5 . Because the focus of this article is on the borctertand, there will not be an in-depth description of neurocognitive decline with age. The reader is referred to Jolles 1986 . Huppert 1991 or La Rue 1.992 fot a more claborate discussion of that subject. Likewise, reviews of cognition in dementia will be found elsewhere $[73,89,101,155]$, as will reviews about the pharmacological treatment of demented subjects $[2,55,158,173]$. An overview of drug treatment studies in relation to cognitive aging can be found in chapter 4 [127].

\subsection{COGNITIVE AGING IN HEALTHY SUBJECTS.}

\subsubsection{Cognitive function and age}

There is a vast limerarure on the relation between age and cognitive performance. It is now generally agreed that healthy individuals are characterized by cognitive decline during the larer drcatles of adult tife $[10,22,89]$. The acquisition of new information becomes less efficient, which, coupled with a diminished retention of this information for later use, results in substantially poorer memory performance $17 \%$. The ability to plan new activities, solve problems, and make complex decisions, as well as flexibility, is noticeably diminished [123]. In addition, attentional 
processes appear to be invariably poorer in old subjects than in young subjects 1141. Ower a third of all individuals aged over 60 yeats complain of problems with sleeping 11751 . Sleeping is dosely related to arousal, which is also impaired in old age: In addition, there appears to be a general slowness, appearing especially in the performance of tasks that have ro be carted out under time pressure and/or in demanding situations. A general sllowing down of central nervous system (CNS) functioning may be at the roor of this slowness [16]. A fruitful model for this slowing is provided by the notion of resources and resource reduction, as discussed by Salthouse [145]. Briefly, any cognitive activicy requires resources, which can be wiewed as time, space, or energy. A reduction of resources results in a diminished capaciry to process information. For a thorough overview of the evidence on this issue, the reader is referred to one of the excellent surveys, especially the ones by Birren and Schaie $[10,11]$ and La Rue $[89]$.

While it is quite clearly established that elderly subjects (i.e., after 65 years of age), show a deterioration in cognitive functioning, or cognitive efficiency, there is also evidence that this deterionation may start in middle age ( 40 years). It has been found that the performance of even normal, healthy subjects has already deteriorated by middle age (above 40 years), at least in some categories of individuals $\left[68_{1} 118\right]$. Age-related cognitive problems may lie dormant for decades, and only become gradually or suddenly apparent as the subject realizes that some aspect of his of her functioning is no longer what it used to be. Loss of CNS neurons may occur as early as the fourth decade [60]. Problems that people aged $40-60$ years experience may have to do with the fact that cognitive functions and abilities deteriorate, giving rise to complaints of defective memory functions, decrease of cognitive energy, especially in demanding situations, and lack of concentration and attention. These problems often arise in their jobs and can cause problems in family and other relations, resulting in an increased use of the social security system, and of health-care facilities and drugs. To date, the problems of middlemaged people in their work or social relations are usually ascribed to social causes, but they might also be the consequence of decreased cognitive functioning. Also, emotional changes may occur in the elderly either due to social or material losses, or as a consequence of the knowledge that many faculties have been lost or are diminished [16].

\subsubsection{Cognitive decline: when and at what tate?}

There are two competing theories relating to the evolution of cognitive changes $[118]$. The continuous decline hypothesis states that the decline starts early in life and gradually goes on or accelerares with age, whereas the terminal drop hypothesis $[129,1301$ implies that the decline mamifests itself abruptly. Terminal drop may occur after a major event, e.g, related to physical health, such as an infective disease, resulting in a sharp decrease in cognitive performance. Of course, terminal drop is more likely to occur in the second half of the life span, but because life expectancy has become much longer during the last century, this period can extend over the fourth to the ninth decades of life. Unfortunately, the majority of experimental cognitive aging rescatch performed until now has focused on performance differences between young adults (mostly students) and elderly subjects. As a consequence, there is little information about cognitiwe deterioration in middle age (but see 169.791 . Yet, studying the ages between 30 and 60 is essential to gain insight into functional development during adulthood and to obtain knowledge about which functions decline when.

In this respect it is important to discern individual subjects and group norms. As most studies on cognitive aging are cross-sectional (i.e., studying two or more age groups at one point in time), there is a distinct possibility that studies reporting gradual cognitive decline are merdy an artefact because of the fact that older age groups contain more poorly performing subjects [118]. This could be because more elderly subjects than younger subjects are in the period between terminal drop and death. This number increases with group age, causing the average group performance to be poorer. Incidentally, this would also result in higher group variance, at 
phenomenon often encountered in cross-secrional research. Individual age-performance trajectories, as Rabbitt [19] put it, may differ widely and yet result in a steadily declining overall trajecrory. Another possibility is that most individuals do indeed show a gradual decline wich age, perhaps as a result of the accurmulation of effects of minor brain dysfunction 168,79]. At first, these minor pathologies may have litele impact but, as they accumulate, and as age advances, their amassed effects result in perceivable cognitive deficits. Terminal drop would then only occur as a result of some major pathology. This latter possibility is clearly the more optimistic one, as it paves the way for adding life to the years. As yet, we do not know which of the two possibilities, or some combination, might apply.

Does continuous decline or terminal drop exist to a comparable extent for all different cognitive functions? This is unlikely, as it is known that even memory is not a unitary function and particular aspects of memory, e.g., recognirion memory, appear to temain relatively intact in later life [53]. The decline of sensory and perceptual performance [164] and physical performance [153] can have great impact on general cognitive functions, but there need not be any direct or causal relation to cognitive performance. Any loss of memory may well lag very much behind perceptual loss, or not occur at all. Likewise, "executive function" appears an important mediator of age-related dysfunction, as it has been shown that afrer correction for executive function, age was not a predictor for test performance.

\subsubsection{Health-related factors and Biological Life Events}

With respect to the question as to what factors might influence cognitive decline apart from the factor "ichronological age" "there is increasing interest in the factor 'health'. Up to a few years ago there were no reports on the influence of health-related factors on age-related cognitive decline. Of course, cognitive dysfunctions in relation to well-established disease states such as brain trauma, depression, and alcoholism are well documented. However, the issue at stake is whether conditions with an unknown or ambiguous relation to cognitive (dys)function -such as very mild closed head injury (CHI), social drinking, borderline hypertension, anesthesia or diabetes mellitus- have some influence on cognitive functioning.

Recently, the term biological life events (BLE) was proposed $[66-68,79]$ to define "those factors that are related to physical or mental health, experienced at any point in life and thought to be related to brain dysfunctioning, other than grossly impairing conditions like dementia and brain trauma". $B L E$ are factors with porential, but up till now unproven influence on the brain. Mild head trauma, operation under general anesthesia and drinking history are examples of BLE. We have shown that the performance on particular memory tests does not decrease with age up till 80 years of age, in BLE-free subjects, whereas performance in BLE subjects is seriously compromised from age 60 on [65, 67]. Follow-up research showed that elderly subjects with memory complaints have suffered BLE in their life significantly more than matched controls [79]. Furthermore, they are more chatacterized by soft indices of brain dysfunction such as primitive reflexes [165]. Fozard [47] and others [29] recently have called for more extensive population-based studies in which complex interplay between health and cognition would be investigated as well as the natural history of cognitive performance and change in order to identify environmental factors associated with cognitive preservation or deterioration. Interestingly, al ready Haxby et al. [61] found age effects of visual memory that were much smaller than those usually reported in the literature after "rigorous healuh serecning" of the subject studied. Likewise, Christensen et al 25$]$ provided evidence in favor of the notion that careful assessment, selecrion and description of subjects, as well as further atcention to health status is needed to aid interpretation of cognitive aging research. Other possible health related factors which may infuence cognitive aging are mild hypertension [41], and medication or exposutre to neurotoxic factors $[58,67]$.

Thus, subtle health-related factors are potentially important to cognitive aging. We assume that they are not severe enough to cause any acute or perceivable trouble for the individual ${ }_{\text {, but that they }}$ 
sill have some long-term impact on brain functioning and with that on cognition. Thus although the patient is considered to have recovered, it is likely that the brain has suffered some functional damage which cannot be diagnosed. This suggests that healthy subjects with BLE may be on the border between normal and pathological aging and are more vulnerable to acceleraced eognitive decline.

An additional problem in cognitive aging research is that tests that are used for neuropsychological assessment in the elderly are characterized by lack of norms for the majority of the relevant tests. Normative data, which take health-related factors and also education into account are as yet nonexistent. However, in order to differentiate normal age-related functional decline from pathological functional aging, we have to know how healthy adults of all ages perform the test used to evaluare the function. Furthermore, as there may be interactions in effects on performance between age on the one hand, and sex, education, and health variables on the other, age norms should ideally be based on data obtained from various subgroups within a given age category. Lack of properly divised tests with good norms, and in parallel versions is also quite an impediment for the proper execution of drug trials aimed at treatment of cognitive dedine [64] and paragraph 5).

\subsubsection{A summing up: what is normal cognirive aging?}

The finding of large individual differences in a group of subjects who can be regarded as normal by any standard used in the experimental literature (see paragraph $2.3 ;[67.68,79]$ raises the issue of normality. Usually, an operational, statistical definition of normality is used: Observations can be regarded as normal if they fall within some fixed boundaries, for instance in the middle $90 \%$ of their range. Rowe and Kahn [138] stressed in their important theoretical review on aging that the variability of a given parameter, for instance the performance on a memory test, increases with age. The authors paid attention to the heterogeneity even in normal, i.e., non-diseased groups of elderly people. They argued that a distinction should be made between succesful and wsual aging. Successful aging refers to changes that are intrinsic to age itself, whereas usual aging is the result of aging plus all non-pathological deficiencies that occurred earlier in life. These deficiencies are not intrinsically related to the process of aging per se but they are closely associated with aging, because their effects are greater in old age (duc to increased vulnerability or reduced resistance) [67.79]. In addition, the chance of being affected by these deficiencies increases with age.

The notion of the normality of usual aging implies the harmlessness of several possibly healththreatening facrors, such as BLE. Normality also implies that what is usual is also natural, and cannot -or even should not- be modified. 'This notion of 'normality' puts too much empliasis on the level of functioning of most old individuals, instead of attempting to explain the reason for the increased heterogeneity. 'It tends to create a gerontology of the usual' [138]. Stones et al [154] identify four different types of aging (see table 1):

\section{Table 1 Types Of Aging}

1. Primary aging (- =uccessful) aging: functional changes that are intrimsic to age;

2. Usual aging: non-parhological defreiencies added to the age-intrinsic processes of successful aging:

3. Secondary aging: pachology-related decrements added to non-pathological aging*

4. Tertiary aging: pathological aging plus the effeces of cerminall illness. Tertiary aging can thus be roughly equared to the "terminal drop" phenomenon $1130 \mid$. 
With this model of multiple types of aging, it becomes understandable why age-associated decline can accelerate and why the varibility increases with age, two often observed trends in aging research. The frequency of aging types $2-4$ must increase with age, as these age-linked conditions and processes are irreversible in most cases, and any brain dysfunction that is caused by them is likely to be permanent. The onset of these age-extrinsic conditions can be assumed to vary between individuals. The aggregated deleterious effects of pathology or life style on the awerage performance in a radom sample of subjects is therefore expected to accumulate with age. Conversely, processes that are age-intrinsic (primary aging) are more likely to cause a linear decline of cognition with age, if a given function is to dedine at all as a result of primary aging. It has been hypothesized that BLE constiture a biological substrate for non-pathological deficiencies that are associated with usual aging type 2 ; $[65,67]$ : Subdivision of subjects based on whether they have a history of BLE an be equated to the distinction between successful and usual aging, between aging type 1 and 2 . This hypothesis should be investigated further in the light of the fundamental issue about when age-associated changes can be regarded as age-intrinsic, that is, physiological, and when the aging process is usual but non-diseased.

\subsection{PATHOLOGICAL COGNITIVE AGING: Concepts and Diagnostic Criteria}

\subsubsection{The borderline berween normal and parthological cognitive aging}

The borderline described in the preceding sections is especially relevant in relation to dementing conditions and their prodromes. The most common form of dementia is AD, which accounts for $50-70 \%$ of all cases of dementia. It is evident that an insidious and progressive disease such as $\mathrm{AD}$ does not manifest itself from the very beginning as the complete syndrome of dementia. Early in the course of $A D$, the patient may exhibit mild memory impairments and changes in other mental domains that are not sufficiently severe to merit the diagnosis of dementia. Recognizing these prodromes of dementia is one of the most complex diagnostic problems to date. This section summarizes what is known about this "grey area". Definitions of dementia and $A D$ are given to show the vague boundary between dementia and non-demented conditions: this is especially relevant because there is no uniformity in assessment strategies and classification systems with regard to the borderline.

\subsubsection{Rationale of the need for an early diagnosis of dementia}

From a scientific point of view, the diagnosis of "early" AD helps to clarify epidemiological aspects such as the natural history of the disease, which is of major importance for planning and developing health-care facilities. The lack of clear diagnostic criterion for early AD is reflected by the estimates of its prevalence. In contrast to severe dementia, in which the prevalence is remarkably consistent in various studies (about $5 \%$ of the population of 65 years and older), the prevalence of mild dementia ranges from $2.6[81$ to $21.9 \%$ and even up to $52.7 \%$ in one Japanese study [63]. The main reason for this extreme wariation is probably differences in the criteria and in the merhods used to identify mild dementia $\llbracket 62,63\}$ and problems with regard to the definition of the boundary between nomal aging and pathological conditions (this paper).

From a clinical point of view, the need for an carly diagnosis is also of vital importance. A significant minority of patients with the diagnosis of dementia suffer from treatable conditions $150,56,93,1491$, and treatment of these diseases is expected to be more successful in the early stages $[28,88]$ before changes in the brain have become structural $[80,173]$. In addition, ir is of great importance to have diagnostic methods that accurately sort out those parients with mild dementia from those with mote benign forgetfulness because of the public's growing awareness of dementia as a major healch problem and the corresponding anxiety that is caused by the media $300-32,77.112]$. 


\subsection{Clinical characteristics of the prodromes of dementia}

The onset of $\mathrm{AD}$ is often dated in retrospect and with imprecision. Information from relatives can provide a lot of insight into the very frot prodromes but is largely anecdotal. Typically. predemented subjects in the grey borderland demonstrate feelings of anxiery, worrying, depression, and psychological vulnerability. These feelings are less pervasive than in patients with major depression $[1,110,139]$. Their inner feelings may be more dependent on their enwironment: they caln down when reassured, but a small amount of stress is likely to put them out of balance [1, 1101. They get exhausted easily. Passivity, loss of interests, and coarseness may be common features. They appear less spontancous and extroverted, and more withdrawn. Some mental features of this syndrome reflect a disruption of compensating abilities, such as the rapid exhaustion and the difficulty to adjust to events that are not part of a daily routine, whereas others are more likely to be secondary phenomena, such as withdrawal, anxiety, and a tendency to worry $[17,23,110,111,140]$, Predemented patients themselves may or may not complain about these changes, but their relatives probably do $[15,24,96,105,109,113]$.

This picture of 'predementia' or prodromes of dementia should be regarded as tentative. It is not known if all patients with AD present with a similar picture to the one described here. Moreover, we do not know its predictive value in terms of specificity. To date, no clear diagnostic categories adequately classify the above clinical picture. The state may be too subte to be described in reliable research criteria. A qualitative approach, i.e., a detailed psychopathological description, is probably the most adequate approach. "The importance of a qualitative assessment is underlined by the relative lack of specificity of the traditional psychometric tests [155].

Neurological examination probably does not reveal any abnormalities nor do ancillary investigations such as laboratory or neuro-imaging data [49.52], although there may be an increase in "soft" neurological signs early in the course of the illness [165]. The subjects may perform within normal ranges on tradirional psychometric tests of memory, but may need more time and show a tendency to get tired and to slow down when testing takes too long $[63,73,155,156]$. If memory is impaired, then it is usually related to tasks measuring delayed recall $[1,110,141,156]$. With respect to the search for biological markers to distinguish between $A D$ and normal and borderline states, up till now, none of these markers has proven successful in individual patients given the findings obtained by computed tomography (CT) [76], single photon emission computed tomography (SPECT) [166], and magnetic resonance imaging (MRI) [146, 150]. Given the lack of reliable and valid eriologically based objective tests, the diagnosis of early $A D$ is still based on detailed dinical description, differentiation from normality and other behavioral diagnoses (e.g., depression), neuropsychological examination, and follow-up studies [105, 133], or see $\$ 161$.

\subsubsection{Definitions}

Considerable progress in the accurate diagnosis of dementia has been made in the last decade. Consensus procedures have yielded operarional criterion for the clinical diagnosis of dementia and the main dementing illnesses $14,26,97,134]$. Although dementia is now generally regarded as a clinical syndrome and not as a disease, important differences exist in the interpretation of this notion.

The term dementia is used by some researchers to denote a clinical condition defined only by observable behavior, irrespective of its etiology. For instance, the report on the NINCD S/ADRDA criterion for clinical AD states: "Dementia is a diagnosis based on behavior and cannot be determined by computerized tomography, electroencephalography, or other laboratory instruments, although specific causes of dementia may be identified by these means" [97]. The consequence of this definition is that dementia can be caused by both organic and functional disorders. Other researchers limit the definition of dementia to organic etiologies. For instance, the DSM-IV states: "Either there is evidence (...) of specific organic factor(s) judged to be 
etiologically related to the disturbanc, or, in the absence of such evidence, an etiologic factor can be presumed if the disturbance cannot be accounted for by any nonorganic mentall disorder, e.g., major depression accounting for cognitive impaiment" [5]. Still others have extended the definition of dementia to include characteristics of irreversibiling or a progressive course (137). In common dinical practice and for lay people, this term is used perhaps the most frequenty, although it is not supported by any official "source".

The most widely used definition of dementia to date is that of the DSM-III-R I4I and DSM-IV [5]. In short, the DSM defintion involves a combination of memory impairnent and impairment in at least one of the domains of abstract thinking, judgement, aphasia, apraxia or agnosia, constructional difficulty, or deficits in executive functions. The impairment must be severe enough to interfere with social functioning. It is important to note here that the DSM-IV definition implies the acceptance of some degree of heterogeneity: not all cognitive domains are necessarily affected. Virtually all current research studies make use of the DSM-IV criterion, except for the last criterion concerning the presumed organic eviology, and diagnostic accuracy has significantly irmproved since its introduction.

With respect to criteria for the diagnosis of AD, wwo sets are widely used: The DSM IV criteria for Primary Degenerative Dementia of the Alzheimer type (PDD) [5] and the so-called NINCDS/ADRDA criteria [97]. The latter criteria are compatible to those of DSM IV but are more daborate and better operationalized. For this reason, they are proposed in most studies. The criteria differentiate between possible, probable and definite $A D$. A diagnosis of definite $A D$ can only be made when the criteria for probable AD are fulfilled and when there is histopathological evidence from biopsy or aucopsy. Probable $A D$ is defined by the presence of dementia, an onser berween 40 and 90 years of age, and the absence of systenic disonders that in and of themselves could account for progressive deficits in memory and cognition. A diagnosis of possible AD is made when there are variations in onset, presentation, dinical course or in the presence of a second possible dementing disorder, which is clinically not considered to be the course of dementia. Allowance is made for plateaus in the course of progression or in the presence of associated psychiatric, somatic or neurological symproms.

The most widely used dinical criteria for vascullar dementia are those of DSM and are based upon clinical description. The features are not defined in detail and leave much room for interpretation. Ischemic scales have long been used for the diagnosis of vascular dementia [57, 135$]$. More recent criteria have also paid attencion to the temporal relationship between dementia and strokes, the number of strokes, and brain imaging data $[26,27,134,162]$

\subsubsection{The classification of mild cognitive syndromes}

The differentiation between dementia and normal states has been especially problematic. In the past 30 years, several attempts have been made to define the clinical and neuropsychological features of the botderline state between normality and frank dementia. As early as 1.958 Kral introduced the terms benign and malignant senescent forgetfulness to describe the memory complaints of the elderly he studied $|85|$. Since then, investigators have tried to describe these states in more detail, e.g. very mild or mild cognitive decline [124], questionable dementia [71], minimal dementia [137], age-associated memory impaiments [36], age-consistent memory impaiment, and late-life forgetfulness 112 . The fourth edition of the Diagnostic and Statistical Manual of Mental Disorders (DSM-IV) includes a new category as well, namely "age-associated cognitive decline" $[2 \%, 151]$. However, the nosological status of many of these proposals is still unclear, especially with regard to what extent they are related to dementia [38].

Nevertheless, the concepts provide a good starting point especially because clear and unequivocal diagnoscic criteria are prerequisite for development of therapeutic strategies for patients with cognitive complaints. The main concepts are described below. 


\subsubsection{Benign Senescent Forgetfulness (BSF) and Malignant Senescent Forgetfulness (MSF)}

The concepts of BSF and MSF were introduced more than 30 years ago. They are probably the earliest attempt to discinguish clinically between normal age-related memory changes in the elderly and those forms of memory change wirh a worse prognosis [85]. The term has often been used in the medical literarure and has become a generally accepted notion among clinicians. BSF presents as "... parchy and wariable, with difficulties remembering details of experienoes (names and places, but with relative ease in recalling the experiences itself. Usually, the forgorten details are recalled later". The condition is not progressive and does not increase the risk of developing dementia. In contrast, MSF is characterized by an unability of the subject to recall events in the recent past, disorientation with regard to personal data, and retrogressive loss of remote memories. Subjects with MSF remain unaware of their deficit and frequenty produce confabulations. BSF and MSF were never appropiately defined in operational terms. As a consequence, reseatch data on the reliability of the criteria are sparse. Only few data exist on the prognostic value of BSF. Kral carried out a 4-year follow-up study with 20 patients with BSF and 34 with MSF; only one parient with BSF deteriorated cognitively, whereas all patients with the malignant form did [86. Death rates in BSF and MSF also differed significantly from one another: $38 \%$ vs. $61,7 \%$ after a 4-year observation period. Recently, a 3-year follow-up study of parients with supposed BSF was reported by O'Brien et al [105]: 6 of the 68 parients with BSF (9\%) had become demented, which was about twice the expected rate. These latter findings cast doubt on the view that BSF always follows a benign course. Because of the ill-defined criteria and their uncertain nosological status, the use of the terms BSF and MSF cannot be recommended for research and dinical purposes, in spite of their widespread popularity.

\subsubsection{Age-Associated Memory Impairment (AAMI)}

AAMI was introduced by Crook et al in 1986 [36). AAMI denotes a condition in otherwise healthy middle aged or elderly subjects (50 years or older) who complain about memory loss and who score at least 1 standard deviation (SD) from the mean for younger adults on neuropsychological testing for secondary memory. The AAMI criteria were provisionally established in order to have a operational definition of normal cognitive aging. In relation to the discussion on 'normality' in section 2.7. A.MI has to do partly with usual aging and party with secondary aging. In addition, several patients who are in the prodromes of dementia will be classified as AMMI.

Blackford and LaRue [12] criticized certain aspects of the AAMI concept, such as the omission of an upper age limit; the omission of any means of quantification of subjective complaints; the criterion that "performance is 1 SD below the mean established for young adults on a standard. ized test for secondary memory", which precludes the use of tests dleveloped especially for old-aged populations; and the likelihood of meeting the above-mentioncd criterion when more tests are administered. Besides, the AMI criteria provide a minimum for the deviation in memory performance (at least one standard deviarion), but no maximum, although dementia should be ruled out.

Blackford and LaRue [12] added to AAMl the following new categories: Age Consistent Memary Impairment (ACMI), for performance within \pm 1 SD of the mean established for age on $75 \%$ or more of the tests administered, and Late Life Forgetfulness (LLF) to denote performance between I and $25 \mathrm{D}$ below the mean established for age on $50 \%$ or more of the tests administered. These modifications can be regarded as an interesting elaboration. Data on the reliability or validify of the AAMI criterion have not been published yet.

Finally no longitudinal dara have been reported and therefore the prognostic significance of the AAMI concept remains unsettled. The use of the term AAMI in clinical practice is fimited. Nevertheless, the criteria are well defined operationally and provide a basis for selecting research 
subjects in order to study the epidemiology, course, and dinical significance of normal aging and to evaluate the effect of pharmacologicall or other forms of intervention [4, 951 . More refined criteria have been proposed which may make the AAMI concept -in a revised form- more fruitful for clinical use $[40]$.

\subsubsection{Mild cognitiwe changes (subthreshold) and Cognitive impairment disorders}

The DSM IV includes a new caregory named "Mild cognitive changes (subthreshold)" as part of the elass of "Cognitive impairment disorders" [115, 151, 152]. In contrast to the first version of the DSM-II, the DSM-III-R specifies the severity of dementia in terms of functional capacity [6]. The prognostic value of the DSM-III criterion for the mildest stages of dementia is high when applied by experienced dinicians in selected patient groups [46, 70]. In field studies, however, the criteria seem to be less accurate [103).

\subsubsection{The Global Deterioration Scale (GDS)}

In 1982, Reisberg and his coworkers [124] presented the Global Deterioration Scalle (GDS) for the grading of primary degenerative dementia. To date, the GDS is one of the most widely used clinucal instruments to stage the course of cognitive decline and $\mathrm{AD}$. The scale describes cognitiwe and behavioral changes in seven stages. Stage 1 describes "normality" (no complaints, no deficits). The description of stage 2 ('very mild cognitive decline') is rather nonspecific. The characteristics of stage 3 ('mild cognitive decline) are more specific, but they refer almost exclusively to memory or related cognitive domains. From stage 4 onwards the DSM-III criterion for dementia are amply met.

The prognostic properties of the various stages are reasonably established. Generally, stage appears to be a major predictor of decline: patients in stage 2 have a low risk of declining in the following years, whereas a large proportion of the patients in stage 3 and especially stage 4 show cognitive decline. It has been suggested that a GDS score of 2 reflects normal aging (i.e. 'usual aging' in terms of the discussion in par. 2.6) in practically all patients, whereas GDS stage 3 represents borderline cognitive functioning. From stage GDS 4 onwards, a progressive course of decline is likely [161].

\subsubsection{The Clinical Dementia Rating scale (CDR)}

The Clinical Dementia Rating scale 771 rates the severity of dementia as questionable, mild, moderate, or severe (scores of $0.5,1,2$ or 3 ). The individual performance is rated separately in ach of the following categories: memory, orientation, judgement and problem solving, community affars, home and hobbies, and personal care. From these ratings, an overall CDR score is calculated according to a complicated algorthm. The criteria carry high face walidiry and are based on a wide range of cognitive activities in daily life. Memory performance in daily life is considered to be the central criterion, the other features are regarded as secondary. Interater reliability and construct validity of the CDR have been demonstrated [20]. The scale has been documented by several longitudinal studies, which make the CDR probably the best-tested rating scale for staging dementia to date [7]. The CDR is considered to be a well-documented scale for rating dementia in selected samples. The scale is more difficult to administer than the GDS. From stage CDR 1 onwards a deterioration of cognitive functioning can be reliably predicted, whereas stage CDR 0.5 reflects the borderline state [1611. 


\subsubsection{The Cambridge Mental Disorders of the Elderly Examination (CAMDEX)}

The CAMDEX consists of a standardized psychiarric interview with the patient and care giver, and a brief neuropsychological battery (the CAMCOG) [136, 137]. The CAMDEX was especially designed for the detection of early dementia and describes four syndromes as guidelines for the staging of dementia: minimal, mild (early), moderate, and severe dementia In contrast to the GDS and the CDR, the CAMDEX can be used to obtain a syndromal and etiological diagnosis. The criterion should be used in a "flexible manner", leaving "some room for clinical judgement" 136\%. The face validity of the criterion is high. The interrater rellability of the CAMDEX is good [137].

In some recent studies in which the CAMDEX was used to assess patients in a longitudinal followup design, it was concluded that although the CAMDEX criteria were in general feasible, the criteria for minimal dementia were difficult to apply in clinical practice [107, 108]. Errors in the diagnosis of minimal dementia occurred, especially in people of a below-average intelligence, in the old and frail, and in patients with sensory impairments. The need for repeated assessments over lengthy periods was stressed in order to document the natural history of dementia correctly.

\subsubsection{Comparison of the differenr criteria for mild cognitive syndromes}

Comparison of the different concepts and criterion discussed above shows that there is at considerable owerlap in clinical characteristics. At the outset, there are few differences between Kral"s: benign forgetfulness and Reisberg's very mild cognitive decline (GDS 2). Likewise, stage 3 of the GDS closely resembles the description of very mild cognitive impairment of the CDR (CDR $0.5)$ and the CAMDEX criterion for minimal dementia, whereas GDS 4, CDR 1, and mild dementia of the CAMDEX are all highly compatible with the criterion for mild dementia as defined by the DSM-III-R criterion. However, the concepts differ in details [48, 102], and thus the comparison of the results of these studies should be approached with some caution.

From the results from the follow-up studies into the prognosis of early $A D$, as defined by the different criteria, it can be concluded that the likelihood of further cognitive decline is low (but not zero) for subjects with mere memory complaints classified as BSF or GDS 2, intermediate for patients with questionable dementia, GDS 3 or CAMDEX minimal dementia, and high for patients with GDS 4, DSM mild dementia, CAMDEX mild (early) dementia and CDR 1 . Stated in another way, subjects who complain only about poor memory, without objective evidence of impaired memory and who perform well in daily activities cannot be regarded as at high risk of becoming demented. In contrast, those who demonstrate objective cognitive impairments that interfere with social funcrioning probably will become demented. It should be borne in mind that these studies were performed with selected samples. It is still impossible to accurately predict the outcome in individuals with mild cognitive changes [161].

\subsection{NONCOGNITIVE AND BEHAVIORAL DYSFUNCTIONS IN BORDER- LINE STATES}

\subsubsection{Subjective cognitive complaints as an eafly marker of dementia}

With respect to the differentiation of a dementing condition from 'normal aging', it is important to know whether the judgement of one's own memory (often referred to as metamemory [72, 148] reflects objecrive cognitive functioning and whether memory complaints have diagnostic meaning. Complaints of memory are quite common in the elderly and in middle-aged subjects. In fact, no less than $73 \%$ of the 40 -year-old and by $91 \%$ of the 70 -year-old subjects in a study reported difficulties in remembering 151 . Although the growing interest of the public media in dementia 
and $\mathrm{AD}$ may have increased the awaneness of memory deficis as a possible first sign of mental deterioration [30.321, a lot of evidence suggests that memory complaints in older adults correlate to a large extent with depression, but only modestly with their performance on objective memory tests $[15,34,157]$. However, the finding that the association of subjective complaints with depression is stronger than with dementia should not be interpreted too dichotomously, since depression may also be a presenting symptom of AD [122]. Moreover, a recent study reported that the relatives" assiessments of the patients" menory, measured by standardiaed questionnaires, was a reasonable predictor of dementia, with an overall dassification accuracy rate of $74 \%$. This rate was improved by $11 \%$ when objective memory tests were also used [06]. These findings emphasize the diagnostic importance of taking a history from a rellative or other informant who can report on the premorbid behavior of the parient. Because metamemory is a poor predictor of cognitive dedine in patients who atre alleady demented, it would be of interest to investigate whether complaints of one's decreasing cognitive functions anticipate manifest dementia.

\subsubsection{Non-cognitive problems in borderline states}

There is good evidence that deficits of memory are among the earliest fearures of AD [70, 135, 168]. However, this does not mean that impaired memory is a prerequisite for the diagnosis of $A D$ in its prodromal stage. That what has to be proven is accepted as proof when memory impairment is considered to be the main characteristic of the preceding stages of dementia [156]. Interestingly, a large amount of evidence from epidemiological and descriptive studies shows that non-cognitive symptoms are equally prominent in the disintegration of psychological organization. These symptoms involve perception, motility, personality organization, emotional experience, and volition $[9,45,120]$. In addition, the continum between subjects characterived by normal and those with pathological cognitive dedine is also found for non-cognitive behavior. For instance, at study of randomly selected 70-to-79-year-old women yielded a smooth and unimodal distribution of cognitive functions and behavioral changes [19]. Recently, Berrios has challenged the view that prodromes of dementia should be defined as a form of "mini-dementia", i.e., only differing quantitively from dementia 191.

The most frequently studied non-cognitive aspects of early $\mathrm{AD}$ are changes in affectivity and in personality. Depression can be related to age-related cognitive decline and prodromes of dementia in several ways: depression may present with the clinical picture of dementia ("pseudodementia") [84], it may coexist with dementia, or depression may precede demencia 187 , 1221. Furthermore, dementia, notably the subcortical types, can mimic depression, and both conditions mayr develop independently from one another [132].

The notion of depression being an early manifestation of dementia is still under debate. In a retrospective study, the relatives of patients with $\mathrm{AD}$ reported depression and agitation as being the first symptom of dementia in about $40 \%$ of the patients [90]. In prospective studies, depressive symptoms in combination with cognitive deficits in elderly patients were also found to increase the risk of the patient developing subsequent dementia [87. 122]. However, other studies did not report an increased prevalence of depressive symptomatology in subjects who subsequently developed dementia $[82.120 \mid$.

The results of these studies have to be evaluated carefully, because the definition used for depression and demencia may be different from those adhered to today [163].

In summary, patients with depressive symptoms and cognitive deficits may often have prodromes of AD. However, these patients have unfortunately been rejected from participation in most studies of $\mathrm{AD}$, probably duc to a dichotomous view in which depression and dementia are regarded as mutually exclusive. More refined clinical and neuropsychological descriptions and prospective neuroimaging and neurochemical studies should be carried out in order to ellucidate the relation between depressive symptoms and mild dementia.

With respect to studies into personalicy changes in relation to $\mathrm{AD}$ it has recently been shown that 
$\mathrm{AD}$ patients become more passive, more coarse, and less spontaneous. The personality changes occurred early in the course of the disease and could not be atributed to the decline in intellectual function [111]. Similar profiles (diminished initiative, loss of self-confudence, decreased extroversion "growing apathy, relinquishment of hobbies; and increased rigidity) have also been found in other studies $[1,17,23,110,139]$. Many subjects had subtle personality changes long before dementia became dinically manifest.

Thus, personality changes are likely to be among the earliest features of $A D$ and are evidant in the phase preceding dementia. Although the assessment of personalicy in demented parients presents unuswal and difficult merhodological problems, personality changes should be seen as a marker of early $\mathrm{AD}$ and warrant further investigation.

\subsubsection{Age and comorbidity}

It should be noted that most of the research into $A D$ has been carried out in relatively young and healthy patients, although dementia is more prevalent among the older and more diseased population. Older populations show higher levels of comorbidity. The relevance of this aspect has been noriced by $\left.\mathrm{O}^{\prime} \mathrm{Connor} \llbracket 107\right]$, who was confronted in his field studies with particular diagnostic errors in very old subjects and those with significant comorbidity. Old patients are more difficult to investigate appropriately. Besides, many of these patients live in nursing homes or other protected environments, where criteria for social and functional decline are harder to meet than in younger subjects who are still working 1371 . Moreover, samples with older subjects will inevitably suffer more from methodological faws such as higher mortality figures and more loss at follow-up. Therefore, data from studies using relarively young patients cannot be directly applied to a rypical geriatric population. It seems likely that the detection of a prodrome of $\mathrm{AD}$ and early $\mathrm{AD}$ in young and healthy subjects requires a different approach to that for older subjects. These aspects have generally been neglected so far in research of the borderline between normal aging and dementia, and the earliest stages of $\mathrm{AD}$.

\subsection{IMPLICATIONS FOR DRUG THERAPY}

\subsubsection{The impact of cognitive aging research}

Research into cognition in usual aging, agemassociated-memory-impairment, and dementia has a common problem, namely the profound heterogeneity within groups of subjects [3]. Many health-related factors, disease states, as well as education and psychosocial factors, contributc [83] to the pattern of cognitive and non-cognitive deficits and complaints. The clinical syndrome of dementia is heterogenous whereas $\mathrm{AD}$ may consist of several different nosological entitics 143.1311. Apart from primary aging (see table 1 ), secondary aging and tertiary aging are associated with other factors in addition to the factor age. As discussed in preceding chapters, the syndrome of complaints and functional deficits in usual aging and in the putative prodromes of dementia is not uniform in the sense that 'only' memory or 'primarily' memory is affected. On the contrary, a number of cognitive and non-cognitive functions are affected (section 4).

This has considerable implications for therapeutic strategies in the field of age-related cognitive deficits. A major point concerns the choice of subject population as a target. Parient groups with AAMI or ACMI may contain quite a number of subjects who suffer from -very early- AD. Drug treatment in this group may be of relevance in order to prevent or postpone the onset of $\mathrm{AD}$. Another relevant aim may be the treatment of non-cognitive behavior in this group (e.g., mood or energetic complaints) as this has an important impact on the funcrional capacitics of the subject and his or her quality of life. A third aim may be the development of strategies for parients who complain of cognitive dysfunctions but who may never develop dementia, yet are handicapped in 
their daly life. There is increasmg evidence that stibjects who are not demented but who do have objective cognitive deficits on neuropsychological investigation should be characterized as a discase group: The new dassification of the DSM IV "age-associated cognitive decline" [21] may improve the possibilities to target this group for drug dewelopment (par. 3.6.3).

It may be important to discern warious subgroups within the heterogeneous group of non-demented subjects with complaints of impaired cognitive functioning $\mathrm{eg}$, those with biological life events and those without. Patient groups for drug srudies can be made more homogeneous, which would improve the detection of possible drug effects. The rationale is that the pathogenesis of the cognitive decline can be expected to differ for the various subgroups of elderly people with complaints. Similarly, it may be of interest to search for drug effects in non-demented elderly people who have an abnormal profile of apolipoprotein E4 (Apo E4), as Apo E4 has been implicated in $\mathrm{AD}$ [33]. Likewise, orher biological markers could be used to select non-demented cognitively impaired individuals for experimental drug studies (hippocampal atrophy). Measurement of hippocampal atrophy or pupillometry could be relevant in this respect because of findings in recent years, which suggest that patients with hippocampal atrophy [150] or abnormal pupil-reaction to low dosis of tropicamide [147] may be individuals in the borderline between normal aging and dementia.

\subsubsection{What can be learned from phatmacological studies into the treatment of AD?}

Current research into the effects of experimental drugs in Alzheimer's disease and Alzheimerrelated conditions has met quite some difficulties. Through the years, it has appeared that the majority of studies has been characterized by methodological flaws [42]. The groups, generally, are often too heterogenous, particularly with regard to symptoms and severity there is a lack of sensitive and reliable evaluation measures and the length of the treatment period may differ considerably from study to study (see also $[64]$ for discussion). Furthermore no reference or benchmark drug exists and in quite some studies subjects experience side effects. The tacrine experience illustrates this: tacrine was given the benefit of the doubt by many countries [54], but was not registered in several countries including the Netherlands, because of its adverse effect profile. A $40 \%$ chance of a positive response set against a $60 \%$ chance of severe adverse events or intolerable side-effects is a cost-benefit problem. Finally, statistically significant results on some psychometric measures are not always reflected by clinically relevant findings. For instance, an improved score on a memory test withour a concomitant improvement of daily life activities is not interesting from a clinical point of wiew.

AD drug studies performed in the last decade have shown that it is not a fruitul strategy to treat $A D$ as a disorder of memory. Memory is not anitary funcrion and consists of various subprocesses which are dependent on various neurotransmitters and centers in the brain. Thus, many classes of drugs can be used for the treatment of memory disorders [174]. Besides, AD is not a one-neurotransmitter disease: various neurotransmitters are affected and these are related to a variety of cognitive behaviors from memory to problem solving [34, 159]. Drugs with possible trearment efficacy could thus be based upon an action at various different neurotransmitter systems. This is especially the case because behavioral problems in AD and related conditions such as mood problems, energetic dysfunctions, personality changes, anxiety, and in more deteriorated subjects, restlessness, wandering, psychosis, and aggression, require trearment as much as the cognitive problems do $[74,167)$. Up to now pharmaceutical companies and drug developing institutions and researchers have been disproportionately interested in the cognitive symptomatology.

Finally, there is a lack of research directed at the very carly stages of AD (e.g., GDS stage 3). In addition, there have not been many clinical trials on possible prodromes of dementia [35]. It has been argued that this is the moment to treat patients with agents which can thalt or slow the deterioration, but industries and researchers have been somewhat reluctant to go deeper into this 
matter. It is possible that the fact that mild cognitive disorder has up rill now not been regarded as a nosological or disease entity is the reason for this reluctance [2]. The development of strict criteria for prodromal or 'predementia' phase of Alshemer's disease and of methods for its dinical diagnosis would be an important step in the right direction: The treatment of AD in its predementia phase would then be possible because $\mathrm{AD}$ is a nosological entity.

Table 2 Future Intervencion Strategies

- Causal pharmacological treatment ("cure")

- Pharmacological treatment for one or more sympitoms (cure, or postpoining or slowing the process)

- Prevention of dementia by phamacological treamene in a predementing stage (e.g. AAMI or related comdition)

- Prevention of age-related cognivive disonders by means of nutrients, vitamins, diecary supplements, herbal extracts

- Improved pharmacological rrearmene during adulchood, of depression, anxicty insomnia, anesthesta, neturotoxic exposure, alcohol abuse, newrotrauma with drugs that do not produce or aggravate cognitive disorders

- Psychological treatment of dementing patient, e.g. function oriented guidance

- Psychological treatment of primary care giver

- Hometraining of primary care givers

Table 2 summarizes the various airns which are explicitly and implicitly present in drug treatment studies. Many have hoped to find a treatment for the cause of AD. This is something else than the symptomatic or palliative treatments which are now the norm. Of course, a cure for the disease should be actively sought, but treatment of one or more symptoms remains of major importance. Finally, as mentioned above, the majority of studies have focused on cognitive symptoms, but the aims of treatment are different depending on whether the clinical psychopharmacological researcher sets out to reverse the course, to postpone further decline, or to slow further decline. The prevention of dementia by treatment in a very early stage is a specific example of postponing or slowing the decline. However, much research is still needed to improwe the methodology of the early identification of $A D$. Relevant furure developments may involve drugs which act upon particular brain mechanisms which underlie age-related defieits, for example, drugs acting upon the aggregation of amyloid, on the clavage of BA4 protein, and on the Apo E4 chaperonnes.

\subsubsection{Towards the prevention and treatment of cognitive disorders}

The prescription of psychoactive drugs scems to become more and more dependent on cost-benefit rationales. If ir can be proven that chronic use of certain psychoactive substances accelerates cognitive aging, then dinicians should be more cautious in prescribing them, also when patients are still young adults. It must be kept in mind, however, that there are many good reasons to prescribe psychoactive drugs, such as for persistent sleeping problems, anxiety, depressive mood, etc. These conditions themselves are accompanied by cognirive disorders [18, 104] and hence justify treatment with cognition enhancers as apposed to classical treatments with antidepressants, hypnotics, and anxiolytics. Nevertheless, it has been argued that in many cases alternatives do exist, for example, antidepressants without anticholinergic side effects [128]. Furthermore,

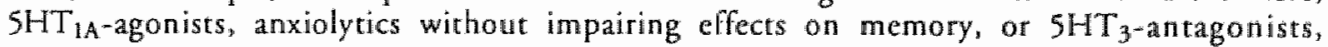
anxiolytics that may even improve cognition, are in this respect preferable to benzodiazepines [92]. 
Athough the side-effect profile of anti-AD drugs should be benign, in the case of treatment of cognirive disorders withour stuch severe consequences as those of $\mathrm{AD}$, it seems reasonable to demand a total absence of side effects. This is another expression of the "cost-benefit" attitude towards treating cognitive disonders that are not primarily associated with accepted parhology. Conversely, cognition enhancers could also be used as co-medication to prevent "sedating' or 'cagnition impairing' side effects of psychoactive drugs. Examples from other disciplines jillustrate this latter point. In the area of allergy treatment, in the last decade there has been a major shift towards the prescription of antihistamines that lack anticholinergic side effects, antihistamines that do not readily penetrate the blood-brain barrier, or even antihistamines combined with CNS stimulants 151, 121]. Major reasons for the development of these "new' anthistamines were not so much to increase their anti-allergic efficacy, but to increase their specificity so as to prevent allergic patients from suffering from drug-induced cognitive impairments on a daily basis and hence to maintain an optimal quality of life.

In general, there is neither a weal th of research nor of clinical experience with drugs to combat the cognitive impairment induced by BLE. Howewer, there are many interesting theoretical possibilitics such as a combination of benzodiazepine anxiolytics, anticholinergic antidepressants, anesthetic agents, alcohol (questionable as it is though, from an ethical point of wiew, to 'treat' the cognitive effects of alcohol consumption without altering its level) and neurotoxic exposure with nootropic drugs or cognition enhancers. The latter category of drugs reverses or attenuates syndromes of cognitive impairment induced by cholinergic dysfunction [81, 100, 117, 169]. Several piracetam analogues i.e. tenilsetam, aniracetam, and oxiraceram $\llbracket 116,172 \rrbracket$ have been shown to attenuate anticholinergic and hypoxic effects on cognition. The piracetam-like nootropic compounds have few side effects and hence could be candidate substances for co-prescription with psychoactive drugs that are known to impair cognition. Finally, it is worth mentioning that, many patients who are treated with antidepressant, anxiolytic, ot hypnotic drugs are probably attenuating their drug-induced cognitive impairment by habitually consuming products containing nicotine and caffeine, i.e. smoking tobacco and drinking coffee. Nicotine, a nicotinic cholinergic agonist has been repeatedly demonstrated to possess the property of antagonizing the effects of anticholinergic agents on cognition $(125,143,171)$. Caffeine attenuates the memory impairment induced by cholinergic blockade [125], attenuates benzodiazepine-induced cognitive impairment [142], and even attenuates the cognitive-impairing effects of alcohol [59],

Chronic use of caffeine has been shown to be associated with an improvement of cognitive performance [75]. Also the use of nicotine, despite its known association with an increased risk of cancer, has been shown to be associated with improved cognitive performance $[170]$ and even with a lower incidence of AD [160].

Dietary supplements, vitamins, trace elements, or flavonoids, may prevent cognitive disorders, particularly those associated wich aging, fatigue, or daily intake of alcohol. Studies have demonstrated an association berween vitamin B1 [98], B6 [39], or B 12 [13] and cognition. However, one has to assume that for some reason, a depletion albeit experimental, clinical or subclinical, of those vitamins must exist to explain these effects.

Alrered levels of trace clements may play a role in the development of cognitive disorders, and memory complaints may be the clinical expression of a disturbed balance in micronutritional elements, such as trace elements or minerals. We found that, among other elements, decreased levels of ninc were associated with increasing age [14]. Furthermore, zinc blood level and psychological performance were positively correlated, independent of age [78]. However, when we searched for the reverse association, i.e, lowered levels of zinc or other trace elements as putative biological markers in persons with age-associated memory impairment as compared to age-matched controls, we could not find one [126]. 


\subsection{CONCLUDING REMARKS}

Research into the borderline states between nomal aging and dementia is underdeveloped compared to the vast amount of knowledge which has been gained on normal cognitive aging and on dementing conditions (especially AD). A major problem may be the fact that the nosological starus and clinical characteristics of these intermediary stages have only recently been elucidated. This has prevented clinicians from deweloping diagnostic and treatment programs and drug companies have not been stimulated to put much effort in developing drugs for a non existing disease. Up rill now, many consider the development of drugs for a normal physiological process (i.e., the aging process) not rational. However, the wiew that 'normal' aging needs no treatment should in our view be replaced by more subtle options, e.g." in which a distinction is made between primary and secondary aging. The borderline between primary aging, which is exclusively determined by chronological age, and clear-cut dementia is very subtle: many people suffer from secondary aging, and the symptoms of secondary aging are only normal in a statistical sense but not in a physiological sense. This is a good reason to develop specific drugs for the nondementing popularion suffering from age-related cognitive decline. The recent incorporation of the classes of 'cognitive disorder' and 'age-related cognitive decline' in DSM IV may herald a positive change of atritude in this respect $[40,91]$. Otherwise it might be worthwile to target subgroups of cognitive disorders in terms of recognized factors that compromise successful aging. The clinical trials with nootropic drugs to prevent cognirive impairment after closed head injury that are currenty being carried out are an example. Nootropic drugs or cognition enhancers as co-medication against the cognitive impairment caused by psychoactive drugs to treat depression, anxiety, insomnia, or allergy could be a positive contribution in the struggle to achicve successful aging. Chapter 4 reviews the state of the art of research into cognition enhancers $1127 \rrbracket$.

\section{REFERENCES}

1. Aevarsson O, Skoog 1. Prodromal symptoms of dementia. Neurobiology of Aging 1992; 13:5L.

2. Amaducci L, Angst J, Bech P, et al. Consensus Conference on the Merhodology of Clinucal "Trials of "Nootropics", Munich, June 1989. Report of the Corisensus Commitree. Pharmacopsychiatry 1990; 23: 171-5.

3. Amaducci L, Fraciglioni L. Epidemiology of AD: Impact on the "Ireament. In: Giacobini $\mathbb{E}$, Becker $\mathbb{R E}$, ed. Altheimer's Disease: Therapeucic Strategies. Basel: Birkhauser Verlag $A G, 1994: 8.16$.

4. APA, ted. Diagnostic and Statistical manual of Mental disorders, DSM-IIl-R. Wasthington D.C.: American Psychitutic Associacion, 1987.

5. APA, ed. Diagnoskic and Statistical manual of Mcntal disorders, DSM.M, Washingtor D.C. American Psychiartic Associarion, 1994.

6. Ban TA. Psychopharmacology and succeful erebral aging. Progress in Neuropsychopharmacology and Biological Psychiatry 1994; 19:1.9.

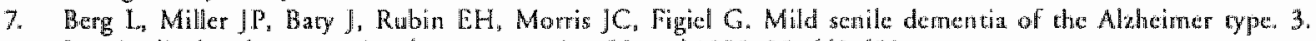
Longitudinal and cross-sectional assessment. Ann Neurol $1990 ; 28: 648-652$.

8. Bergmann K, Kay D. Foster EM, McKechnic A.A, Roth M. A follow up study of rendomly selected community residents to assess the effeces of chronic brain syndrome and cerebrovascular discase. Sth world congress of psychiarry. Amstendam: Excerpra Medica, $1971: 856.865$.

9. Berros GE. Non-cognitive symptoms and the diagnosis of dementiat history and clinical aspects. Butish Journal of Psychiarry 1989, $154: 11-16$.

10. Birren JE, Warner Schaie K, ed. Handbook of the psychology of aging. 2nd ad. New York: Wan Nostand Reinhold Company 1985.

11. Birren JE, Wameir Schaic K, ed. Handbook of the psychohogy of aging. 3rd cd. New York: Van Nostrand Reinhold Company, 1990 .

12. Blackford RC. LaRue A. Criteria for dhanosing age-associaced memory impairment: Proposed improvements from the field. Developmental Neuropsychology 19:9: 5: 295-306.

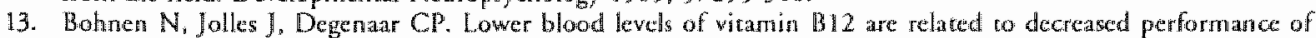
thealdhy subjecs in the Stroop Color Word Test. Neutoscience Rescarch Communications 1992; 11:53-56. 


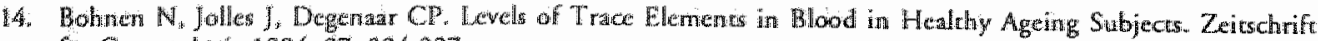
fir Grentologige 1994; 27:324-327.

15. Wolla Ki Lindgren KM, Bonacorsy C, Blecker ML. Memary complaines in alder adults. Fact or ficrion? Arch Nerrol 1991; 48:61-4.

16. Wowwinick J. Aging and Behavior. (3rd ed.) New York Springer, 1984

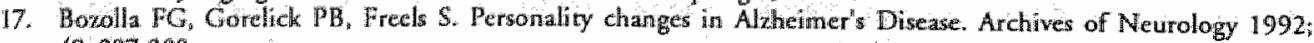
$49: 297-300$.

18. Brand $N_{;}$Jolles J. Information processing in depression and anxiety. Psychological Medicine 1987; 17: 145IS3.

19. Braync C. Calloway P. Nornal ageing impaired cognitive function, and semile demencia of the Alaheimer"s type concinum Lancet 1988; 1: 1265-7.

20. Burke WI, Miller JP, Rebin EH, et al. The reliability of the Washington University Clineal Demencia Rating Archives of Neurology 1988; $45: 31-32$.

21. Caine LD, Should aging-associated cognicive decline be included in DSM-rV? Journali of Neuropsychiarry and Clinical Nearosciences $1993 ; 5: 1.5$.

22. Charness $W$, ed. Hing and human performance. Waterloo, Canada" John Wiley \& Sons, Chichester, 1985.

23. Chaterjee A, Strauss ME, Smyth KA, Whitehouse PJ. Personality changes in Alzheimer's disease. Arehives of Neurology $1992 ; 49: 486491$.

24. Chrigtensen H. The walidy of memory complaints by elderly people. Irtermational Journal of Geriatric Psychiatry $1991 ; 6: 307-312$

25. Christersen KJ, Moye J, Armson RR, Kern TM. Health screening and random recruitrnent for cogniriwe aging research. Psychology \& Aging 1992; 7: 204-208.

26. Cinui HC, Teng EL, Hernderson VW, Moy AC. Clinical subtyper of dementia of the Alahcimer type. Neurology 1985: 35: 1544-1550.

27. Chui HC, Victoroff Jl, Margolin D, Jagust W/ Shankle R, Kanmann R. Criteria for the diagnosis of ischemic vasicular dementia proposed by the State of Califormia Altheimet's Disease Diagnosicic and Treatment Centers. Neurology 1992; $42: 473-480$.

28. Clarfeld AM. The reversible dementia"s: do they reverse? Annals of Internal Medicine 1988; 109:476-486.

29. Colsher PL, Wallace RB. Epidemiologic considerations in studies of cognitive funcrion in the elderly: methodology and nondementing acquired dysfunction. Epidemiol Rev 1991; 13:1-27.

30. Commissaris CJAM, Jolles J, Verhey FRJ, Ponds RWHM, Damoiseaux V, Kok GJ. Forgetfulness or dementia? Who is worried and why. European Joumal of Public Health 1995; accepted:

31. Commissaris CJAM, Ponds RWHM, Verhey FRJ, Damoiseaux V, Kok G], Jolles J. Public education about normal forgerfulness and dementia: Effectiveness of a systemarically developed information brochure.. Educational Gerontology 1995; accepted: .

32. Commissaris CJAM, Verhey [RR], Ponds RWMM, Jolles J, Damoiseaux V, Kok GJ. Public education abont normal forgetfulness and dementia: Importance and effects. Patient Education and Counseling 1994; $24: 109$ 115.

33. Conder E, Sauders A, Stritmaier W, al. Gene dose of apolipoprotein E Type 4 allele and the risk of Alaheiner's diseare in Late anset families Science 1993; 261: $921-923$.

34. Corkin $\$$, Growdon JH, Suliwan EV, Nisen MJ, Huft FJ. Assessing Treatment Effects: A Neuropsychological Batery. In: Poon LW ed. Handbook for Clinical Memory Assesment of older adulss. Washirgton: American Psychological Association, 1986: 156-157.

35. Crook T. Phannacotherapy of copnitive deficits in Alzheimer"s: Disease and Age Associaced Memory Impairment. Psychopharmacological Bulletin 1988; 24:31-38.

36. Crook $T$, Bartus $R T$, Ferr is $\$ H$, whichouse $P$, Cohen GD, Gershon $S$. Age-associated memory impairment: Proposed diagnostic criteria and measures of climical change: Report of a Nacional Institure of Mental Healch work group. Developmental Neuropsychology $1986 ; 2: 261-276$.

37. Crystal H, Dickson D, Fuld P, et al. Clinico-pathological wodies in denentian nondemented subjects with pathologically confirmed Alwheimer's disease. Neurology $1988 ; 38: 1682$; 1687 .

38. Dawe B, Procter A, philpot M. Concepts of memory impairment in the elderly and their relationship to dementia-a revew. International Journal of Geriatric Psychiatry 1992; 7:473-479.

39. Deijen JB, Van der Beek EJ. Orlebeke $J$, Van den Berg H. Vitamin B-6 supplementacion in elderty men: Effects on mood, memory, performance and mental effort. Psychopharmacology 1992, 109: 489-496.

40. Derouesnd C, Kalafat M, Guez D, Malbezin M, Poitrenaud J. The Age-Associated Memory Impairment Construct Rewisited. International Journal of Geriatric Psychiatry 1994; 9: 577-587.

41. Wilias MF, Robbins MA. Schula NR, Pierce TW. Is blood pressure an important variable in research on aging and neuropsychological tese performance? Jowrnal of Cerontology 1990; 45: 128-135.

42. FDA. Tacrine a treatment for Alzheimer's Dementid. An interim report from the FDA. New English Journal of Medicine $1991 ; 324: 349-352$. 


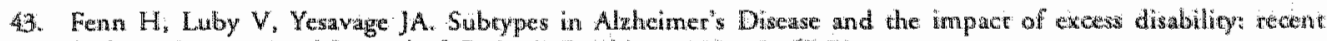
fundings. Incemacional Joumal of Geriatric Psychatry $1993: 8: 67-73$.

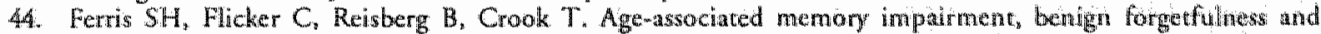
dementia. In: Bergener M, Reisberg B, ed. Diagnosis and reatment of senile denentia. Berlin-Heideberg: Springer Werlag, 1989:72-82.

45. Folstein MF, Bijlsma PW. Noncognitive symptoms of Alaheimer"s Diseise In: 1994:

46. Forene F, Henry J, Orgogomo ]. Reliability of clinical criterion for the diagnosis of dementa. Arehives of Neurology 1989:46: 646-648.

47. Fotard 1L; Metter E], Brant L]. Nexe steps in describing aging and disease in longitudinal snudies. Journal of Gerontology: Psychological Sciences 1990; $43: 116-127$.

48. Fratiglioni $17 Y$, Grut $M$, Vitanen GM, Winblad B. Clinical staging of denentia in a population survey:

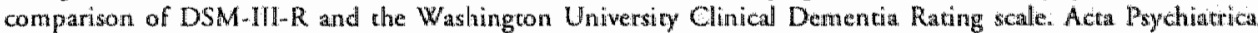
Scandinavica $1992 ; 86: 49-54$.

49. Frederiks JAM. The neurology of aging and dementia. In: Bruyn $D$, ed. Handbook of Clinical Neurology. Armsterdam: Elseviers Science Publishers BV, 1985: 199-219.

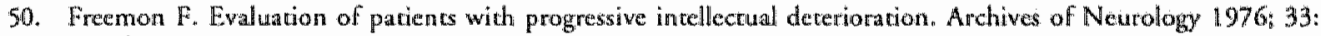
658-659.

51. Gaillard AWK, Gruisen A, De Jong R. The Influence of Andihistamines on human Performance. Eur ] Clin Pharmacol 1988; 35:249-254.

52. Galasko D, Kwo-on-"Yuen PF, Klaber MR, "Thal L. Neurological fundings in Alztheimer"s diwease and normal aging. Archives of Neurology 1990; 47:625-627.

53. Geffen $\mathrm{G}$, Moar KJ. O'Hanlon AP, Clark CR, Geffen LB. Performance measures of 16- to 86-yeatr-old males and females on the auditory verbal learning test. The Clinical Neuropsychologisk 1990;4:45-63.

54. Giacobini dis, Becker R. Development of Drugs for Alzheimer Therapy: A Decade of Progress. In: Gilacobini l:, Becker $\mathbb{R E}$, ed. Alzheimer" s Discase: Therapeutic Strategies. Basel: Birkhäuscr Verlag AG, 1994; 1-7.

55. Gray JA, Enz A, Spiegel R. Muscarinic agonists for senile dementia past expericnce and future trends. Trends Pharmacol Sci 1989; 10: 85-88.

56. Hachinsk $V$. Preventable dementia: a call for action against the vascular dementias. Lancer 1992; 340:645-648.

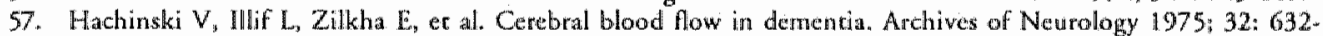
637.

58. Hartman DE. Neuropsychological toxicology: Identification and assessment of human nemroroxic syndromes. New York: Perganom Press, 1988.

59. Hatenfratz M. Bunge A, Dal Pra G, Battig K. Antagonistic effects of caffeine and alcohol on mental performance parameters. Pharmacol Biochem Behav 1993; 46: $63-5$.

60. Haug. H. Are neurons of the human cerebral cortex really lost during aging? In: Traber. J, Cispen. WH ed. Senile dementia of the Altheimer type. Berlin: Springer, 1985: 150-163.

61. Haxby JV, Grady $C L$, Duara $R$, et al. Relations among age, visual memory, and resting cerebral metabolism an 40 healthy men. Brain and Cognition 1986; 5:412-427.

62. Henderson AS, The epidemiology of Alaheimer's discase. Britista Medical Bullecin 1986; 42: 3-10.

63. Henderson AS, Huppert FA. "The problem of mild dementia. Pyychological Medicine $1984 ; 14: 5-11$

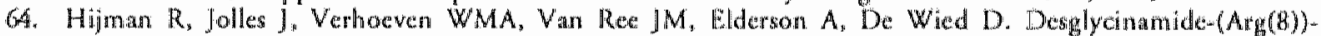
vasopresisin in five trials with memoryodisturbed patients. Hum Pychopharmacol $1992 ; 7: 7 \% 23$.

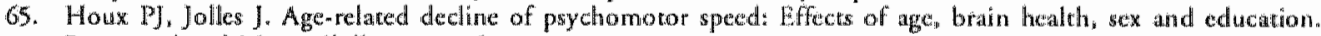
Perceptual and Motor 5kill: 1993; 76: 195-211.

66. Houx IJ), Vreeling FW, Jolles J. Cognirive aging and rish facrous for dementia. In: R. J. Wurtman SHC, \& J. H. Growdon., ed. Alaheimert's Disease: Procedings of the Sth meeting of the international study group on the Pharmacology of Memory disorders associated with aging. Center for Brain Sicicnees and Metabolism Charitable Trusi, 1989:4130417.

67. Houx PJ, Vreeling IFW, Jolles J. Age-associated cognitive declime is related to biological life ewents. In: lobal K, McLachlan DRC, winblad B, Wignicwski HM, ed. Alaheimer"s Disease: Basic Mechanisms, Diagnosis and Therapentic Strategics. Chichester, UK: John Wiky \& Sons Ltd, 1991: 353-359.

68. Houx PJ. Vreeling FW, Jolles J. Rigorous health screening reduces age effect on memory scanning taxk. Brain Cogn 1991; 15:246-60.

69. Houx PJ, Vreeling FW, Jolles I. Stroop interference: aging effects assessed with the Stroop Color Word Test. Experimental Aging, Research 1993: 19:209-224.

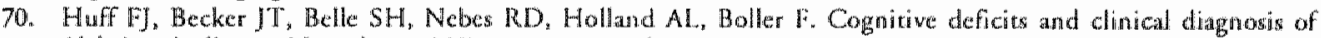
Alzheimer's disease. Neurology 1987; 37:1119\%1124.

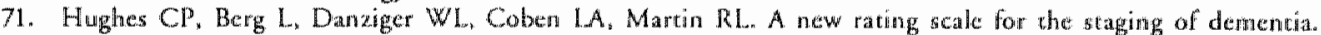
Buitish Jow mal of Psychiatry 1982; 140:566-572. 


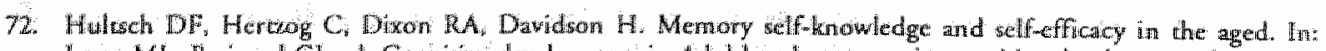

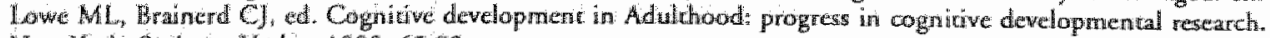

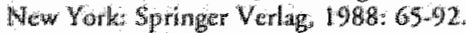

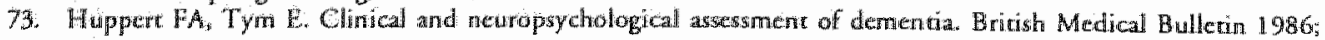
42:11-18.

74. Janisen KLR. Is treating memong imparmen in Alhetmer Disease an obfectre Trends in Neuroscience $1980.11: 210$.

75. Jarwis M. Does caffeine intake emhance absolute lewels of cogrative performance Psychopharmacology 1993 ; $110: 45-52$

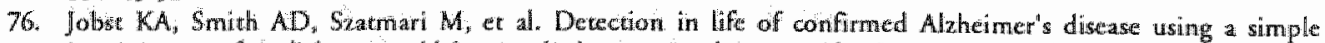
measurement of thedial remporal lobe atrophy loy computed tomography. Lancer 1992; 340:1179-1183.

77. Jolle J. Cognitive, emotional and behavioral dysfunctions in aging and dementia. In: Swab DF, Fllers $\mathrm{E}$, Mrmirian M, van Gool WA. Haaten. FW, ed. Progress in Brin Research. Amsterdam: Elsevier Science Publishers, $1986: 15-39$.

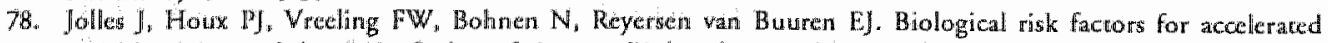
cognitive aging and dementia: findings from a multiple cohort scudy. Neurobiology of Aging 1990; $11: 293$.

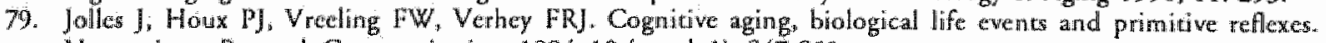

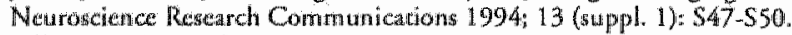

80. Jolles J, Verthey PRJ. On the racionale bethind treatment srudies in cogmitiwe aging and dernentia. In: Wolters EC,

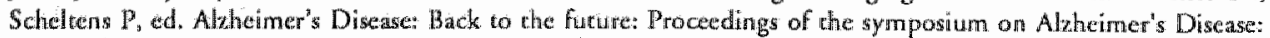
recent ad wances in diagnosis and ureatenent. Amsterdam, Vripe Universiteic Amisterdam. 1993: 75-84.

84. Jones RW" Wesnes KA, Kirlyy J. Effects of NMDA modulation in scopolamine demenria. Ann N Y Acad Sci $1991 ; 640: 241-4$

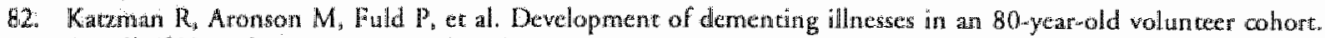
Annalis of Nourology 1089; 25:317-324.

83. Karman $\mathrm{N}$, Kawas $\mathrm{CH}$. "The epidemiologr of Dementia and Alameiner's Dise ine. In: 1994:

84. Kiloh LG. Pseudodemenvia. Acta Pyycharrica Scoindinavica 1961; 37: 336-351.

85. Kral VA. Neuro-psychiartic observations in an Old People"s home. Joumal of Gerontology 1958; 13: 169.176.

86. Kral VA. Senescent forgetfulness: Benign and malignant. Canadian Medical Association Journall 1962; 86: 257. 260.

87. Kral VA, Encry $O$. Long term follow-up of depressive pseudodenentia. Canadian Journal of Psychiarry 1989; 34: 445-447.

88. Larson EB, Reifler BV; Sumi SM, Canfield CG, Chinn NM. Diagnostic evaluation of 200 elderly outpatients with suspected dementia. Jourmal of Gerontology $1985: 40: 536-543$.

89. LaRue A. Aging and Neuropsychological Assessment. New York: Plenum Press, 1902.

90. LaRue A, Watson J, Plotkin DA. Rirse symptoms of dementia: a study of relatives' reports. International Journal of Geriamic Psychibitry 1993:8:239:245.

91. Levy R. Aging-Associated Cognitive Dedine: Working Party of the Inkernational Psychogeriatric Assaciation in Collaboration with WHO. Internat Psychogeriatric $1994 ; 6 ; 63 \% 68$.

92. Lister RG. The Effecs of Benzodianepines and 5-HT A Agonists on Learning and Memory. Lm: Rodgers RJ. Cooper S1, ed. 5-HTLA Agonists, 5.HT3 Antagonists and Benzodiazepines. Chichester: Wiley, 1991: $267-280$.

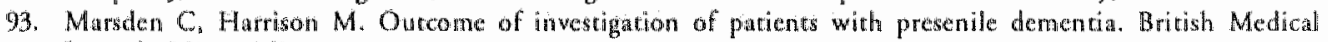
Jountal $1972 ; 2: 249$.

94. Masur DM, Sliwinki M. Lipton RB, Blau AD, Crystal HA. Metropspoloological predicrion of dementia and the absence of dementa in thealdy elderly persons. Neurology 1994; 44 : $1427-1432$.

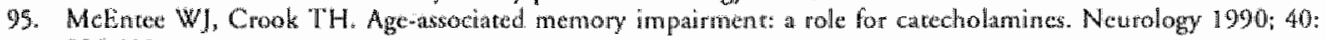
526330.

96. MeClone J. Gupta S, Humphry D, Oppenheimer $S_{1}$ Mirsen T, Ewans DR. Screning for carty dementia using memory complaints frem patients and relatuves. Archives of Neurology 1990; $47: 1189.1193$.

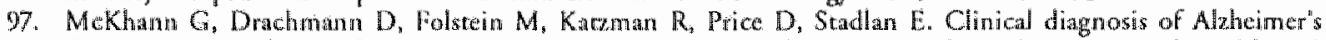
Disemse: report of the NINCDS-ADRDA workgroup under the auspices of the alcpartment of Heall and Human Serwecs task forct on Alltweimer's Disease: Neurology 1984: 34:939-944.

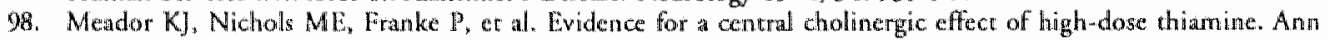
Neurol $1993 ; 34: 724-6$.

99. Michel B, Sambuc R, Sconto JC. French tecommendations for dinical drug trials in cognitive disonders of the elderly. Int. J. Geriatr. Psychaury 1994; 9: 823-828.

100. Molchan SE, Mellow AM, Lawlor BA, er al. TRH attertuates scopolanine-induced memory impairment in humans. Psychopharmacology Ber 1990; 100: 84-9.

101. Morris JC; Heyman A, Mohs RC, et al. The Consortum ro Establish a Registry for Alzheimer's Discase (CERAD). Nourology 1989:39: 1159-1165. 


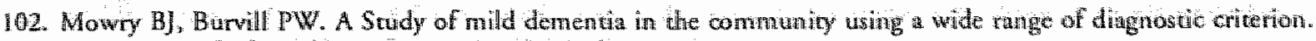
Bricish Journal of Pychumy 1988; $153: 328-344$.

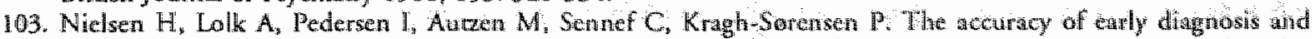

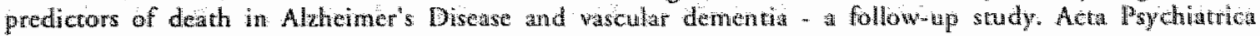
Scandlinav"lca $1991 ; 84: 277 \cdot 282$.

104. Nilsson LG, Backman L, Karlson. T. Priming and cued recall in elderly, alcohol intoxicated and steep

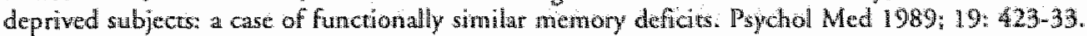

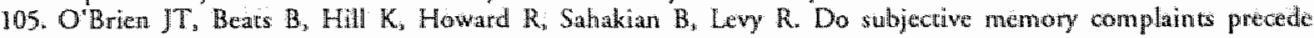
dementia? A three year follow up study of patients with supposed benign senescent forgetfulness" International Journal of Ceriatric Psychiatry $1992 ; 7 ; 481-486$.

106. O'Brien JT, Levy R. Age associated memory impaiment. BMJ 1992; 304:5-6.

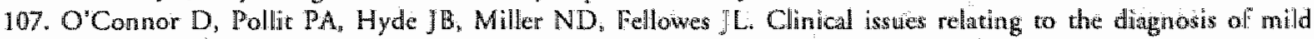
dementia in a Brish community survey: Archiwes of Neurology 1991: $48: 530-534$.

108. $0^{\circ}$ Connor DW, Pollit PA, Hyde JB, Fellows JL, Miller ND, Roth M. A follow-up study of dementia diagnosed in the commuitricy using the Cambridge Mental Disorders of the elderly examination. Acta Psychiarrica Scandinavica 1990;81:78-82.

109. O'Connor DW, Pollitr IPA, Roch M, Brook CPB, Reiss BB. Memory complants and impaiment in normal, depressed and demented elderly persons identifed in a community survey. Arohives of General Psychatry 1990 47: 224-227.

110. Persson G, Berg $S$, Nilsson L, Swanborg A. Subclinical dementia. Relation to cogntion, personality and psychopathology: a nine-year prospective study. International Journal of Geriatric Psychiatry 1991:6: 239-247.

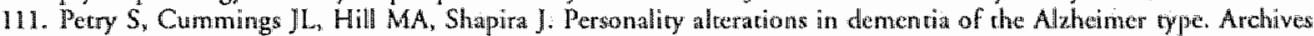
of Neurology 1988: $45: 1187-1190$.

112. Philpot MP, Levy R. Memory clinuc for the early diagnosis of dementa International Journal of Geriatric P'sychilatry 1987; 2: 195-200.

113. Plotkin DA, Mintz JM, Jarvik L." Subjective memo"y complaints in geriatric depression. Amertican Joutnall of Psychiatity $1.985 ; 1.42: 1103-1105$.

114. Phode DJ, Hoyer WJ. Artencion and performance: Ldencifying and localizing age deficits. In: Chatress $N$, ed. Aging and humin performance. Chicheser, UK: Wiley, 1985:47-99.

115. Popkin MK, Tucker G, Caine E, Folstein M, Grant I. The fate of organic mencal disorders in DSM VI: a progress report. Psychosomatics $1989 ; 30: 438,441$.

116. Preda $L$. Alberoni $M$, Bressi $S$, Cattuneo $C$, ex al. Effects of acture doses of oxiraceram in the scopolamine nudel of human amnesia. Psychopharmacology 1993; 110: 421-426.

117. Preston GC, Ward C, Lines CR, Poppleton P, Haigh JR, Traub M. Scopolamine and benzodiazepine models of dementia: cross-reversals: by Ro 15-1788 and physostigmine. Psychopharmacology Berl 1989; 98: 487-94.

18. Rabbit PMA. Applied cogniveive gerontology: some problems, methodologies and data. Applied Cognitive Psychology $1990 ; 4: 225 \cdot 246$.

119. Rabbitt PMA, Goward LM. Effects of age and raw $1 Q$ test scores on mean correct and mean error reaction times in serial choice tasks: A reply ro Smith \& Brewer. British Journal of Psychology 1986; 77: 69-73.

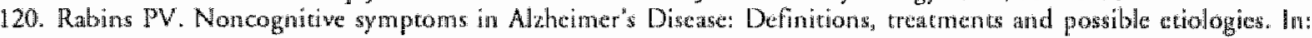
$1994:$

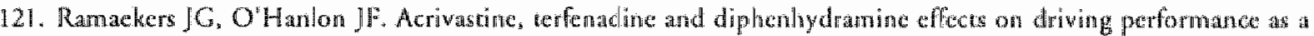
function of dose and rime after dosing, Bur. J. Clin. Pharmacol. 1994; 47: 261-266.

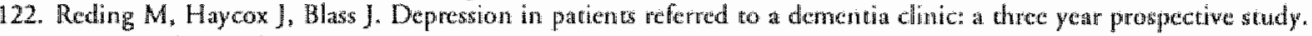
Archives of Nourology $1985 ; 42: 894 ; 896$.

123. Reese HW, Rodeheaver. D. Problem solving and decision noking. In: Birren JE, Schaie KW, ed. Handboole of the psychology of aging. 2 ed. New York: Van Nostrand Reinhold, 1.985:474 499.

124. Reisberg B, Ferris SH, De Leon MJ "Crook "T". The Global Deterioration Seale for assessment of primary degeneratiwe demencia. Anerican Journal of Psychiatry 1982; $139 ; 1136-1139$.

125. Riedel WJ, Hogervorst E, Leboux RLAM, Verhey FRI, Van Prang HM, Jolles J. Caffeine arenuates scopolamineminduced memory imparment in humans. Psychopthamacology 1995; in press: .

126. Riedel W], Jolles J. Decreased blood lewel of zinc: Does it explain Agenssoctated-Memory-Impayment? Neuropsychopharmacology $1923,9: 57$.

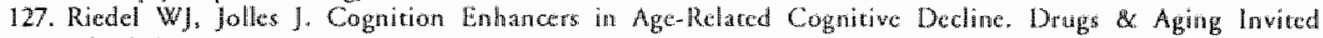
submission.

128. Riedel WJ, Van Pratg HM. Asoiding and Managing Anticholinergic Effects of Ancidepressants. CMS Drugs 1995: $3: 245-259$.

129. Riegel KF, Riegel RM. A study of the drop-out rates in longicudinal research on aging and the predictiosu of death. Journal of Personality and Social Psychollogy $1967 ; 4: 342-348$.

130. Riegel KF, Riegel RM. Development, drop, and death. Developmental Psychology 1972, 6: 309-316. 
13. Ritchic $K$, Touchen J. Heterogenciry in sente dementia of the Altheinter type: Individual differences, progressive deterioration or dinical suldypes? Clin Epidemial 1992:45:1391-1398:

132. Tobers JKA. Differential diagnosis in meuropsychiatry. Whley \& Soms, 1984.

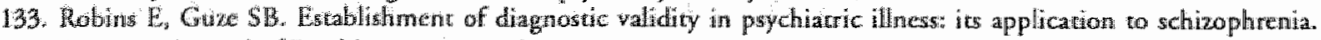
Arterican Jounal of Pychiatry 1970; 126.983 .987$.

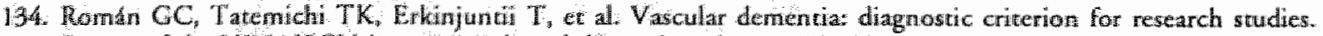
Report of the NDUAIRE internitional workshop. Neurology 1993; 43: 250.260.

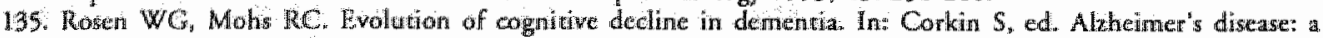
repore of progress New York: Raven Press, 1982: 183188.

136. Roth M, Huppert FA, Tym E. Moumtay CQ. CAMDEX: the Cambridge examination for mental disorders of the ederly. Cambridge: Unjwersity Press; 1988.

137. Roth $M$, Tym $\mathrm{E}_{\text {, Mountioy }} \mathrm{CQ}$ et al. CAMDEX: a standardised instrument for the duagnosis of mental disorder in the elderly with special reference to the early detection of dementia. British Journal of Psychiarry 1986; 149 : 698-709.

198. Rowe JW, Kahn RL, Human aging: Usual and successful. Science $1987 ; 237: 143-149$.

139. Rubin: EH, Kinscherf DA. Psychopathology of very mild dementia of the Alzheimer type. American Journal of Psychiatry 1989\%: 146:1017 -102:

140. Rubin $\mathrm{EH}$, Morris JC, Barg $\mathrm{L}$. The progression of personaliry chunges in patients with mild senule dementia of the Alathener rype. Journal of American Geriatric Sociey 1987; 35:721-725.

141. Rubin EH, Morris JC, Grant EA, Vendegna " $T$. Very mild senile dementia of the Alzheimer type: 1 . Clinical assessmentio Archives of Neurology $1989 ; 46: 379-382$.

142. Rush CR, Higgins 5T. Hughes JR, Bickel WK. Acute Behawioral Effects of Triazolam and Caffeme, Alone and in Combination, in Humans. Experimental and Clinical Pyrchopharmacology 1994:2: $211-222$.

143. Rusted J. Eaton-Willams P. Distinguishing between actentional and amnestic effects in information processing: The separate and combined effects of scopolamine and nicotine on verbal frec recall. Piychopharmacology 1991; 104: 363-366.

144. Salthouse TA. Speed of behavior and its implication for cognition. In: Birren JE, Schaie KW, ed. Handhook of the psychology of aging. New York. Wan Nastrand Reinhold, 1985: 400-426.

145. Salthouse TA. Resource reduction interpretations of cognitiwe aging. Developmental Review 1988; 8: $238-272$.

146. Schelicens $P$; Leys D, Batkhof F. Hippocampal atrophy on magnetic resonance imaging in Alahemer's disease and normal aging. Neurology $1991 ; 41: 341-342$.

147. Scinto LWM, Daffiner KM, Dressler D, et al. A Potential Noninwasive Neurobiological "Jest for Alaheimer's Discasc. Science 1994; 266: 1051-1054.

148. Shimamura AP, Squire LR. Memory and metamemory a study of the feeling-ofmonowing phenomenon in amnestic patients. Journal of Experimental Psychology 1986; 12: 452-460.

1.49. Smith J, Kiloh L. The investigation of demerntia: results in 200 consecutive admissionss. Lancet 1981; it: 824 827.

150. Soininen HS, Partanen K. Pitkanen A, et al. Volumetric MRL analysis of the amygdala and che hippocampus in subjects with age-aswociated memory impaiment correlation to visual and verbal memory. Neurology 1994; 44 : $1660=8$.

151. Spicker R, lirst MB, Whlliams JBW, Kendler K, Pincus HA, Tucket G. Now is the time to retire the term "organic mentall disorders". American Journal of Psychiatry 1992; $149: 240-244$.

152. Spitzer $R$, Willians JBW, Pirst M. A proposal for DSM-IV" solwing the "organic-nonorganic" problem. J Neuropsychatity and Clinical Neurosciences 1989 ; Spriag: 261127.

153. Stones MI, Kowma A. Physical performance. In: Chamess $\mathrm{W}$, ed. Aging and human performanoe. Chichester: UK: Willey, $1985: 261-291$

154. Stones Mf, Kouma. A. Hannah TE. The measurenent of individual differences in aging: The distinction betwen thual and successful aging. $\| n$ : Howe $M L$, Stones $M$ ], Brainerd $\mathrm{CJ}$, ed. Cognitive and behavioral performanec factous in arypical aging. New York: Springer, 1990: 181-218.

155. Storande M, Botwinick $]$. Danziger WL, Berg L, Hughes CP. Psychometric differentiation of mild dementia of the Alzheimer type. Archives of Neurology $1984: 41: 497-499$.

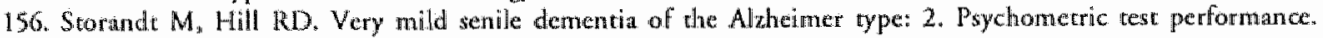
Archives of Neurology $1989 ; 46: 383-386$,

157. Sunderland A, Wate K, Baddeley AD, Harris JE. Subjective memory assessment and teste performance in eiderly adults. Journat of Gerontology $1986 ; 41: 376-384$.

158. Thal L. Clinical turits in Alxheimer's Disease. In: Terry RD, Katuman R, Bick KL, ed. Alzheimer"s Disease. New York: Raven D"ess, $1994: 431.444$.

159. Tyrell I, Hardy J. Rosor M. Tetrahydroaminoacridine and Alzheimer"s disease. The Lancex 1987; I: 444.

160. Van Duijn M, Hofman A. Relarion beween nicotine intake and Alaheimer's discase. BMJ 1991; 302: 1491. 1494 
161. Verhey FRJ, Jolles J, Ponds RWWM, et al. Dingnosing dementiat comparison between monodisciplinary andi a

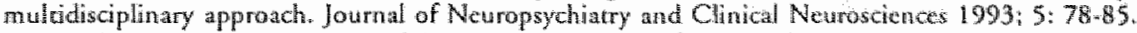

162. Verhey FR], Lodder J, Rozendal N, Jollug J. Criberia for the clinical diagnosis of vasular dementian a comparison between seven current sets. Neurobiology and Aging 1995: 15: in press.

163. Verhey FR: Rozendaal N, Ponds RWHM, Jolles J. Dementia, Depression and Awaneness. International Joumal of Geriatric Psychiary 1993; 8:851-856.

164. Verillo RT, Werillo $\mathrm{V}$. Semsory and perceptual performance ln: Chames $N_{n}$ ed. Aging and human performance. Chichester, UK: Wiley, 1985: 1-46.

165. Vreeling FW, Jolles], Verhey FR, Houx PJ. Primitive reflexes in Alzheimuer's disease and vascular dementia. Journal of Geriatric Psychiatry and Neurology 1995; in press: .

166. Weinstein H. SPECT in Alzheimer's disease. Amsterdam: Universin Press, 1992.

167. Weinstein HC, Teunisse $\$$, Van Gool WA. Terrahydroamineacridine and lecithme in treatment of Azhemerm's Disease: effect on cognicion, funcrioning in daily life, behavioral disturbances and burden experienced by the carers. Jourmal of Neurology 1991; 238: 34-38.

168. Welsh K, Buters $N$, Hughes J. Mohs R, Heyman A. Decetion of abnormal memory docline in mild cases of Alzheimer"s disease using CERAD neuropsychological measures. Archives of Neurology 1991; 48:278-281.

169. Wesnes $\mathrm{K}$, Jones RW, Kirby J. The effects of D-cycloserine, a glycine agonist, in a human model of the $\infty \mathrm{gnhive}$ deficits associated with ageing and dementia. Br J Clin Pharmac 1991; $31: 577-578$.

170. Wesnes K, Parrot A. Smoking, Nicoune and Humarn Performance. In: Handbook of Human Performanoe. Academic Press Lad, 1992: 127-167.

171. Wesnes $K$. Revell $A$. The separate and combined effects of seopolamine and nicotine on human intormation processing. Psychopharmacology 1984; 84:5-11.

172. Wesnes KA, Anand R, Simpson IPM, Christmas L. The wse of a scopolamine model to study the poteneial nowtropic effects of aniracetam and piracetam in healthy wolunkers. Jouryal of Psychopharmacology $1990 ; 4$ : 219-232.

173. Whalley 1.J. Drug treatments of dementia. British Journal of IDychiatry 1989; 155:595-611.

174. Wolkowic OM, Tinklenberg JR, Weingartner HA. Psychopharmacological perspective of cognitiwe Functions. Netropsychobiology $1985 ; 14: 88-96$.

175. Woodruff DS. Arousal, sleep, and aging. In: Birren JE, Schaie KW, ed. Handbook of the psychology of agitug. Now York: Van Nostrand Reinhold, 1985:261-295. 


\section{Chapter 2}

\section{Memory Scanning, Automatic Processing and Focussed Attention in AAMI*}

Abstract. The relation between memory complaints and cognitive dysfunction was inwestigated in a group of 36 subjects fulfilling the criteria describing Age-Associated Memory Impairment and a group of 36 control subjects who were matched for Age, Sex, Educational level and History of exposure to Health-related factors. The groups could be considered equal except for the presence and abscence of memory complaints. Measures of memory scanning, encoding, reading, color naming and collor-word interference were obtaimed using different versions of a letter-cancellation task and the Stroop task. The results showed that subjects with memory complaines were slower on all target/non-target discrimination tasks, especially when targets and non-targets were both leters. Their basic reading speed was also significantly slower compared to controls. The speed of the memory scanning process was the same in both groups. However, non-scanning stages were impaired (same slopes, different intercepts). It was concluded that these results yielded an objective basis for the memory complaints and were most likely related to a general slowing in the encoding stage of information processing.

- Riedel W], Houx PJ, Jolles J. Submitted for publication 


\subsection{INTRODUCTION}

Age-Associated Memory Impaiment (AAMI) refers to a condition which may exist in people over 50 years of age, suffering from memory complaints and fulfilling a number of criteria referring to their objectively measured memory performance as well as the exclusion of specific medical conditions [3]. Certain aspects of the AAMI concept have been criticized [1]. Blackford \& Lakue $\mid 1]$ added to the following new categories to AAMI: Age-Consistent Memory Impairment (ACM1) for performance within \pm 1 SD of the mean established for age on $75 \%$ or more of the formal tests administered, and Late Life Forgetfulness (LLF) to denote performance between 1 and $2 \mathrm{SD}$ below the norm established for age on $50 \%$ of the tests administered. Yer, the AAMI criteria are well-defined operationally and provide a basis for selecting research subjects for studies into epidemiology of normal aging and to evaluate the effect of pharmacological or other forms of intervention. More refined criteria have recently been proposed which render the AAMI concept more fruitful for research and clinical applications [4, 10].

With respect to the nature of cognitive deterioration with age, it becomes increasingly clear that apart from memory, various other cognitive processes deteriorate as well. Various authors favour the notion that decreased processing speed is a central deficit underlying these processes $[6,11,14]$. The notion of decresed availability of resources and/or working memory is also relevant in this respect [15]. Information processing tasks prove especially sensitive to the effects of aging [16, 19]. Thus, Houx et all. [7] showed, that a paper and pencil version of the memory search task (P\&P-MST) based upon the Sternberg-paradigm, and the Stroop-task, were more sensitive to the effects of age, than performance on a secondary memory task [8]. In the latter task, individual differences were largely explained by the presence or absense of health related factors or so-called Biological Luffe Events (BLE). In particular it was found that subjects in older age groups needed more time for both scanning and non-sicanning stages of memory search when performing the P\&P-MST and that their overall accuracy was decreased. Movements and scanning of the test sheets were slower, as was memory search. With respect to the Stroop task, a very slight decrement with age, of basic reading speed was observed. Color naming was more slowed down, but a striking age effect was found as for word interference with color naming, both for subjects with and without BLE. These results suggest an application of these tests in the study of normal subjects with memory complaints, i.e., subjects with AAMI or a related condition.

Although Crook et al. [3] focus the core of AAMI around age-associated decline of performance upon secondary memory tasks, the data presented by Houx et al. [7, 8], suggest that other tasks may be more sensitive to the effects of age-associated decline and also that health related factors play an important role. Futhermore, in the criteria defined by Crook et all, the objective memory performance of AAMI subjects is compared with reference values obtained from young adults. In order to answer the question whether memory complaints in AAMI subjects really refer to abnormally diminished performance, one should compare the AAMI subjects to non-complaining age-matched controls. Aso, the influence of other factors contributing to performance, such as BLE, educational level and sex should be controlled for.

The question then becomes, after taking into account the known effects on cognitive functions of age, BLE, level of education and sex: Are subjective memory complaints associated with impaired cognitive functions? The operationalisation of that question is as follows: Do persons suffering from AAMI perform worse in terms of cognitive processes that have been shown to be sensitive for the effects of normal aging; i.e., memory scanning and Stroop color-word interference, when compared to normal controls of the same age, sex level of education and having the same BLE-history? 


\subsection{METHOD}

\subsubsection{Subjects}

The subjects consisted of two groups. An experimental group of 36 persons who had responded to a newspaper advertisement and were screened for meeting the AAML-criteria [3] and control group, taken from the database described by Houx [5], which comprised a sample of 36 persons whose sex, age, education and BLE-history matched with those of the experimental group.

Table 1 Age, Education, Sex and BLE-history of the AAMI- and control subjects

\begin{tabular}{|c|c|c|}
\hline & AAMI $(\mathrm{n}=36)$ & Controls $(n=36)$ \\
\hline $\begin{array}{l}\text { Age (meant se) } \\
\text { (range) }\end{array}$ & $\begin{array}{l}64.47 \pm 1.16 \\
(5 H-81)\end{array}$ & $\begin{array}{l}64.67 \pm 1.19 \\
(47-78)\end{array}$ \\
\hline $\begin{array}{l}\text { Education (mean } \pm \text { se) } \\
\text { (range) }\end{array}$ & $\begin{array}{l}4.64+.23 \\
(1-7)\end{array}$ & $\begin{array}{l}4.72 \pm .22 \\
(1-7)\end{array}$ \\
\hline $\operatorname{Sex}(M / F)$ & $17 / 19$ & $17 / 19$ \\
\hline BLE $(0 />-1)$ & $17 / 19$ & $17 / 19$ \\
\hline
\end{tabular}

\subsubsection{Assessments}

Memory Scanning Test. The paper \& pencil memory scanning task consists of 9 different subtasks, each on a separate sheet of A4 paper, containing a matrix of $12 \times 12$ letters, digits or other characters. For each subtask, the subject is requested to memorize 1-4 target characters the memory set) and to check on them as quickly as possible, without making mistakes, each time they occurred on the test sheet. The method of distractor sellection is adapted from Logan [12]. The subject was accurately instructed and checked out to work line by line, to prevent the subject from scanning a whole page for one target. Non-targets (distractor characters) were always letters. Each test sheet contained 24 targets and 120 distractors. In the 9 successive subtasks, divided in three types, the targets were: Subtask 1 and 9: the percentage $\operatorname{sign}(" \% ")$. Subtask 2-4: 1, 2 or 4 different digits. Subtask 5-8: $1,2,3$ or 4 leters. The total time needed by the subject to complete each subtask was timed with a stopwatch. Two individual total time $x$ set size functions were calculated, one for the 3 digit subtasks, and one for the 4 letter subtasks. These functions were defined by the equation $T t=A^{*} S_{s}+B$, in which: $T t=T$ otal time, $A=$ slope of the function (i.e. the amount of extra time needed per item in the memory set). Ss $=$ memory set size, and $\mathrm{B}=$ intercept with the $Y$-axis (in contrast to other studies, the $X=1$-intercept was calculated to avoid theoretical dispute). The linearity of the function was also calculated. Theoretically, the 1intercepts for the digits and letter functions are the same, but the slope of the letters subtasks is markedly steeper than that of the digit subtasks, as the subject can adopt the strategy of crossing out all digits whatsoever, instead of paying attention to each separate character. The linearity ( $r$ ) of the time $x$ set size function can be taken as a measure of the consistency with which the subject completed the tasks. Usually, the correlation coefficient is as high as .90 in the letter subtasks [2]. Evaluating the degree of automatic processing is achieved by comparing the results as a function of 
arget/non-target similarity: the response times when the target is a $\%$-sign, 1 digit and 1 letter respectively, arce assumed to increase as a function of increasing target/non-target similarity, since the non-targets are always letters.

Stroop Color Word Test. We used the wersion of three cards of $10 \times 10$ items [13]. The three cards contained respectively, written color names, colored patches, and written color names printed in an incongruent manner as to the color denoted by the word and the color of the ink. The task yielded tresponse thes of reading speed, color-naming speed, and color-naming speed while suppresing reading.

\subsubsection{Design and Analysis}

The between groups factor in the design is called memory complaints and its two levels (presence, abscence) refer to the AAMI and control group respectiwely. In the memory scanning task, the scores for the \%-sign and the slopes and intercepts as calculated in the regression functions for digits and letters are the dependent variables. In the analysis of the effect of target/non-target similarity, the average score for the \%-sign, and the calculated 1 -intercepts for digirs and letters constitute the low-, medium- and high levels of within subjects factor target/non-target similarity. On the Stroop task, scotes on the reading-, color-naming- and collot-word interference are the dependent variables.

The differences between test scores of patients and controls were compared using univariate and multiwariate analysis of variance. One between groups factor (memory complaints) was prominent in each analysis. Tasks with one dependent variable were analyzed with a univariate analysis of variance. Tasks with mulriple dependent parameters were analyzed with a multivariate analysis of variance.

\subsection{RESULTS}

The results from all Memory Scanning subtasks and their regression functions for digits and letrers as well as the Stroop subtasks are listed in Table 2. As can be seen, the AAMI group is generally slower than the control group irrespective of the nature of tasks. This effect is significant when multivariately tested with dependent variables $\% 1, \% 2$, slopes and intercepts of digits and letters $\left(F_{6,65}=2.17 ; \mathrm{p}=.05\right)$. Univariate tests yield only a significant group difference for the 1 intercept of the letter function $\left(F_{1.70}=9,02 ; \mathrm{p}<.005\right)$. The 1 -intercept of the digit function is not significantly different between the groups and neither are the slopes of both digit and letter finctions.

In figure 1 the regression funcrions as found for the AAMI and the control group are plotted with the raw data, with respect to the letter subtask. In figure 2 the response times are plotted as a function of target/non-target similarity. The target/non-target similarity variable consists of three lewels referring to increasing similarity. The average response time of the \%-sign condition is taken as the lowest simillarity lewel. The 1-intercepts of the digit- and letter regression functions are taken as the medium and high similarity levels respectively. Hence, the target was a sign, a digit; or a letter. Non-targets were always letters. Multivariate analysis of these data reveal a main effect of $A A M l\left(F_{1,70}=4.94, p<.05\right)$, a main effect of target/non-target similarity $\left(\mathrm{F}_{2,69}=113.5, p<.0001\right)$ and an interacrion effect of AAMI with target/non-target similarity $\left(F_{2,69}=3.6, p<.05\right)$ 
Table 2

Response times for Mennory Scamrung tasks and Stroop Tank

\begin{tabular}{|c|c|c|c|c|c|c|c|c|}
\hline & \multirow{2}{*}{\multicolumn{2}{|c|}{$\begin{array}{l}\text { AAMI }(\mathrm{n}=30) \\
\text { Mean s.e }\end{array}$}} & \multirow{2}{*}{\multicolumn{2}{|c|}{$\begin{array}{l}\text { Controls }(n=36) \\
\text { Mean se. }\end{array}$}} & \multicolumn{2}{|c|}{ Uniwariate rest } & \multicolumn{2}{|c|}{ Multivariate } \\
\hline & & & & & $\mathrm{F}_{(1,70)}$ & $p<$ & $F(2,69)$ & $\mathrm{p} 2$ \\
\hline \multicolumn{9}{|l|}{ Memory Scanning } \\
\hline Signss & & & & & & & $2 \pi$ & \\
\hline$\% 1$ & 30.7 & 1.4 & 28.1 & 1.2 & 20 & & & \\
\hline$\% 2$ & 30.3 & 1.5 & 26.6 & I.1. & 3.8 & 05 & & \\
\hline \multicolumn{9}{|l|}{ Digits } \\
\hline 1 & 32.9 & 1.6 & 30.0 & 1.1 & 2.4 & & & \\
\hline 2 & 42.7 & 2.2 & 38.7 & 1.4 & 2.4 & & & \\
\hline 4 & 45.7 & 2.5 & 41.1 & 1.6 & 2.4 & & & \\
\hline Regression: & & & & & & & 1.3 & \\
\hline Slope & 3.9 & 0.4 & 3.4 & 0.4 & 0.8 & & & \\
\hline Invercept & 35.3 & 1.7 & 32.1 & 1.1 & 2.5 & & & \\
\hline Linearity & .84 & .03 & .73 & .05 & & & & \\
\hline \multicolumn{9}{|l|}{ Letrers } \\
\hline 1 & 36.8 & 1.4 & 32.3 & 1.2 & 6.1 & .02 & & \\
\hline 2 & 53.5 & 2.4 & 46.2 & 1.5 & 6.8 & .01 & & \\
\hline 3 & 62.2 & 3.1 & 55.3 & 2.0 & 3.5 & & & \\
\hline 4 & 70.9 & 4.1 & 66.6 & 2.5 & 0.8 & & & \\
\hline Regression: & & & & & & & 4.7 & .01 \\
\hline Slope & 11.1 & 1.0 & 11.2 & 0.8 & 0.0 & & & \\
\hline Intercept & 39.2 & 1.5 & 33.3 & 1.3 & 9.0 & .004 & & \\
\hline Linearity & .93 & .01 & .95 & .01 & & & & \\
\hline Stroop & & & & & & & 8.0 & .0001 \\
\hline Reading & 48.6 & 1.6 & 41.5 & 0.8 & 15.6 & .0001 & & \\
\hline Color_mamingr & 59.3 & 1.8 & 57.4 & 1.6 & 0.6 & & & \\
\hline Interference & 99.7 & 4.1 & 105.0 & 4.8 & 0.7 & & & \\
\hline
\end{tabular}

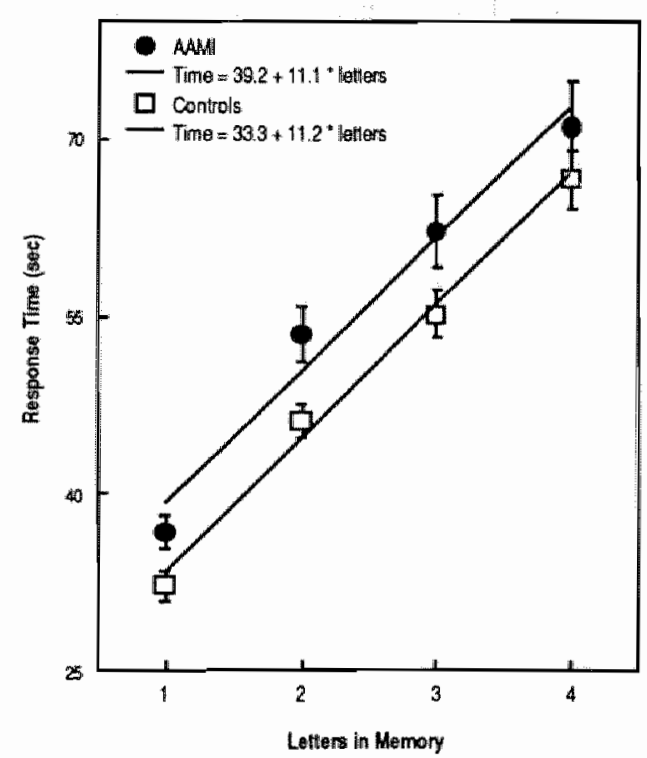

Figure 1 The function of Memory Load on Response Time

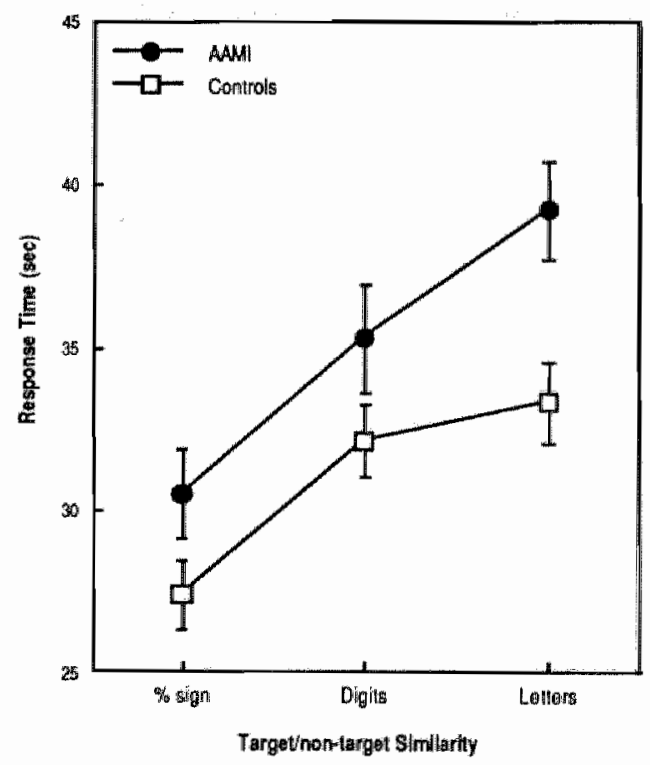

Figure 2 The function of Similarity on Response Time 


\subsection{DISCUS5ION}

The results showed that memory complaints are associated with increased response times on the memory scanning task, unrelated to the memory scanning process itself. Furthermore, memory complaints are also associared with a relatwely prolonged processing time in the high target/nontarget similarity condition of distinguishing target letters from non-target letters. These data point to both an increased time to encode verbal stimulli (i.e. letters as opposed to signs or digits) in memory complainers, as well as a prolonged time to prepare and /or execute al manual response. The results of the Stroop test show that reading speed in the memory complainers is significantly prolonged relative to the control group, whereas color naming speed in memory complainers is the same as in the control group. The latter result strongly suggests, that there exists neither a difference between the groups in terms of centrally mediated motor preparation, nor in verbal response execution speed. This makes it less likely that the difference between the groups in terms of overall response speed on the memory comparison task should be atributed to a manual response execution speed effect. It could also be explained by assuming that besides a slower specific verbal encoding as observed in the high target/non-target similarity condition, the memory complainers are characterized by slower encoding of symbolic stimuli (signs, digits and letters, but not colors). However, from these analyses it cannot be concluded whether the results are explained by the encoding effect or by the manual response execution effect. A simple index of manual response execution speed (e.g. tapping) could be a decisive measure in this respect.

The encoding process of symbolic stimuli, especially with respect to those stimulus features that are necessary to discriminate target letters from non-target letters (i.e. their characteristics as different letters of the alphabet) is for some reason more prolonged in memory complainers. The encoding of letters is an automatic (i.e. overlearned) process which is a prerequisite for the reading process. Therefore, the results seem to be consistent across the Memory Comparison and the Stroop Task, since a prolonged basic reading speed in the Stroop Task was also observed in the memory complainers. Automatic information processing is unrelated to conscious awareness whereas controlled processing is experienced as mental effort $[17]$. Hence, increased time allocated to controlled processing is more likely to be related to subjective complaints. However, the distinction between automatic and controlled processing is not as absolute as it seens. Alrhough there is evidence that certain processes are $100 \%$ automatic, most automatic information processing is regularly interupted by controlled processing. These interruptions lead to automatic attention reactions that are experienced consciously [18]. Hence in certain automatic processing tasks one could say that the balance automatic processing / controlled processing is for cxample 90\% / 10\%. An explanation that would bring these data in line is that in the encoding of letters and hence in the reading process in the AAMI group the balance automatic/controlled processing is shifting towards controlled processing. Firstly, the shift towards controlled processing or intertupted aucomatic processing explains the prolonged time to perform the relevant tasks, secondly it explains the development of complaints.

In conclusion, we can say that a group characterized by AAMI when compared with a non-AAMI control group, displayed prolonged time to perform target/non-target discrimination- and reading tasks. Detailed analysis showed that especially the encoding of letters and in line with this basic reading speed, were prolonged.

The findings support the notion that, first, subjects who are sercened against the AAMI citeria and compared to carefully matched controls are characterized by decreased performance on various information processing tasks. This suggests that these subjects do in fact show objective cognitive dysfunction when compared to the age norms and that they may form a group between "normal and healthy aging" and more pathological conditions (see [9] for a discussion). Secondly, the present findings show that cognitive proceses apart from remembering and forgetting (memory") are important to take in consideration when evaluating the effects of age. The present results suggest that information processing tasks such as those used here may be of more relevance than the 
traditionaly used tests for secondary memory for studies which evaluate the effects of incerventions such as in drug trials.

\section{REFERENCES}

1. Blackford RC, LaRue A. Criteria for diagnosing age-associated memory impairment: Proposed improwements from the field. Developmental Neuropsychology 1989; 5: 295-306.

2 Brand $N$, Jolles J. Information processing in depression and anxiety. Psychological Medieitie 1987; 17: 145. 153.

3. Crook T, Bartus RT, Ferris SH, Whitehouse $\mathrm{P}$, Cohen GD, Gershon S. Age-associated memory impaurment: Proposed diagnostic criteria and measures of clinical change: Report of a National Institute of Mental Health work group. Developmental Neuropsychology 1986: 2: 261-276.

4. Derouesné $C$, Kalafat $M$, Guez D, Malbezin M. Poitrenaud J. The Age-Associated Memory Impairment Construct Revisited. International Journal of Geriatric Psychiatry 1994; 9: 577-587.

5. Houx PJ. Cognitive aging and health-related facrors. Maastricht: Datawyse, 1991.

6. Houx PJ. Jolles J. Age-related decline of psychomotor speed: Effects of age, brain health, sex and education. Perceptual and Motor Skills 1993; 76: 195-211.

7. Houx PI, Vreeling FW, Jolles J. Age-associared cognitive decline is related to biological life events. In: Iqbal K, McLachlan DRC, Winblad B, Wisniewski HM, ed. Alzheimer's Disease: Basic Mechanisms, Diagnosis and Therapeutic Strategies. Chichester, UK: John Wiley \& Sons Ltd, 1991: 353-359.

8. Houx PJ, Vreeling FW, Jolles J. Stroop interference: aging effects assessed with the Stroop Color-Word Test. Experimental Aging Research 1993; 19: 209-224.

9. Jolles J, Verhey FRJ, Riedel W]. Houx PJ. Cognitive Impairment in Elderly People: Predisposing Factors and Implications for Experimental Drug Studies. Drugs \& Aging; in press.

10. Levy $\mathbb{R}$. Aging-Associated Cognitive Decline: Working Party of the Intemational Psychogeriatric Association in Collaboration with WHO. Internat Psychogeriatric 1994; 6: 63-68.

11. Lindenberger $U$, Mayr U, Kliegl R. Speed and intelligence in old age. Psychol Aging 1993; 8: 207-20.

12. Logan GD. Atrention in character-elassification tasks: Evidence for the automaticity of component stages. Journal of Experimental Psychology General 1978; 107: 32-63.

13. Nehemkis AM, Lewinson PM. Effect of left and right cerebral lesions in the naming process. Perceptual and motor skills $1972 ; 35: 787-798$.

14. Salthouse TA. Speed of behavior and its implications for cognition. In: Birren JE, Schaic KW, ed. Handbook of the psychology of aging. New York: Van Nostrand Reinhold, 1985: 400-426.

15. Salchouse TA. Working memory as a processing resource in cognitive aging. Special Issue: Limited resource madels of cognitive development. Dewelopmental Review 1990; 10: 101-124.

16. Salthouse TA. Mediation of adult age differences in cognition by reductions in working memory and speed of processing. Psychological Science 1991; 2: 179-183.

17. Schneider W, Shiffrin RM. Controlled and automatic human information processing: I. Detection, starch, and attention. Psychological Review 1977; 84: 1.66.

18. Shiffrin RM, Sehneider W. Controlled and automatic human information processing: II. Perceptual lcarning, automatic attending and a general theory. Psychological Rewiew 1977; 84: 127-190.

19. Verhaeghen $P$, Marcoen A, Goossens I... Facts and Fiction About Mernory Aging: A Quantitative Integration of Research Findings. Journal of Gerontology 1993; 48: P157-P171. 


\section{The Scopolamine Model of Cholinergic Depletion: Model of Memory Dysfunction ?*}

Abstract. One of the key elements of the cholunergic hypothesis of geriatric dysfunction is the scopolamine model of cholinergic deplecion. The question whether scopolamine-induced cognitive deficits resemble those seen as a consequence of aging has been addressed many times. In this study, scopolamine was administered to 16 healthy young $(25-35$ yr) volunteers. The effects of scopolamine on cognition was evaluated using a neuropsychological test battery. "The effects of scopolamine were compared with the effects of age on cognitive functions which were obtained previously in a large cross-sectional aging study. The effects of scopolamine on cognition were assessed at 2, 4, and 6 hours after drug administration and were compared to baseline performance. The results showed that scopolamine impaired memory functions severely and cognitive and motor speed consistently. However, executive functions not involving memory, such as response inhibition were spared by the effect of scopolamine. When the effects of scopolamine were compared to those of age, it appeared that while age has a pronounced effect on cognitive functions that heavily depend on the general awailability of information processing resources, scopolamine more specifically impairs memory functions. It could be interpreted that scopolamine induces a depletion of resources specifically for memory processes (such as storage, consolidation, search and retrieval). Hence the general resource depletion hypothesis of scopolamine could not be supported.

"Riedel WJ, Hogervorst E, Houx PJ, Jolles J. Submitted for publication 


\subsection{INTRODUCTION}

Age differences in memory performance are lange and omnipresent [13,33". Apart from memory, various other cognitive processes appear to deteriorate as age adwances. General speed of information processing declines as well as attentional processes and problem solving. With respect to memory function, evidence of an important cholinergic role in age-related disturbances has led to the cholinergic hypothesis of geriatric memory loss [1].

The cholinergic hypothesis of geriatric memory dysfunction has stimulated much of the research that has been done using the scopolamine model of cholinergic dysfuncrion. At the same time, cholinergic drugs were introduced as tools to study the psychology of information processing [35]. Despite many criticisms, particularly with respect to the validity of the scopolamine model as a model of dementia or age-related cognitive decline $[22,30]$, the number of studies on the effects of scopolamine on human cognition and its use as a screening model for cognirion enhancing drugs, is still increasing rapidly. In the past five years only, 21 studies have been published in which the scopolamine model was used as a screening model for putative cognition enhancing drugs [23].

The most persistent effects of scopolamine on human cognition are its impairing effects on shortand long-term memory [14]. For this reason, it has been assumed that the memory effects of scopolamine could be atributed to cholinergic blockade of neurons particularly involved in memory functions. However, it was not clearly resolved whether the memory impairments induced by scopolamine are brought about by the disruption of storage processes, retention processes, or retrieval processes in memory [36]. The comparison of the effects of scopolamine on memory functions in healthy volunteers using clinical neuropsychological assessments similar to those used in Alzheimer"s disease and Korsakoffs disease parients, led to the conclusion that cholinergic blockade, induced by scopolamine, is a model for tholinergic depletion and not for clinical amnesia such as in Alzheimer's disease and Korsakoff's disease [15]. The discussion has shifted towards the view that scopolamine induced sedation and impaired attention and hence impaired memory indirectly, rather than impairing memory processes such as storage, retention, or retrieval directly [6]. Scopolamine impaired working memory and its impairing effects were attributed to a decrement at the level of the central executive mechanism rather than at the subsystems under its control [25]. Scopolamine was found to impair early processes in the selection of attention which led to the contention that scopolamine disrupted the automatic capture of attention, inducing more serial processing $\llbracket 4 \rrbracket$. Scopolamine was also found to broaden the focus of attention, thus hampering focussed attention in particular [5]. The opposite, i.e. the association of cholinergic dysfunction with divided artention deficits, has also been suggested [22]. The resource interpretation of the effects of scopolamine on cognition includes the attribution of the impairing effects of scopolanine on controlled information processing, presumably due to a reduced awailability of resources, rather than on automatic information processing $[24]$. Comparison of the effects of scopolamine in young and elderly volunteers revealed an increased sensitivity of elderly humans to the cognition impairing effects of scopolamine, a finding which appears to be consistent with the cholinergic hypothesis of geriatric memory dysfunction [19].

The revived interest in cholinergic drugs as cognition enhancers and anti-dementia drugs, the many untesolved questions as to the effects of scopolamine on human information processing, and the availability of studies into the effects of scopolamine and aging carried out in our memory clinic using the same assessments, call for a re-evaluation and a re-validation of the scopolamine model in terms of its validity with respect to modelling cognitive deficits seen in normal human aging. In the study described in this paper, the effects of scopollamine on human cognition were assessed using a battery of tests of cognirion and performance that had previously been shown to be sensitive to the effects of normal aging ${ }^{19-12]}$. The test battery is also used as a diagnostic tool in the clinical assessment of memory problems in patients attending the memory dinic [34]. One of the major conclusions from the investigation of the effects of age on cognitive function was that age-related decline of cognitive-, perceptual- and psychomotor speed was found to be at least as 
prominent as age-related decline of memory function. It was taken to support the notion that decreased resource availability precedes age-relared decline of memory function $128 \mathrm{j}$. The latrer, and the notion that scopolamine would act via a decreased availability of resources for controlled processing was one of the questions to be answered by comparing the effects of scopolamine and age on cognition and performance. It led to the hypothesis that scopolamine would not onlly impair memory, but also induce slowing of perceptual-, atrentional, executive-, and psychomotor functions. Another question, that was addressed as a new testable hypothesis, was the introduction of a specific measure of storage in memory: the index of subjective organisation in free recall $[2$, 311. This is a numerical index of the way verbal material is organized, or chunked, in working memory. If the effect of scopolamine would be primarily on storage in memory, the predicrion would be that this index indicates decreased efficiency of storage, in short-term or working memory, particularly in long-term memory.

\subsection{MATERIAL AND METHODS}

\subsubsection{Subjects}

Sixteen healthy volunteers, balanced for gender, between 25 and 35 years of age were recruited. All subjects agreed to refrain from taking any form of medication, except oral contraceptives, during the study. All had normal binocular acuiry. The fermale volunteers were ascertained not to be pregnant. Exclusion criteria were any cardiac, hepatic, renal, pulmonary, neurological, gastrointestinal, hematological, or psychiatric conditions, as determined from the history, physical examination, EGG, and routine laboratory blood screens, a body weight $10 \%$ outside of population norms, a history of alcohol or drug abuse, excessive drinking ( $>28$ units/week; 1 unit $=$ $12.5 \mathrm{ml}$ pure ethanol), glaucoma, allergic reactions to cholinergic drugs, and sensory or motor impairments which could reasonably be expected to affect psychomotor performance.

The study was conducted in accordance with the Declaration of Helsinki as modified in Tokyo (1975), Venice (1983) and HongKong (1989) and was approved by the Medical Ethics Review Committee of the University Hospital Maastricht. Written informed consent was obtained from all subjects. The subjects were paid for their participation.

\subsubsection{Study Design}

The study was conducted according to a within subjects, repeated measurements model. The main factor, Time after scopolamine administration, consisted of one baseline assessment before scopolamine administration and three effect measures starting at 2, 4, and 6 hours after scopollamine administration $\left(\mathrm{T}_{2}, \mathrm{~T}_{4}\right.$, and $\mathrm{T}_{6}$, respectively).

A few days before the first experimental session, all subjects had individual training sessions in which they were shown and required to practice and to complete all the assessments and tasks used in the study. The subjects were not allowed alcohol or other CNS drugs from $24 \mathrm{~h}$ before the testing sessions began. They were allowed a light caffeine-free (except for one cup of tea) breakfast and were provided lunch on the testing days. Neicher smoking nor beverages or food containing caffeine (coffee, tea cacao) were allowed during this time until the end of testing.

\subsubsection{Drug treatment}

On each occasion, scopolamine was injected subcutaneously in the back of the upper arm. The dose was $0.5 \mathrm{mg} / 75 \mathrm{Kg}$ body weight. Our first clinical impression of the effects of scopolamine pointed out that there was no possibility that a comparison between this dose of scopolamine and placebo could have remained blind to either investigator or subject. The effects of scopolamine 
were always dearly noticable to both investigator and subject within 15 minutes after dosing. $A$ follow-up assessment was done for each subject one week later, mainly to confirm absence of any adverse effects of scopolamine. On this occasion none of the subjects had any complaints or showed disturbances of wital signs or neuropsychological functions.

\subsubsection{Assessments}

The cognitive test battery consisted of several tests that have been shown to be sensitive to the effects of aging 101 . It was assumed that that each test measures a different cogritive, psychomotor, or CNS function and hence results can be evaluated independently. Also, hypotheses concerning memory are not expected to influence non-memory measures. It cannot be excluded however, that for the proper performance of a full test battery, subjects draw on common pools of cognitive resources that may be assumed to influence performance on all tests. The bartery took approximately 45 minutes to complete. The following tests were used.

Word Learning Test (WLT). One of twelve parallel lists of 15 monosyllabic meaningful nouns matched for word frequency was presented. Every 2 seconds a new word was presented during 1 second on a computer screen. The subjects were asked to recall verbally as many words as possible as soon as the presentation stopped. This first immediate recall trial was followed by four more rrials in which the same words were repeated in the same order. When the fifth trial was completed, the subjects performed the subsequent tasks and after 20 minutes were asked to recall as many of the previously learned words without prompting (delayed recall). The number of correctly recalled words and the number of erroneous words (intrusions) were noted after each trial. The trials yielding the total and the maximum number of recalled words were taken as the dependent variables (total and maximum immediate recall). The total number of erronecusly mentioned words divided by the total number of correct plus the total number of erroneously mentioned words was another dependent variable (\% of intrusions). The number of words correctly recalled after 20 minutes and the percentage of intrusions at that time were the dependent measures of long-term memory (delayed recall and delayed \% of intrusions). A 30 word list containing the initial 15-word list was then presented after 20 minutes and after presentation of each word the subject had to respond "YES/NO" as fast as possible to indicate recognition of the word (delayed recognition). Every 3 seconds, a word appeared on the screen for 1 second. The reaction times (RT) were recorded. YES-responses could be classified as correct detections (CD) or false detections (FD) whereas NO-responses could be classified as missed detections or correct rejections. The sensitivity measure of word recognition (A') was the proportion of $\mathrm{CD}$ 'corrected' for the proportion of $\mathrm{FD}$ according to the following formula [8]:

$$
A^{*}=\frac{C D-F D}{2^{*}(C D+F D)-(C D+F D)^{2}}
$$

$A^{\prime}$ is in fact the proportion of correctly recognized words, corrected for the subject's response tendency. Because the distribution of $A^{\prime}$ was skewed due to a ceilling effect, these data were subjected to the conventional arcsin transformation [37] before entering statistical analysis.

Subjective organisation of free recall was assessed by calculating an index of the extent to which organization had occurred between recall trials. The index was based on the number of response pairs that remain linked on two consecutive trials, corrected for the chance of response pairs due to response lengrh 311. This index had been shown to discriminate between closed-head injury parients and normal controls [2]. The formula used for compuring the degree of subjective organisation between two free recall trials $i$ and $j$ was as follows: 


$$
S O_{i j}=\operatorname{ITR}_{i j}-\frac{2^{*} c_{i j}\left(c_{i j}-1\right)}{w_{i}^{*} w_{j}}
$$

$\mathrm{SO}_{\mathrm{ij}}=$ index of subjective organisation between trials $i$ and $j$

$I T R_{i j}=$ number of word pairs mentioned consecutively (in either direction) at trials $i$ and $j$

$c_{i j}=$ number of common words mentioned at trials $i$ and $j$

$\mathrm{w}_{\mathrm{t}} \quad=$ number of words recalled at trial $t$ where $t \in(i, j)$

Over the five immediate and one delayed recall trials, four scores pertaining to the subjective organisation in immediare recall, and one to delayed recall, were obtained. These were summed into one estimate of the degree of subjective organistaion during immediate recall $\left(\mathrm{SO}_{12345}=\right.$ $\mathrm{SO}_{12}+\mathrm{SO}_{23}+\mathrm{SO}_{34}+\mathrm{SO}_{45}$ ). The degree of subjective organisation that was maintained between the last immediate recall trial and the delayed recall trial, $\mathrm{SO}_{56}$, was the dependent variable pertaining to subjective organisation after delayed recall.

Short-Term Memory

Long-Term Memory

Recognition Memory
Maximum Immediate Recall Total Immediate Recall Immediate Recall Intrusions Subj.Org of Immediate Recall

Delayed Recall Memory Delayed Recall Intrusions Subj.Org of Immediate Recall Delayed Recognition A't Delayed Recognition RT

\begin{abstract}
Max of correcr words recalled in a free necall crial Total \# of correct words recalled over 5 trialis $\%$ of erroneously mentioned words over 5 rtials $\mathrm{SO}_{1235}$

\# of correct words mentioned at delayed tecell trial $\%$ of erroneously mentioned words at delayed recall $\mathrm{SO}_{56}$

recognition sensitiwity of learned/non-lewarned words Reaction Time of correct responses
\end{abstract}

Memory Serteks. The subjects were briefly shown a ser of one or more target symbols and told to memorize them. This was called the memory set. The subjects then saw a series of 120 items (20 targets and 100 distractors), equally spaced in a marrix of 10 lines and 12 positions on a sheet of paper. Their task was to decide and respond, as rapidly as possible, by marking the target with a pencil, whether or not each successive target was one of those contained in the memory set. This task was performed six times, with memory sets consisting of 1 symbol (" $\left.{ }^{\circ},{ }^{\prime \prime}\right), 1$ digit, and 1,2 , 3 , and 4 letters, respectively. The total time needed by the subject to complete each sheet was timed with a stopwatch. The four subtasks with letters as targets allow, subjectwise, the statistical estimation of the regression function of the speed of search in short-term memory, based upon the additive factor method [32]. This regression function is defined by the equation $T t=A * S_{s}+B$, in which $T t=$ total time, $A=$ slope of the function (i.e. the amount of extra time needed per item in the memory set), $S s=$ size of the memory set, and $B=$ intercept with the $Y$-axis. The slope is a measure of the speed of search in short term memory whereas the intercept measures psychomotor speed. The three subtasks with one symbol, one digit, and one letter as target to discriminate from non-target letters were analyzed separately, introducing "Target/Non-Target Similarity" as a Task Factor wih three levels of Similarity (Low, Intermediate, High). The analysis of this factor may show whether specific encoding deficits exist as to the perceptual identification of targets among non-targets. 
Table 2

\section{Tush Hactor}

Memory Load

"Tanged Non-Target Similarity $(1,1,1)$
Assessments whe Mernory Search Tas

$$
\text { of trigets Targets }
$$

Non-Targets Information Procensing Stages

Letwers. Leters
Symbol, Digit, Letter Letrersi

Motor Choice Reaction Time Task. The subject held one button pressed and was asked to press one of five other buttons located equidistantly from the hold button when lit. This yielded reaction times consisting of a decision phase (time from stimulus onset until release of the hold button) and a movement phase (time from release of the hold button until the response button is pushed). The response set consisted of pressing the only one button that lit up (simple RT), pressing one of three buttons which lit up (3-choice RT), or pressing the button to the right of the lit button (incompatible three-choice RT) as quickly as possible. Decision times and mowement times thus comprised the dependent variables obtained for each of the three reaction time tasks. Hence, in these three subtasks, two task factors were systematically varied within subjects: the number of response alternatives, and the degree of compatibility of the stimulus and the required response.

Table 3 Assessments with the Motor Choice Reaction Time Task

Task Factors Conditions Dependent Measures Information Processing Stages

$\begin{array}{llll}\text { \# of Responses } & (1,3) & \text { decision time, movement time } & \text { Response Choice } \\ \text { S-R compatibility } & (+,-) & \text { decision time, movement time } & \text { Response Inhibition }\end{array}$

Stroop Color-Word Interference. The Stroop Color-Word test is a well-known test for the ease of shifting perceptual sets to conform to changing task requirements, which is indicative of executive function. It also yields measures of reading speed and speed of naming colors. In subtest $I, 10$ rows by 10 colunns of color names (red, blue, green, and yellow) were printed in black on white cardboard. In subtest II, the same number of correspondingly colored parches were printed, and in subtest III a number of color names were printed in incongruously colored ink. For instance, the word 'green ${ }^{4}$ could be printed in red. For card I, the subject was requested to "read the color names row by row, as fast as possible, without making mistakes'. The time needed to complete the whole card was recorded with a stopwatch. In the second subtest (card II) the instruction was 'to name the colored patches'. The third trial (card III) involved naming the color of the ink the color words were printed in, without paying attention to the word itself. For each subtest the time taken to finish the card and the number and type of errors were recorded. Outcome parameters were: Times to complete Reading $\left(\mathrm{t}_{1}\right)$, Color Naming $\left(\mathrm{t}_{11}\right)$ and Interference $\left(\mathrm{t}_{111}\right)$.

Table 4

Task Factors and Assessmenns with the Stroop Task

"Task F"actors

Conditions

Dependent Measures Information Processing Stages

Color Naming (Words, Colors) $\mathrm{c}_{\mathrm{I}}$ and $\mathrm{qI}$

Color Word Incerference (Conflict, No Conflice) tin and till
Feature Extraction. Identification?

Resporse Inhibition 
Pysiolagical Measures. Pulse Rate and Blood Pressure were measured while the subjecr was in a relaxed sirting position before the start of each test battery, using an automated vital signs moniror (Dinamap 1800 BP; Critikon Inc., Tampa FL).

Subjective Assessments. Mood was assessed by using the Bond and Lader 191 Mood Raring Scale, which consists of 16 bipolar analogue scales with two opposed mood related adjectives at the ends of the scales. These have been shown to yield three mood factors, alertness, contendedness, and calmness. These factor scores were used as dependent variables, higher walues representing greater amounts of each assessment. Subjectively experienced peripheral cholinergic side effects; dry mouth, blurred vision, and nausea were assessed the same way.

Table 5

Subjective Assessments

Visual Analog Sicales

Dependent Measures

0

Items

100

Side Effects

\begin{tabular}{|c|c|}
\hline $\begin{array}{l}\text { Drynacs of the mouth } \\
\text { Bilurred Vistion } \\
\text { Natusea }\end{array}$ & $\begin{array}{l}\text { Wet } \\
\text { Sharp } \\
\text { Well }\end{array}$ \\
\hline Alertness Factor & 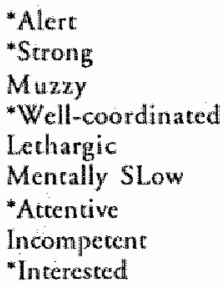 \\
\hline Contentedness Factor & $\begin{array}{l}\text { *Concented } \\
\text { Trombled } \\
\text { "Happy } \\
\text { Antagonistic } \\
\text { Withdrawn }\end{array}$ \\
\hline Calmness Factor & $\begin{array}{l}\text { "Calm } \\
\text { Tense }\end{array}$ \\
\hline
\end{tabular}

\begin{tabular}{|c|c|}
\hline & Dry \\
\hline & Bllurred \\
\hline- & Nauscated \\
\hline - & Drowsy \\
\hline - & Pecble \\
\hline- & Clear-headed \\
\hline : & Clemsy \\
\hline- & Energeric \\
\hline - & Quick-witted \\
\hline . & Dreamy \\
\hline & Proficient \\
\hline . & Bored \\
\hline - & Discontented \\
\hline$*$ & Tranquil \\
\hline * & Sad \\
\hline . & Amicable \\
\hline- & Gregorious \\
\hline- & Excited \\
\hline . & Relaxed \\
\hline
\end{tabular}

Items marked with an asterisk were transformed $(\mathrm{x}=100-\mathrm{x})$ before averaged linte the respective factor scores:

\subsubsection{Statistical Analysis}

Dependent variables were analyzed separately in repeated measures multivariate and univariate (MANOVA using SPSS 4.0 on Apple MacIntosh) analysis of variance, to test the main effect of scopolamine. Beside the multivariate tests, three univariate a priori contrast comparisons were carried our between baseline and $T_{2}, T_{4}$, and $T_{6}$ respectively. Correction for multiple testing was accomplished by using the "sequential Bonferroni-Höl $\mathrm{m}$ ' procedure for adjusting the $\alpha$ probability criterion [21]. According to this procedure, the adjustment of three consecutive $\alpha$-criterions of $p<.05$ is accomplished by dividing $\alpha$ by 3,2 , and 1 respectively and hence obtaining $\alpha-c r i t e r i o n s$ of $p<.0167, p<.025$ and $p<.050$, when contrasts are tested sequentially from the strongest to the weakest effect.

Independent variables within tasks, were evaluated as main effects, and their interaction effects with scopolamine, in orthogonal repeated measures within-subjects analyses of variance. This 
pertained to the task factors: ${ }^{2}$ thesponser ( 2 levels: 1 or 3 responses)' and 'S-R Comparibiliry (2 Levels: Compatible, Incompatible)' in the Motor Choice Reaction Task, 'Color Naming (2) levels: Words, Colors)' and 'Color-Word Interference (2 levels. Response Confict, No Response Conflict)' in the Stroop Task and 'Target/Non-Target Similarity (3 levels: Low, Medium, Highy" in the Memory Search Task. "The only exception to this way of analyzing the influence of task factory and of scopolamine according to an orthogonal design, was the analysis of the factor "Memory Load (4 levels: 1, 2, 3, 4 letters in memory)' in the Memory Search Task. The slopes and intercepts derived from the regression equations describing the relation between memory load and response time, were entered as dependent variables and analyzed in repeated measures MANOVA, to test the main effect of scopolamine, as described at the beginning of this paragraph.

\subsection{RESULTS}

Table 6 The means and standard errors for all variables measured in the study, at baseline and at different times after scopolamine administration ( $\mathrm{n}=11 \mathrm{G}$ ).

\begin{tabular}{|c|c|c|c|c|c|c|c|c|c|c|}
\hline \multicolumn{3}{|c|}{ Time after Scopolamine Administration } & \multicolumn{2}{|c|}{ baseline } & \multicolumn{2}{|l|}{$\mathrm{T} 2$} & \multicolumn{2}{|l|}{$\mathrm{T} 4$} & \multicolumn{2}{|l|}{ T 6} \\
\hline Task & Subrask & Measure & mean & $(\mathrm{sec})$ & mean & $(\mathrm{se})$ & mean & (se) & mean & $(\mathrm{se})$ \\
\hline \multirow[t]{10}{*}{ Word learning } & Immediate Recall & First trial. & 8.3 & $(6)$ & 6.1 & (.6) & 68 & (.6) & 7.2 & (.6) \\
\hline & & MX \# of Words & 14.5 & (3) & 11.6 & (7) & 13.0 & (.6) & 13.4 & $(.5)$ \\
\hline & & to of Words & 61.8 & (1.8) & 45.2 & (3.2) & 51.1 & (2.5) & 54.6 & (2.6) \\
\hline & & $\%$ intrusions & 1 & (0) & 8 & (3) & 3 & (1) & 3 & (1) \\
\hline & & subj org & 3.3 & $(.7)$ & 2.9 & $(.6)$ & 2.6 & (.8) & 4.3 & 0.97 \\
\hline & Delayed Recall & \# of Words & 13.1 & (.6) & 8.2 & $(1.0)$ & 10.6 & (.9) & 11.4 & (8) \\
\hline & & $\%$ intrusions & 1 & (1) & 24 & (G) & 14 & (4) & 10 & (3) \\
\hline & & subj org & 2.8 & (.6) & 1.9 & (.5) & 3.2 & (.6) & 2.8 & $(6)$ \\
\hline & Delayed Recogn & $A^{\circ}$ & .88 & (02) & .82 & (.04) & .82 & $(.04)$ & .91 & $(.02)$ \\
\hline & & $\mathbb{R T}$ (msec) & 578 & (13) & 644 & (12) & 619 & (14) & 604 & (12) \\
\hline \multirow[t]{4}{*}{ Memory Search } & Memory Load & lecter $-s$ lope & 9.3 & (1.4) & 13.4 & $(1.4)$ & 13.0 & $(1.3)$ & 13.2 & (1.5) \\
\hline & & letter-intcpt & 19.4 & (.9) & 20.2 & $(1,2)$ & 21.7 & $(1.0)$ & 20.2 & (.9) \\
\hline & Target/Non-Target & symbol & 12.4 & (.6) & 14.0 & $(.8)$ & 13.2 & (.7) & 13.1 & (7) \\
\hline & Similarity & digit: & 14.8 & (.7) & 17.6 & $(1,2)$ & 17.3 & (1.0) & 15.8 & (.8) \\
\hline \multirow[t]{6}{*}{ Motor Choice RT } & decision time & Simple RT & 281 & (4) & 297 & (G) & 2688 & (7) & 276 & $(6)$ \\
\hline & & 3-choice $\mathbb{R T}$ & 324 & (6) & 352 & (9) & 350 & (10) & 333 & (10) \\
\hline & & incompat. $\mathrm{RT}$ & 396 & (12) & 423 & (15) & 421 & (16) & 405 & (15) \\
\hline & movement time & Simple $\mathbb{R T}$ & 95 & (3) & 113 & (4) & 110 & (4) & 106 & (4) \\
\hline & & 3-choice RT & 105 & (3) & 122 & (4) & 121 & (5) & 120 & (6) \\
\hline & & incompat. $\mathrm{RT}$ & 105 & (4) & 130 & (8) & 124 & (5) & 126 & (6) \\
\hline \multirow[t]{3}{*}{ Stroop Color-w Words } & Reading & 4 & 34.3 & (1.2) & 36.5 & (1.3) & 35.4 & $(1.4)$ & 35.3 & (1.3) \\
\hline & Color Naming & til & 45.7 & (1.9) & 49.2 & $(23)$ & 45.0 & (1.9) & 45.4 & (1.6) \\
\hline & Interfurence & min & 65.9 & (2.6) & 73.0 & $(3.5)$ & 68.1 & (3.2) & 68.2 & (3.4) \\
\hline \multirow[t]{3}{*}{ Vital Signs } & Blood Pressure & Systolie & 126 & (3) & 114 & (3) & 113 & (2) & 111 & (3) \\
\hline & & Diascolic & 61 & (2) & 58 & (3) & 51 & (2) & 52 & (2) \\
\hline & Heart Rate & Beats / min & 68 & (3) & 52 & (2) & 58 & (2) & 58 & (2) \\
\hline \multirow[t]{6}{*}{ Sulbjective Ratings } & Side Effecrs & Dry Mouth & 35.7 & $(5.7)$ & 80.8 & $(5.7)$ & 56.9 & $(4.7)$ & 44.3 & $(5.7)$ \\
\hline & & Vision & 16.9 & (4,4) & 51.4 & $(7.2)$ & 44.5 & $(8.8)$ & 38.0 & (8.4) \\
\hline & & Nausea & 15.7 & (4.4) & 49.0 & $(5.4)$ & 41.6 & $(6.9)$ & 34.4 & (5.5) \\
\hline & Mood & Alertness & 65.2 & (4.4) & 40.7 & $(2.7)$ & 47.1 & $(3.8)$ & 47.9 & $(3.6)$ \\
\hline & & Contentedness & 69.0 & (3.3) & 63.4 & $(3.3)$ & 64.6 & $(3.8)$ & 67.9 & (3.5) \\
\hline & & Calmoness & 72.4 & (4.8) & 64.2 & $(4.8)$ & 67.3 & $(3.0)$ & 69.3 & $(3.2)$ \\
\hline
\end{tabular}


The effects of scopolamine on assesments of memory-, cognitive and psyclaomotor performance, wital signs and subjective mood and sideeffect ratings in thealthy wolunteers and the results of statistical evaluation of the scopolamine effects are described in this section. The means and standard errors of the assessments deseribed in the previous section are listed as a funcrion of scopolamine in table 6. The effects of scopolamine on assessments of memory psychomotor performance were compared to the effects of age on the same measures by means of twin-plots of their effects. These plots are identical graphical representations, using identical $x$ and $y$-axes, of the effects of the independent factors (age and scopolamine) on the dependent measures that were used in the cognitive aging study 191 and the scopolamine study described here, respectiwely. The twin-plots allow instant comparison of the magnitude of the effects of age and scopolamine on measures of cognitive function.

\section{Word Leaming.}

The multivariate effect of scopolamine on immediate recall was significant $\left(F_{3.13}=8.5, p<.005\right)$. Significantly less words were recalled inmediately after presentation of the word lists at T2 $\left(F_{1,15}=25.6, p<.0001\right)$, at $T 4\left(F_{1.15}=14.2, p<.005\right)$, and at $T 6\left(F_{1,15}=8.2, p<.05 ;\right.$ see fig. 1$)$. The multivariate effect of scopolamine on delayed recall was significant $\left(\mathbb{F}_{3,13}=22.6, p<.0001\right)$. Delayed recall performance at the word lists was significandy inferior to baseline performance at $T 2\left(F_{1,15}=42.6, p<.0001\right)$, at $T 4\left(F_{1,15}=21.6, p<.0001\right)$, and at $T 6\left(F_{1,15}=14.4, p<.005\right.$; see fig. 1). The multivariate effect of scopolamine on delayed recognition sensitivity was significant $\left(\mathbb{F}_{3,13}=5.1, \mathrm{p}<.05\right)$, but univariate tests of the individual scopolamine-baseline comparisons of delayed recognition sensirivity revealed that none were significantly different at $T 2, T 4$, and $T 6$.
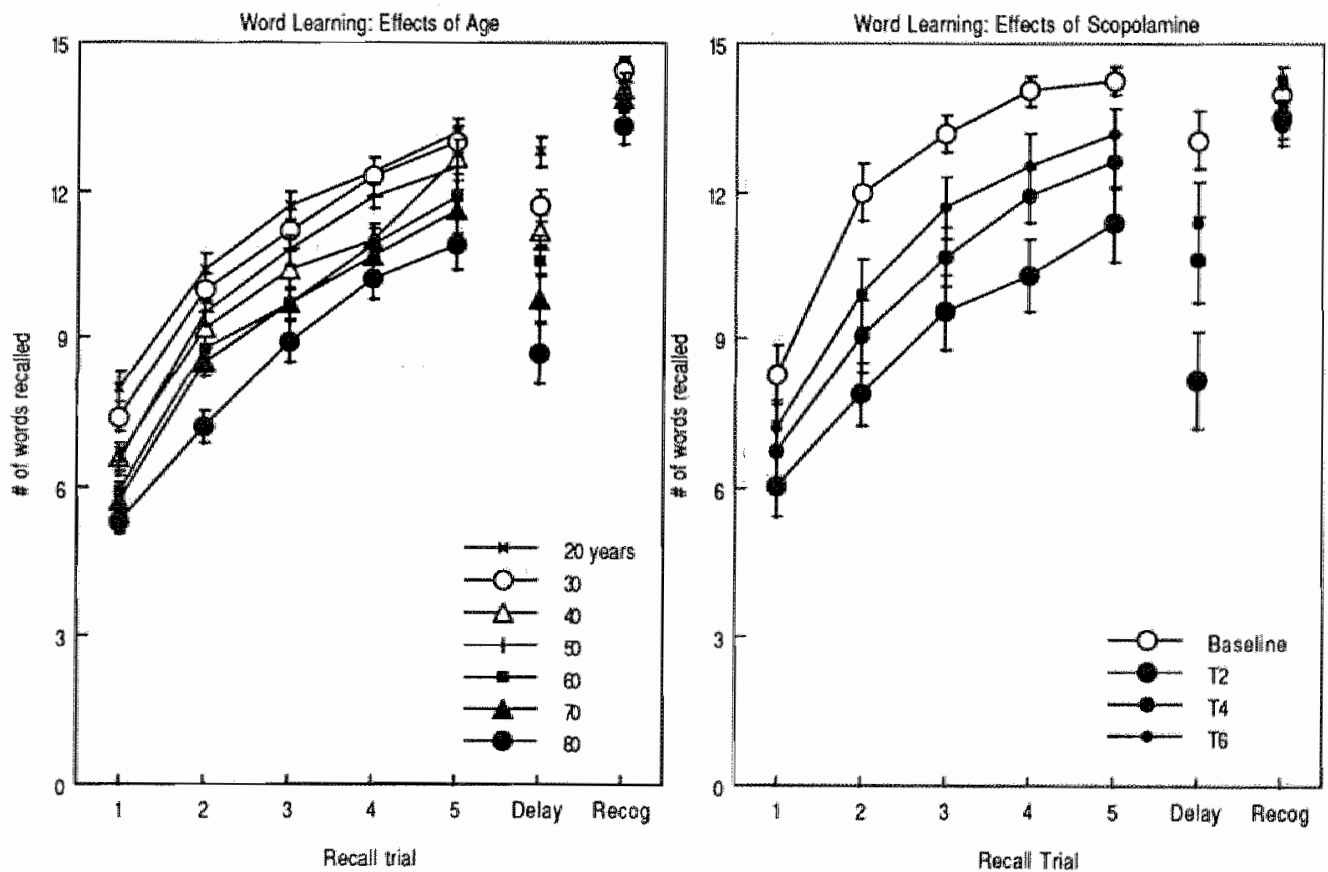

Figure 1 Twin-plot of the effects of age (left graph) and scopolamine (right graph) on means and slandaro errors of immediale recall, delayed recall and delayed recognition scores on the word learning task

The results plotted in the left graph were obiained in a study on the effects of aging on cognilion. The distinct age groups were comparable as to the distribution of gender and educalion. The sarmple sizes of the respective age groups were: $n_{20}=31 ; n_{30}=29 ; n_{40}=34 ; n_{50}=35 ; n_{60}=35 ; n_{70}=43 ; n_{80}=40[9]$. 
In order to examine the effects of scopolamine on word recall in more detail, for each recall trial, the probability of recall was calculated per word. If all subjects recalled a particular word the probabiliny of recall was expressed as $100 \%$ (sec figure 2).
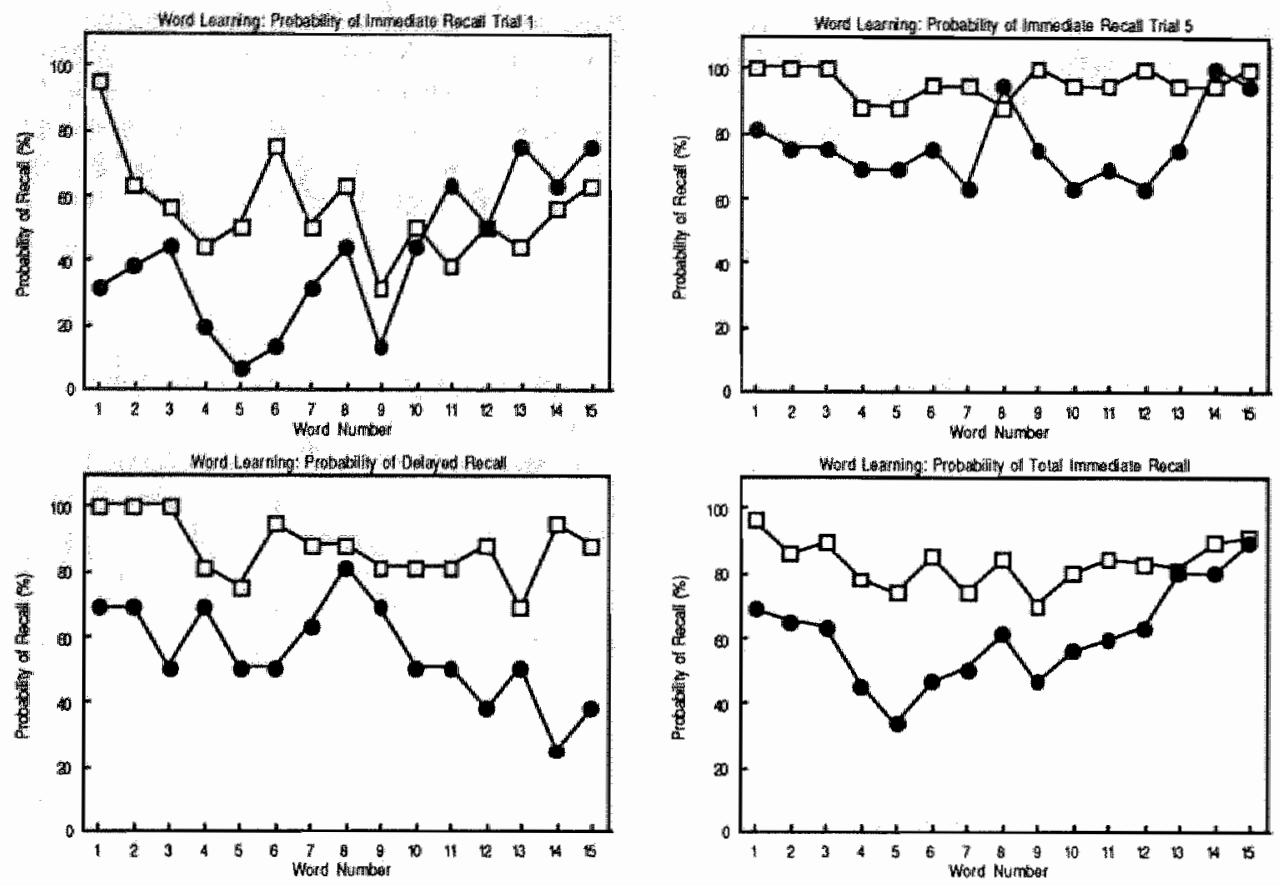

Figure 2 The effect of scopolamine at T2 on the probability of recall ol leamed words as a function of serial position in the word lis. The serial posilion elfect in shor-term memory experiments is due to increased attention of early items (primacy effeci) and the easy recall of late items (recency effect) from primary memory [20]. The memory impairing effect of scopolamine at immediale recall is due to the decieased recall probabilities of the words presented in the beginining of the list and not to the worcs presenled last in the list. After the first presentation of the word list, the recall probabilities of the last fiwe words are even better after scopolamine relative to baseline, but recall probabilites of the first len woirds are decreased (Left upper graph:. 1 st Immediate Recall Triall. Alter the fillh presentation of the word lisl, rocall piobabilities have drastically improved, showing that memory impairment alter scopolamine is quanlliativo raither than qualiative, but selectively spares the recall probabilities of the last two words (Right Upper Graph: 5th Immodialo Recall Trial). This pattern becomes more clear when looking at the recail probabililes calculated over the tolal of 5 immediale recall trials: the scopolamine-induced memory impairment is due to the lirst twelve words in the list. The lasi three words are apparently still in the unaffected "printary memony" (Left Lower Graph: Immediate Recall over 5 triais). This seems to be consistent with the finding that alter delayed recall (when the list is not again presented) subjects can not utilize this 'recency effect' and the last words in the list appear to have the lowest probability of recall (Pight Lower Graph: Delayed Recall Trial).

The mulrivariate effect of seopolamine on intrusion errors in immediate recall was significant $\left(F_{3,13}=5.4\right.$, p<.05). Significantly more erronous words were mentioned immediarely after presentation of the word lists at $T 2\left(F_{1,15}=12.7, p<.005\right)$, and at $T 6\left(F_{1,15}=8.6, p<.01\right)$. The multivariate effect of scopolamine on intrusion errors in delayed recall was significant $\left(\mathrm{F}_{3,13}=7.8\right.$, p 4.005$)$. Significantly more erronous words were mentioned at the delayed recall trial of the word lists at $T 2\left(F_{1,15}=17.6, p<.001\right)$, at $T 4\left(F_{1,15}=14.0, p<.005\right)$, and at $T 6\left(F_{1,15}=13.3, p<.005\right)$. Neither multivariate or univariate analyses of subjective organization at immediate or delayed recall showed significant differences between baseline and scopolamine assessments. 

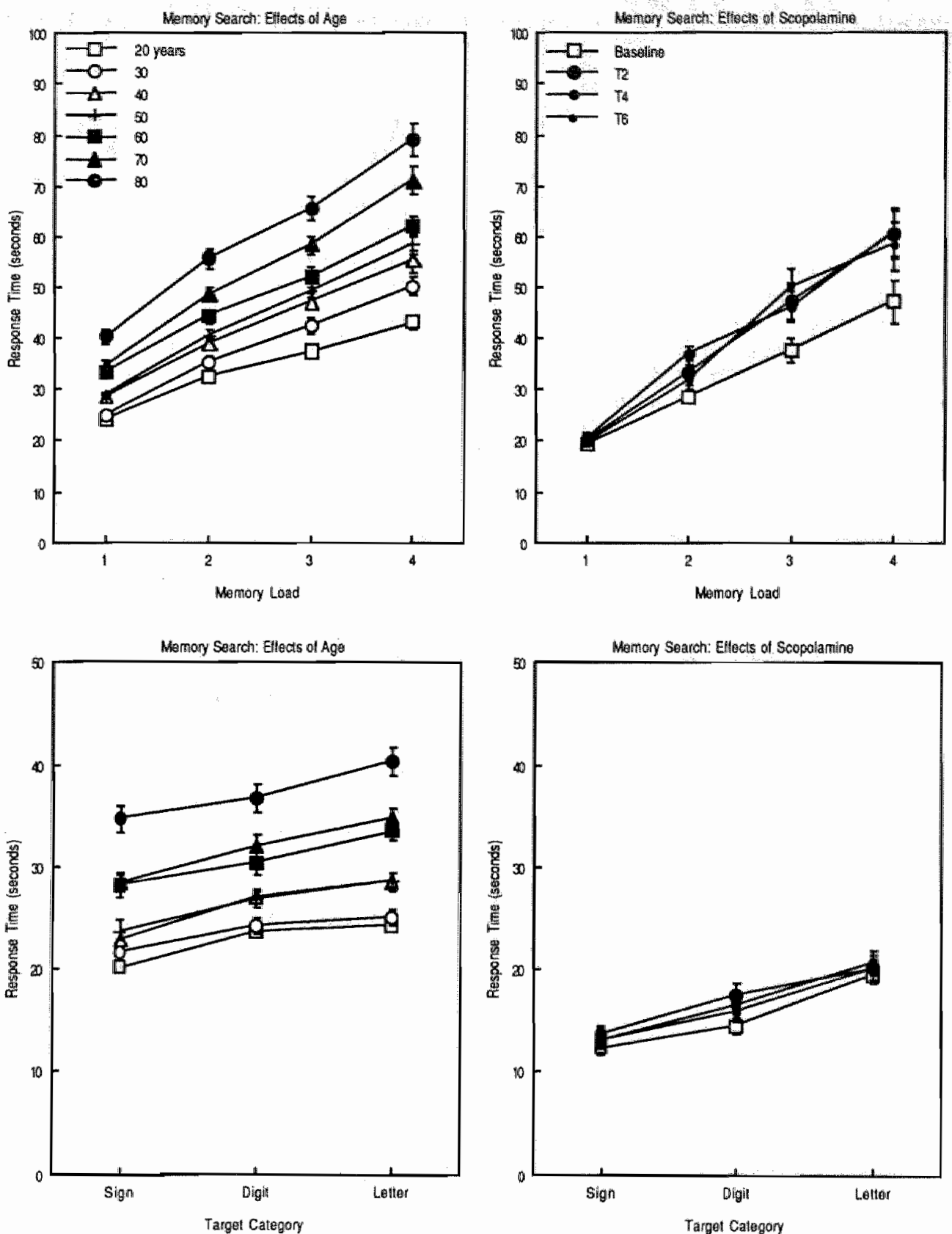

Figure 3 The effects of age (left graphs) and scopolarnine (right graphs) on response lime as a function of memory load (upper graphs) and targeunon-target similarity (lower graphs) in the memory search task.

The ditlerent aftset of response times is due to the lact that the resulits displayed in the left graph were oblained using response sheets consisting of 12 rows $\times 12$ columns containing 24 largets and 120 distractors, whereas those in the right graph were oftained using response sheets consisting of 10 rows $\times 12$ columns containing 20 targets and 100 distractors. Hence one should not consider the absolule differences between the iwo graphs, but rather the relative elfects 0 : age (lett) and scopolamine (right). 
The mulcivariate offect of scopolamine on delayed recognition $\mathrm{RT}$ was significant $\left(\mathrm{F}_{3,3}=19.3\right.$, $\mathrm{p}<0001)$. Delayed recognition $\mathrm{RT}$ was sugnificantly prolonged at $\mathrm{T} 2\left(\mathrm{~F}_{1,15}=54.1, \mathrm{P}<.0001\right)$, at $\mathrm{T} 4\left(\mathrm{~F}_{1,15}-29.2, \mathrm{p}<.0001\right)$, and at $\mathrm{T} 6\left(\mathrm{~F}_{1,15}=10.9, \mathrm{p}<.005\right)$.

\section{Memary Sedrch}

Memory Load. The multivariate main effect of scopolamine on the slope of the regression function of memory load on response time was significant $\left(\mathrm{F}_{3,13}=10.3, \mathrm{p}<.001\right)$. The slope of memory load was significantly increased at $T 2\left(\mathrm{~F}_{1,15}=34.8, \mathrm{P}<0001\right)$, at $\mathrm{T} 4\left(\mathrm{~F}_{1,15}=19.2\right.$, pe.001), and at $T 6\left(F_{1,15}=20.4, p<.0001\right)$. The multivariate effect of scopolamine on the intercept of the regression function of memory load on response time was significant $\left(F_{3,13}=5.4, p<.05\right)$. The intercept of memory load was significantly increased at $T 4\left(\mathrm{~F}_{1,15}=8.9, \mathrm{p}<.01\right)$, and was unchanged at $\mathrm{T} 2$ and $\mathrm{T} 6$.

Target/non-target similarity. The multivariate main effect of scopolamine on response time with one target in memory, irrespective of the target type, was significant $\left(\mathrm{F}_{3,13}=6.1, \mathrm{p}<.01\right)$. Response rime was significantly increased at $T 2\left(F_{1,15}=11.7, p<.005\right)$, and at $T 4\left(F_{1,15}=19.6, p<.0001\right)$, but not at $T 6$. The multivariate main effect of target/non-targer similarity on response time was significant $\left(F_{3,13}=53.6\right.$, p<.0001). Higher similarity was associated with longer response time (see figure 3 ). The multivariate interaction effect of scopolamine with target/non-target similarity was significant $\left(F_{6,10}=5.2, p<.05\right)$. Uniwariate contrasts revealed that the interaction effect of scopolamine with similarity was only significant at $T 4\left(F_{2,14}=9.8, \mathrm{p}<.005\right)$, but not at $T 2$ and $T 6$.

\section{Motor Choice Reaction Time}

Decision Time. The multivariate main effect of scopolamine on the decision phase of reaction time was significant $\left(F_{3,13}=8.8, p<.005\right)$. Decision $R T$ was significantly increased at $T 2$ $\left(F_{1,15}=24.6, p<.0001\right)$, and at $T 4\left(F_{1,15}=9.8, p<.01\right)$, but not at $T 6$. The multivariate main effect of the number of response choices on decision $\mathrm{RT}$ was significant $\left(\mathrm{F}_{1,15}=92.1, \mathrm{p}<.0001\right)$. More response choices was associated with a longer decision RT. The multivariate interaction effect of scopolamine with the number of response choices was significant $\left(F_{6.10}=6.1, p<.01\right)$. Univariate contrasts revealed that the interaction effect of scopolamine with the number of response choices was significant at $\mathrm{T} 2\left(\mathrm{~F}_{1,15}=6.9, p<.05\right)$, at $\mathrm{T} 4\left(\mathrm{~F}_{1,15}=17.8, \mathrm{p}<.001\right)$ and at $\mathrm{T} 6\left(\mathrm{~F}_{1,15}=7.9, \mathrm{p}<.05\right)$. The multivariate main effect of $S-R$ Comparibility on decision RT was significant $\left(F_{1,15}=100.2\right.$, p<.0001). Incompatible responses were associated with a longer decision RT. The mulcivariate interaction effect of scopolamine with S-R Compatibility on decision RT was not significant and neither were any of the uniwariate contrasts at $T 2, T 4$ and $T 6$.

Movement Time. The multivariate main effect of scopolamine on the movement phase of reaction time was significant $\left(\mathrm{F}_{3,13}=8.2, \mathrm{p}, 005\right)$. Movement $\mathrm{RT}$ was significantly increased at $\mathrm{T} 2\left(\mathrm{~F}_{1,15}=25.1, \mathrm{p}<.0001\right)$, at $\mathrm{T} 4\left(\mathrm{~F}_{1,15}=20.3, \mathrm{p}<.0001\right)$, and at $\mathrm{T} 6\left(\mathrm{~F}_{1,15}=12.3, \mathrm{p}<.005\right)$. The nultivariate main effect of the number of response choices on movement RT was significant $\left(\mathbb{P}_{1}, 15=49.4, \mathrm{p}<.0001\right)$. More tesponse choices was associated with a longer movement RT. The multivariate interaction effect of scopolamine with the number of response choices was not significant and neither were any of the uniwariate contrasts at $T 2, T 4$ and $T 6$.

The muleivariate main effect of S-R Compatibility on movement RT was not significant and neither were any of the univariate contrasts at T2, T4 and T6. The multivariate interaction effect of scopolamine with S-R Compatibility on movement RT was not significant and neither were any of the univariate contrasts at $T 2, T 4$ and $T 6$.

\section{Stroop Test}

The multiwariate main effect of scopollamine on response time, irrespective of stimulus type (written collor words, or painted color patches) was significant $\left(F_{3,13}=7.3, p<.005\right)$. Response time was significantly prolonged at $T 2\left(F_{1}, 15=12.4, p<.005\right)$, but mot at $T 4$ and $T 6$. The multivariate 

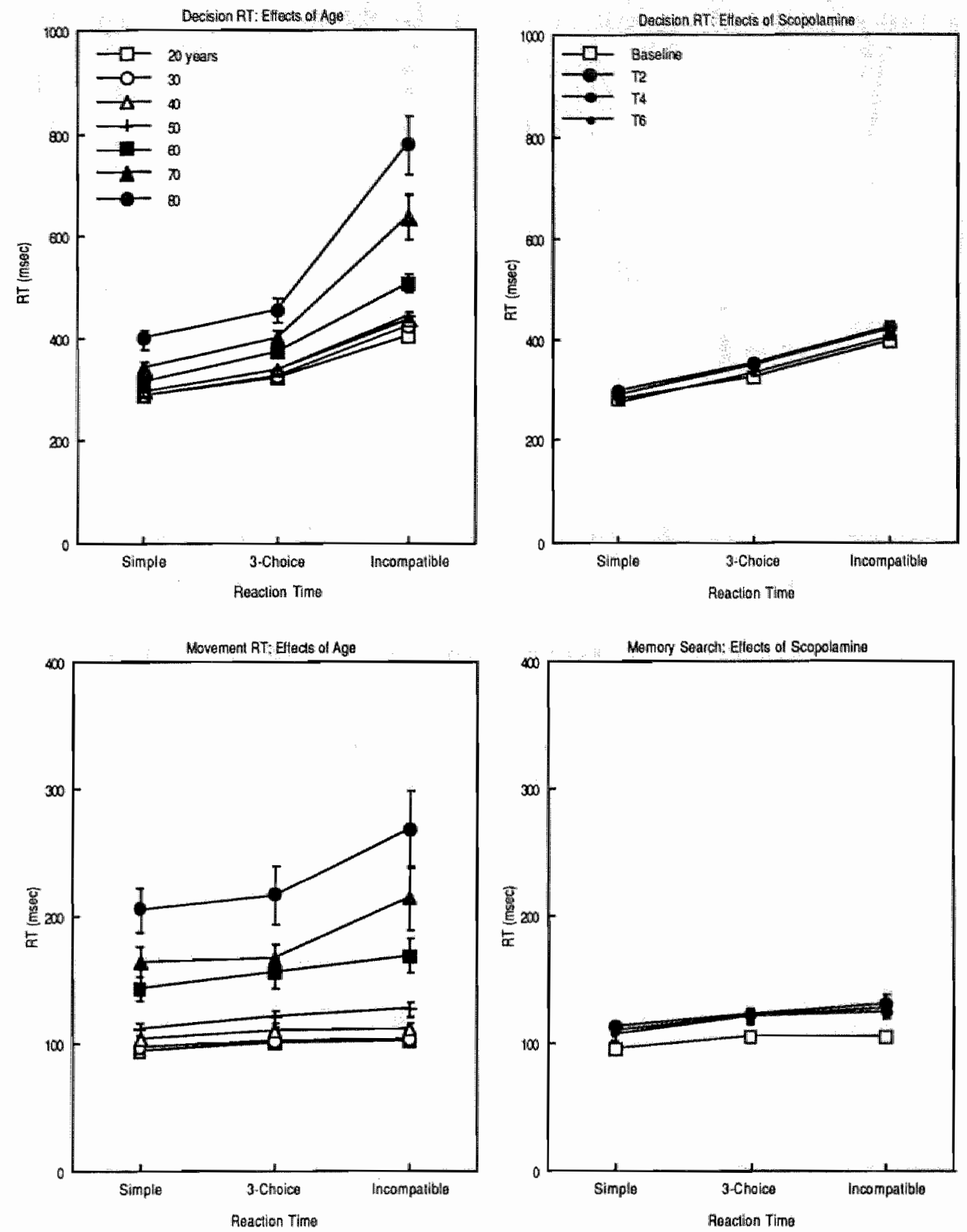

Figure 4 The effects of age (left graphs) and scopolamine (right graphs) on decision RT (tupper graphs) and movement RT (lower graphs) as a function af number of response choices and response compalibilly in the molor choice reaction task. 

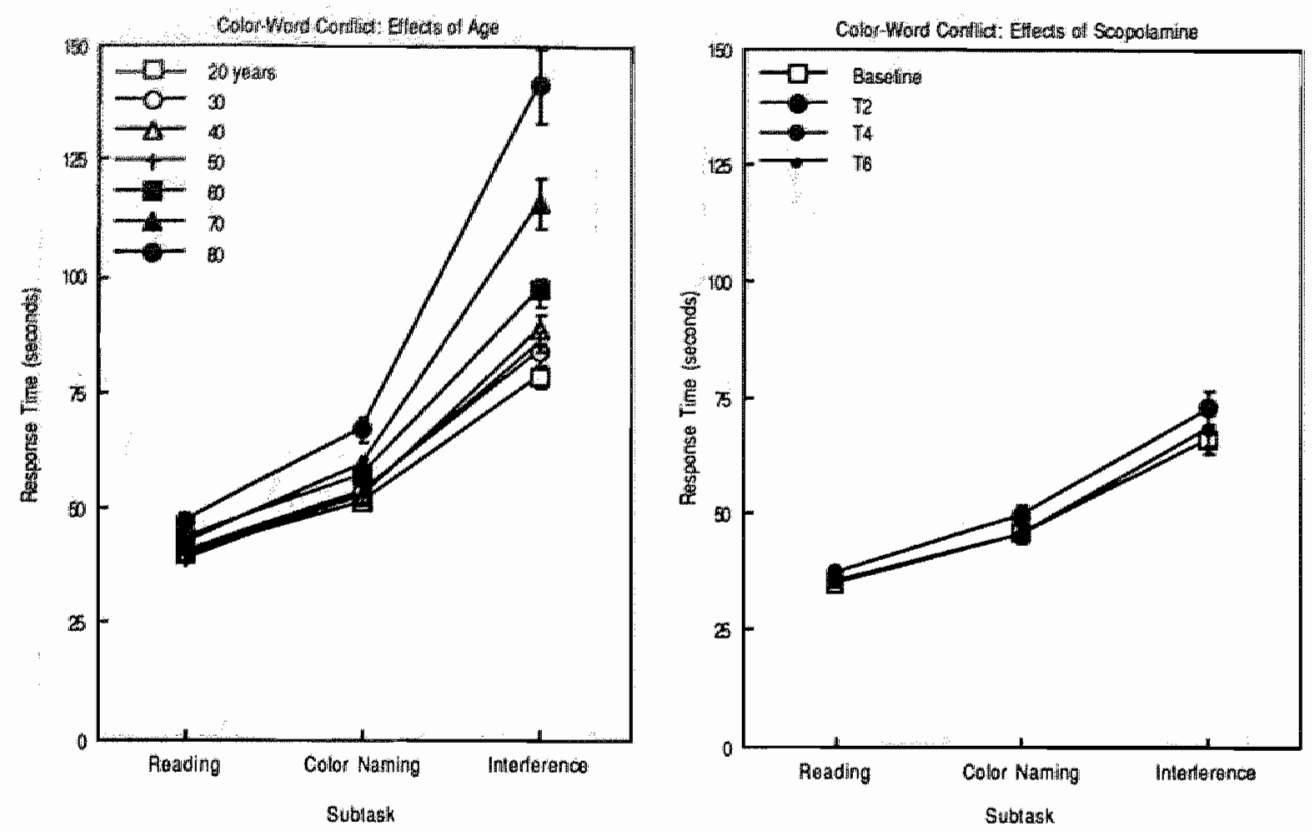

Figure 5 The effects of age (lleft graph) and scopolamine (right graph) on response time in the reading, color-naming and color-word conflict subtasks of the stroop task.

main effect of stimulus type was significant $\left(F_{1,15}=97,3, p<.0001\right)$. Painted patches of colors as stimuli took more time to verbalize than written words. No multivariate or univariate interaction effects of scopolamine with stimulus type were significant. The multivariate main effect of Response Conflict was also significant $\left(F_{1,15}=210.4, p<.0001\right)$. Conflict stimuli took more time to verbalize than non-conflict stimuli. No interaction effects of scopolamine with Response Conflict were significant.

\section{Vital Signs.}

Blood Pressure and Heart Rate. The multivariate effect of scopolamine on systolic blood pressure was significant $\left(\mathrm{F}_{3,13}=14.6, p<.0001\right)$. Systolic blood pressure was significantly decreased at $\mathrm{T} 2$ $\left(F_{1,15}=22.1, p<.0001\right)$, at $T 4\left(F_{1,15}=23.0, p<.0001\right)$, and at $T 6\left(F_{1,15}=50.3,<.0001\right)$. The multivariate effect of scopolamine on diastolic blood pressure was significant $\left(\mathrm{F}_{3,13}=12.9\right.$, $\mathrm{p}<.0001)$. Diastolic blood pressure was unchanged at T2 and significantly decreased at $\mathrm{T} 4$ $\left(F_{1,15}=23.0, p<.0001\right)$, and at $T 6\left(F_{1,15}=50.3, p<.0001\right)$. The multivariate effect of scopolamine on heart rate was significant $\left(F_{3,13}=16.0, p<.0001\right)$. Heart rate was significandly decreased at $T 2$

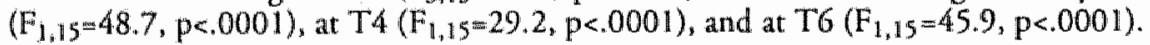

\section{Subjective Meatsures.}

Peripheral Side effects and Mood Scales. The multivariate effect of scopolamine on the subjectively experienced degree of oral dryness was significant $\left(F_{3,13}=21.8, p<.0001\right)$. The degree of subjectively experienced oral dryness was significantly increased at $T 2\left(\mathrm{~F}_{1,15}=48.6, \mathrm{p}<.0001\right)$, at $T 4\left(F_{1,15}=10.9, p<.0001\right)$, and unchanged at T6. The multiwariate effect of scopolamime on the subjectively experienced degree of blurred vision was significant $\left(\mathrm{F}_{3,13}=7.4, \mathrm{p}<.005\right)$. The degree 
of subjectively experienced blurred wision was significandy increased at $T 2 \quad\left(F_{1,15}=20.1\right.$, $\mathrm{p}<.0001)$, at $\mathrm{T} 4\left(\mathrm{~F}_{1,15}=9.3, \mathrm{p}<.01\right)$, and at $T 6\left(\mathrm{~F}_{1,15}=5.8, \mathrm{p}<.05\right)$. The multivariate effect of scopolamine on the subjectively experienced degree of nausea was significant $\left(\mathbb{F}_{3,19}=8.0,0<.005\right)$. The degree of subjectiwely experienced nausea was significantly increased at T2 $\left(F_{1,15}=22.1\right.$, $\mathrm{p}<.0001)$, at $\mathrm{T} 4\left(\mathrm{~F}_{1,15}=10.1, \mathrm{p}<.01\right)$, and at $\mathrm{T} 6\left(\mathrm{~F}_{1,15}=8.8, \mathrm{p}<.05\right)$. The multivariate effect of scopolamine on the subjectively experienced degree of alerness was significant $\left(F_{3,13} 11.7\right.$, $\mathrm{p}<.001)$. The degree of subjectively experienced alertmess was significantly decreased at T2 $\left(F_{1,15}=30.4, p<.0001\right)$, at $T 4\left(F_{1,15}=16.3, p<.001\right)$, and at $T 6\left(F_{1,15}=18.8, p<.001\right)$. None of the assessments of subjectively experienced degree of contentment and calmness were significantly affected by scopolamine.
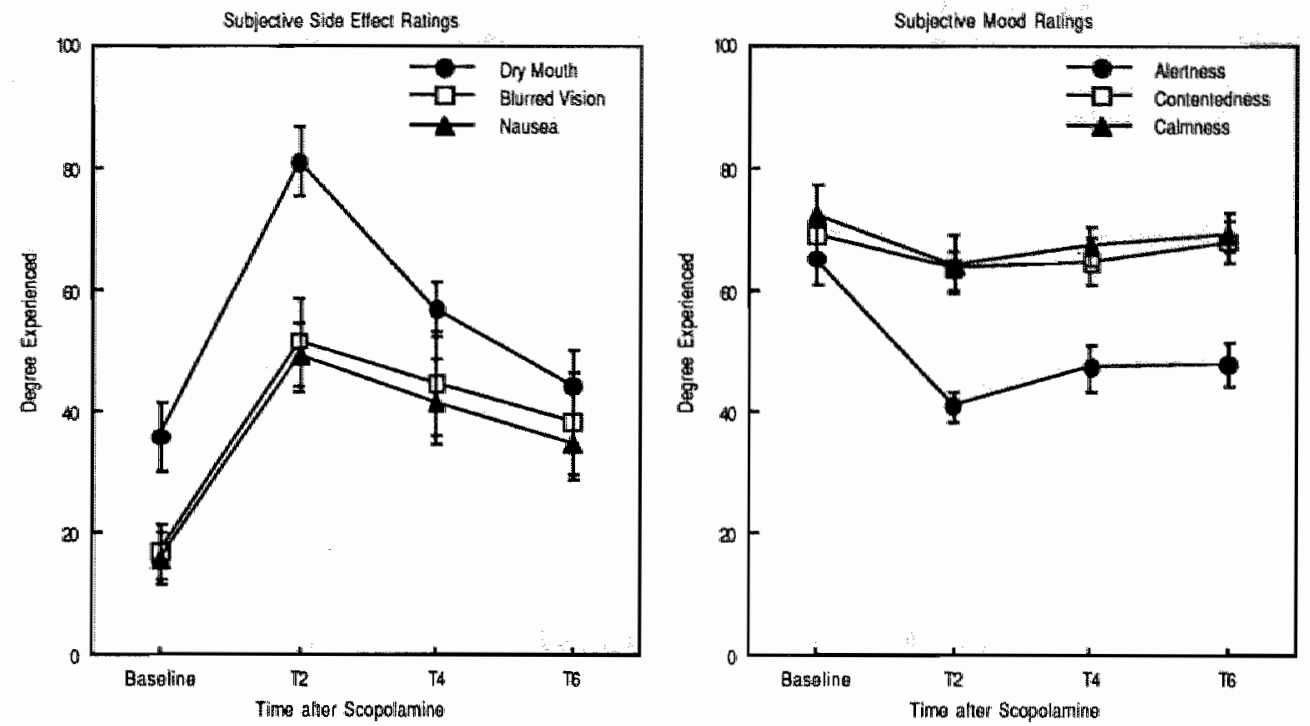

Figure 6 The effects of scopolamine on subjective side-effects and mood ratings.

\subsection{DISCUSSION}

\section{The effects of scopolamine}

In general, the impairing effects of scopolamine on performance were maximal at 2 hours after its administration, as was expected on the basis of its pharmacodynamic properties. However, quite a number of effects persisted until as long as 6 hours after the administration of scopolamine.

Scopolamine impaired immediate and delayed free recall memory for word lists. The lack of significance as to the effect of scopolamine on the measures of subjective organization in shortand long-term memory may indicate, that scopolamine does not, or in any case not severely, affect acquisition, or storage into secondary memory. The measure of sensitivity of delaycd recognition of learned words showed that the quality of passive recognition of learned words was as good as undisturbed by scopolamine, which can be taken to indicate that all words were indeed stored in memory, but cholinergic blockade disrupted its active recall and not the passive recognition from memory. The learning curves of the word lists in figure 1 showed that the 
probability of free recall was quantitatively impaired rather than qualiatively. The serial position curves of the word lists in figure 2 showed that the recall probabilities of words that were presented last in the list were not affected by scopolamine. This effect could be explained by the distinction berween primary and secondary memory. The latter is impaired by scopolamine leaving the former unaffected. Retrieval was also quantitatively impaired by scopolamine, as assessed by prolonged recognition reaction times. It can also be interpreted as diffuculties associated with accessing information which was processed less deep when it was stored in menory $[24]$.

The search time in short-term or working memory was clearly prolonged after scopolamine. This finding further lends support to the observation that processes of search in memory are particularly disrupted by cholinergic blockade. The response time of the letter cancellation task increased as a function of the number of letters to be held in memory as a target. Only the slope of this function, and not the intercept, was affected by scopolamine. This finding indicates, that in a condition with almost no memory load, neither visual encoding time (blurred vision apparently did not handicap the subjects), nor response execution time, were affected by scopolamine. This result might not have been obtained when a computerized discrete response paradigm (i.e. button pressing) would have been employed. Cancelling target letters in arrays of letters on a sheet of paper with the possibility of preview allows subjects to employ highly automated visual encoding processes requiring only a minimal amount of time, as well as highly automated motor preparation and response execution processes, which also require minimal processing time. A central sedative effect would have slowed down all these processes. This can further be illustrated by the observation that simple discrete reaction times were slowed down after scopolamine, at $T_{2}$ only. At $T_{4}$ and $T_{6}$, the decision times in the simple $R T$ paradigm were no longer impaired, whereas immediate and delayed recall memory, recognition memory RT, and the slope of the memory search function were still significantly impaired. Discrete responses obtained in choice reaction time paradigms showed that decision time in the simple RT paradigm was only impaired by scopolamine at T2. The interaction-effect of scopolamine and the number of response choices on decision RT yielded significantly prolonged decision RT throughout T2, T4 and TG. Movement times also remained significantly increased across all conditions at $T 2, T 4$ and $T 6$. This suggests that scopolamine has persistent cognitive and motor effects, while the possibility of slowed perception is only apparent at T2. On the other hand, scopolamine consistently had no influence on variables reflecting processes of response inhibition. This was apparent as to the absence of an interaction effect of scopolamine with stimulus-response compatibility on decision and movement reaction times and also as to the absence of an effect of scopolamine on color-word interference in the Stroop task. It suggests that the effects of scopolamine on cognition are selective, i.c. memory functions pertinent to free recall from secondary (long-term) memory were markedly impaired, just as search in short-term memory and choice reaction time, but executive functioning sucti as inhibiting a dominant response by ignoring distracting- or conflicting input stimuli, appeared unaffected by scopolamine. Furthermore, subjective ratings of mood, showed that subjects were aware of an effect of scopolamine on their level of alermess, while at the same time they did not show other signs of disturbed mood that could explain their declined alertness.

The cardiovascular parameters, heart rate and systolic- and diastolic blood pressure, indicated that scopolamine significantly lowered heart rate and blood pressure in a persistent manner. Unfortunately, it is not possible to distinguish between peripherally and centrally mediated cardiovascular effects of scopolamine. Similar effects of scopolamine on heart rate and blood pressure were found before $|7|$ and were attribured to centrally med iated effects of scopolamine. The subjectively rated side-effects of scopolamine showed that the peripheral anticholinergic signs were marked, particularly the "dry-mouth" effect, with a peak at T2 and a tendency to decline afterwards. 
The effects of scopolamine campured to the effects of age

The twin plots clearly showed that the effects of scopolamine on memory parameters of the word jearning task and the slope of search in short-term memory were of comparable magnitude as the effects of age. This was however, very clearly not the case with respect to parameters reflecting perceptual, psychomotor and cognitiwe speed. The decrease of perceptual, psychomotor, and cognitive speed as a function of age is far larger than that observed after scopolamine. This finding seems to disclaim the "decreased resource" effect of scopolamine. This is not to say that we found different results pertaining to scopolamine when our results are compared with those found in other scopolamine studies, but mainly because others have attributed significant, but very small effects of scopolamine to the "decreased resources' phenomenon. Often, conclusions about the effect of scopolamine on cognition in healthy volunteers were formulated in statements such as: the observed performance decrement after scopolamine might have been secondary to a more general decline in cognitive processing speed' [7]. We have now shown that there is an enormous discrepancy between the effects of scopolamine and age on cognitive processing speed. Firstly, the magnitude of the effects of age on cognitive processing speed are far larger than those of scopolamine. Secondly, the selectivity of the effects of scopolamine on cognitive processing speed appeared to be much larger than those of age. All of this was in contrast with the apparent similarity of both the nature and the magnitude of the effects of scopolamine and age respectively, on memory. A conceptual problem as to this comparison of magnitudes remains, however. It is difficult to decide whether it is a far comparison between the magnitude of the effects of age and scopolamine on cognitive processing speed. The first is only a temporarily induced functional change of state in the CNS, leaving the structure in tact whereas the second, aging, is a very gradual change, probably both structural and functional, but more importantly, allowing the organism time to develop strategies to compensate for the effects of declined cognitive processing speed, e.g. on memory. Furthermore, this comparison is a typical example of a conflict between statistically significant and dinically relevant changes. We found significant changes as to the effects of scopolamine on aspects of reaction time that were so small that they cannot be seen with the naked eye on a graph, at least not when we want to put these changes into the perspective of comparing them with changes typically found as a function of normal aging. It illustrates the power of neuropsychological testing while using a within subjects design: an average change of 1 millisecond can become a significant effect in such a design, provided that each of the subjects consistently show this change (i.e. when the within-subjects correlation of this repeated measure is 1.0).

The majority of our results on the effects of scopolamine on memory and cognitive functions were clearly consistent with those reported in similar previous studies $17,15,19,361$. Memory was most affected by scopolamine and there was evidence that primary memory was not affected, which is: consistent with the observation of others that digit $\mathrm{span}$ word $\mathrm{span}$, and the recency component of free recall is nor affected by scopolamine [26]. We provided additional evidence that processes of storage into memory were not parricularly affected by scopolamine and that the explanation of its effects on memory must be sought in its clearly present search deficits, that showed up in prolonged memory search as a function of memory load and in terms of prolonged recognition (from long-term memory) reaction times as well. Such an explanation is compatible with that of a working memory deficit induced by scopolamine [25] and also with the interpretation of the scopolamine effect as a retrieval deficit, rather than an acquisition deficit 127). We cannot agree however, on the basis of our results, with an explanation of the effects of scopolamine on memory in terms of an impairment of central executive funcrion, at least not when this is used as a single unitary concept. This objection of ours is based on the absence of any effect of scopolamine on two different measures of response inhibition. An alternative explanation of the absence of effects of scopolamine on the color-word conflict could have been that of scopolamine-induced blurred vision, which would facilitate ignoring the distractor words. However, in the orher task with which response inhibition was assessed, blurred vision could not possibly facilitate the correct response 
since the distracting response was a relatively large white light, the focussing of which would not be necessary to perceive its location and moreover, blurred wision could be expected to hamper this particular condition for it could have made the search for the correct, but unlit, response button more difficult, but it did not. This makes the interpretation of the scopolamine effect in terms of a general imparing effect on all effort-demanding controlled processing less well defendable. Some very easy tasks, such as simple reaction time were even significantly impaired by scopolamine, whereas the notoriously difficult color-word conflict task was not and neither was the stimulus-response incompatible condition of choice reaction time. The significant effects of scopolamine on some of the easy tasks, such as for example simple and choice reaction time were by no means large and could partly be explained by a central sedarive effect, which was implied by the physiological effects of scopolamine on heart rate and blood pressure.

\section{Conclusion}

A rigorous interpretation to be drawn from the findings presented here might be that the effects of scopolamine on memory resemble those of age-related decline of memory performance and hence that age-related decline of cholinergic function would predict memory disturbances. The effects of scopolamine on the speed of perceptual, psychomotor, and cognitive processes may explain scopolamine-induced memory dysfunction, but these effects do not resemble age-related decline of cognitive processing speed and for that reason seem to disclaim the so-called decreased processing resources" interpretation of the effects of scopolamine on cognition. Cholinergic dysfunction may nevertheless contribute to age-related decline of cognitive processing speed, but the enormous discrepancy between the small effects of scopolamine versus the large effects of age on cognitive speed is more likely to be explained by age-related decline of other neurotransmission functions such as that of the catecholamines [16], serotonine $[17]$, but also glutamate [18] . Furthermore, it is likely that these systems interact and hence that their influences on cognition, as well as on memory, are interactive and not independent.

\section{REFERENCES}

1. Bartus RT, Dean RL, Beer B, Lippa AS. The cholinergic hypothesis of geriatric memory dysfunction. Science $1982 ; 217: 408-417$.

2. Berg [J. Memory Rehabilitation for Closed-Head Injury Patiemes. Groningen: University Press, 1993.

3. Bond A, Lader $M$. The use of analogute scales in rang subjectiwe feelings. Bricish Journal of Medical Psychology 1974: 80: 1.46.

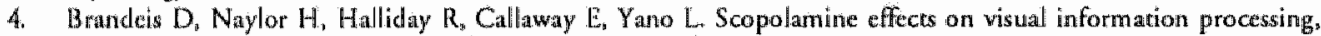
atrention, and eventerelated potential map latencies. Psychophysiology 1.992; 29:315-36.

5. Callangy L, Halliday $R$, Naylor $H$. Cholinergic activicy and constraints on information processing. Biological Psychology 1992; 33:1-22,

6. Dunwe MP. Hartey LR. Scopolamine and the control of artention in humans. Psychopharmacology 1986: 89: 94-97.

7. Flicker $\mathrm{C}$, Serby $\mathrm{M}$, Ferris $\mathrm{SH}$. Scopolamine effects on memory, language, wis urospatial praxis and psychomotor speed. Psychopharmacology Berl1 1990; 100:243-50.

8. Frey PW, Colliver JA. Sensitivity and responsivity measures for discrimination learning. Learning Motivation $1973 ; 4: 327-342$.

9. Houx PJ. Gognitive aging and healkh-related factors. Mastricht: Datawyse; 1991.

10. Houx PJ, Jolles J. Agemrelated decline of psychomotor speed: Effects of age, brain health, sex and education. Perceptual and Motor Skills 1993; 76: 195-211.

11. Houx PJ, Vreeling FW, Jolles J. Age-related decline of sustained tapping performance: Calender or Health: In:

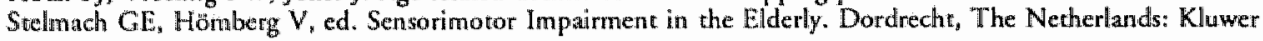
Academic Publishers, 1993: 31-39.

12. Houx PJ, Vreeling FW, Jollew J. Stroop interferenco: aging effects assessed with the Stroop Color-Word Test. Experimental Aging Research 1993; 19:209-224.

13. Jolles J, Verhey [RJ, Riedel W]. Houx PJ. Cognitive Impaiment in Elderly People: Predisposing Factors and Implications for Experimental Drug Studies. Drugs \& Aging in press; : . 


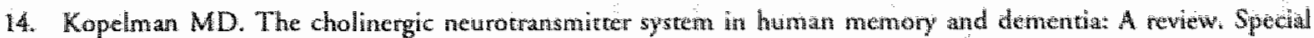
Issue: Human memory. Quarterly Journal of Experimenta Psychology Human Experimemal Psychology 1926 ; 38: $535-73$.

15. Kopelman $M D_{\text {, Corn }} \mathrm{TH}$. Cholinergic blockade' as a model for cholinergic depletion. A comparison af the memory deficits with those of Alzheimer-type dementia and the alooholic Rorsakoff syndrome. Brain 1988; 111: 1079-1110.

16. McEntee W], Crook TH. Age-associated memory impaiment: a rolle for carecholamines. Neurology $1990 ; 40:$ $526-530$.

17. McEntee W], Crook TH. Serotonin, menory, and the aging brain. Psychopharmacology Bew 1991; 103:143-9.

18. MeEntee WJ, Crook TH. Glutanate: Its role in learning memory, and the aging beain. Psychopharmatology 1993; 111:391-401.

19. Molchan SE, Martinez RA, Hill JI. ex al. Increased cognicive sensitivity to scopolamine with age and a perspercive on the scopolamine model. Brain Research Revinews 1992; $17,215-226$.

20. Norman DA. Memory and Aatencian. (2nd ed.) New York: Wiley, 1976.

21. Overall JE, Rhoades HM. Adjusring $p$ values for multiple tests of significance. In: Melaen $H Y_{\text {: }}$ ed. Psychopharmacology. The third. Generation of Progress. New York: Raven Press, 1987: 1013 1018.

22. Parroti A, Deary I. Scopolamine, cognirion and dementia. J of $\mathbb{P s y c h o p h a r m a c o l o g y ~} 1992 ; 6: 541 \% 542$.

23. Riedel W], Jolles J. Cognition Enhancers in Age-Related Cogmitive Dedine. Drugs \& Aging submitted: :

24. Rusted J. Cholinergic blockade and human information processing: Are we asking the right questions: Journal of Psychopharmacology $1994 ; 8: 54-59$.

25. Rusted $J M$, Warburton DM. The effects of scopolamine on working memory in hatdhy young woluntecrs. Psychopharmacology Berl 1988; 96: 145-52.

26. Rusted JM, Warburton DM. Cognitive modelis and cholinergic drugs. Neuropsychobiology $1989 ; 21: 31-36$.

27. Rusted JM, Warburton DM. Effeces of scopolamine on werbal memory? A retrieval or acquisition deficit? Neuropsychobiology $1989 ; 21: 76-83$.

28. Salthouse $\Gamma$. Cognition, motor behavior, and the assessment of atypical aging. In: Howe ML, Stones MJ, Brailnerd $\mathrm{CJ}$, ed. Cognitive and behavional performance factors in atypical aging. Now York: Springer, 1990: $221-234$.

29. Sarcer M. Neuronal mechanisms of the atrentional dysfunctions in senile denentia and schizophreniat two sides of the same coin? Psychopharmacology 1994; 114: 539-550.

30. Schifano F, Curran HV. Pharmacological models of memory dysfunction? A comparison of the effects of scopolamine and lorazepam on word valence ratings, priming and recall. Psychopharmacology 1994; $115: 430$. 434.

31. Stermberg RJ, Tulving E. The Measurement of Subjective Organization in Free Recall. Psychological Beillerin 1977; 84: 539-566.

32. Sternberg S. Memory scanning: mental processes revealed by reaction cime experiments. American Scientist $1969 ; 57: 421-457$.

33. Verhaeghen P. Marcoen A, Goossens L. Facts and Fiction About Memory Aging: A Quantitative Integration of Research Findings. Journal of Gerontology $1993 ; 48:$ P157-P171.

34. Verhey FRJ, Jolles J, Ponds $\mathbb{R}$ WHM, De Lugt M, Vrecling DW. Psychiatric disorders in paticmes atrending a memory clinic. Ine J Geriatric Psychiacry 1995; in press: .

35. Warburcon DM, Wesnes $K$. Drugs as research tools in psychology: Cholinergic drugs and information processing, Neuropsychobiology 1984: 11:121-132.

36. Wesnes $K_{*}$ Smpson $P, K$ idd A. An investugation of the range of agnitive impairmentio induced by scopolamine 0.6 mis.c. Hum Psychophamacol 1988: 3:27-41.

37. Winer B]. Statistical principhes in experimental design. New York: MeCraw-Hill, 1971. 



\title{
Part II: COGNITION ENHANCING DRUGS
}

\author{
Chapter 4
}

\section{Cognition Enhancers in Age-Related Cognitive Decline $^{*}$}

Abstract. A review of studies published in the past 5 years on the effect of cognition enhancers in non-demented human subjects is presented. The heterogeneity of the therapeutic targer, age-associated cognitive decline, is a problem, which can be solved to a certain extent by separately treating groups in whom age-extrinsic factors riay underlie cognicive pathology. World-wide standardization of cognitive assessments would help, since many different tests are applied to answer the same question. Modelling cognitive dysfunction, either by pharmacological or non-pharmacological means in humans is highly recommended, since it allows hypotheses to be tested in a clearly operationalized way. Predicrive validity of the currencly applied models for the clinical situation, remains a problem however. The scopolanine-model has, to a reasonable extent, predictive validity for the cholinergic agents. The results of 67 acute dose studies and 42 repeated dose studies are summarized. All acute dose studies and 14 repeated dose studies were carried out in young or elderly human volunteers. In 45 of these rotal of 81 volunteer studies, models of cognitive dysfunction were employed. The scopolamine-model was the most used (21). The others induced cognitive dysfunction by means of benzodiazepines (8), hypoxia (7), alcohol (5), and sleep-deprivation (4). The remaining 28 repeated dose studies were clinical trials of a duration varying between 2 weeks and one year (average duration was 14 weeks). In 21 clinical trials, the effects of cognition enhancers were assessed in non-demented elderly people in whom impairment of memory, psychomotor performance, or cognitive function was determined. These induded age-associated memory impairment (AAMI) and age-associated cognirive decline (AACD). In the remaining clinical trials the same question was addressed in other neuropsychological patient groups in whom treatment of cognitive dysfunction was the primary aim of the study. There were many studies in which the cognitive enhancing properties of substances in humans were reliably demonstrated. The cognicion enhancing properties of substances that are widely used such as eaffeine, nicotine and vitamins may already be active against AACD, but this remains to be proven. New developments such as $5 \mathrm{HT}_{3}$-antagonist and $\mathrm{NMDA}$-antagonists have provided marginal and disappointing results as to the treatment of age-associated memory impaiment. There is no cognition enhancer, that has reliably and repeatedly been demonstrated to be efficacious for the treatment of age-associated cognitive decline. This situation may change however, as selectivity, specificity and adverse effect profiles of some substances, that are now developed for the treatment of Alaheimer's disease, may be expected to be improved in the future.

- Riedel WJ, Jolles J. Drugs \& Aging; Invited subminssion. 


\subsection{INTRODUCTION}

Cognivive aging, or age-associated cognitive dedine, is a phenomenon that is characterized by the dedine of many aspects of cognitive functioning with age $144,34,76,90 \%$. There is however, a considerable variability between subjects as to the rate of cogniriwe dedine. Not only does the physiological aging process influence cognition in the elderly, but also warious biological factors such as medical conditions. There is a borderline between so-called 'normal cognitive aging', and parhological conditions such as dementia, notably Alzheimer's disease (AD), in which there are disonders of memory and other cognitive functions 110al. Dementia and related pathologicall conditions, including prodromes of dementia, have a great impact on society because of the financial and organizational consequences for both family and society (76). Furthermore, the aging of the population results in an increasing prevalence of age-associated cognitive decline, and a widespread request for therapeutic agents aimed at least at improving the conditions of cognitive impaiment or halting cognitive decline [10\%, 135]. Unfortunately, although great progress has been made in our understanding of mechanisms of drug action in the brain, and in our understanding of brain changes in elderly subjects with cognitive deficits or AD patients, a breakthrough in the treatment of these conditions does not seem to be at hand. Yet, there has been a rapid increase in the interest of clinicians, researchers, and the pharmaceutical industry in the development of new classes of drugs for wespecially-palliative treatment of age-related cognitive deficits and AD condicions 15,115, 13:1],

As a consequence, the number of putative cognition enhancing agents (nootropics) presently under preclinical and clinical investigations is exceedingly high. Hundreds of pharmacological compounds have been developed and tested $12 \%, 46,1683$, with regards to their effects upon memory, in animals, in healthy subjects, and in $\mathrm{AD}$ patients. Cognition enhancers that have been tested in humans, have faced the problem that age-associated cognitive decline was, and is, not recognized as a disease. No consensus existed as to whether age-associated cognitive decline actually should be a therapeutic target for cognition enhancers [139. "The same compounds have been tested in $\mathrm{AD}$ parients, governed by the hope that once a drug would be registered for that disease, the next step would be to apply it to the treatment of age-associared cognitive decline [1761. Furthermore, the question whether dementia is the endpoint, and age-associated cognitive decline or brain aging is the prodrome, is srill open [121]. Though both the incidences of $\mathrm{AD}$ and age-associated cognitive decline are increasing, the latter constitute a far larger proportion of the population, and in the last decade of the twentieth century the number of persons over 65 years of age, will have been doubled. Age-associated cognitive decline has recently become a diagnostic entity in DSM IV 128), and therefore it is likely that the interest in the pharmacological treatment of this condition will revive.

Nootropic properties of drugs were defined by enhancement of learning and memory, facilitation of intercallosal transfer, neuroprotection and a lack of adverse effects 1531. As such, this definition can be taken as the forerunner of that of cognitive enhancing drugs, and we will use mainly the latter term, but the meaning of the term nootropic by now has evolved towards the point that it refers to drugs that affect mental function, for which there are many possible candidate mechanisms, of which no single one is very certain.

In the past 5 years, numerous controlled experiments and clinical trials in demented, but also in non-demented, physically healthy humans, young and old, with or without age-associated cognitive decline, have been conducted. Excellent updates, as to the state of the art in research in cognition enhancers in animals $1168,16 \%)^{\prime}$ and in parients suffering from $\mathrm{AD}[27,501$, have recently been published.

Sarter 168,1691 explaned difficulties that thawe emerged in the search for drugs to enhance cognitive performance in demented and aged patienrs. A systematic and rigorous evaluation of validity (predictive, face, and construct) for the animal models most frequently used in preclinical research, was deemed a necessary prerequisite for further research. Cacabelos [27] concluded that the 
cholinesterase inhibitor tacrine, the first antidemencia drug, is but a pallarive substiturive approach to $\mathrm{AD}$ and that the ultimate treatment that repairs the multisystemic dysfunction in the CNS of $A D$ patients is far from reality. Giacobini and Becker isol categorized putative cognition enhancers for the treatment of AD; into drugs that survived (cholinesterase inhibitors), drugs that: revived (muscarinic agonists), drugs that never made it (nootropics, cholinergic function entrancers; acerylcholine releasers and modulators, neuropeptides and homone precursors and growh factors), unfulfilled promises (Cat+ uptake blockers or antagonists, glutamate agonists/antagonists, ancioxidant compounds and anti $\beta$-amyloid drugs) and winner drugs (second and third generation cholinesterase inhibitors with higher selectivity and specificity).

This paper is an attempt to review the results from controlled experiments and clinical trials with cognitive enhancers in non-demented humans that have been published since 1990. "Two general questions governed the review process. The first question is the cognition entancers" proof of existence: Do they work, that is: do cognition enhancers indeed enhance cognition? The second question addresses the search for underlying (brain) mechanisms: If cognirion enhancers work, how do they work? In this paper one can translate the latter question into: which particular compounds work more than others $s_{*}$ as specified in terms of the mechanism that they manipulate. In chapter 2. the subject groups, from healthy young wolunteers, to elderly patients with memory complaints or cognitive disorders, are described. A distinction is made between experiments performed under normal conditions and experiments performed under conditions intended to model age-associated cognitive decline. In chapter 3 , the dependent measures used in most studies, cognitive and psychomotor tests, clinical- and psychophysiological (EEG) assessments, are briefly described. In chapter 4 , a review of studies whose primary aim was to investigate the cham of substance-induced cognition enhancement in non-demented human subjects, is presented. This was accomplished by performing literature searches in the various relevant journals themselves as well as their abstracts published on the CD-Rom"s of MedLine, PsycLit and Excerpta Medica / Embase from 1990 until march 1995. As far as possible, abstract books of congresses cowering the subject matter were searched for relevant contributions and our own non-systematic exposure to knowledge about experiments and trials with cognicion enhancers was utilized. In the last two chapters, discussion and concinding remarks respectively, the results are put in perspecrive.

\subsection{SUBJECTS AND EXPERIMENTAL MODELS}

\subsubsection{Subject Populations}

In our previous paper on cognitive impairment in elderly people 176, several concepts, sucth as

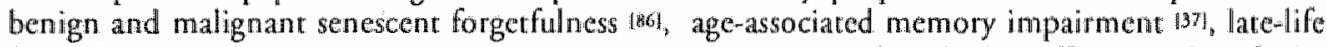
forgetfulness and age-consistent memory impairment 1181 , were described as efforts to identify the target population of elderly people suffering from cognitive aging. Since the proposal of the criteria for Age-Associated Memory Impairment [37, AAMI has been the most used description, particularly in drug trials. However, according to some of the many criticisms $14,15,13 \%, 152,182,1961$, the AAMI-criteria allow some 67\% of the population over 50 years of age to suffer from AAML. Recently, stricter criteria for the condition Age-Associated Cognitive Decline have been published 128:.

Other descriptions of populations studied include 'Aged parients with impaired cognitive function' 11, 'Elderly Patients with Pronounced Memory Problems of unknown Origin' '331, 'Elderly' deficient drivers" $[136,173\}$, "Memory-disturbed Patients' $[621$, and 'Elderly Subjects with mild to moderate Memory Impairment" according to NINCDS-ADRDA 145, 100, 1451. These are variations on the same theme, albeit that the latter two seem to include more severe cases and hence constiture truly the borderline between normal and pathological aging.

Furthermore, some studies have been published on the effects of cognition enhancers in other 
neuropsychological populations, such as epilleprics, organic brain syndrome after prolonged exposure to organic solvents and after alcoholism respectively, in which alleviation of cognitive dysfunction was the prime target of drug therapy.

There are also many stwdies on the effects of cognition enhancers in wolunteer subjects. These can be subdivided in young and elderly volunteers. The rationale to studying the effects of cognition entiancers in healthy elderly volunteers does not differ very much from that of studying cognition entancers in AAMI. It is often assumed that normal elderly volunteers are also affected by, but. not necessarily suffering from, cognitive aging. In addition, studies of cognition enhancers in elderly wolunceess yield the phamacokinetic- and tolerability data appropriate for that age-group.

In most of the studies into the effecrs of cognition enhancers in healthy young volunteers, specific experimental manipulations or paradigms are applied to induce aspects of cognitive dysfunction. These will be explained in the next paragraph.

\subsubsection{Experimental Models}

Understanding age-associared cognirive decline and treating it pharmacologically, calls for the wish to be able to model its presumed mechanism and hence predict the therapeutic response of putative cognirion enhancers. Several human models have been the subject of debate, particularly the scopolamine-, benzodiazepine- and hypoxia-models of cognitive dysfunction $148.58 .140 \%$.

The major problem in predicting clinical efficacy from human experimental results and phase I data is the lack of resemblance between the models used and the dinical condition. This problem is complicated by the diversity of the potential mechanisms of action of new compounds. A further question is whether Phase I studies should be used as predictors of clinical efficacy at all: It has nonetheless been suggested that some human models (c.g. scopolamine-induced amnesia; hypoxia-induced performance deficits) were indeed potential predictors of clinical response 1581. $^{2}$ These models have, in the past 5 years, frequently been used in the process of screening the effects of cognition enhancers in humans. Below, they are described briefly.

The Scopolamine Model. Deterioration of cholinergic system functioning has been postulated to contribute to the memory impairment in normal aging and $A D[6,7$. The anticholinergic drug scopolamine, which acts by blocking muscarinic acetylcholine receptors, has been used to study the role of acerylcholine in attention and memory and to model aspects of the memory and other

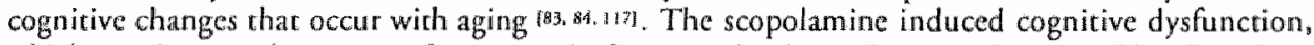
which consists to a large part of memory dysfunction, thas been shown to be reversible when drugs stimulating the cholinergic system are administered concomitantly [144, 212-214], but this effect is nor al ways found with CNS stimulants $178,111,129,1721$, which is another indication that anticholinergic effects are specifically related to impaired memory functions.

The Benzodiazepine Model. Anterograde amnesia is a well-known side-effect of benzodiazepines 1991. These transient drug-induced effects lave been related to clinical attentional and memory deficits [131, and dementia [170]. Amnesia caused by benzodiazepines may provide a useful model for some organic amnesias and thereby allow straregies to be developed for treating these amnesias 1961 . Furthermore, the rationale has been proposed that beta-carbolines with antagonist or partial inverse agonist properties at the gamma-aminobutyric acid (GABA) benzodiazepine receptor complex may offer a treatment for senile dementia [170].

Tbe Hypoxia Model. The CNS is particularly sensitive to thypoxia with resultant demonstrable effects on cognitive function 1.3. Most models of hypoxia and ischemia are used for evaluating the metabolic consequences of cerebral insult $|89|$. They have also been used for inducing cognitive disturbance [61]. The pathological cascade after severe hypoxia or ischemia includes decreased 
ATP, influx of $\mathrm{Ca} 2+$ and $\mathrm{Na}+$ with decrease in intracellular $\mathrm{K}+$ leading to depolarization, telease of glutamate, noradrenaline and acetylcholine, changes in meuronal plasticity, cell deat, amd cognitive impaiment [206]. Possible pharmacological mechanisms for protecting brain function include blockade of $\mathrm{Ca} 2+$ influx, inhibition of cell swelling, regulation of membrane potential, inhibition of neurotransmitter release and inhibition of excitatory amino-acid receptors [206].

Acate Ethanol Intoxication. The behavioral toxicity of alcohol in humans is characterized by impaired performance on a great number of cognitive tasks [65?. Alcohol-induced memory deficits have been claimed to mimic age-relared memory deficits because of their functional similarity as to the state of depleted processing resources "1281. The central effects of alcohol have also been said to be mediated through the GABA system and hence to resemble those of benzodiazepines [32! Furthermore, allcohol effects may induce histotoxic (as opposed to bypoxic) hypoxia since it reduces oxygen uptake of tissue cells [34l.

Sleep Deprivation. Functional similarities have been postulated berween age-associated cognitive decline and sleep deprivation, and also that memory deficiss in these conditions are more likely to occur in tasks which require effortful rather than automatic processes [128y, Lowering arousal, by means of sleep deprivarion, is a frequently used task manipulation in order to induce depletion of cognitive processing resources $[167]$. The decline in cognitive performance during sleep deprivation has been shown to be mediated by brain catecholamines [10s].

\subsection{DEPENDENT VARIABLES IN EXPERIMENTS AND CLINICAL TRIALS}

\subsubsection{Cognition}

Observable behaviour as a function of physical stimuli, interconnected by an unobservable black box, was roughly the psychology of the behaviourists. Nowadays, psychology is the science of cognition, the black box between stimulus and response. Cognition is the label for all processes that mediate non-reflexive behaviour in living organisms. The central theme of cognitive psychology, is that of the organisms' internal tepresentation of the outside world 1701 . For example, novice and experienced clinicians differ in the way they perceive their patients and subseguenty form their diagnosis. The explanation is not that their perception is different, but their internal representation of the problem, to which their perception is compared, differs. The cognitive explanation is than that perception, judgement, decision and overt response are governed by expectations, based on prior knowledge and experience $[66]$. Thus, an internal representation cannot do without memory. Perceived images are stored in working-or short-term memory and compared with knowledge retrieved from long-term memory. Though memory is known to reside in the brain, it is certainly not one observable organ, but its vital functions, such as storage, search, consolidation and retrieval, can be assessed using neuropsychological tests, EEG measures, clinical ratings, or elaborate computerized methods. The vulnerability of memory is nicely, but sadly, illustrated by the gradual, but in the end complete, disruption of this cognitive system in denconted patients. So, functions of memory are indeed the most important, but not the only, cognitive functions. It is therefore rather logical that most trials on the efficacy of cognition enhancers primarily aim to assess improvements of memory functions.

\subsubsection{Cognitive Performance}

There is no uniformity in the testprocedures or experimental tasks to evaluate the efficacy of cognition enhancers 161 . The way in which memory processes or cognitive functioning has been operationalized differs amongst the studies. 
The moxt frequendly used procedure is wondlist learming. The relevance of a word learning task for cognitive pharmacology is that this task provides the possibility to examine the effectiveness of retrieval strategics. The multi-trial free recall procedure is as such a powerful paradigm to eamine verbal memory processes 19. . Unfortunately, as in the presentation of wordlist learning procedures, standardization has been lacking. Some studies only refer to the wordlist learning procedure without specification of how many words were used or how often the list of words was presented. Specification of procedures as delayed recall and delayed recognition was often lacking. Some studies did report the number of words in the list, but no information was given about whether parallel lists were used. Some studies explicitly reported the use of the Rey Auditory-Verbal Learning Test [147], a standardized procedure, while others only mentioned the use of a 15-word learning test, without further specification. The evaluation of drug effects over studies is thus hindered by the lack of uniformity in the procedures used. The number of words per list, the rate of presentation, the retention interval, the number of monosyllables versus bisyllables, the frequency of the words in the native language and other variables also vary across studies.

A well-defined procedure which differs from the Rey procedure is the Buschke's Selective Reminding Method (26). In this procedure, parallel lists are used, consisting of 15 related nouns. The subject has to recall the list within 1 minute. Nouns that are left our by the subject are read again by the experimenter. This is done repeatedly for ten trials (bur less in many studies). The procedure provides information about short-term memory, long-term memory and the retrieval strategy. Another frequently used test on visual memory is the Benton Visual Retention Test. The test howewer, has been subject to criticism, because it is not very sensitive. Moreover, it is disputed that the test measures immediate visual memory and the notion is supported that it is a test of visuo-motor performance 6 wly.

The second most important paradigm in memory assessment is perhaps the well-known Sternberg paradigm, in which the speed of retrieval from short-term memory is measured [188]. This is accomplished by means of the instruction to the subject to compare new stimuli to target stimuli held in short-term memory (memory set). By repeating the tests while increasing the memory set, measures reflecting the speed of scanning one item in short-term memory are obtained separately from the off-set speed component of the task, which is not memory-related. This task has been shown very sensitive to aging [198]. Non-computerized versions of this principle are also available. The task is interesting because it allows separate estimates, obtained in one test, of speed of memory- and non-memory related information processing [20].

The operationalization of the different aspects of memory is poor in most studies investigaring cognition enhancers. Testing has been done with numerous different procedures. Standardization and a description of the procedures are often lacking. Testing procedures from experimental psychology should be used in which aspects of memory processes would be better suited to assess the underlying biological mechanisms. Standardized procedures of memory testing with well-evaluared patallel test versions can be regarded as an essential prerequisite for an experimental study into the efficacy of a cognition-enhancing drug.

\subsubsection{EEG Measures}

A distinction must be made between EEG assessed at rest, the so-called background EEG, or task related measures such as obtained using the ERP paradigm, of which the P300 is the most used. The latter seem to be more important, since changes in EEG activity when subjects are at rest point primarily to changes in vigilance and not necessarily cognition. Nevertheless, background EEG-measures after the administration of cognition enhancers are used quite of en, especially applied in models of cognitive dysfunction. The background EEG is used in a number of trials primarily with the aim to assess the brain-bioavailability of cognition enhancers and also offers the possibility to evaluate the distribution of changed acrivity over the different regions of the cortex $[1597$. Brain imaging techniques as PET and SPECT may be superior as to the location in 
space (i.e. where in the brain), of drug-induced changes. Task-related AEG measures, ERP's, are superior in terms of location in time (i.e. speed of cognirive processing), of drug-induced changes. The P300 is perhaps the best measure of drug-induced changes in cognitive processes in the brain, as compared to measures of cognirive test performance which are the end-products of those processes.

\subsubsection{Clinical Ratings}

Some inwestigators have evaluated efficacy with the help of clinical rating and mood scales, such as the Mini Mental State Examination (MMSE) or the Sandoz Clinical Assessment-Geriatric (SCAG). The true end-products of all cognitive and non-cognitive processes are reflected in clinical rating scales. The most typical of these is simply the clinical global impression, which reflects the judgement of the clinician abour a patients mental status, expressed in a number in the $1-7$ range. Although the meaning of the term siggests that it is always the clinician who performs the ratings, subjective ratings by the patient are also included, and there is a growing number of trials in which ratings of the partners or carers of the patients are used as primary measures of outcome. An important development in clinical trials in $\mathrm{AD}$ has been the 'Clinician's Interview Based Impression of Change' (CIBIC). It is doubtful, whether this measure would be sensitive in the case of AACD. Applied in placebo-controlled double-blind drug trials however, these ratings can, in general, be sensitive, but highly non-specific indicators of drug effects [176).

Clinical rating scales are generally seen as the counterbalance against the often heard criticism that cognitive performance tests as well as EEG measures yield at most microscopic changes, that can never been seen through the naked eye. This phenomenon is most obviously present in clinical research in $\mathrm{AD}$ patients, where, even though the claim of $\mathrm{AD}$ being a memory or cognitive disease is still always made, clinical assessments are far more important than any of the cognitive or process measures.

\subsection{AN OVERVIEW OF COGNITION ENHANCERS IN ACUTE AND REPEATED DOSE STUDIES}

\subsubsection{Introduction}

The results pertaining to experiments and clinical trials with cognition enhancers in non-demerited humans can be categorized along several dimensions, such as population studied, type of drugs dosage used, duration of the study. We chose to make a distinction between 67 acute dose studies and 42 repeared dose studies, which are listed in tables 1 and 2 , respectively. Virtually all acute dose studies were carried out in healthy volunteers, table $\mathbb{1}$ therefore may contain many phase 1 and II studies. In 45 of the volunteer studies, models of cognitive dysfunction were employed. The scopolamine-model was the most used (21). The others induced cognitive dysfunction by means of benzodiazepines (8), hypoxia (7), alcohol (5), and sleep-depriwation (4). Most repeated dose studies were carried out in patients experiencing some kind of memory, psychomotor, or cognitive impairment and hence table 2 includes a great deal of large-scale clinical trials.

The main modes of action of the classes of cognition enhancers studied are described below, as well as the major results obtained from repeated dose studies. 


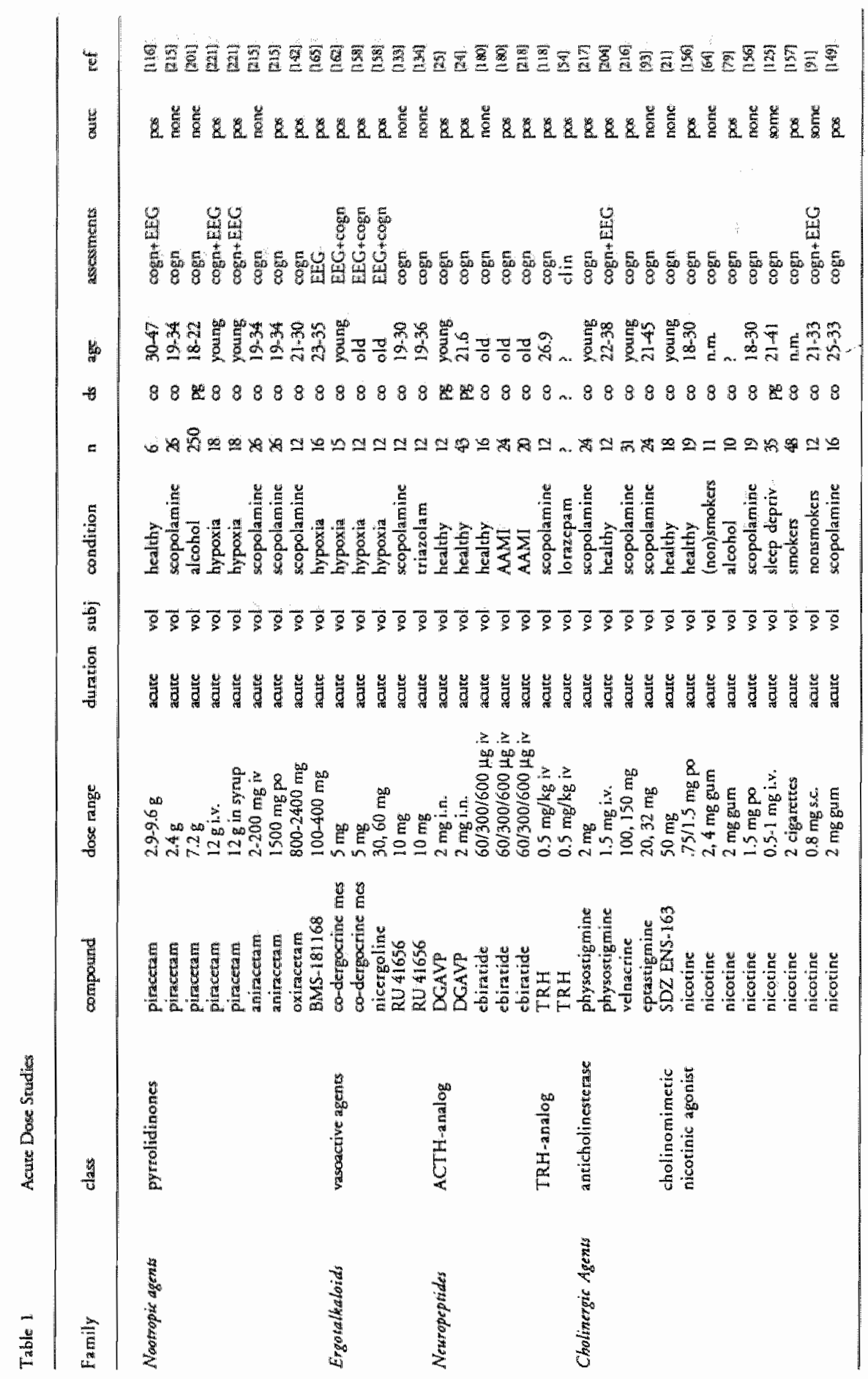




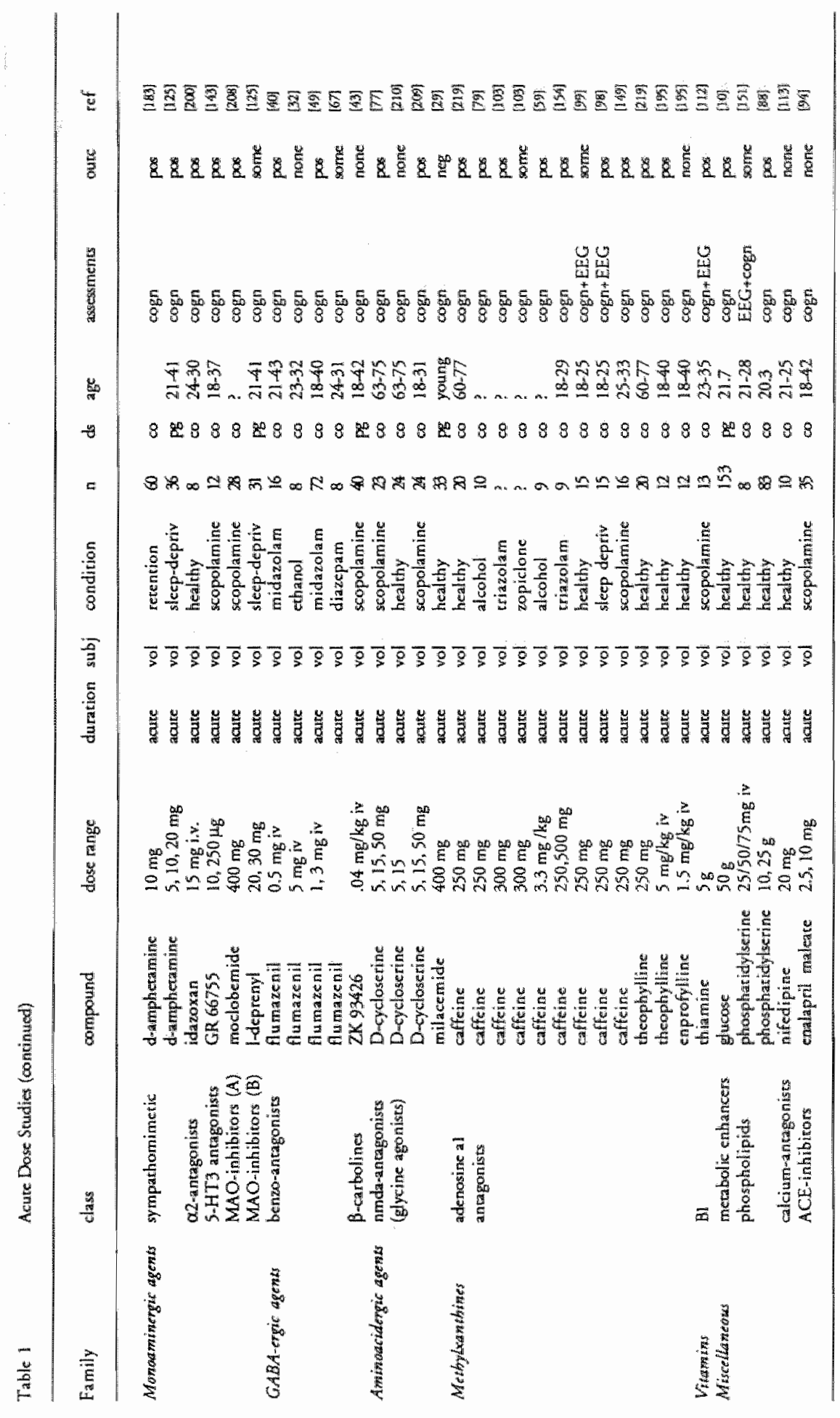


造

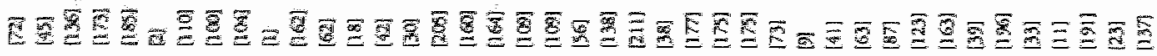

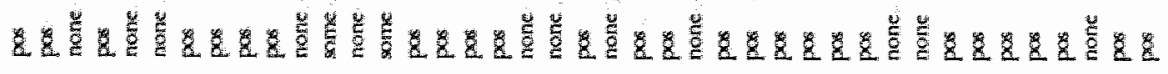
离

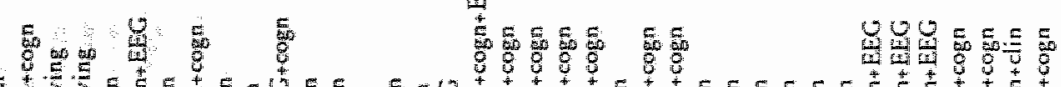

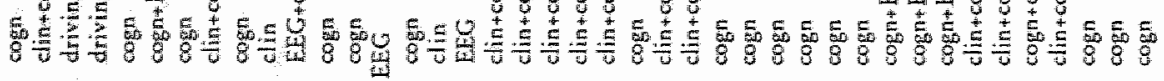

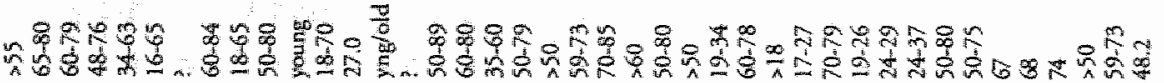

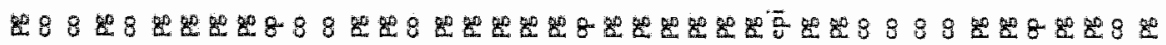

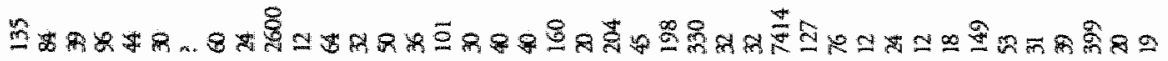

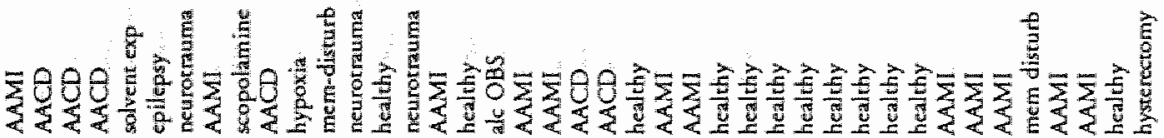

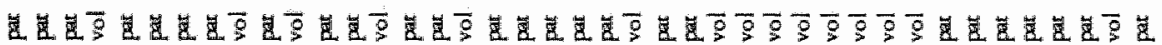

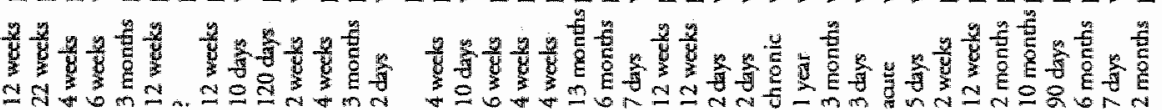

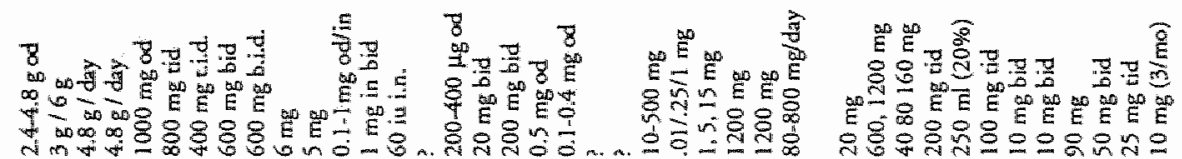

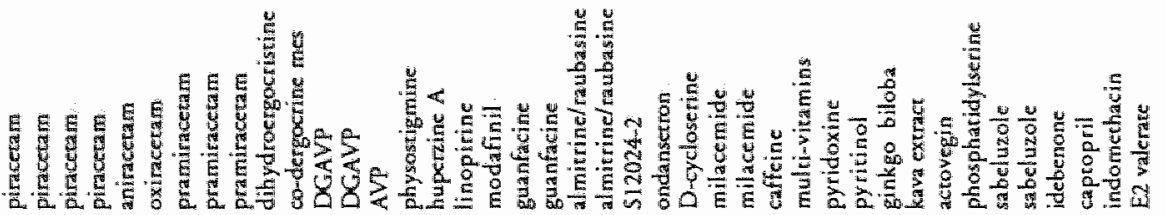

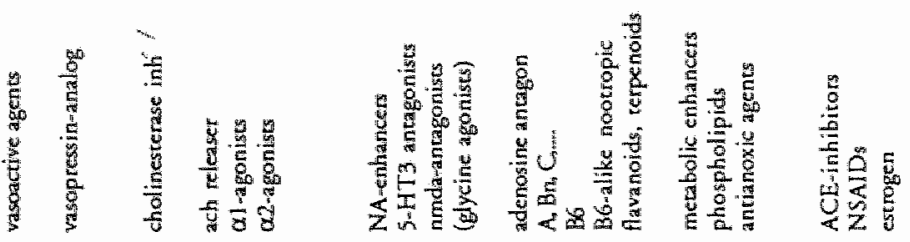

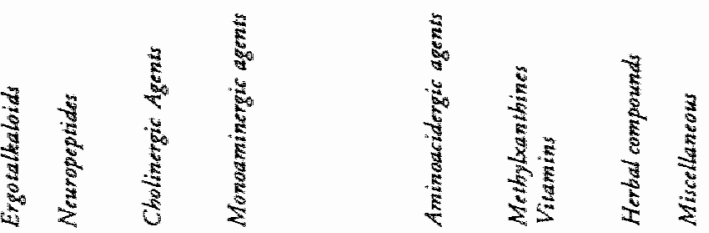




\subsubsection{Nootropic agents}

Even recent rewiews about piracetam and related compounds state explicitly that, in spire of a tremendous amount of research in the latter 30 years, no commonly accepted mechanism of action has been established $155 ;{ }^{199}$. Some benefit of piracetam-like nootropics in clinical studies with patients suffering from mild to moderate degrees of dementia has been demonstrated, although the clinical response is estimated to lie in the 10-30\% range [tim. "The latest hypotheses are that the effect of the racetams is due to a potentiation of already present neurotransmission, is steroid-sensitive and that much evidence points in the direction of a modulated ion Aux. Effects on carrier mediated ion transport are also held possible 155.119],

Despire its being 'the oldest drug on the block", there are still: new, sometimes intriguing results published about the effects of piracetam and its successors. A clinical trial in non-demented patients with mild to moderate memory impairment yielded positive effects of puracetam 3 and $6 \mathrm{~g} / \mathrm{day}$ on tests of attention and memory and also clinical improvement 1491 . An interesting combination of piracetam $2.4 \mathrm{~g}$ and $4.8 \mathrm{~g} /$ day treatment with memory training therapy showed that combined therapy was most effective with $4.8 \mathrm{~g}$ of piracetam in patients whose baseline performance on memory tests was lowest ${ }^{1321}$. Despite the intriguing combination of drug treatment with a memory training program, it must be noted here that a post-hoc split-half analysis in order to evaluate treatment effects is a dubious practice which invalidates the analysis. The two studies of piracetam $4.8 \mathrm{~g} /$ day on the ability of deficient elderly drivers to perform tests of car driving in real traffic 1136,173$)$ were, in this sense, more adequate. In both studies elderly people were selected on the basis of objectively assessed deficits in psychomotor performance. In the first, selection was based on psychomotor test performance below the median of the age-reference group. This study showed that piracetam trearment reduced the number of errors made in real traffic, as compared to placebo treatment (ix3). In the second study " elderly subjects were selected on the basis of performing 'deficient' in one established driving test in real traffic and scoring below the median on another. This study showed no beneficial effects of piracetam on car driving performance. However, enhanced postural stability, after piracetam, showed that the drug was active [136. In a 1991 review of piracetam's therapeutic use in senile cognitive disorders it was concluded that its clinical usefulness was still the subject of much debate because it continued to give mixed results [199]. In the light of what is presented here, this appears not to have changed.

A clinical trial with patients suffering from cognitive disorders related to the behaviourally toxic effects of repeated prolonged exposure to organic solvents, showed that daily doses of aniracetam $1000 \mathrm{mg}$ during a 3 monch period had no effect on cognitive functions [185].

A clinical trial of oxiracetam $800 \mathrm{mg}$ tid during a 12 -week period in epilepsy patients with cognitiwe impairment failed to show meaningful changes in memory function and neither was an effect seen on P300 [al.

Pramiracetam $600 \mathrm{mg}$ bid administered during a 12 -week period to elderly subjects with memory impairment led to significant improvements in memory performance relative to placebo thooj. Pramiracetam $600 \mathrm{mg}$ bid administered during a period of 10 days, when compared to placebo, was able to parrially reduce the amnesic effects induced by scopolamine both in young (18-42) and old (55-65) subjects [106]. Pramiracetam $400 \mathrm{mg}$ tid was administered to males who have sustained brain injuries. Memory, especially delayed recall, showed dinically significant improvement after pramiracetam. This was maintained during an 18 -month open-trial period on the medication as well as during a 1 -month follow-up period after the pramiracetam was discontinued [110).

\subsubsection{Ergotalkaloids}

Co-dergocrine mesylate (CDM) is a comoination of the mesylated forms of dihydroergocomine, dihydroergocristine, dihydro-alpha-ergocryptine and dihydro-beta-ergocryptine. A dual effect of 
CDN: on central monoaminergic neurotransmitter systems, compensating for both hyperactivity and deficits of the adrenergic, setotonergic and dopaminergic systems has been hypothesized.

A large-scale open study in which 2600 elderly with impaired memory and behavioral funcrions were assessed before, during and at the end of 120 days of arearment with dilhydroergocristine 6 mg / day revealed that subjective and clinical ratings improwed during the study period m. Despite the large number of observations, the value of stuch a trial is questionable since no placebo or other internal control, such as multuple dose-range, was employed in the study. Furthermore, no acute objective measure, such as standard neuropsychological or cognitive testing was used.

In a double-blind placebo-controlled trial, using the hypoxia-model, in 12 healthy young volunteers, an acute dose of CDM $5 \mathrm{mg}$ significantly attenuated hypoxia-induced brain dysfunction and psychometric performance [162]. In a similar subsequent trial, further augmentation of the severity of hypoxia resulted in a loss of brain protection, even when CDM was given over 2 weeks daily $[16]_{*}$

A review 12023 on the results from controlled studies of elderly patients with age-related cognitive decline established that co-dergocrine mesylate in some studies, had statistically significant positive effects on symptoms of cognitive dysfunction. Nevertheless, the specific place of co-dergocrine mesylate in the treatment of age-related cagnitive decline remains undetermined, despite many years of clinical use [202].

\subsubsection{Neuropeptides}

Several neuropeptides, namely the ACTH- and TRH-analogues, and hormones such as estrogen [17\%, have been shown to exert significant effects on motivational, learning and memory processes [46]. The effects of ACTH appeared to be independent of its endocrinologic action on the adrenal cortex.

Neuropeptides related to the pituitary hormone vasopressin have also receiwed profound interest [71). A series of five consecutive clinical trials was published in which the neuropeptide desglycinamide-(Arg(8))-vasopressin (DGAVP) was administered to 64 human subjects suffering from cognitive and memory complaints. The patients selected for the study were carefully screened with the aid of neuropsychological assessment procedures. The trials were conducted according to a structured design in which the variables 'dose', "route of administration', 'treatment schedule", 'diagnostic group', and 'severity of deficit' were varied from trial to trial in order to find optimal conditions for the possible expression of a peptide effect. The results indicated a statistically significant effect of DGAVP on word list learning in patients with mild brain trauma, suggesting that learning performance and memory retrieval were improved after peptide treatment in these patients. Patients with more severe brain trauma did not respond to peptide treatment. Some DGAVP effects, e.g. increased speed of memory search, were observed in patients with age-associated memory deficits ${ }^{[62]}$. In an attempt to replicate the first finding, the effect of intranasal DGAVP treatment in 32 patients who had sustained a mild head injury for 3 months in a double-blind, placebo-controlled, matched-pairs design, was investigated. DGAVP did not have a positive effect on cognitive recovery in this group of mildly affected patients [1a]. Event-related potentials (ERPs) were recorded in 22 old and 28 young subjects who received 3 times $10 \mathrm{JU}$ arginine vasopressin (AVP) intranasally 22, 12 , and 1 hour(s) prior to experimental sessions. The results indicated that AVP improved ERP signs of stimulus processing associated with attentional mechanisms. However, the ERP signs of age-related cognitive impairment remained unimproved after AVP $[42]$,

\subsubsection{Cholinergic Agents}

The cholinergic hypothesis of geriatric memory dysfunction entails that cognitive decline can be counteracted by cnhancement of central cholinergic functions [6]. This hypothesis has stimulated 
interest in cholinergic function of the brain in relation to human cognition and age-related cogniw tive dedine. It is undear whether normal aging results in a loss of cholinergic innervation to cerebral cortex and hippocampus, as in AD, but the prevailing evidence suggests that certain aspects of brain cholinergic function are diminished with advancing age nos. Cholinergic receptors in the brain are of the muscarinic or nicotinic type. There are muscarinic and nicotinic agonists ${ }_{3}$ that stimulate these two subtypes of acerylcholine neurotransmission, respectively. Within the muscarinic agonists, the development of more selective compounds that are specifically aimed at muscarine $m$, recpetor subtypes, is a new avenue in the treament of $A D$. Studies in humans have been reported to show the selectivity and specificity of these agents, but unfortunately reports on their cognitive effects in humans are lacking "16]. The main development in nicotinic agonists is reflected by the interest in the influence of nicotine on cognition. Furthermore, there are precursors of acetylcholine, aimed to increase the synthesis of acetylcholine in the brain. Cholinesterase inhibitors, increase acerylcholine neurotransmission by means of inhibiting the activity of the enzymes that normally degrade acetylcholine. Cholinesterase inhibitors are currently in the focus of interest since tacrine has been registered as the first drug against dementia of the Alaheimer type 1203\%. This has stimulated research with cholinergic agents in general and cholinesteraseinhibitors in particular, a second and third generation of these compounds is currently studied and developed, respectively [s1. These compounds are, because of their adverse effect profile, perhaps less interesting in relation to the trearment of age-related cognitive decline, but the results obtained in phase I studies with healthy volunteers are interesting from a theorerical and methodological point of view.

Of 36 patients with neurotrauma who were assessed using neuropsychological measures and measures of clinical balance, 16 showed an improvement in memory scores while taking oral physostigmine, a cholinesterase inhibitor. The most sensitive measure was the Buschke Selective Reminding. Test, specifically Long-term Storage. Physostigmine improved standing balance in the responders. Results supported the potential benefit of cholinergic agonists on memory after TBI and the need for further research of possible clinical markers for the drug ${ }^{304}$. The influence of the cholinesterase inhibitor huperzine A, 200-400 $\mu \mathrm{g} / \mathrm{d}$ during a period of 4 weeks, administered to 101 benign senescent forgetful.ness patients, on memory complaints, was found superior over that of piracetam 2.4-3.2 g/d [205]. The encephalotropic effects of repeated (20 $\mathrm{mg}$ bid) doses of linopirine (a phenylindolinone deriwative enhancing the release of acetylcholine in cholinergic nerve terminals), during a 10-day period, were investigated in 30 elderly men. EEG showed significant central effects of linopirine, indicative of an improvement in vigilance "I60).

\subsubsection{Monoaminergic agents}

Diminished catecholamine function is implicated in dementing illness of the aged and may allso be important in age-related cognitive decline. The positive mnemonic effects of adrenergic agonists in the treatment of memory impairments in aged nonhuman primates and in patients with Korsakoffs disease have motivated studies of these drugs in persons with AAM1, in which deficient central notadrenergic function is also implicated [106]. It has also been suggested that noradrenaline (norepinephrine) is crucial in certain cognitive functions associated with the frontal lobes, particularly the prevention of distractibility by irrelevant stimuli 336 . There is some evidence that serotonin (SHT) exers an inhibitory influence on learning and memory and also that changes in the $5 \mathrm{HT}$ system occur with aging 1071 . Cognitive improvement in therapy with $5 \mathrm{HT}_{2}$ re-uptake blocking antidepressants, particularly when administered to elderly cognitively impaired depressed parients are a topic of current interest that we chose, however, not to address in this paper. Specific interest goes to $5 \mathrm{HT}_{3}$-antagonists, compounds that have, among other applications, specifically been targeted as cognition enhancers 11411. Inhibitors of monoamine-oxidase (MAO) and catechol-o-methyltransferase (COMT) have, besides their antidepressant properties, specifically been considered for their cognition enhancing properties in 
neurodtegeneration $1420,18 \%$.

The al-agonist modafinil $200 \mathrm{mg}$ b.i.d. was administered to patients with alcoholic organic brain syndrome (ODS) during a 6-weck period. The drug augmented the spontaneous remission of the OBS relative to placebo. EEG analysis showed that the drug had a vigilance-improving effect Psychometric tests revealed significant improvement of performance on a number of tasks including simple and complax reaction times and letter cancellation, whereas no effects on mood and at number of psychopliysiological indices were seen [16].

Dally doses of the 0.2 -agonist guanfacine $0.1,0.2$ or $0.4 \mathrm{mg}$ and of $0.5 \mathrm{mg}$ respectively were administered during a 4 -week period to groups of 40 and 160 elderly who mer the AAMI criteria. The data suggested that guanfacine may have modest mood-improving effects but had no significant effects on learning and memory ton.

Almitrine/rabasine (almitrine bismesilate $30 \mathrm{mg}$ b.i.d. + raubalsine $10 \mathrm{mg}$ b.i.d) was administered during a 6 -month period to 155 elderly patients complaining of cognitive disorders and displaying an objective cognitive impairment. Evaluations included a visual analogic self-rating scale and psychomerric tests. Statistical analysis did not show any significant difference between the almitrine-raubasine and placebo groups concerning changes in assessment criteria from baseline to treatment. However, post-hoc division of the patient groups into qualitatively different subgroups on the basis of baseline data followed by statistical re-analysis led to the erroneous suggestion that almitrine-raubasine enhanced concentrated attention in patients with mild to moderate impairment of this function $[138]$.

The efficacy of almitrine/raubasine was studied in twenty elderly patients with age-associated cognitiwe decline during an open 13-month treatment period. Efficacy was evaluated at 2 -month intervals using clinical rating scales and tests of primary and secondary memory. On treatment, scores on all scales improved significantly throughout the study, as did scores in the two objective memory tests [561.

A clinical trial in which the $5 \mathrm{HT}_{3}$-antagonist ondansetron in doses of $0.01,0.25$ or $1.0 \mathrm{mg}$ bid was administered during a 12-week period to 198 elderly subjects with AAMI showed significant improvements in some tests of memory performance after ondansetron $0.25 \mathrm{mg}$ relative to placebo [38i].

\subsubsection{GABA-ergic agents}

Benzodiazepines ( $\left.B Z Z^{\prime} s\right)$, the best known anxiolytics and hypnotics of the past three decades, are agonists at the GABA-BZ receptor complex. Flumazenil is an antagonist, and can hence completely and immediately stop the action of a $B Z$. $\beta$-carbolines are inverse agonists, antagonists, or partial inverse agonist/antagonists. It has been hypothesized, that if sleepiness is associated with increased levels of some kind of endogenous BZ-ligarid, fumazenil's antagonism would immediately 'wake up' a sleeping or sleepy person and hence maintain wigilance [220]. An attempt to test the vigilance-enhancing propertives of flumazenil in sleep-deprived subjects showed that this effect, if it existed at all, was very transient, and immediately followed by a vigilance decrement [132]. Nevertheless, flumazenil remains an interesting substance, particularly from a theoretical point of view relating to models of amnesia and because of its highly specific pharmacological action [144]. Cognitive enlyancentent using $\beta$-carbolines is perhaps one of the best theoretically defined treatment strategies. $\beta$-carbolines with antagonist or partial inverse agonist properties at the GABA-BZ receptor complex have been hypothesized to possess the property of disinhibiting remaining (in the case of dementia) cholinergic neurons of the basal forebrain [170\%. 


\subsubsection{Aminoacidergic agents}

Age-related changes of $\mathrm{N}$-methyl-D-aspartate (NMDA) receptors have been found in cortical areas and in the hippocampus of many species. On the basis of a variety of expermenal observations it has been suggested that the decrease of NMDA receptor density might be one of the causative factors of the cognitive decline with aging. Based on these findings several strategies have been developed to improve cognition by compensating the NMDA receptor deficits in aging. The glutamate NMDA receptor can be modulated by glycine: Under appropriate conditions, stimulation by the amino acid glutamate results in long-term potentiation (LTP) of future neural stimuli $[60)$. The most promising approaches are the indirect activation of glutamatergic neurotransmission by agonists of the glycine site or the restotation of the age-related deficit of receptor densiry by several nootropics 11221 . Two drugs, milacemide and cycloserine, that stimulate the strychnine-insensitive glycine binding site and hence might facilitate NMDA-mediated neural transmission, have been under investigation. Milacemide was administered in doses of $1200 \mathrm{mg}$ on two consecutive days, to 32 young and 32 elderly volunteers. Milacemide relative to placebo facilitated speed and quality of retrieval of learned words $1175 \%$. The efficacy of D-cycloserine 1,5 and $15 \mathrm{mg}$ b.i.d. in the treatment of AAMI was investigated in 340 patients using compurerized assessments of memory and attention. The results only showed non-significant trends of improvement $[177]$.

\subsubsection{Methylxanthines}

As early as in 1901, the effects of caffeine on cognition were studied in man. Improved comprehension, and greater speed and accuracy in information processing, particularly evident under conditions of fatigue, were noted non. Improved performance on psychological tasks has, since then, frequently been reported after caffeine intake in normal subjects, even with dosages as low as $32 \mathrm{mg}$ [02]. The methylxanthins, caffeine and theophylline, are generally viewed as CNS stimulants, but recently their identification as adenosine-a, receptor antagonists [12] has stimulated the research into their effects on memory and cognition. A study investigating the effect of age on the response to caffeine showed that the stimulant effects of caffeine predominated in young people, whereas cognitive enhancing effects of caffeine were seen in the elderly 11921. Adenosine antagonism is assumed to be the most important mechanism for explaining the effects of caffeine on behaviour [124, 186]. Potential cognition enhancers include adenosine $a_{1}$-antagonists since inhibitory adenosine $a_{1}$-receptors have been found on cholinergic terminals in the hippocampus and the cortex $[221$.

Though many studies have investigated the acute effects of caffeine in acute dose paradigrns, controlled studies on the subchronic and chronic use of caffeine are difficult to find. There is however, one very interesting study describing a positive effect of caffeine on cognitive function, including memory. The study involved 7414 people distributed over age groups of about 20,30 , 40,50 , and 60 years. A positive linear relationship existed between the daily coffee consumprion and cognitive performance. Older people appeared to be more susceprible to the performance-improving effects of caffeine than were younger people [73].

\subsubsection{Vitamins}

Although traditionally it has been assumed that the vast majority of those living in industrialised countries have an adequate micro-nutrient intake, there is a growing interest in the suggestion that an increased vitamin intake may have advantages for at least some in the population 19l. It has been argued that the first symptoms associated with micronutrient deficiency are psychological is!. An association was demonstrated between vitamin B.12 blood level and cognitive performance independent of age [17]. Furthermore, short-term nicotinamide (B3) suppletion was shown to inprowe memory [9\%. On the other hand, a 1991 review of 53 controlled trials in humans $[80]$ on the effects 
of niacin, vitamin $B 6$, and multivitamins on mental functions established that wirtually all trials showed serious methadological short-comings. The only positive results were found with very high dosages of vitamin $B 6$ combined with magnesium in auristic children.

Positive effects of vitamin B-6 supplementation (20 mg od for 3 months) in 38 healthy elderly men as compared with 38 controls who received placebo and were matched for age plasma pyridoxal-5-phosphate concentration, and intelligence score, yilded a modest, but significant, improvement of storage of information in long-term memory, but not with respect to the phasic pupil responge, an index of mental effort. It was suggested that cognitive effects are primarily associated with a certain range of vitamin B-6 status increment wid.

Ten times the recommended daily dose of nine vitamins (A palmitate $333.4 \mathrm{IE}$; thiamin mononitrate $14 \mathrm{mg}$ riboflavin $16 \mathrm{mg}$ pyridoxine hydrochloride $22 \mathrm{~g}, \mathrm{~B} 120.030 \mathrm{mg}$; ascorbic acid $600 \mathrm{mg}$; $d$ - $\alpha$-tocopherol-acetate $100 \mathrm{mg}$; folic acid $4 \mathrm{mg} ;$-biotin $2 \mathrm{mg}$; nicotinamide 180 mg) or placebo was administered to 27 healthy volunteers, for a year. At the end of the treatment period, there was some evidence of improved atrention in females only and an association between improved thiamin status and improved cognitive performance in females.

Pyritinol is a synthetic compound containing two molecules for pyridoxine (vitamin B6) joined by a disulphide bridge. Despite this similarity with vitamin B6, pyritinol, has no vitamin action, but is regarded as an encephalotropic or nootropic compound. Twelve healthy volunteers received doses of pyritinol 600 or 1,200 mg for 3 days. Significant improvements in critical flicker fusion and choice reaction time, but not of memory, were found after pyritinol $6.63 \%$.

\subsubsection{Herbal compounds}

Currently, herbal compounds known by ancient medicine in the far east are of growing popularity in the domain of cognitive enhancers. One such very popular compound is ginkgo biloba extract $(\mathrm{GbE})$. Its main indication of interest here is that of "cerebral insufficiency", a condition related to that of cognitive decline of organic origin. Among the proposed mechanisms of action, are antioxidant effects of flavonoids, ingredients of GbE. In 1992, a review of 40 clinical trials investigating the effect of GbE was published [82]. Only 8 clinical trials were judged to be of good quality [8]. The latter revealed mainly positive effects of GbE. Most trials did not include cognitive assessments howewer. A comparison was made between the best clinical trials with $\mathrm{GbE}$ and co-dergocrine and it was concluded that these were of equal quality whereas both were showing significant effects of the investigational substances [82]. Since then, we only found one study in which the brain bio-availability of three days of treatment with doses of 40,80 and $160 \mathrm{mg} G \mathrm{GE}$ was investigated in 24 healthy volunteers [ 87 ). No effects were found on cognitive performance whereas $E E G$ measures indicated the bio-avalability of GbE due to significant changes in EEG-patterns, without changes of indices of alertness.

Another herbal compound, kava root extract $200 \mathrm{mg}$ t.i.d., was assessed for its effects on recognition memory using an ERP paradigm in 12 healthy volunteers, during a period of 5 days ins], Though trends towards improvement were reported, no significant main effects of kava were seen.

\subsubsection{Miscellancous}

Amtimfammatory agents: Although dassically defined inflammation is not a characteristic of the pathologically aging brain, numerous acute phase reactants and immume-related markers have been found. Furthermore, retrospective studies suggest that rheumatoid arthritis parients, many of whom could be cxpected to be taking anti-inflammatory medication, have a lower incidence of AD. This has led to the hypothesis that anti-inflammatory agents might be effective as brain, or cognition enhancers. As steroid drugs may have neurotoxic properties, the non-steroidal anti-inflammarory drug (NSAID) indomethacin appears to cross the blood-brain barrier and has been shown in a very small controlled dinical trial to exert some protective effects on cognitive 
dedine in mild to moderate $A D$ patients $1150 \%$.

Indomethacin $25 \mathrm{mg}$ ti.d. was administered to 20 thealthy elderly volunteers during an 8 -day. period. Arousal, attention, integration, coordination, memory and mood were investigated using a battery of psychomoter tests and clinical ratings. Assessments were performed before and after the first and last doses of a 8-day course of medication. While critical flicker fusion threshold. significantly decreased after the first dose, a beneficial effect on choice reaction time latency was seen both after acute and continuing administration of indomethacin. No change was seen in performance on the symbol-digit substitution test and the continuous attention task and in anxiety and depression scores. Cognition may improve in healthy volunteers following indomethacin administration, whereas attention and psychomotor speed remained unaffected [23).

Antianoxic agents. Protection against hypoxia and ischemia by improving brain merabolism is the main denominator of the term antianoxic agents. Sabeluzole $10 \mathrm{mg}$ b.i.d. was studied during a 2-month period in 53 elderly patients complaining spontaneously about their memory. They were selected if they fulfilled the AAMI-criteria and if, additionally, they were poor performers on a Selective Reminding Procedure (SRP). No significant sabeluzole-placebo difference was found. Significant improvements in learning, memory (but not on the SRP) and verbal fluency however. were found within the sabeluzole treatnent group (1961. A selection consisting of 31 of the poorer performers among the previous group was followed during a 10-12 month period of open treatment with sabeluzole $10 \mathrm{mg}$ bid. The results showed that the same effects as in the previous trial emerged, but also significantly better results were obtained on all parameters of the SRP. These improvements were parallelled by improvements of dinical ratings 133 . The efficacy of idebenone $45 \mathrm{mg}$ bid in treating 79 elderly subjects with very mild or mild cognitive decline (GDS $2-3$ [1461) during a 90-day period was compared with that of oxiracetam $800 \mathrm{mg}$ bid in an unblinded study 111. Significant improwements after idebenone treatment relative to oxiracetam treatment were found on 2 out of 5 rating scales and on a verbal memory test. A recent review on the therapeutic experience obtained with idebenone established that in the absence of a proven alternative, the preliminary evidence with idebenone, indicating primarily slight improvement in cognitive function in some patients combined with good tolerability, may be sufficient to warrant its consideration in the trearment of dementia in elderly patients, particularly those with mild disease [52].

Phospholipids. Phospharidylserine (100 mg tid) administered during a 12-week period to 149 AAMI patients led to significant improvements relative to placebo on performance tests related to learning and memory tasks of daily life. The investigators report that analysis of clinical subgroups suggested that persons within the sample who performed at a relatively low levell prior to trearment were most likely to respond to phosphatidylserine. Within this subgroup, there was: improvement on both computerized and standard neuropsychological performance tests, and also on clinical global ratings of improvement 399 . Again this is an example of post-hoc split-half evaluation on the basis of observed data, an unacceptable way of analyzing and interpreting data. rendering the conclusion drawn by the authors, in terms of the treatment being a promising one for" this indication, less likely.

Metabolic Enbancers. The encephalotropic and psychotropic effects of Actowegin, a protein-frec metabolically active hemoderivative improving oxygen and glucose utilization, were investigated in 18 age-associated memory impairment (AAMI) patients during a period of 2 weeks with 250 $\mathrm{ml} 20 \%$ Actovegin. Pharmacodynamic evaluations were carried out after the administration of one acure infusion on day 1 , and before and after one additional superimposed infusion on day 15 . EEG brain mapping demonstrated that Actovegin exerted an improvement of vigilance accompanied by improved cognitive performance, increased physiological arousal and increased P300 amplitude, confurming the hypothesis that nootropic drugs may influence the P300 amplitude in the sense of an improved availability of cognitive processing resources 1178. Time-efficacy calcularions exhibited more effect after subacute than acute administration with the pharmacodynamic maximum after the superimposed dose [163]. 
Angiotensin Converting Enzyphe (ACE) Inbibitors. Analysis of clinical rrials over a treatment period of 6 months with captopril $50 \mathrm{mg}$ bid in 280 normotensive patients with AAMI revealed litue to no ewidence that captopril improved cognitive performance [1\%!. In a recent review on the effects of ACE Inhibitors on Cognituve Function, it was concluded that these agents do not have a deletrious effect on cognitive function 1300 . No evidence for cognitive improvement by ACE unhibitors in humans was found.

Hormones. The effects of estrogen E2 walerate $10 \mathrm{ing}$ i $\mathrm{m}_{\mathrm{g}}(3 / \mathrm{month})$ on memory were assessed in 19 women before and 2 monthis after hysterectomy and bilateral oophorectomy. Contrary to the estrogen group. the placebo-treated group showed significant decline of immediate and delayed recall of paired associates. This change was found related to a decline in plasma oestrone and oestradiol levels. The estrogen treared group improved significantly on the immediate recall of paragraphs, an effect not seen in the placebo group. A number of other parameters remained unchanged $113 \%$.

Glucose. The role of glucose in the action of cognitive enhancers is supposedly mediated by the release of adrenalin from the adrenals. The hypothesis that cognition enhancers produce their effect. by increasing the avalability and uptake in the brain of glucose is suggested by the abservations that some cognition enhancers do not cross the blood-brain barrier or are only effective peripherally, many are ineffective alter adrenalectomy and cognitive function is correlated with glucose regulation in aged animals and humans [207].

Dual mode of action. $\$ 12024$ is a compound whose mechanism of action involves facilitation of noradrenergic and vasopressinergic systems [57]. Repeated administration of doses in the range of 10-200 mg S12024-2 were claimed to be capable of correcting age-associated cognitive decline in healthy elderly volunteers in a dose-dependent fashion [211].

\subsection{DISCUSSION}

\subsubsection{An Evaluation of Treatment Effects}

Different categories of different drugs have passed the review. First were the piracetam-like compounds. The results obtained with this category of cognition enhancers are a good example of the problems we encounter when we want to interpret the results obtained with cognition enhancers in general. First, there is no clear answer to the question 'do they work?'. Of course, there have been many demonstrations of efficacy, but also too many without. Especially with piracetam, the most ingenious studies have been undertaken, but still there seems to be no single paradigm in which the drug always works. Furthermore, there were indications that piracetam is efficacious against disturbances of the equilibrium, while it is not effeacious as a cognition enhancer 1136, 2011. These results actually present evidence that piraceram is violating its own definition of being a mootropic drug and hence would neither be a cognition enhancer. This is not meant to say that these results are not interesting. If drugs improve postural stability, there is evidence that the central availability of cognitive processing resources is suppleted $[187,194]$, and hence cognition enhancement could be the restilt. Such a hypothesis seems prominent in the case of the piracetam-like drugs and could very simply be tested by thaving the subjects cognitive performance tested in standing position while simultaneously measuring their postural stability. Yet, this has, to our current knowledge, never been done. Furthermore, there is some evidence that the more recently developed drugs in this category, such as praminacetam for example, are more potent and perhaps more efficacious.

The central hypothesis underlying the cognition enhancing propertics of the ergot-alkalloids is that of improved brain perfusion. Notwithstanding the fact that there is at least some evidence of a weak effect of the drug, there is no clinical study that clearly confirms the cognition enhancing effects simultaneously with the assessment of improved brain perfusion. Several examples of 
protection by an ergot-alkaloid, against disturbed brain perfusion, using the bypoxia model, were obtained from acure dose studies. The study that addressed this problem in perthaps the best possible way, namely by applying the hypoxia model at the end of a subchronic reacment with co-dergocrine mesylate, did not show the desired effect [6at.

Vasopressin peptides have been found to have effects in parients with milld to moderate brain trauma, but not in patients with severe brain trauma 1624 , al rhough an attempt to confirm this finding in patients with mild neurotrauma failed 4 8). Whether there would be efficacy with respect to cognitive decline in aging, could not be decided upon on the basis of the most important clinical trials with the neuropepride DGAVP ${ }^{1621}$. As both DGAVP and TRH exerted a number of cognitive effects in healthy volunteers, it remains of interest whether these substances would be efficacious in age-associated cognitive decline.

The relative success of cholinesterase inhibitors as a palliative treatment in $A D$, is not so apparent: in age-associated cognitive decline. A high incidence of adverse events, particularly hepatotoxicity, combined with relatively few possibilicies for cognitive improvement, has led to a negative cost/benefit ratio of these agents in age-associarive cognitive decline. This situation could change if second and third generarion cholinesterase inhibitors, developed for $\mathrm{AD}$, would lack the adverse event profle such as that of tacrine 2031 . This seems to be the case for huperine $A$ [205I, but more data as to the demonstration of its efficacy need to be gathered. Furthermore, it can be noted that experiments using the scopolamine-model of cognitive dys function have shown that cholinesterase inhibitors can completely reverse cholinergic defucits in humans, whereas the influence of most other substances tested using this model are reported in terms of a significant attenuation. If a substance shows no effect in the model, its development, at least in the doses studied, should be halted. The predictive validity of the scopolamine-model is perhaps the highest in cholinesterase inhibitors. Furthermore, despite frantic search, no scopolamine trial in humans could be found demonstrating the cholinergic activity of tacrine. This would have been interesting; since it has repeatedly been claimed that the progress in the search for cognition enhancers is hampered by the lack of an established active drug control.

Phospholipids could achieve the same result as cholinesterase inhibitors provided that they be available in the brain. Perhaps new formulations of phosphatidylcholine and phosphatidylserine fulfil this requirement to some extent, since their brain bioavailability in volunteers was demonstrated. The demonstration of phosphatidylserine"s efficacy in AAMI however, was undermined by its manner of post-hoc analysis. Therefore, the evidence for this type of phospholipid can be considered weak.

The relevance of studies into the cognition enhancing potential of nicotine may be further illuminated by the report of an inverse association between smoking and the incidence of AD among subjects having a family history of dementia [ig7, suggesting that nicotine may have a protectivio role in the etiology of AD. Furthermore, acure nicotine administration has been shown to improwe atrention and speed of information processing in $A D$ patients. Whether these phenomena also apply to age-associated cognitive decline remains to be seen, but the relation between nicotine and cognition seems to be beyond dispute. The acute blockade of nicotinic receptors was shown to induce cognitive dysfuncrion in healthy volunteers 1126. The degree of cognitive dysfunction induced by nicotinic blockade appeared to be age-related 1271 . Cognitive dysfunction in airline pilots after the cessation or prohibition of smoking is currently a matrer of great concern 1184$]_{\text {. }}$ Though the health hazard of smoking is beyond any doubt too, the interesting thing is that nicotine intake through smoking is still so widespread that epidemiological studies on the redation between nicotine intake and cognition can be carried out.

Though theoretically there would have been much to be expected from monoaminergic stimulants, the clinical evidence was generally weak. The assertion that the noradrenergic system appears to be involved in the focussing of attention 1361, would bear relevance for age-associated cognitive decline. Focussed attention, as measured by the Stroop-effect, was shown to be one of

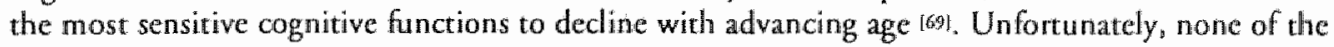


revicwed studies included such a test, but focussed on memory instead.

It is not very likely that $d$-amphetamine will be applied in large scale trials, but the result which showed that a low dose of the general catecholaminergic stimulant d-amphetamine, could act as a cognitive enhancer, without adverse effects, could have some impacr as ro new developments with thils category of substances.

MAO-B inhibitors have been considered as agents for AD 1931 , and as nonspecific cognitive enliancers (17), but application as stimulant appears to have failed "125). The finding that a MAOA inhibitor attenuated the scopolamine-induced cognitive dysfunction may indicate that this substance increases cholinergic neurotransmission and hence may have a multi-neurotransmitter effect, since its primary mode of action is increasing the circulating levels of noradrenaline and serotonin. Though there are many studies on their cognitive effects in depressed patients, these agents have as yet, not been investigated primarily for their effects in age-associated cognitive decline, but perhaps they are suited for a combination of age-associated cognitive decline and depression in old age.

The theory of indirect cholinergic facilitation by the $5 \mathrm{HT}_{3}$-antagonists is very well-described and seems to explain the positive results obrained in their application with the scopolamine-model of cognitive dysfunction and also in AAMI. Their additional anxiolytic potential perhaps calls for application to another subclass of age-associated cognitive decline. A definitive positive conclusion is difficult however, after only one clinical trial.

For the moment; the label of 'unfulfilled promise' is perhaps the best we can stick to the NMDA-antagonists. It was demonstrated that these drugs are active in humans, but one of these studies provided the only negative result in this teview, that is: a putative cognitive enhancer; milacemide, producing cognitive impaiment. The latter was explained by the potential neurotoxicity of this type of substance. This problem of neurotoxicity should have been overcome with cycloserine, a partial agonist/antagonist of NMDA. Furthermore, the clinical trial with cycloserine in AAMI, showed some positive effect after 2 weeks of administration, but not at the intended 12 weeks. Perhaps tolevance to the intended positive effects of the drug nulled the treatment response.

Though caffeine is widely known as a CNS-stimulant, it seems also to be a cognitive enhancer. An explanation might be that its adenosine antagonism has a suppletory effect on cholinergic function. That is, it doesn't affect memory in pcople when they are young and cholinergic funcrion is optimal. When cholinergic dysfunction is induced experimentally, or in nature due to age, caffeine might exert a positive effect on memory through this system. It is difficult to imagine a controlled clinical trial with cafteine, but it would be feasible to study the relation between age, daily caffeine intake and changes thereof, and cognitive function, between and within subjects. Furthermore, in clinical trials with putative cognition enhancing drugs, one should keep track of the amount and time of daily caffeine consumption. The results could then either be magnified or artenuated after correction for caffeine incake.

The possibilities of vitamins as cognition enhancers remain obscure, despite some remarkably well carried out experiments and trials. The case for vitamin B6 seems not to be very strong, however. The association of vitamin $B \|$ deficiency with memory dysfunction and cognitive disorders has been related to an impairment of cholinergic activity [114], and this association was shown in man using the scopolamine-model. Vitamin Bl. (sulbutiamine) has been advocated for the treatment of cognitive dysfunction and fatigue of central origin (asthenia), prevalent after prolonged physical exercise in endurance athletes [35], but also in aging [7]. It has been suggested. that the cognition enhancing potential of thiamine in $\mathrm{AD}$ is equivalent to that of physostigmine and due to its general lack of adverse effects would deserve the benefit of the doubt [112]. Whether this is also the case in age-associated cognitive decline remains to be demonstrated.

Despite their excellently well defined theoretical basis, there seems to be no basis for the GABA-ergic agents in age-associated cognitive dedine. They might however, remain interesting pharmacological tools in research on cognitive funcrioning. The discovery that flumazenil selec- 
tively antagonizes the sedaring, but not the amnesic effects of $B Z$-agonists, may contribute to the next generation of pharmacological models of memory dysfunction.

The observation that an NSAID improves cognitive function in the dlderly might lead to the speculation that larent subclinical inflammatory processes impairs cognition in otherwise healthy aged individuals.

Although only one study was described as for estrogen replacement therapy, this study bears the appearance of the prototype of prevention of cognitive and homonal dystunction by appropriate pharmacotherapy. It should be noted however, that the example is dissimilar in that a discrete event, hysterectomy, rather than a gradual process, aging, is the cause of associared physiological and cognitive changes.

The point to be taken from the cognition improving effect of glucose is simply that if cognitive functions are measured precisely enough, using sensitive tests, variations as a function of nutritional status will al ways be found.

The antranoxic compound sabeluzole has been studied wery thoroughly with regard to its cognition enhancing effects in memory disturbed patients. Particularly the cognitive assessments and the parient population were well described. For that reason and because there were no studies into the mechanism of sabeluzolle, it would be interesting to see what the drug would do in human models of cognitive dysfunction.

\subsubsection{The Subject Population as a Target for Drug Studies}

With respect to the nature of age-associated cognitive decline, several remarks can be made. The AAMI-concept was well formalized, allowing for the possibility to perform many clinical trials on the same target popularion. This target population however, was allmost as big as the aging population itself and for that reason, was very heterogenous. One particular aspect of AAMI was the presence of memory complaints. The presence of memory complaints was operationalized as a score on a questionnaire and the 'patienr' did not need to have complained him-or herself. So, in some cases, this population was described as: "elderly people fulfilling the AAML-criteria". The core of the problem is, in our opinion, not so much that cognitive aging, or age-associated cognitive decline, is not a disease according to a classic medical model, but the fact that the inevitable consequences of a 'natural phenomenon' (aging) is in many cases indistinguishable from the consequences of present or past disease states.

Many age effects reported in the literature can be largely explained by suboptimal brain functioning, induced by other factors than aging per se. These age-extrinsic factors were called biological life events (BLE) (68). Examples of BLE are repeated exposure during ones sifectime to, general anaesthesia, organic solvent exposure, neurotrauma, chronic use of psychotropic medication and alcohol. It may be important to discern various subgroups within the hererogencous group of non-demented subjects with complaints of impaired cognitive functioning, e.g., those with Bl.E and those without 176$]$. Patient groups for drug studies can be made more homogeneous, which would improve the detection of possible drug effects. The rationale is that the pathogenesis of the cognitive decline can be expected to differ for the various subgroups of elderly people with compllaints. Examples of this approach were already presented in this review, namely the studies investigating the effects of cognition enhancers in parients suffering from the cognitive impairment due to neurotrauma $11 \% 62 \|$, alcoholic organic brain syndrome $[164)$, epilepsy 12], organic solvent exposure [185: and hysterectomy [137].

\subsubsection{Methods Used for Ttreatment Evaluation}

The use of rest batteries covering an array of cognirive functions is seldom explained and therefore one may wonder why so many tests were carried out to assess the answer to one simple question (does this drug enhance cognition ?). The field suffers from a lack of explicit standardization, 
drhough it has often been specified what the contents of a cognitue test battery, applied for drug resting, should be 147,148 . Regarding this problem, research in $A D$ is more advanced, because an international sandardization of effec measures (eg. ADAS, CIBIC) has been accomplished, although the specificity and the sensitivity of these measures may be questioned. In the domain of age-associated cognitive decline, there is no such standardization. There exist some good examples of cognitiwe test batteries used in seweral of the AAMI dinical trials [8\%. 181]. One such test battery was entirely based on the assessment of memory functions (99), without controlling for levels of alertness or vigilance. Furthermore, the latter test bartery lacks a firm theoretical basis, particularly with respect to its application of word list learning and yields no single measure of cognitive speed. The other cognitive test battery 18 81, that has been used in a number of clinical trials and experiments, yields many measures of cognitive speed, while no free recall measures of memory functions are taken. The best solution would perhaps be to apply tests that assess both memory performance and measures of cognitive speed, that have been shown to be sensitive to aging and drug effects, and are applicable within standard clinical neuropsychological assessment. $162,75 \%$.

Another problem often encowntered in using test batteries providing many dependent measures is that of an increased type II error. An often heard criticism is therefore that using a battery of cognitive tests always leads to some kind of a positive result. Indeed, this may be so. However, it should be noted here that it is a matrer of good scientific practice to specify hyporhesis explicitly a priori and fully operationalize these into descriptions of outcome parameters. This allows for distinctions to be made between primary and secondary outcome parameters. In dinical trials the former refer to the "intent-to-treat' analysis. If these basic scientific rules are adhered to, there is nothing against using a test battery yielding a wide range of dependent measures. In fact, it often yiclds more information than global measures $[47$. Furthermore, it is of interest in the search for cognition enhancers, whether hyporheses about the effects of a substance, are in any manner specific, as to the cognitive functions that are the target of enhancement. Some distinctions have been made, particularly regarding the specificity of memory enhancement, but if a drug simply claims to enhance cognition, indeed, this is an implicit hypothesis stating that the performance on all tests should be significantly enhanced by the particular treatment. In such a case, compiling all the dependent measures into one very aspecific but sometimes sensitive performance index, may be a way to circumvent extensive statistical procedures. In recent years, some drugs (the aminoacidergic agents) have been developed claiming to enhance long-term potentiation (LTP) of memory consolidation. Such an hypothesis lends itself for relatively precise operationalisation. It would not be necessary to observe enhanced performance on all but a few dependent measures of cognition measuring precisely the expression of LTP, such as improved recall and recognition of learned material. In fact, the absence of effects on aspects of cognition that are not predicted is a primer in such a case. Whether eventual significant improvements are clinically relevant, remains a topic that can simultaneously be dealt with employing dinical rating scales.

With respect to the application of EEG measures, we feel that the application of this technique to demonstrate the brain bionvalability of a substance, does not make much sense in relarion to a demonstration of its efficacy. This does seem to be the case however, for the application of ERP-paradigms such as P300. The latter provides a well defined measure of cognitive processing and as such seems to be a relevant index. If background EEG is changed, i.e. a change in the dominant rhythms in the EEG, this would in the first place indicate changes in arousal, activation, vigilance. etc.

\subsubsection{Betrer Models and Future Possibilities}

One problem that this review has shown is that the many promising results from human models are rarely followed by successful results in large-seale clinical trials. In some cases, the models are therefore blamed because of their lack of predictive validiry. However, if a drug claims to 
entance cholinergic function and this can be demonstrared in a scopolamine paradigm with heal thy volunteers, there is nothing wrong scientifically, about doing 50 . On the contrary, experiments like these are absolute prerequisites for clinical trials. If after demonstrating the cholinergic activicy of a substance, it appears that no good clinical results are obtained with it, then perhaps one ought to conclude that the clinical population was not suffering from a cholinergic deficit. In other words, the scopolamine model's validity for assessing the cholinergic activity of a drug, seems beyond doubt, but whether it adequately mimics age-associated cognitive decline, is a matter of great dispute $1155 \%$.

Rather than to do away with these kind of models, it might be a betcer strategy to devise new human models and refine current ones. In the furure, the scopolamine model will probably be replaced by more selective and specific models employing muscarinic $\mathrm{m}_{1}$-antagonists, such as biperiden [166], and micotinic antagonists like mecamylamine [126, 127], to model aspects of (age-related) cognitive dysfunction and to test new drugs specifically aimed at improving those aspects of cholinergic transmission. For example, the new selective and specific muscarinic $\mathrm{m}_{1}$-agonists that are currently under investigation for $\mathrm{AD}$, should reverse the cognitive deficits in humans, induced by scopolamine or biperiden, but not those by mecamylamine. If these drugs would not satisfy such hypotheses, they would not be true $m_{1}$-agonists and hence could as such be discarded. It is also evident that the ultimate demonstration of clinical efficacy of substances in patients are perhaps more important until truly predictive human models are established. The value of human models is that they ane of help to find out if drugs really do what they claim to do in humans.

Pertaining the $B Z$-model of amnesia, the possible refinement of this model has already been mentioned. When subjects were pretreated with the specific $B Z$ receptor antagonist, flumazenil, the sedative and attentional effects of diazepam were blocked, but a marked impairment in episodic memory still accurred. This selective pattern of cognitive dysfunction may serve as a model for clinical cognitive syndromes $\{13,84,67\}$.

A variation of the hypoxia model is that of hyperventilation-induced cognitive dysfuncrion. This model has previously been shown to be more valid for the simulation of ischaemic events in the brain than the hypoxia model and also that it is a sensitive model to test the neuroprotective effects of nootropic drugs such as aniracetam [851. Recently, hyperventilation-induced cognitive dysfunction was demonstrated employing a variety of cognitive tests (153).

In principle, models of cognitive dysfunction are pharmacological, physiological, or psychologücal conditions, known to cause cognirive dysfunction. In this review we have seen seweral relatively litule used applications such as sleep deprivation [325), and the possibility of physical exhaustion (asthenia) has also been mentioned 135. Many more of those models exist, for example all those in which the availability of resources for cognitive processing are manipulated, and could be tried for the screening of cognition enhancers. Whether or noc such models have direct relevance for the etiology of age-associated cognitive decline is not the most important question. As long as it is not entirely clear what a drug does in terms of biological and pharmacological modes of action, behavioral models in humans may supply the evidence to the daimed effect of cognition enhancement.

\subsection{CONCLUDING REMARKS}

In general, it can be concluded that there are many active substances that have been shown to be capable of enhancing cognition in non-demented humans. The question as to the reliable demonstration of clinical efficacy of cognition enhancers in age-associated cognitive decline however, is still difficult to answer. We deliberately to chose to include as many reports of clinical trials as possible, thereby accepting the impossibility to critically comment some of the findings. The compounds that have been under investigation for many years, such as the nootropics, the 
ergotalkaloids, the neuropeptides, the precursors of acetylcholine, the monoaminergic enhancers, the $\mathrm{QABA}$-ergic agents, the $\mathrm{ACE}$-inhibitors and the calcum-antagonists seem not to have made it for age-associated cognitiwe decline. Recent developments in research with cognition enhancers for the treatment of $\mathrm{AD}$, i.e. cholinesterase inhibitors, muscarinic agonists, and multi-transmitter substances, also promise new developments in age-associated cognitive decline. The data on these substances in non-demented humans are interesting, but are currenty insufficient to predict the benefits and conts of their use in the treatment of age-associared cognitive dedine. The substances that have been the most promising substances, as predicted from, theory, animal research, and human experimental studies, were the compounds aimed at facilitating glutamate or NMDA-mediated neurotransmission and the compounds aimed at indirecrly facilitating cholinergic transmission via the antagonism of $5 \mathrm{HT}_{3}$, receptors. The latter have been demonstrated to be active in experimental and clinical human trials, but in spite of this, have not found their way to the market. The former have provided us with promising results in experimental human studies followed by disappointing results in the clinic.

If a substance can be demonstrated to exert positive effects on cognirion in elderly people in a reliable manner, and if that substance would lack adverse events, it would be a billion seller, regardless of the question whether we know what it does in the human brain, or how it works. Drugs on the market, such as piracetam, co-dergocrine, and ginkgo biloba extract may have already achieved this starus. In Germany and France, substances like these are among the most commonly preseribed drugs. This may also be a nice example of the phenomenon that economical, political, sociological as well as all kinds of irrational behaviours such as fear of dementia and the firm belief that a particular substance will help, rather than the questions that we asked

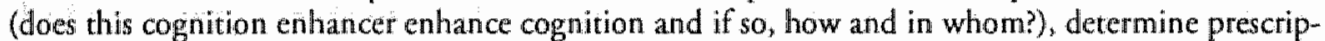
tion $\|$ \% scale, presumably not with the primary aim to improve cognition, but the evidence that they might do so, is increasing. There are many more substances which have cognition enhancing properties, but to a limited extent, rendering them inefficacious for age-associated cognitive decline. The wonder substance that fulfils all prerequisites does not (yet) exist. Perhaps this situation allows scientists in the meantime to agree on the target symptoms and population characteristics of age-assiociated cognitive decline, as well as on standardization of models and measures of cognition necessary to demonstrate the effects of cognition enluancers. With this and our previous article (chapter 1) [76], we hope to have stimulated the interest and to have illuminated the achieved results in this exciting field of research.

\section{REFERNCES}

1. Abate $C$, Angeleri $F$, Bartorelli $L$, ett al. Epidemiologic study on the effectiveness and safety of dihydroegocristine in impared memory and behavioral functions in aged humans. Arzneimittelforscheng $1992 ; 42 \div 1 \%-21$.

2. Alderikump AP, Wieringen Aw, Alpheres WC, et al. Double-Blind Placebo-Contmolled, Neuropsychological and Neurophysiological Inveswigations with Oxiraceram (CGP 21690E) in Memory-Impaired Patients with Epilepsy. Neuropsychoblology 1990; 24: 90-101.

3. Bahrke MS, Slukte HB. Effects of altieude on mood, behaviour and oognitive functioning. A review. Sports Med 1993: $16: 97 \div 125$.

4. Barnford KA, Cainc $\mathbb{E D}$. Dow "benign senescent forgetfulnes" exist? Clin Geriatr Med 1988* 4: 897-916.

5. Ban TA. Psychopharmacology and succesful cerebral aging. Progress in Meuropsychopharmacology and Biologicall Psychiatioy $1994: 19: 1-9$.

6. Bartus RT. Dean RL, Beer B, Lippa AS. The cholinergic hypothesis of geriatric memory dysfuncion. Science $1982 ; 217 ; 408+417$.

7. Bartus RT, Dean RL, Pontecorvo MJ, Fllicker C. The cholinergic hypothesis: A historical overview, current perspective, and future directions. Annals of the New York Academy of Sciences 1985; 444: .

8. Benton D. Vitumin-mineral supplements and intelligence. Proc Nutr Soc 1 992; 51: 295-302. 


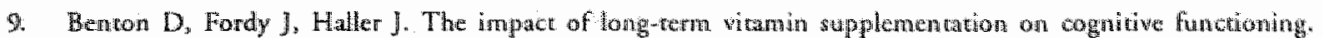
Psychopharmacology $1995 ; 117: 298-305$.

10. Benton D, Owens DS. Blood glucose and human memory. Psychophanacology 1993. 113.83-88.

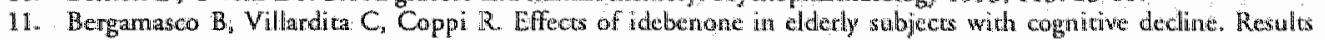
of a mula-contre dinical trial. Arch Gerontol Geriatr 1992: 15:279-286.

12. Biaggioni I, Subir I, Puckete A, Arabiaga C. Caffeine and Theophyline as Adenosine Receptor Autagonists in Humuans. The Journal of Pharmacology amd Experimental Therapeutios $1991 ; 258: 588-593$.

13. Birch $B$, Curran HV. The differential effects of fumazenil on the psychomotor and amnesic actions for midazolam. Journal of Psychopharnacology 1990; 4: 29-34.

14. Birren JE, Warner Schaie K, ed. Handbook of the psychology of aging. 3rd ed. New York: Van Nostrand Reinhold Company, 1990.

15. Blackford RC, LaRue A. Criteria for diagnosing age-associated memory impairment Proposed improvements From the field. Developmental Neuropsychology $1989 ; 5: 295-306$.

16. Bodick $N C$, Delong Ala, Bonate PL, al. Xanomeline, a specife M1 agonist Early dinical studies. In: Giacobini E, Becker RE, ed. Alheimer's Disease: Therapeutic Strategies. Basell Birkhäuser Verlag AG, 1994 : 234-238.

17. Bohnen N, Jolles J. Degenaar CP. Lower blood levels of witamin B 12 are related to decreased performance of healthy subjects in the Stroop Color Word Test. Newroscience Research Commanications 1992; $11: 53-56$.

18. Bohnen NI, Twijnstra Ay Jolles ). A controlled trial with wasopressin analogue (DGAVP) on cognitive recovery immediately after head trauma. Neurology 1993; 43: 103-106.

19. Brand N, Jolles J. Learning and retrieval rate of words presented audirorily and visually. Journal of General Psychology 1985; 112: 201-210.

20. Brand $\mathrm{N}$, Jolles $\mathbb{J}$. Information processing in depression and anxicty. Psychological Medicine 1987" 17: 145 153.

21. Brass EP, Polinsky R, Sramek J], et al Effects of the cholinomimetic SDZ ENB-163 on scopolamine-induced cognitive impaiment in humans. J Clin Psychopharmacol 1995; 15: $588-62$.

22. Briley M. Bochemical strategies in the search for cognicion enhancers. Pharmacopsychiary $1990 \% 2: 75-80$.

23. Bruce-Jones PN, Crome $\mathrm{P}, \mathrm{Kalr}, \mathrm{L}$. Indomethacin and cognitive function in healthy elderly volunteers. Bu J Clin Pharmacol 1994: 38: 45-51.

24. Bruins J, Hijman R, Van Ree JM. Effect of a single dose of des-glycinamide-[Argd] vasopressin or oxycocin on cognitive processes in young healthy subjects. Peptides 1992; 13: $461-8$.

25. Bruins $J_{i}$ Kumar $A$, Schneider Helmert D. Inthence of desglycinamide-(arg8) vasopressia on memory in healthy subjects. Neuropsychobiology $1990 ; 23 ; 82-8$.

26. Buschke H. Selective Reminding for Analysis of Menory and Learning. I of Verbal Learning and Verbal Behavior $1973 ; 12 ; 543-550$.

27. Cacabelos R, Nordberg $A_{*}$ Caamano J, ex al. Mollecular strategies for the first generations of antidementia drugs (1). Tacrine and related compounds. Drugs of Today 1994: 30: 295-337.

28. Caine ED. Should aging-associated cogninive decine be included in DSM-IV? Jounal of Neuropsychiatry and Clinical Neurosciences 1993; 5: 1-5.

29. Camp-Bruno JA, Herting RL, Winsberg BG. Millacemide Effects on Memory and Vigilance. Biol Psychiacry $1991 ; 29: 286$.

30. Cardenas DD, Mclean A, Jr., Farrell Roberts L. Bakcr L, Brooke M, Haselkorn J. Oral physostignines and impaired memory in adults with brain injury. Brain Inj 1994; 8: 579-87.

31. Charness $N$, ed. Aging and human performance. Waterloo, Canada John Wiley $8 \times$ Sons, Chicheater, 1985.

32. Clausen TG, Wolf $]$, Carl $P$, Theilgaard $A$. The effect of the benzodiazepine antagonist; Aumazenil, on psychometric perfotmance in acute ethanol intoxication am man. Eut ] Clin Pluarmacol 1590 ;8: $233-6$.

33. Clincke GH, Tritsmans L, Peelmans B. Long-term Follow-Up Treament Wirk Salueluzole in EIderly Patients With Pronounced Memory Problems of Unknown Origin. Drug Development Research 1991; $23: 301$. 305.

34. Collins WE, Mertens HW. Age, aloohol, and simullared altirude: effects on peformance and breathalyzer scores. Aviar Space Environ Med 1988; 59: 1026-1033.

35. Consolis S, Mas M. Intrêt d"un antiasthonique polyvalcnt, Arcalion 200 sur la vigilance er le stresse tés sportifs en have competition. Psychologie Médicale 1988; 20;2.

36. Coull JT. Pharmacological manipulations of the alpha 2-noradrenergic system. Effects on cognition. Drugk Aging 1904; 5: 116-26.

37. Crook T, Bartus RT, Ferris SH, Whitehouse P, Cohen GD, Gershon S. Age-astsociated memory impairment: Proposed diagnostic criteria and measures of clinical change: Report of a National Institute of Mentall Health work group. Dewelopmental Neurapsychology 1986; $2: 261-276$.

38. Crook IH, I. akin M. Effects of andanseron in age associated memory impairment. Biol Psychiatry 1991; 2: $888-890$. 


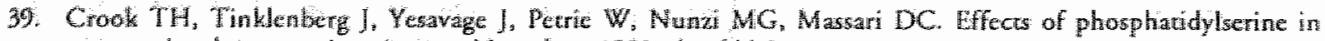

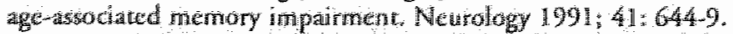

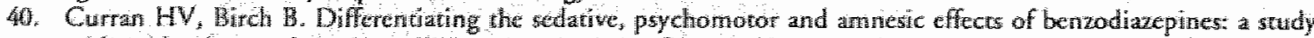

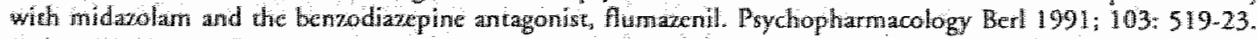

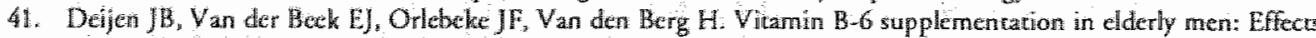
on mood, nemony performance and mental eftor. Psychophamacology 1992; 109:489-406.

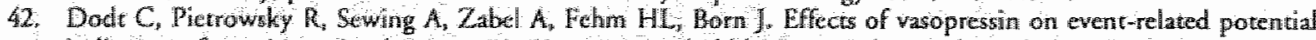
indicator of cogninve timulus processing whoung and old humans. J Gerontol 1994; 49: M183m.

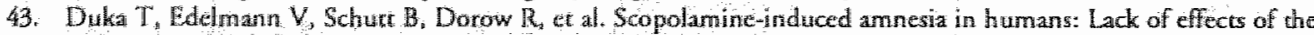

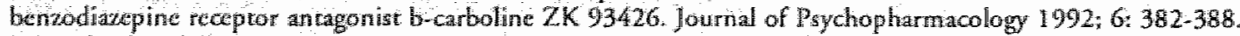

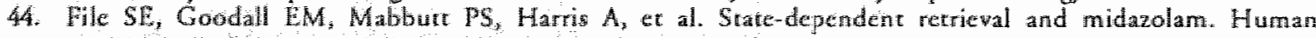
Pychophamacology Clinical and Experimental 1993; 8:243-251.

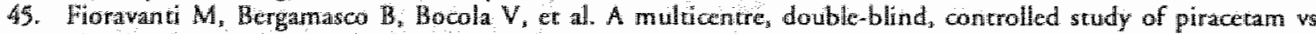
placebo in geriarric patients whth nonwascular mildmoderate impairment in cognirion. New Trends in Clinicall Neurophamacology $1991 ; V_{i}, 27-34$.

46. Frost W, Maite L. Mhe families of cognition enhancers. Pharmacopsychiacry 1989:2:54-100.

47. Gallard $A$ The ewaluation of drug effece in laboratory tasks. In: Hindmarch $\mathrm{I}$, Aufdembrinke $\mathrm{B}, \mathrm{Ort} H$, ed. Psychopharnacology and rection tume. Chichesixer, England: John Wiley 8 Sons, 1988: 15-24.

48. Giamzis ER, Birkhimer LJ, Hoover $\mathrm{T}$, Gracoin $\mathrm{ST}$. Early human trials in the assessment of cognition activators. Pharmacopsychiatry $1990 ; 2: 44 \%$.

49. Ghoneim MM, Block RI, Ping ST, a Zallaby HM, Hinrichs JV. The inceractions of midazolam and flumazenil on human memory and cognition. Anewthesiology 1993; 79: 1183-92.

50. Giacobini $E_{\mathrm{s}}$ Becker $\mathrm{R}_{\mathrm{n}}$ ed. Althemer's Disease: Therapeutic Strategies. Basel: Birkhăuser Verlag $\mathrm{AG}, 1994$.

51. Giacobini E. Becker R.. Development of Drugs for Alzheimer Therapy: A Decade of Progress. In: Giacobini E,

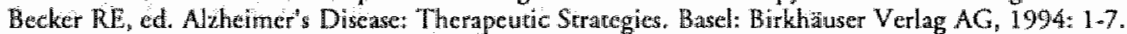

52. Gillis JC, Benefield P. McTavish D. Idebenone. A review of is pharmacodynamic and pharmacokinetic properties, and therapetic use in age-related cogniaive disorders. Drugs Agring 1994: 5: 133-52.

53. Giurgea $\mathrm{CE}$, Debruyne H. Target symptoms and experimental basis of the Nootropuic therapy. In: al. Be, ed. Senile dementias: carly detection. John Libbey Eurotext, 1986:367-393.

54. Glue $\mathrm{P}, \mathrm{Batll}$ cy $\mathrm{J}$, Wilson $\mathrm{S}$, Hudson A. Nutt DJ. Thyrotropin-releasing hormone selectively reverses lorazepam-induced sedation but not slowing of saccadic eye movements. Life Scil 1992; 50: PI25 30."

55. Goullacv AH, Senting A. Pitacetam and other scructurally related nootropics. Brain Res Brain Res Rev 1994 ; 19: $180-222$.

56. Gucz D. Longuterm effects and safery of almirrine-raubasine in age-associated cognitive decline. Clin Neuropharmacol 1990:13:109-116.

57. Guex. D, Malbezin M, Neuman E, Head W, Brackman $\mathrm{F}_{\mathrm{m}}$ S12024, a new drug in development for the reatrnent of Alzheimer's Disease. Update on dementia and functional disonders in old age. London, UK: , 1994: .

58. Hall ST, Puech A, Schaffler K, Wesnes K, Gamzu ER. Early clinical resting of cognition enthancers: prediction of efficacy. Pharmacopsychiatry $1990 ; 2: 57-8$.

59. Wasenfratz $M$, Bunge $A$, Dal $P$ ra $G$, Batrig $K$. Antagonistic effects of caffeine and alcohol on mental performarios parame ters. Pharmacol Blochem Bchaw 1993:46:463-5.

60. Herting RL. Milacemide and Other Drugs Acrive at Glutamate NMDA Receptors as Potential Treatment for Dementua. Ann N Y Acad Sei 1991; 640:237-240.

61. Higman R. Desglyenamide-(Arg (8))-vasopressin in patients with memory-disturbances. Utreche: University Press, 1992

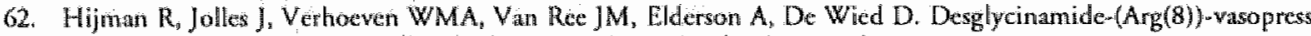
in in five tials with menory-disturbed patientw. Ham Psychopharmacol 1.992: $7: 7-23$.

63. Hindmatich 1, Coleston $\mathrm{DM}, \mathrm{Kerr} \rrbracket \mathrm{S}$. Psychopharmacological effects of pyritinol in normal volunteers. Neuropsychobiology 1990:24: 159-64.

64. Hindmarch 1 , Kerr JS, Sherwood N. Effects of nicotine gum on psychomotor performance in smokers and nonsmokers. Psychopharmacology 1920, 100: 535-54:1.

65. Hindmarch I, Kerr IS, Sherwood N. The effeces of alcohol and other drugis on psychomotor performance and cognitive function. Alcohol Alcohol 1991; 26: 71\%9.

66. Hobus: P. Expertise wan huisartsen. Praktijkervaring, kennis en diagnostische hypothesevorming. Maastrichr: Rujkenniversiteic Linmburg, 1994.

67. Homner D, Weingartner HJ, Breier A. Dissociation of benzodiazepine-linduced ammesia from sedation by Auruatenil pretreatment. Psyehopharmacology 1993; 112:455-460.

68. Houx PJ, Veeling FW, Jolles J. Rigorous hedth screning reduces age effect on memory scanning task. Brain Cogn $1991 ; 15: 246 \times 60$. 


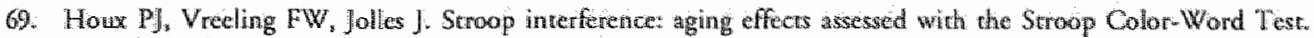
Experimercal Aging Research 1993: 19:2092224.

70. Hunt E. What do we need to know about aging? Wn: Cerella J, Rybash J, Hoyer W, Commons MLod Adult Intornation Processing: Limits on Loss. San Diego: Acadernic Press Incic 1993:

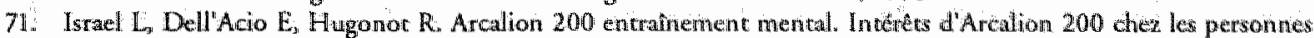
agés astheniques. MMP 1989: Suppl: 19224.

72. Israel L. Melac M. Milinkevitch D, Dubos G. Drug therapy and memory training programs: A double-blind

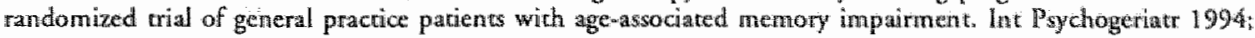
6: $155-170$

73. Jarvis M. Does caffeine intake enhance absolute levels of cognitive performanae? Psychophaimacology 1993 ; $110: 45-52$.

74. Jolles J. Vasopressin and Human Behavior. In: Gash DM, Boer GJ, ed. Vasopressin, Principles and Propertics. New York: Plenum Press, 1987: 549-578.

75. Jolles ]. Aging of brain $\&$ behavior: biomedical, clinical and behavional research in the domain of arging at the University of Limburg. In: Van Bezooijen CFA, Ravid $\mathbb{R}$, Verhofsad AAl. ed. From Gene to Man. The Hague, The Netherlands: J.H. Pasmars publishers, 1990: 146-150.

76. Jolles ], Verhey FRJ, Riedel WJ, Houx PJ. Cognirive Impaimene in Elderly People: Predisposing Wactors and Implications for Experimental Drug Studics. Drugs \& Aging in press; : :

77. Jones RW, Wesnes KA, Kirby J. Effects of NMDA modulation in scopolamine demencia. Ann $\mathrm{N} Y$ Acad Sai 1991; $640: 241-4$

78. Kennedy RS, Odenheimer RC, Balceley DR, Dunlap WP, Wood CD. Differential effects of scopolamina and amphetamine on microcomputer-based performance tests. Aviat Space Environ Med 1990; 61:615-21.

79. Kerr JS, Sherwood N, Hindmarch I. Separate and combined effects of the social drugs on psychomotor penformance. Psychopharmacology Berl 1991: 104: 113-9.

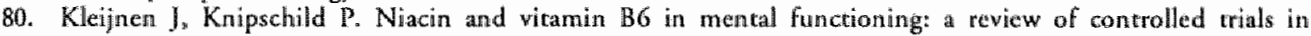
humans. Biol Psychiatry 1991; 29: $931-41$.

81. Kleujinen J. Kmipschild P." Ginkgo biloba. Lancet 1992; 340: 1136-9.

82. Kleijnen J, Knipschild P. Ginkgo biloba for cerebral insufficiency. Br J Clin Pharmacol 1992; $34: 352,8$.

83. Kopelman MD. The cholinergic neurotransmitter system in human memory and dementia: A review. Special Issue: Human memory. Quarterly Journal of Experimental Psychology Human Experimental Psychology 1986 ; 38: $535-73$.

84. Kopelman $\mathrm{MD}$, Corn "TH. Cholinergic "blockade" as model for cholinergic depletion. A comparison of she memory deficits with those of Alzheimer-type dementia and the alcoholic Korsakoff syndrome. Brain 1988; 111: $1079-1110$.

85. Kraiter $V$, Van Huffelen AC, Wieneke GH. The hyperwentilation-induced ischaemian model in human neuropharmacology: neurophysiological and psychometric studics of aniracetam and 3-OH aniracetam. Eur J Clin Pharmacol 1989; 36: 605-11.

86. Kral VA. Senescent forgetfulness: Benign and malignant. Canadian Medical Association Journal 1962; 86: 257. 260.

87. Kunkel H. EEG Profile of Three Different Extractions of Ginkgo Biloba. Neuropyschobiology 1993; 27: 40. 45

88. Ladd SL, Sommer SA, LaBerge S. "Toscano W. fffect of phosphatidyleholine on explicre memory. Clin Neuropharmacol 1993; 16:540-549.

89. Larrabee G., Crook II. A computerized everyday memory batery for" assessing treatment effects. Psychopharmacol Bull 1988; 24:695;.

90. LaAke A. Aging and Neuropichological Assessment. New York: Plenum Press, 1992.

91. Le Houezec J, Halliday R, Benowity NL, Callaway E, Niylor H, Heriag K. A low dose of subicuraneous nicotine improver information processing in non-smokcrs. Psychophammacology 1994; 114: 628-634.

92. Lieberman $H R$, Wurtman $R$. Ende $G G$, Roberts $\mathrm{C}_{4}$ et all The effects of low doses of caffeine on human performance and mood. Psychopharmacology 1987; 92:308-312.

93. Lines CR. Ambrose JH, Heald A, Traub M. A double-blind, placebo-controlled study of alue effects of eptascigmine on scopolamine induced cognitive deficits in healthy male wubject. Hum Psychopharmacol $1993 ;$ 8: $271-278$.

94. Limes $C R$, Preston $G C$, Dawson $C E$, Brazell $C$ et al. The effects of pre-treatrnent with enalapril maleate on scopolamine-induced cognicive deficits in healchy volunuecrs. Journal of Psychopharmacology $1991 ; 5: 228$ 233.

95. Lister RG. The amnesic Action of Benzodiazepines in Man. Neurosci Biobehav Rev 1985; 9: 87-94.

96. Lister RG. The Effects of Benzodiazepines and 5-H'THA Agonists on Learning and Memory. In: Rodgers Rl, Cooper SJ, ed Sim HTA Agonists, S-HT3 Antagonists and Benzodiazepines. Chichester: Wiley, $1991: 267-280$. 


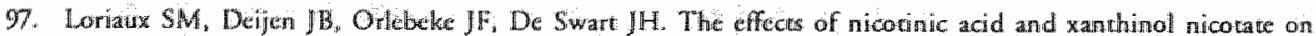

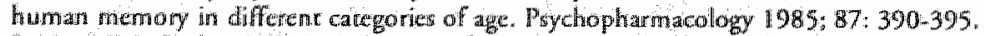

98. Torise MM, Shel I. Kot. A Infuence of caffeine bu information processing stages in well rested and faxigued subjects. Pychopharmacology 1994, $113: 41,121$

99. Lorist MM, Sne J. Kolk A, Mulder G. Influenot of caffine on selective atwention in well rested and facigued subjects Psychophysiology $1994: 31: 525,534$.

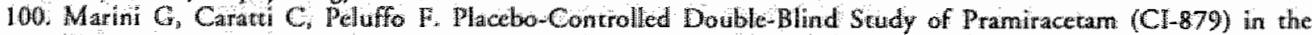
Treatment of Elderly Stbject With Memory Impairment Advances in Therapy 1992; 9: 136-146.

101. Mathowich H. Intellecual Functions and the Brain. An Hiscrical Perpective. Searte: Hogrefe 8 Huber, 1592 .

102. Masur DM, Sliwinski M. Lipwon RB, Blat AD, Crystal HA. Newropsychological prediction of dementia and the alsetice of dementin healtry elderly persons. Neurology $1994,44: 1427-1432$.

103. Mattila ME, Matila MJ N $\mathrm{Mont}$ E. Caffeine moderately antagonizes the effects of triazollam and zopiclone on the psychomotor performance of healiny subjects. Pharmacol Toxicol 1992; 70; 286-9.

104. Mauri M, Sirforiani E, Reverberi F, Merlo P, Bono G. Pramiracetam effects on scopolamine-induced amnesia in therdothy wolunteers. Areth Gerontol Geriat 1994; 18: 133-139.

105. McCann UD, Penetar DM, Shatham Y, et al. Sleep deprivation and impaired cognicion. Possible role of brain catecholamines. Biol Pspchiatry 1992; 31:1082-97.

106. MeEnre WJ, Crook TH. Age-associated memory impaiment: a role for catecholamines. Neurology 1990; 40: $526-530$.

107. MeEntee W], Crook TH. Serotomin, memory, and the aging brain. Psychopharmacology Berl 1991; 103: 143-9.

108. McEntee W], Crook TH. Cholinergic function in the aged brain: Implications for treatment of memory impairments associated with aging. Special Issue: Pharmacological approaches to learning and memory. Behavioural Pharmacology 1902; 3: 327-336.

109. MeEnted WJ, Crook TH, Jenkyn LR, Petrie W, Larrabee G], Coffey DJ. Treatment of age-associared memory impasiment with guanfacine. Psychophamacol Bull 1991; 27:41-6.

110. MeLean A $A$ r., Cardenas DD, Burgess D, Gamzu E. Placebo-controlled study of pramiracetam in young males with memory and cognitiwe problems resulting from head injury and anoxia. Brain Inj 1991; 5: 375-80.

111. Meador KJ, Loring DW, Lee GP, Taylor HS, Hughes DR, Feldman DS. In vivo probe of central cholinergic systerns. J Gerontol 1988; 43:

112. Meador KJ, Nichols $M\left[E_{*}\right.$ Franke $P_{n}$ et al. Exidence for a central cholinergic effect of high-dose thiamine. Ann Neurol 1993; 34: 724-6.

113. Meyer FP. Influence of nifedipine on human performance following a single dose - Differenrial psychopharmacological aspects. Hum Psychopharmacol 1994; 9: 93-100.

114. Micheau J, Durkin TP, Destrade C, et al. Chronic administration of sulbutiamine improves long term memory formation in mice: Possible cholinergic mediation. Pharmacol Biochem Behav 1985; 23: 195-198.

115. Michel B, Sambuc $\mathbb{R}$, Sootto JC. French recommendations for dinical drug trials in cognitive disonders of the elderly. Inc. J. Geriatr. Psychiatry 1994; 9;823-828.

116. Michel CM, Lehmann D. Sungle Doses of Piracetan Affect 42-Channel Event-Related Botential Microstare Maps in a Cognitive Daradigm. Neuropsychobjology $1.993 ; 28: 212-221$.

117. Molchan SE, Marune. RA, Hill JL, er al. Increased cognitive sersitivity to scopolamine wirh age and a perpective on the scopolamine model. Brain Rescarch Rewiews 1992;17:215-226.

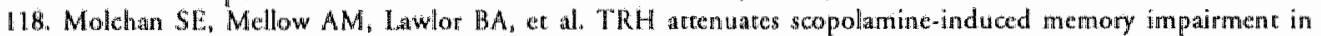
humans. Psychopharmacology Berl 1990; 100: 449.

119. Mondadori $C$. In scarch of the mechanism of action of the nootropics" new insights and potential elinical implications. Life Sei 1994; $55: 2171-78$.

120. Muller "T, Kuhn W. Prentek H. Therapy with central active catedhol-O-nnethyltransferase (COMT)-inhibito is: is addition of monoamine oxidase (MAO)-inhibitors necessary to slow progress of neurodegenerative disorders? J Neural Trarusm Gen Sect 1993; $92 \% 187-95$.

121. Miller WE, Pedigo NW. Brain Aging: A Risk Facror of Neurodegenrative Disorders and a Target for therapeutic Intervention. Life: Señ 1994; 55:1975-76.

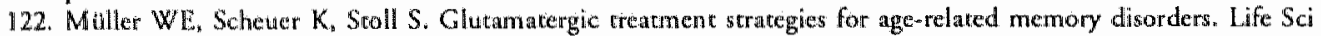
$1994: 55: 2147-53$.

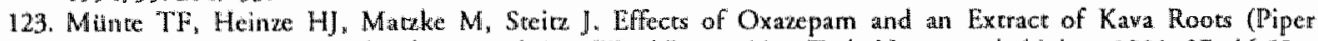
methyscicum) on Bvent-Relared Potentials in a Word Recognition Task. Neuropsychobiology 1993; 27 : 46-53.

124. Nohlig A, Daval J L, Debry G. Caffeine and the central nerwous system: mechanisms of action, biochemical, merubolic and psychostimulant effects. Brain Research Reviews 1992; 17:139-170.

125. Newhouse PA, Penetar DM, [äerig JB, Thorne DR, et al. Stimulant drug effects on performance and behawior after prolonged sleep deprivation: A comparison of amphetamime, nicotine, and deprenyl. Special Issue: Stimulants to amelioran sleep loss during sustaned operations. Military Psychology 1992; 4: 207-233. 


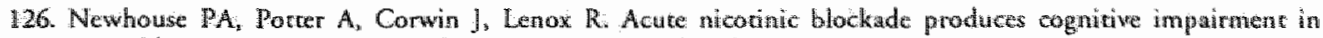
mormal humans. Psychopharmacology Bed 1992; 108: $480-4$.

127. Newhouse PA, Porter A, Corwin J, Lenox R. Age-Relaced Effecrs of the Nicotinic Antagonist Mecanylanine on Cognition and Behavior. Neuropsychopharmacology $1994 ; 10$; $93-107$.

128. Nilsson LG, Backman L, Karlsson T. Priming and oued recali in elderly, aloohol intoxicated and slowe depriwed subjects: a case of funcrionaly similar memory deficits. Pychol Med 1989; 19:423-33.

129. Nugto E. Psychomotor, physiological and cognitive effects of scopolamine and ephedrine hn healthy man. Eur J Clin Pharmacol 1983; 24: 603-9.

130. O'Bricn A, Bulpit CD. The Efeces of ACE Inhibitors on Cognirive Function. Drugs \&: Aging 1995: 6: 173180.

131. O'Brien JT, Levy R. Age associated memory imparment. BMI 1992; 304: $5-6$.

132. O'Hanlon JF, Vermeeren A. Effects of Ro 15 -1788 on the vigillance performance of sleeptedeprived men. Hum. Psychopharmacol 1988; 3:267-274.

133. Parat A, Klein MJ, Surjus A, Hucher M, Granier J. RU 41,656 does not reverse the scopolamine-induced cogmiüve deficit in healthy volunteers. Eur J Clin Pharmacol 1991; 41:225-31.

134. Patat $A$, Klein $M]$. Surjus $A$. Hucher $M$, Granier 1 . Study of the potential reversal of triazolam memony and cognicive deficits by $\mathbb{R U} 41656$ in healthy subjects. Psychopharmacology Berl 1991:104:75-80.

135. Pepeu G. Memory disorders: novel treatments, clinical perspective. Life Sei 1994; 55: 2189-94.

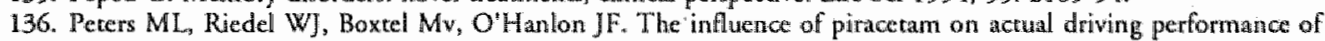
elderly subjects. 1992.

137. Phillips SM, Sherwin BB. Effects of estrogen on memory function in surgically menopausal women. Psychoneuroendacrinology 1992;17:485-495.

138. Poitrenaud J, Piete F, Malbezin M, Sebban C, Guez D. Almitrine-rambasine and cognitive impaiment in the elderly: results of a 6-month controlled multicenter study. Clin Neuropharmacol 1990;13:100-8.

139. Porsolt RD. Strategies in Psychopharmacology: Cognition Enhancers - From Animals to Man; Concluding Remarks. Pharmacopsychiacry 1990; 23; 99-100.

140. Porsole RD. Strategies in Psychopharmacology: Cognicion Enhancers " Prom Animals to Man: Preface. Pharmacopsychiatry 1990; $23 ; 2930$.

141. Porsolt RD. Serotonin: neurotransmiter "a la mode". Report on the Third Internacional I.T.E.M. IABO symposium on strategies in psychopharmacology secotonin: animal models and clinical targetis. Pharmacopsychiarry 1993; 26: 20-4.

142. Preda $L_{3}$ Alberoni $M$, Bressi $S$, Cactaneo $C_{3}$ ec al Effects of acute doses of oxiracetam in the scopolamine model of human amanesia Psychopharmacology 1993; 110:421-426.

143. Preston GC, Millson DS, Ceuppens PR, Warburton DM. Effects of the 5-HT3 receptor antagonist GR68755 on a scopolamine induced cognicive deficit in healthy subjects. Br J Clin Pharmacol 1992; 33: 546.

144. Preston $\mathrm{GC}_{3}$ Ward $\mathrm{C}$, Lines $C \mathrm{R}$, Poppleton $\mathrm{P}$, Haigh $\mathrm{IR}$, Traub M. Scopolamine and benzodiazepine models of dementia: cross-reversals by Ro 15-1788 and physositigmine. Psychopharmacology Berl 1989; 98: 487-94.

145. Rai GS, Showlin C. Wesnes KA. A double-blind, placebo controlled study of Ginkgo biloba extract ("tanakan") in elderly outpatienes with mild to moderate memory impairment. Curr Med Res Opin 1991; 12:350-5.

146. Reisberg B, Ferris SH, De Leon M], Crook "T. The Global Deterioration Scale for assessment of primary degenerarive dernentia. American Journal of Psychiatry 1982; 139: 1136-1139.

147. Rey A. L'examen psychologique dass les cas d'encephalopathie tramatique. Puris: Pusses Universitaires de France, 1964 .

148. Riedel WJ, Hamers HMW, Robbe HWJ, Vermeeren A, OHanlon JF. Automated behaviomal testimg int psychotropic drug research. In: Mulder LJ M, Maarse FJ, Sjouw WDB, Akkernan AE, ed. Compurers un psychol. ogy: Application in educazion, research and psychodiagnostics. Amsterdam, Netherlands: Swets 8 . Zeithinger $1991:$ pp. $166-170$.

149. Riedel WJ, Hogervorst $\mathbb{E}$, Leboux RLAM, Verhey ERJ, Van Prag HM, Jolles: J. Caffeine atrentiattes scopolamine-induced memory impaiment in humans. Psychopharmaoology 1995; in press: .

150. Rogers J. Kirby LC, Hempelman SR, et al. Clinical trial of indomethacin in Alaheimer" disease. Nouralogy $1993 ; 43: 1609$-1611.

151. Rosadini G, Sannta WG. Nobili F, Cenacchi T. Phosphatidylserinc: Quanticative EEG effects in healthy volunteers. Neuropsychobiology $1990 ; 24: 42-48$.

152. Rosen T]. "Age-associated memory impairment": A critique. Special Isstue: Cognitive gerontollogy. Furopean Journal of Cognitive Psychology 1990; 2: 275-287.

153. Rother M, Kessler J. Funke $M$, Rother I, Windisch M. Memory impaiment after hyperventiation-a physiological model of cognixive dysfuncrions. Neurobiology of Aging 1994; $15: 92$.

154. Rush CR, Higgins ST, Hughes JR, Bickel WK. Acute Behavoral Effects of Triazolam and Caffeine, Alone and in Combinarion, in Humans. Experimental and Clinical Psychophamacology 1994; 2: 211-222. 
155. Nusted J. Cholinergic blockade and human information processing: Are we asking the right questions? Joumal of Psychopharmacology 1994; 8: 54:59.

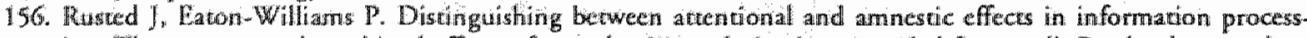
ing: The separate and combined effects of scopolamine and nicotine on verbal free recall. Psychopharmacology 1991; 104 : 363366

157. Rusted J, Grauprer L, O'Connell N. Nicholls $C$. Does nicotine improve cognirive funcrion? Psychopharmacology 1994 ; $115: 547-549$.

158. Saletu B, Anderer P, Crunberger J. Topographic brain mapping of EEG after acute application of ergotalkaloids in the elderly. Arch Gerontol Geriatr 1990; 11: 1-22.

159. Saletu B, Anderer $\mathbb{P}$, Kinsperger $K$, Grunberger J. Topographic brain mapping of EEG in neuropsychopharmacology Part 11. Clinical applications (pharmaco ELG imaging). Methods Find Exp Clin Pharmacol 1987; 9: $385-408$.

160. Saletu $B$, Darragh $A_{0}$ Breuel HP, Herrmann W, et all. EEG mapping central effects of multiple doses of linopininie-a cognitive enhancer-a healthy elderly male subjects. Hum Psychopharmacol 1991; 6: 267-275.

161. Salletu B, Grunberger J. "The hypoxia model in human psychopharmacalogy: neuropsychological and $P$ [sychometric studie with aniraceam. Human Neurobiology 1984; 3: 171-181.

162. Saletu 13, Grunberger J, Anderer R. On brain protection of co-dergocrine mesylate (Hydergine) against hypoxic hypoxidosis of different severity: double-blind placebo-controlled quantitative EEG and psychometric situdies. Int J Clin Pharmacol Ther Toxicol 1990; 28: 510-24.

163. Saletu B, Grunberger J, Linzmayer $\mathbb{L}$, Anderer P, Semlitsch HV. EEG brain mapping and psychometry in age* associated memory impairment after acute and 2-week infusions with the hemoderiwacive Actovegin: doubleblind, placebo-controlled trials. Neuropsychobiology 1990; 24: 135-48.

164. Saletu B, Saletu M, Grünberger J, Frey R, Anderer P, Mader R. Treatment of the Alcoholic Organic Brain Syndrome: Double-Blind, Placebo-Controlled Clinical, Psychometric and Electroencephalographic Mapping Seudies with Modafinil. Neuropsycliobiology 1993; 27: 26-39.

165. Saltetu B, Schulz H, Herrmann WM, Anderer P. Shrotriya RC, Vanbrabani E. BMS-181168 for protection of the human brain againse hypoxia: Double-blind, placebo-controlled EEG mapping studies. Pharmacopsychiatry 1994; 27: 189-197.

166. Sallin PR, Granados FD, Galicia PL, Nieves E, Gillin JC. Development of tolerance after repeated administration of a selective rnuscarinic M1 antagonist biperiden in healthy hurman volunteers. Biol. Psychiacry 1993; 33: $188-93$.

167. Sanders AF. Towards a model of stress and human performance. Acta Psychologica 1983; 53:61-97.

168. Sarter $M$, Hagan J, Dudchenko $\mathbb{P}$. Behavioral sereening for cognition enhancers. From indiscriminate to valid testing: 1. Psychopharmacology 1992; 107: 144-159.

169. Sarter $M$, Hagan ], Dudchenko P. Behavioral screening for cognition enhancers: From indiscriminate to valid testing: II. Psychopharmacology 1922; 107: 461-473.

170. Sarter $M$, Sehneider HH, Stephens DN. Trearment strategies for senile dementia; Antagonist b-carbolines. Trends in Neurosciences 1988; 11: 13-17.

171. Sarter M, Stephens DN. Beta-carbolines as tools in memory research: animal data and speculations. Psychopharmacol Ser 1988; 6: 230-45.

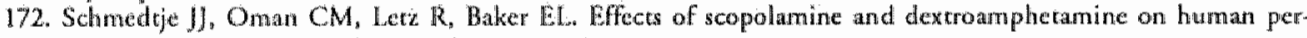
formance. Aviat Space Enviton Med 1988; 59: 407-10.

173. Schmidt U, Brendemuhl D, Engels K, Schenk N, Ludemann E. Piracetan in elderly notorists. Pharmacopsyehiatry $1991 ; 24: 121-126$.

174. Schneider LS, Tariot PN, Goldstein B. Therapy with l-deprenyl (sellegiline) and relation to abuse liability. Clin Pharmacol Ther 1994; 56:750-6.

175. Schwarte BL. Hashtroudi S, Herting RL, Handerson H, Deutseh SI. Glycine prodrug facilitates memory retrieval in humans. Neurology 1991: 41:1341-1343.

176. Selhwartz $G$, Bisserbe JC, Bradford D, Sennef C, Hollister L. Late clinical resting of cognition enthancers: demonstration of efficacy. Pharmacopsychiatry 1990; 2:60-2.

177. SEARLLE \& Co GD. Multicenter, Randomized, Double-Blind Study of $1 \mathrm{mg}$, $5 \mathrm{mg}$ and $15 \mathrm{mg}$ b.i.d. of Cycloserine va Placebo in the Treatment of Age-Associated Memory Impairment. Skokie Illinois: 1993.

178. Semlitsch $H V_{n}$ Anderer $P_{\text {, Saletu }} \mathbb{B}_{*}$ Hochmayer $\mathbb{1}$. Topographic mapping of cognitiwe event-related potentials in a double-blind, placebo-controlled study with the hemoderivative Actovegin in age-associated mernory impairment. Neuropsychobiology 1990; 24: 49-56.

179. Sherwin BB. Estrogenic effects on memory in women. Ann N Y Acad Sici 1994; 743: 213-30;.

180. Siegfried KR. First dinical impressions with an ACTH analog (HOE 427) in the trearment of Alzheimer's disease. Ann N Y Acad Sci 1991; 640: 280.3.

181. Simpson PM, Surmon DJ, Wesnes KA, Wilcock GK. The Cognitive Drug Researeh computerized Assessment System for demented patients: A validation study. International Journal of Geriatric Psychiatry 1991; 6: 95-102. 


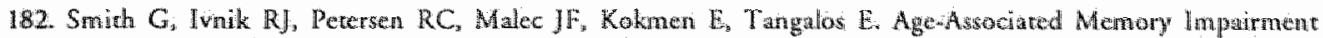
Diagnoses: Problems of Reliabiligy and concerns for Terminology. Psychology and Aging 1991; 6:551-558.

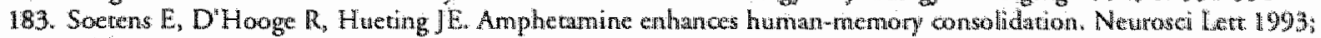
$161: 942$

1B4. Sommese T, Paterson JC. Acure Effects of Cigargte Withdrawal. A Review of the Literature. Aviat Space Environ Med 1995, 66: 164167.

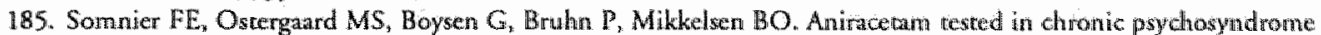
after long-rerm exposure to organic solvents. A randomized double-blind placebo-controlled cross-over study widi neuropsychological teses. Psychopharmacology $1990 ; 101: 49-46$.

186. Stawric B. An update on research with coffed cafleine (1989-1990). Food Chem Toxicol 1992; 30:533-55.

187. Stelmach GE, Zelaznik $H N$, Lowe D. The influence of aging and attentional demands on recowery from postural instability. Aging 1990; 2: 155 w161.

188. Sternberg S. Memory scanning: mental processes revealled by reacton time experiments. American Scientist $1969 ; 57 ; 421-457$

189. Stoll $S$, Hafner U, Pohl $O$, Muller WE. Age-related mernory decline and longevity under treatmente with selegiline. Life Soi 1994: 55: 2155-63.

190. Stoppe $\mathrm{G}_{*}$ Sandholzer H, Staedr J, et al. Prescriprion Praxis of Cognition Fnhancers in Primary Care - Results of a Representative Survey in Germany: Neuropsychopharmacology 1994; 10: 385.

191. Sudilowsky A, Crook T, Repeta S, Zadeik-Hipkins A, Youniss E. Angiotensin Convercing Enayme Inhibitors (ACEI) and Cognitive Functioning in Animals and Marn. Biol Psycharry 1991: 29: 287.

192. Swift CG, Tiplady B. The effects of age on the response to caffeine. Psychopharmatology 1988; $94: 29-31$.

193. Tariot PN, Cohen RM, Sunderland T, et al. L-Deprenyl in Algheimer"s Disease. Arch Gen Psychatry 1987: 44: $427-433$

194. Teasdale $N$, Bard C, LaRue J, Fleury M. On the cognitive penetrability of posture control. Exp Aging Res 1993 ; 19:1-13.

195. Tiplady B, Fagan D, Lamont M, Brockway M, Scote DB. A comparison of the CNS effects of enprofylline and theophylline in healthy subjects assessed by performance testing and subjective measures. B J Clin Bharmacol $1990 ; 30: 55-61$.

196. "Tritsmans $L$, Clincke G, Peelmans B. Does AAML constitute a real discase enticy" A placebo-controilled doubleblind study with sabeluzole (R58 735) in a patient population with real memory problems. Drug Dev Res 1990 ; 20: 473-482.

197. Van Duijn M, Hofman A. Reition between nicotine intake and Alzhemer"s diseast. BMJ 1991; 302; 1491 1494.

198. Wethaeghen $P_{3}$ Marcoen $A_{n}$ Goossens L. Facts and Fiction About Memory Aging: A Quantitative Integration of Research Findings. Journal of Gerontology 1993; 48: P157-P171.

199. Vernon MW, Sorkin EM. Piracetam. An overvicw of its pharmacological properties and a revicw of its therapeutic use in senile cognitive disorders. Drugs Aging 1991; 1: $17-35$.

200. Vincent A, Risinger $R$, Schmidt $M$, et al. Cognitue Effects of Idaraxan in Normal Voluntects. Neuropsychopharmacology 1994; 10:115S.

201. Vuurman EFPM. Piraceram attenuates alcohol-mduced posturat in tability, in preparation 1995.

202. Wadworth AN. Chrisp P. Co-dergocrine mesylate. A review of the phamacodynamic and pitarmacokinetic propertive and therapeutic ase in age-related cognitive decline. Drugs Aging 1992; 2, 153,73.

203. Wagstaff AJ, McTavish D. Tacrine. A review of its pharmacodynamic and pharmacolinctic properties, and therapeutic efficacy in Alyheimer's disease. Drugs Aging: 1994: 4: 510 -40.

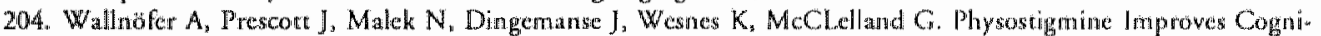
tive Performance and Arers EEG in Healthy Volunters. An Approach ro Study Central Cholinergic Effectr. Neuropsychopharmacology 1994; 10: 395 .

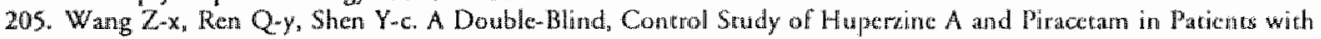

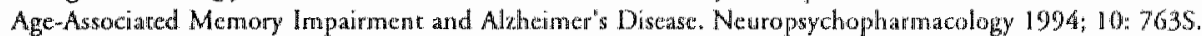

206. Weinachter SN. Blaver N, ODonnell RA, Mackenete Fi, Rapin JR. Models of hypoxia and cerebral ischemia. Pharmacopsychiary 1990; 2: 94-7.

207. Wenk GL. An hypothesis on the role of glucose in the mechanism of action of cognitive enhancers. Psychopharmacolopy 1989; 99 : 431-438.

208. Wesnes $K$, Anand $R$, Lorscheid $T$. Potential of moclobemide to improve cerebral unsufficiency identified using a scopolamine model of aging and dementia. Acta Psychiatr Scand Suppl 1990; 360: 71-2.

209. Wesmes $\mathrm{K}$, Jones $\mathbb{R} W$, Kirby J. The effects of D.cycloserine, a glycine agonist, in a human model of the oognitive deficits associated with ageng and dementia. Br J Clin Pharmac 1991; 31:577-578.

210. Wesnes $\mathrm{K}$, Jones $\mathbb{R} W$, Kirby J, Curtis L. D-Cycloserime antagonixes scopolamine induced memory impairments and improves memory in the elderlf. Biological Psychiatry 1991; 29: 7005. 


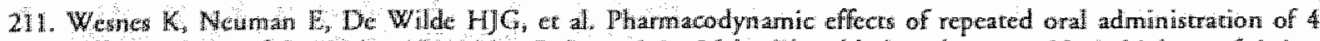
different doses of $\$ 120242$ (Cogntive Enhancer) in 36 healthy elderly wollunteers. Neurobiology of Aging. $1994: 15: 100$.

212. Wesnes $K$, Revell $A$. The separate and combined effects of scopolamine and nicotine on human information processing. Psycliopharmacology $1984 ; 84: 5-11$.

213. Wesnes Ko, Simpson PM, Kidd A. The usc of a scopolamine madel to study the nootropic effects of tenilsetam (CAS 997) in man. Medical Sciersce Reseanch Psychology and Psychiarry 1987; 15:1063-1064.

214. Wesnes $K$, Warburton DM. EEffect of scopolamine and nicotinc on human rapid information processing performanece. Psychopharmacology 1984, 82:147-150.

215. Wesines $\mathrm{KA}$, Arand $\mathrm{R}$, Simpson PM, Chrismuas L. The use of a scopolamine model to study the potential nowtropic effects of aniracetarn and pincetam in heallty voluntecrs. Journal of Psychopharmacology 1990; 4 : 219.232 .

216. Wesnes KA, Simpson P. Chrismas $\mathrm{L}_{\mathrm{n}}$ Siegfried K. Effects of HP029 in a scopolamine model of ageing and dementia $17 \mathrm{th}$ Congress of C.IN.P. Kyoto, Japan: 1990: 235.

217. Wesne: KA, Simpson PM, White L, et al. Cholinesterase inhibition in the scopolamine model of dementia. Ann N Y Aad Sci 1991: 640:268-71.

218. Wenes $K A$, Simpson PM, White $L$, Weaver $A$, Siegfried $K$. HOE-427, a cholinergically active neuropeptide, improwes cognitive efficiency in the elderly. Biological Psychiatry $1991 ; 29: 691$.

219. Yu $G$, Maskray $V$, Jackson $S H, S$ wift $C G$. Tiplady B. A comparison of the central nervous system effects of caffene and theophylline in elderly subjects. Br J Clin Pharmacol 1991; 32:341-5.

220. Ziegler G, Ludwig L, frik G. Effect of the specific benzodiazepine antagonist Ro $15-1788$ on sleep. Pharmacopsychiatry 1986; 19:200-201.

221. Zylilarz G, Saleeu B, Hitzenberger $G$, et al. Double-Blind, Placebo-Controlled, Pharmaco-kinetic and dynamic Studies with Two Mew Formulacions of Piracetam (Infusion and Syrup) Under Hypoxia in Man. Neuropsychopharmacology 1994; 10: 1175. 


\title{
The Influence of Piracetam on Actual Driving Behaviour and Postural Stability of Elderly Subjects*
}

\begin{abstract}
A group of 38 elderly $(60-80 \mathrm{yr})$ deficient drivers were examined with regard to their driving ability. Their lane-tracking performance during highway driving as well as their car-following performance were measured in real traffic. Their postural stability was also measured. They were given a daily dose of $4.8 \mathrm{~g}$ piracetam or placebo over two separate four-week periods in a double-blind, placebocontrolled, cross-over study. Overall, driving performance did not change under the influence of piracetam, although there was a trend towards improvement after 4 wecks of treatment. Postural stability improved during piracetam treatment. Given the scrutiny with which deficient performers on the driving tests were selected, the results concerning the hypothesized performance enhancing effects of piracetam were considered disappointing. The improved postural stability due to piracetam treatment was an interesting result however, and seems to confirm that its indication is vertigo of central origin and should not be changed into the indication of cognitive or psychomotor deficiency in the elderly.
\end{abstract}

“Riedel WJ, Peters MLA, Vau Boxrel MPJ, O'Hamion JF, Submirted for publication. 


\subsection{INTRODUCTION}

Nootropic drugs were defined as drugs which are supposed to act directly on the higher functions of the brain, and thus to influence cognitive processes specifically isi. The prototype of this class of drugs is the cyclic CABA-derivarive piractan (2-oxy-1-pytrolidinone acetamide). It has been claimed that piracetam can enhance memory and learning in normal subjects and that it is able to reverse mild age-related psychological deficiencies [6]. Piraceam has also been applied in the treatment of the symptoms of clinical dementia "2». The mechanisms of action of piracetam are largely unknown. No direct effect (agonistic or antagonistic) on any known CNS-receptor has been demonstrated. Instead, it has been hypothesized that piracetam potentiates already present neurotransmission. Piracetam's effects are strongly dependent on the presence of normal steroid neuromodulation [19. Animal experiments have suggested that piracetam can protect or restore neurone membrane stability and also that it might affect second messengers such as cyclic AMP, thereby improving neurotransmitter efficiency. Another possible mode of action is by enhancing microcirculation in the brain $[16,16363$.

Piracetam is registered for various indications in different countries. In the Netherlands it is registered for one indication only, namely vertigo of central origin. However, in most countries the main prescription of piracetam seems to be for the treatment of age-related complaints. This is in spite of the fact that up to now research into the beneficial effects of piracetam on age-related deficiencies is equivocal 136. Some clinical investigators have reported improvement in geriatric parients alter 4 to 12 weeks of treatment with piracetam $[4,6,7,13)$. However, a large number of reviews expressing scepticism and negative results have also been published $110,12,17,23,2$. . 29].

Piracetam was also investigated in human models of age-related decline. It was shown to possess protective properties in healthy volunteers with hypoxia-induced cognitive dysfunction $[27,4]$, but not in healthy volunteers with scopolamine-induced cognitive dysfunction [40]. It can be speculated that the severe impairments which are seen in dementia are very resistant to improvement. Mild age-related impairments might prove to be more susceptible to change. This could mean that piracetam is perhaps not so much effective in the treatment of dementia as it is in improving minor cognitive performance deficits of normally aging individuals $\| 2]_{\text {. }}$

The objective of the present study was to investigate wherher piraceram can exert a beneficial effect on the accual driving performance of non-demented elderly subjects. Accident statistics show that per $\mathrm{km}$. driven, older drivers become increas"ngly involved in traffic accidents 11.34 , 39l. One of the causes of an impairment in driving performance in the elderly could be the general slowing of central information processing which has been demonstrated to occut with aging 130 . It remains to be established whether piracetam can improve psychomotor performance in the mildly impaired elderly, e.g. by facilitation of neurotransmission and a consequent speeding of information processing. One recent double-blind study has provided some evidence that piracetam can improve driving in the elderly 281. The initial performance of $10 \mathrm{~L}$ motorists over the age of 60 during real traffic conditions was compared with their performance after 6 weeks of treatment witly either placebo or piraceram. The percentage of correctly solved sign-observance irems, which reflects orientation and perception in real traffic conditions, significantly increased more in the piracetam-treated group than in the placebo-treated group. However, driving performance in this study was established by means of subjective ratings of an observer. The present study was designed to examine the effect of piracetam with more objective and reliable measures of driving performance. Two different aspects of driving were assessed. The precision of vehicle control was established during an uninterrupted high speed travel over a standard highway circuit. A carfollowing test was used to measure the subjects ability to react rapidly and adequately while interacting with another vehicle. Subjects between 60 and 80 years of age, who were judged to be deficient drivers in a prior screening test, were admitted to the study. It was hypothesized that 4 weeks of treatment with piracetam could reverse the mild defiency in driving performance, whereas 4 weeks of placebo treatment would have no effect on our driving tests. 
A secondary objective of this study was to measure the effect of piracetan on static body balance in the elderly. The measurement of postural instability is recognized as a very senstive indicatoir of aging [31, as well as of the impairment induced by many psychoactive drugs 166. Furthemore, it has been shown that piracetam can improve both dymamic and static postural stability in patients with chronic balance disorders is. Disturbed equilibrium is a very common problem in the aged, and even though our subjects were not specially selected or screened for balance disorders, a poorer static body control in comparison with younger people can be expected ins.. Therefore, piracetam could have a beneficial effect on the objective assessment of body balance in our sample.

\subsection{METHOD}

\subsubsection{Subjects}

Subjects were recruited by means of announcements in seweral local newspapers. Eilderlly drivers; aged between 60 and 80 , were requested to apply to participate in a study assessing the effects of a drug on driving behaviour. All respondents received detailed information concerning the design and purpose of the study as well as details about the drug. After written informed consent was obtained the candidares first participated in the selection procedure specified below. The subjects were paid for their participation. The protocol of this study was approved by the Medical Ethics Committee of the Uniwersity Hospital Maastriche. The study was conducted in accordance with the Declaration of Helsinki as modified in Tokyo (1975), Venice (1983) and HongKong (1989).

\subsubsection{Screening and Selection Procedure}

Medical exclusion criteria were: (1) any sign of parhological cardiac conduction abnormalities in ECG recordings, (2) body weight $15 \%$ outside of population norms, (3) alcohol or drug abuse or the Medical Supervisor's suspicion of the same, (4) present psychiatric disorders requiring outparient or regular inpatient therapy, (5) overt severe cardiovascular, cerebtovascular, respiratory, renall or hepatic disorders or history of such, (6) epilepsy or any other severe neurological disorder, (7) diabetes or any other endocrine/merabolic disorder, (8) severe sleep disorders, (9) articular disease, and (10) use of CNS-active medication (e.g. benzodiazepines, nootropics, ancidepressants and opioids). Screening of these criteria was batied on information from medical history and a physical examination (including a 12-lead ECG). Moreover, subjects had to possess a valid driver's license, have a total driving experience of at least 20 years, and a recent driving experience of $3000 \mathrm{~km}$ during the last year.

The purpose of the screening which followed was to identify "deficient driwers". Only subjects who were classified as such, according to two separate criteria, entered the study. The first crirerion was the performance of a subject during a standard ciry driving test. The test involved driving a car ower a preselected urban circuit in the presence of a licensed driving instructor. Approximately 30 minutes were required to complete the test. The subjects were requested to driwe according to the instructions given by the instructor and commonly accepted safety standards. The performance of a subject was scored by the instructor using a 111-item checklist (the Advanced Driver's Examination), developed by the Royal Dutch Organization of Drivers (ANWB). These items were scored as either "sufficient" "moderate" or "insufficient". "The criterion for discriminating acceptable, or safe, driving from deficient, or unsafe, driving, was exceeded when less than $80 \%$ of 22 items pertaining to visual perception or anticipation of traffic events were scored sufficient; i.e. $>4$ items rated insufficient or $>8$ items rated moderate $[3]_{*}$

The second criterion of deficient driving was derived from the standard highway driving test which is described below 120. In short, this test gives a measure of road-tracking error, or weaving. 
An index of weaving can be obtained from the standard deviation of lateral position (SDLP) of the wehide within the traffic lane. Extensive experience with this measure has indicated that the mean SDLP for yourg and middle-aged drivers for a $100 \mathrm{~km}$ driving test is about $21 \mathrm{~cm}$. No normatiwe data for elderly drivers were yer availablle. However, a study with a $60 \mathrm{~km}$ version of the standard rest showed that older people had a higher SDLP on average than younger people [35]. A mean difference in SDLP of abowt $20 \%$ was found. In the present study, a candidate was classiffed as "deficient" if his/her SOLP equalled or exceded $24 \mathrm{~cm}$.

\subsubsection{Drug Treament}

Piraceram and placebo were orally administered in the form of identically appearing tablets. Two tablets of $1.2 \mathrm{gram}$ were ingested twice a day (i.e. a total dose of $4.8 \mathrm{gram} / \mathrm{day}$ ) for four weeks. The daily doses of medication were self-administered at approximately 8.00 and $20.00 \mathrm{~h}$. Urine samples were obtained during the visits at the institute on day 7 and day 28 in both periods. The purpose was to ensure that for each subject the proper medication was dispensed and to check for compliance. Samples were stored frozen until the conclusion of the data collection period. All samples were assayed for the presence of piraceram.

\subsubsection{Study Design}

Drug treatments were administered in separate 4-week periods according to a double-blind, cross-over design. The order of trearment was balanced across subjects and assigned to the subjects using a randomization list.

Baseline assessments were carried out on the day before treatment started, whereas the doubleblinded assessments were carried out after $\mathbb{1 4}$ days of treatment and after 28 days of treatment in both periods. A washout period of ar least 4 weeks and usually 5 weeks, interspersed between the successive treatment periods for a given subject.

\subsubsection{Testing Procedure}

During the treatment periods, all subjects participated in 2 driving tests: the standard highway driving test and the car-following test. In addition, measures of postural stability (body sway) were obtained. Before the start of the data collection the car-following task was trained for each subject individually. As all subjects had already participated in an initial highway driving test during the screening, no further training of this task was deemed necessary. Subjects came to the institute on a weekly basis for five successive weeks in both treatment periods. At day 0, 1.4 and 28 of each treatment period, the two driving tests and body-sway measurement took place. An additional body-sway measurement took place on day 35 of both periods, i.e. one week after medication was withdrawn.

An appointment with either the medical supervisor or the investigator was scheduled every week, from week 0 to week 5 . The purpose of this was to check for adverse side-effects, to hand out new medication and to secure compliance of drug intake by collecting the empty drug-containers and by examining the diaries on which drug intake times were recorded by the subject. On day 7 and day 28, unine was collected. Medication started on the evening of day 0 (i.e. after the baseline test) and ended in the morning of day 28. A schematic overview of all visits to the institute and the activities taking place during the various periods, is presented in figure $\mathbb{1}$.

On test days, visits were always scheduled at the same time of the day for a particular subject. The order in which the tests took place was the same on each occasion: the standard highway test was done first, immediately followed by the car-following test and at the subject's return to the institute, body sway was assessed. The subjects were not allowed to drink caffeine containing beverages before or during the tests. 


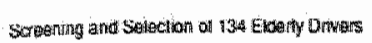

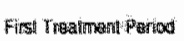

Westorition

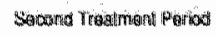

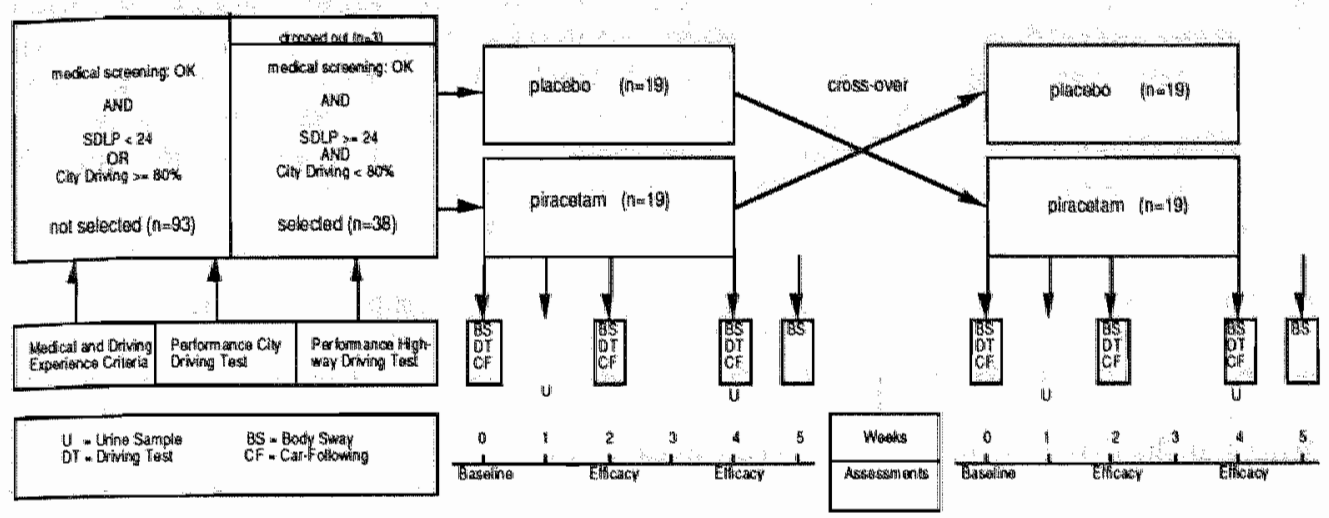

Figure 1 Flow chart sumimarizing the difterent stages, scieening proced wres, selection criteria, assessments, and expertmental design of the sludy.

\subsubsection{The highway driving test}

Each subject was informed beforehand of his/her legal responsibility to drive safely at all times. The subjects were informed of the possibility that some of the treatments might impair their ability to do so. They were encouraged to tell the driving instructor immediately if they ever doubted their ability to continue driving in a safe manner.

The driving test was conducted over a $95-\mathrm{km}$ circuit on a primary highway. The highway consisted of rwo traffic lanes $(3.75 \mathrm{~m}$ wide) in each direction. The subjects were instructed to maintain a constant speed $(95 \mathrm{~km} / \mathrm{h})$ and a steady lateral position within the right traffic lane, preferab. ly in the middle. They were allowed to deviate from these instructions in order to pass a slower vehicle. The test vehicle was an extensively modified station wagon. Modifications consisted of an electro-optical device ("Lane-Tracker") for measuring the lateral position of the vehicle relative to the painted stripe at the side of the road, an electromagnetic pullse counter, attached to the rear axis, to determine forward velocity, and an 11 -bit shaft-encoder linked to the steering axis for measuring the steering wheel angle. The analog signals from lateral position and speed sensorts were A/D converted and sampled, along with the digital steering angle signal, on-line, at $4 \mathrm{H} x$ by an inboard 80286 microcomputer. These measures yielded mean values and standard dewiations over time of the lateral position, speed, and steering wheal angle. Based on this information, the future path of the vehicle was continuously predicted and time-to-line-crossing (TLC) was calculated. TLC represents the time available for a driver to neglect path errors until the moment at which any part of the vehicle reaches one of the lane boundaries [9]. TLC distributions over time were obtained for lane crossings to the left and right. The 15 th percentile value was averaged over both left and right distributions. The standard deviation of Jateral position (SDLP) and TLC15 were the primary dependent variables. This method was standardized and has been repeatedly applied for measuring the effects of drugs on driving 23 .

\subsubsection{The car-following test}

This test has been applied previously in studies into the effects of anxiolytics and antihistamines on car-following performance $[22,25]$. The car-following test measures the driver's ability to perceive changes in a preceding vehicles speed and to react in a manner maintaining a constant head. 
way. It began with two vehicles travelling in tandem on a secondary highway at $90 \mathrm{~km} / \mathrm{h}$ separated by a distance of about $30 \mathrm{~m}$. The leading wehicle"s speed was automatically controlled and the subjects controlled the speed of the following vehicle. The subjects were instructed beforchand that the purpose of the test was to measure their reactions to the movement of the leading vehicle. They were told to maintain the initial headway throughout the test by matching their vehicle's velocity to the outher's. Furthermore they were informed that it would be necessary to constantly attend to the leading wehicle since it might slow down and then speed up at unpredictable times.

The investigator in the leading wehicle activated its modified cruise control system at the beginning of a test. In the initial phase and during intervals between manoeuwres, it was set to maintain a constant speed of $90 \mathrm{~km} / \mathrm{h}$. To start a speed manoeuvre, the inwestigator actiwated a microprocessor. To command deceleration, it added to the speed signall which was interpreted by the cruise control as a deviation requiring a reduction in fuel flow. As the program continued, the microprocessor gradually ceased adding to the speed signal. When the vehicle's actual speed arrived at the desired minimum the process was reversed until the leading vehicle recovered its original speed, whereupon the microprocessor again became quiescent. In this manner the wehicle's speed manoeuvres described a sine function over time within each manoeuvre, dropping from 90 to $70 \mathrm{~km} / \mathrm{h}$ and returning to $90 \mathrm{~km} / \mathrm{h}$ within $50 \mathrm{~s}$. Unless interrupted by other traffic, this manoeuvre was repeated five or six times within $12 \mathrm{~min}$. with interpolated periods of constantspeed driving of at least $20 \mathrm{~s}$. The entire test took place on a straight and level $12-\mathrm{km}$ section of a four-lane secondary highway.

The velocity of the leading vehicle and a signal indicating the beginning of each manoeuvre were cransmitted via telemetry to a receiver in the following vehicle. These signals, along with the following veliicle's own velocity were recorded in parallel, timecoded files on computer. Data recorded during manoeuvres entered a power spectral analysis for yielding the phase-delay between the vehicle"s velocities at the manoeuvre cycle frequency (i.e. $1 / 50 s=0.02 \mathrm{~Hz}$ ). Phase delay, a measure of the subject's average reaction time to the novements of the leading vehicle (RT in s), was then taken as the primary dependent variable from the car-following test.

During each manocuvre, two direct measurements of separate distance between the following and leading vehicle were made by means of a super-VHS camcorder which was mounted berween the following vehicle's front seats, facing forward through the windshield. From this information the distance (d) separating the two vehicles, or "headway" was calculated according to the equation

$d($ in $\mathrm{m})=k[1 / \tan (\theta / 2)]$

where $k$ is a proportionality constant and $\theta$ the horizontal angle subtended by the camera lens. Once the starting distance was determined from a single measurement, headway clanges during the manoeuvre were calculated using differential speed according to the equation,

$$
H(\mathrm{t})=\int V_{p} \mathrm{dt}-\int V_{f} \mathrm{dt}+H_{o}
$$

where headway varies as a function of time $(t)$ according to the difference between integrals of vellocities of preceding and following whicles $\left(V_{p}, V\right)$ plus the headway ( $\left.H_{0}\right)$ that existed at the beginning of the manoeuvre. Standard deviation of headway (SDHD) during the deceleratio n/acceleration manoeuvres was taken as the other major dependent variable.

\subsubsection{Body Sway}

Postural instability, or body sway, was measured using the stabilometry method 114. It involved the use of a balance platform that measured the location of the vector of force which extends vertically downward from the body's centre of gravity, and its movement over time. Analog output of force transducers within the platform were digitized and analyzed to yield simultaneous 
meastres of lateral and sagitcal motion. Subjects were instructed to maintain a static, erect posture while standing over the centre of the balance platform with their feer together (at a comfortable, but small distance). Two 30-second recordings followed. The first with the subject's eyes open, the second with eyes closed. While standing with the eyes open, the subject was requited to fixate on a target mounted on the wall from distance of $2.0 \mathrm{~m}$. Measures obtained from the electroposturograph were: lateral-1ateral sway velocity, anterior-posterior sway velocity, quad. ratic velocity (a composite score of both velocities), curve length (path length of vector) and curve surface (the area circumscribed by the path). Analysis of the body sway parameters were performed separately for measurements with eyes open, eyes closed and for the ratio eyes closed / eyes open. This latter variable is known as the Romberg Quotient and indicates the decrease of postural stability due to the elimination of visual compensation. A quotient close to 1 means that stability can be maintained in spite of the absence of visual input. The higher the quotient, the more one relies on the visual system for postural control.

\subsubsection{Data analysis}

First, the reliability and consistency of driving performance parameters measured in the successive. baseline and placebo conditions were evaluated. We felt this was a necessary step, because this was the first application of the driving test to measure the effects of drugs in elderly drivers. Moreover, the specific selection of subjects with a high SDLP, might be prone to the statistical regression to the mean effect and hence corroborate the aimed stability of baseline measures, and the periods berween assessments was much longer than usual in applied research of drugs on driwing. Test-retest reliability coefficients were determined and mean differences between data collected in successive conditions were rested for significance using paired t-tests. Previous studies wherein unmedicated subjects performance was repeatedly measured in the standard highway driving test have failed to sthow any significant changes over time intervals as long as one week; and, test-retest reliability coefficients for the SDLP measure in young volunteers have always been higher than $r=70$ 121.26. The reliabilities of measures obtained in the car-following test are less well-known but have been shown to lie in the range .45-.81 [26.

Subsequently, MANOVA for repeated measurements was used to test the influence of the treatment on the dependent variables measured in the driving and postural stability tests. Two within subject factors were specified: treatment ( 2 levels: piracetam or placebo) and day of treatment $(2$ levels: day 14 and day 28). The baseline scores were used as covariates, when necessary; i.e. variables whose baseline values were not the same. Analyses were performed with and without an additional between subjects factor, namely order of trearment ( 2 levels: piracetam first or placebo first). Additionally, individual piracetam-placebo comparisons for the assessments at day 14 and day 28 were made irrespective of the outcome of the multivariate test, using one-tailed paired t-tests.

\subsection{RESULTS}

None of the drug treated subjects had to be excluded from the analysis because of failure to find the drug in the urine.

\subsubsection{Comparison between selected and rejected subjects}

A total of 134 candidates were screened for participation in the study. Ninety-three of these were rejected because of a SDLP below the criterion of $24 \mathrm{~cm}$. Forty-one subjects passed the initial screening, three of which dropped out later for reasons unrelated to the treatment. Because the last 2 drop-outs were not replaced, 19 subjects received the treatments in the order piracetam-placebo, 
whereas 19 subjects received the treatments in the order placebo-piracetam.

The mean ( $t$ standard error) SDLP upon screening, of the selected subjects was $27.5( \pm 0.5) \mathrm{cm}$ as compared to $19.3( \pm 0.3) \mathrm{cm}$ for the subjects not selected.

There were no demographic differences between selected and rejected subjects. The mean age and sex distribution of the two groups are shown in table 1 , along with the variable " $\mathrm{km}$ driven during previous year". On none of these variables there were significant differences between the rejected and selected subjects:

Table 1 Demographic variables and driving cxperience for sellected and rejected subjects

\begin{tabular}{|c|c|c|c|}
\hline & $\begin{array}{l}\text { selewted subjects } \\
(\mathrm{n}=38)\end{array}$ & $\begin{array}{l}\text { rejected subjects } \\
(n=93)\end{array}$ & $\begin{array}{l}\text { total } \\
(\mathrm{n}=131)\end{array}$ \\
\hline $\begin{array}{l}\text { Metan Age it sern } \\
(\operatorname{range})\end{array}$ & $\begin{array}{l}66.9 \pm 0.8 \\
(60.79)\end{array}$ & $\begin{array}{l}65.6 \pm 0.5 \\
(60-80)\end{array}$ & $\begin{array}{l}66.0 \pm 0.4 \\
(60-80)\end{array}$ \\
\hline Proportion male : female & $32: 6$ & $79: 14$ & $111: 20$ \\
\hline $\begin{array}{l}\text { mean Km driven in } \\
\text { previlous year (t sem) }\end{array}$ & $\begin{array}{l}13200 \\
(1135)\end{array}$ & $\begin{array}{l}13600 \\
(518)\end{array}$ & $\begin{array}{l}13500 \\
(524)\end{array}$ \\
\hline
\end{tabular}

There was not one significant correlation between SDLP, age and km's driven. There was a significant difference in standard deviation of speed between the two groups. The selected group had a SD speed of $2.4( \pm 0.1) \mathrm{km} / \mathrm{h}$, whereas the rejected group had a SD speed of $2.1( \pm 0.1) \mathrm{km} / \mathrm{h}$. This was a statistically significant difference $\left(t_{125}=-2.56, p<.05\right)$. Thus, subjects who showed poorer control of road-tracking behaviour also had more difficulty in keeping a constant speed. This is also shown by a slight but significant correlation between SDLP and SD speed $(r=.27$ $\mathrm{p}<.001)$. In addition, $\mathrm{SD}$ speed allso correlated significantly with age $(\mathrm{r}=.33, \mathrm{p}<.001)$.

The relation berween SDLP and performance on the city driving test was also determined. A toral test score was derived on the basis of the scores on the 22 safery-critical items. the number of irems scored as "sufficient" was expressed as a percentage of the maximum number. Items scored as "moderate" counted for half. "Thus, when 11 of 22 items were scored as "insufficient", or when all 22 irems were scored as "moderare", a score of $50 \%$ was obtained.

It was shown that the score on the ciry driving test did not correlate significantly with SDLP. There was neither a significant difference in city driving test performance berween selected and rejected subjects. Subjects included in the study had an average score of $55 \%$ (sd 20\%) on the ciry driving test, against $60 \%$ (sd $18 \%$ ) for the subjects not included in the study ( $\mathbf{t}_{125}=1.41, \mathrm{n} . \mathrm{s}$.). Howewer, ciry driving test performance did seem to be weakly related to some other wariables. A significant cotrelation appeared with age $(r=24, p<.01), \mathrm{km}$ driven in previous year $(r=.22, p<.01)$ and SD speed $(r=32, p<.001)$.

\subsubsection{The highway driving test}

Standard Deviation of Lateral Position (SDLP). Table 2 shows the means and standard errors obtained in the screening, baseline, and placebo driving tests. T-tests for paired comparisons showed that there were no significant differences between the scores obtained during the differenc non-medication measurements.

Previous studies have shown that SDLP has a high test-retest reliability 12, 20. For young drivers the 
correlation between successive assessments normally ranges between .75 and .90. The conrelations obtained in this scudy berween the screening assessment and the two baseline assessments among the two baselime assessments and between the two placebo assessments are shown in table 2. Even though most correlations are somewhat lower than those obtained for young people, adjacent assessments (screen/bas1 and placl/plac2) do show a fair correlation. Therefore, it can be concluded that the SDLP has an adequare test-retest reliability also for older subjects.

Table 2. Mean SDLP and sem for the screering, the wo baselime and the rwo placelbo driving teses and correlations among these measures $(n=38)$

\begin{tabular}{|c|c|c|c|c|c|}
\hline & mean & sem & baseline 1 & baseline 2 & placebo 2 \\
\hline screening & 27.5 & 0.5 & .74 & .57 & \\
\hline baseline 1 & 28.0 & 0.7 & & .73 & \\
\hline baseline 2 & 27.1 & 0.6 & & & \\
\hline placebo 1 & 27.3 & 0.7 & & & .70 \\
\hline placebo 2 & 27.6 & 0.7 & & & \\
\hline
\end{tabular}
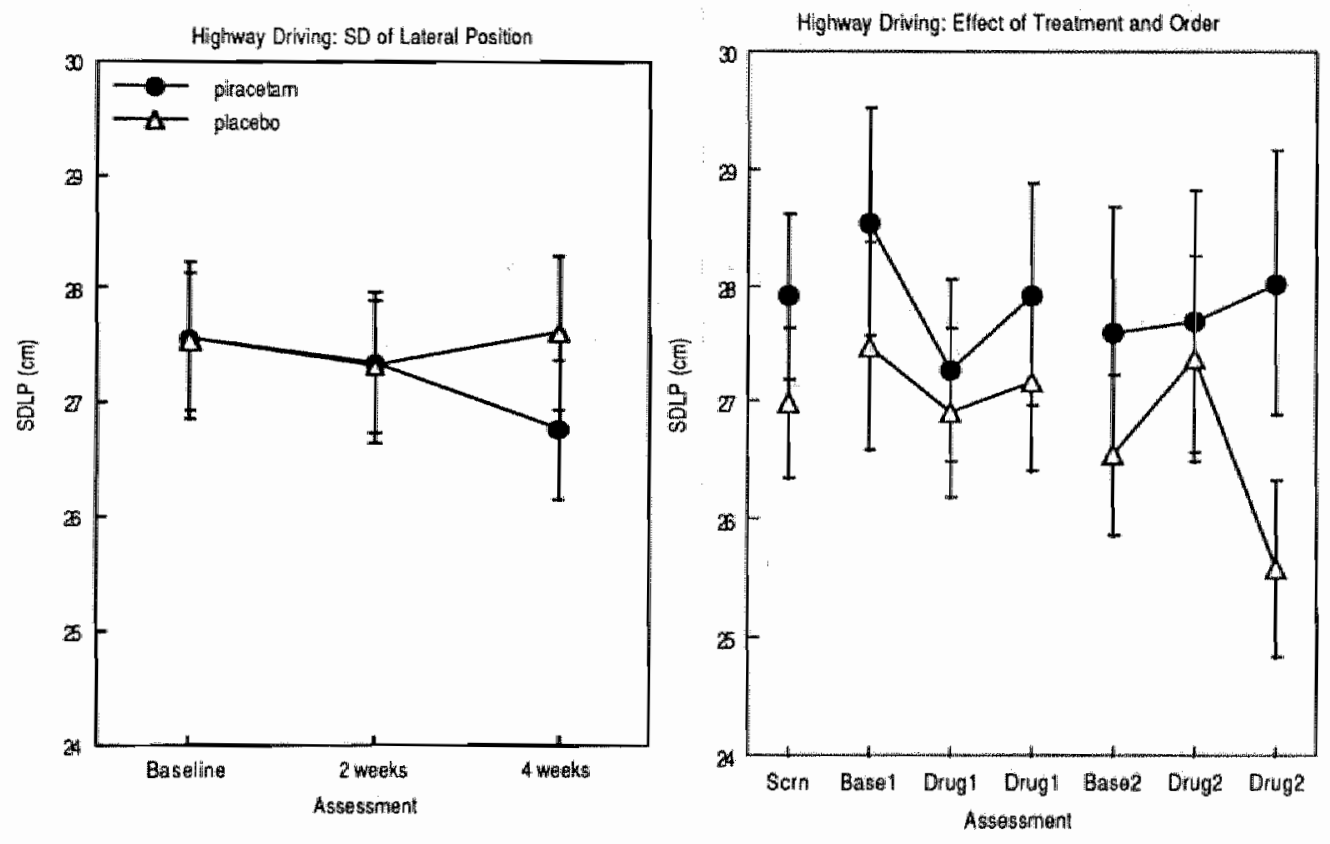

Figure 2 The effect of 4 weeks of treaiment with piracetan and placebo on the standard deviation of lateral po sillion in the highway driving lest, lakem al baseline, and after 2 and 4 weeks of frealment. Left: mean and se of SDLP of the whole group ( $n=38$ ). Right: mean and se of SDLP as a lunction of order of treatiment (n=19 for bolth freatment orders).

The mean values obtained during the different conditions are shown in figure 2 . The treatment effect on the difference scores was not significant $\left(F_{1,37}=0.6\right.$; n.s.). There was neither a significant. 
effect for day of treatment $\left(F_{1,3}=0.08 ;\right.$ n.s. $)$ nor for the treatment by day interaction $\left(F_{1,37}=1.32\right.$; $\mathbf{n}_{\text {s. }}$, Individual drug-placebo comparisons enploying one-tailed tests revealed that there was no difference after 14 days of treatment $\left(t_{37}=0.04 ; n, s\right)$, but that SDLP wals somewhat lower (i.e. better) after 28 days of piracetam relative to placebo $\left(\mathrm{t}_{3 \mathrm{~g}}=1.80 ; \mathrm{p}<.05\right)$. In figure $2 \mathrm{~b}$ the results as to the effecrs of piracetam on SDLP are plotted as a function of treatment order. There was no effect of treatment order as evidenced by the multivariate analysis lacking an interaction of treatment by treatment onder $\left(F_{1,37}=1.84 ; \pi, s_{n}\right)$.

Mean Speed and SDspeed Mean speed was very similar in the various conditions, ranging from 94.5 to $94.7 \mathrm{~km} / \mathrm{h}$. There were no significant differences between conditions (treatment effect: $\left(F_{1,3}, 0.26, n . s\right)$. SDspeed ranged from 2.4 to $2.6 \mathrm{~km} / \mathrm{h}$ between conditions. There was mo significant treatment effect $\left(\mathrm{F}_{1,37}=1.21 ; \mathrm{n} . \mathrm{s}\right)$.

Titwe to line crassing. The median TLC ranged from 5.47 to 5.73 seconds between conditions and did not differ between treatment conditions $\left(F_{1,37}=0.09 ; n . s\right.$. $)$. The 15 th percentile of TLC ranged from 3.31 to 3.53 seconds in the various conditions and did not differ between treatment conditions either $\left(\mathrm{F}_{1,3,}=0.96 ;\right.$, n.s. $)$.
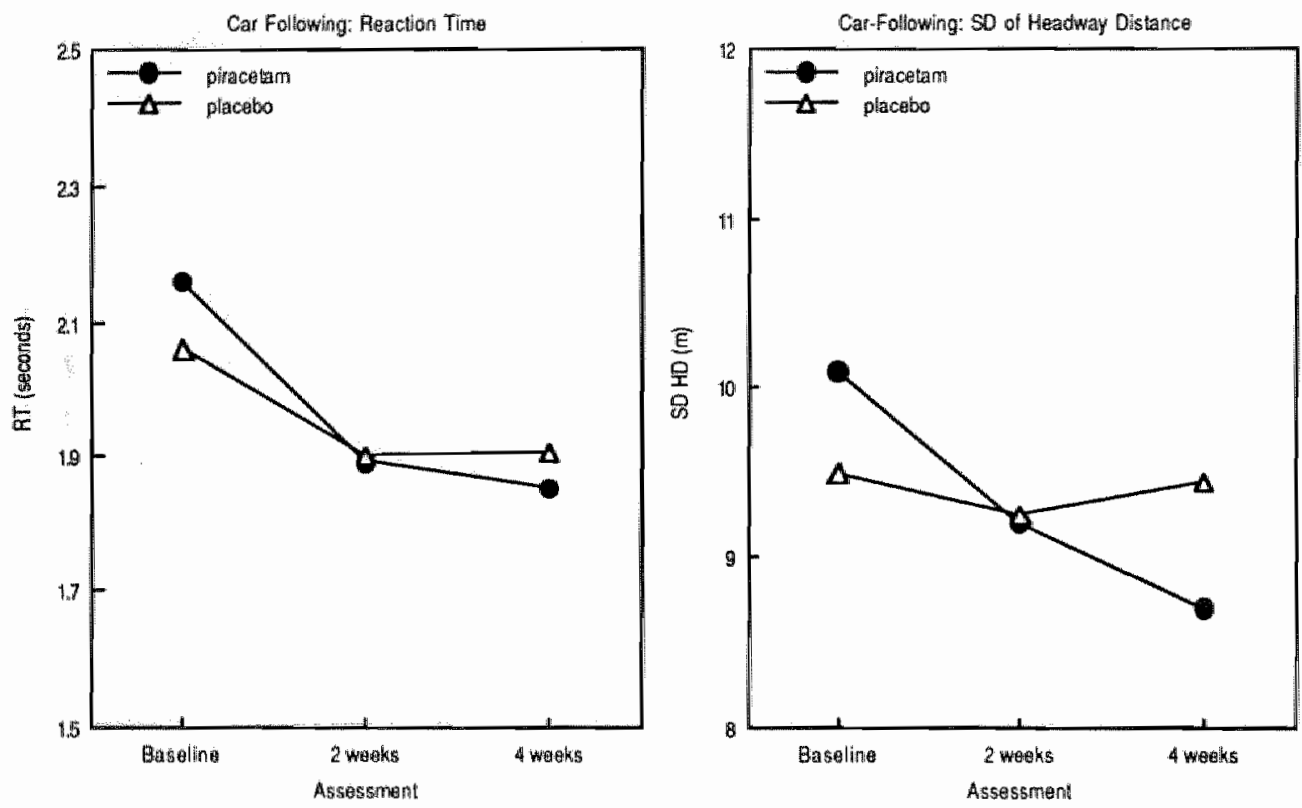

Figure 3 The froct of 4 woeks of treatment with piracetam and placebo on measures of car -lollowing liaken at baseline. and after 2 and we weks of treatment. Lell: Feaction fime to manoewres of the leading car. Aight: lndex of variability (SD headway) pertaining to the headway maintained in retation to the leading car.

\subsubsection{The Car-following Test}

Headuay Distance and SD Headway Distance. The mean headway distance between the two cars during car-following manoeuvres varied between 36.6 and 39.4 meters in the various conditions. There was no significant drug effect on mean headway distance. The standard deviation of headway distance (SDHD) for the various conditions is displayed in figure 3. Changes from baseline 
were tested for the two treatments and the two testing days by means of the MANOVA approach. There was no significant treatment effect $\left(\mathrm{F}_{1,37}=1.86, \mathrm{w} . \mathrm{s}.\right)$, nor a significant treatment $x$ day interaction $\left(F_{1,3 ;}=1.12 ;\right.$ n.s. $)$.

The difference as to the linear trend was tested by means of polynomial contrasts. It showed that there was no significant difference in the linear trend for two periods $\left(F_{1, g 7}=2.74 ; \mathrm{n} . \mathrm{s}_{\mathrm{s}}\right)$. The testretest reliability of the SDHD measure proved to be only moderate. The correlation berween the two baseline driving rests was .49 and between the two placebo driving tests was .56 . Both were significant $(\mathrm{p}<.001)$.

Reaction Time (RT). Mean RT is shown in figure 3 for the various conditions. The main effect of treatment was not significant $\left(\mathrm{F}_{1,37}=0.78 ; \mathrm{n} . \mathrm{s}_{\text {. }}\right)$ and neither was the interaction effect of treatment by day of treatment $\left(F_{1,37}=0.06 ; n .5\right.$.). The polynomial erend analysis showed that there was an overall linear trend $\left(F_{1,36}=5.19, p<.05\right)$ for $R T$, indicating faster reactions with repeated measurement in each treatment condition. However, there was no treatment effect on the linear trend $\left(F_{136}=0.69 ;\right.$ n.s. $)$ thus showing that RT's did not decrease more in the piracetam condition than in the placebo condition. Test-retest reliability for RT was low in this srudy. The correlation between the two baseline tests was .32 (n.s.) and between the placebo tests .42 (p<.01). In a study with young volunteers $[26)$ the test-rerest correlations of this measure were higher $(\mathrm{t}-45, .61, .68$ and .81 ).

Coherence and Velocity Response Gain (VRG). The coherence between the velocity signals of the leading car and of the following car were wery high in all conditions, .98 or .97 . There were no differences between conditions. VRG ranged from 1.09 to 1.11 , neither differing significantly between conditions.

\subsubsection{Body Sway}

Anterior-Posterior Velocity (A-PV). Curves for the Romberg Quotient appear in figure 4. As can be seen, in the piracetam condition, the quotient decreases from baseline to treatment period. The treatment effect was significant $\left(\mathrm{F}_{1,37}=5.59, \mathrm{p}<.05\right)$. This seems to have been due to an increased stability in the eyes-closed condition, where there was also a significant difference between the treatments for A-PV $\left(\mathrm{F}_{1.37}=4.8, \mathrm{p}<.05\right)$. Stability with eyes open did not improve as a result of piracetam treatment.

Lateral-Lateral Velocity (L-LV). The lateral sway proved to be a less sensitive indicator for the treatment effect than the anterior-posterior sway. No significant treatment differences were obtained for the Romberg Quotient or for separate measurement with eyes open or eyes closed.

Quadratic Velocity (V2). The Romberg Quotient for the composite score of sway in both directions (V2) was significantly different between treatments $\left(F_{1,39}=4.35, p e, 05\right)$. Neither the two separate eyes open or eyes closed measurements differed significandy berween conditions.

Curve Length (CL). For curve length (figure 4), the treatment effect on the Romberg Quotient was significant $\left(\mathrm{F}_{1,37}=4.68, p<.05\right)$. Neither of the two separate measures (eyes open or closed) were significantly different in the two treatment conditions.

Curve Surface (CS). No significant differences between treatments emerged for the Romberg Quotient or for the separate eyes open, eyes closed measures.

\subsection{DISCUSSION}

The primary objective of the present study was to test the hypothesis that actual driving performance after piracetam treatment would be different than after placebo treatment in a group of nondemented elderly people who were judged to be deficient drivers according to two different criteria. It was hypothesized that performance on our two driving tests would improve more after 2 and 4 weeks of treatment with piraceam than it would after 2 and 4 weeks of treatment with 

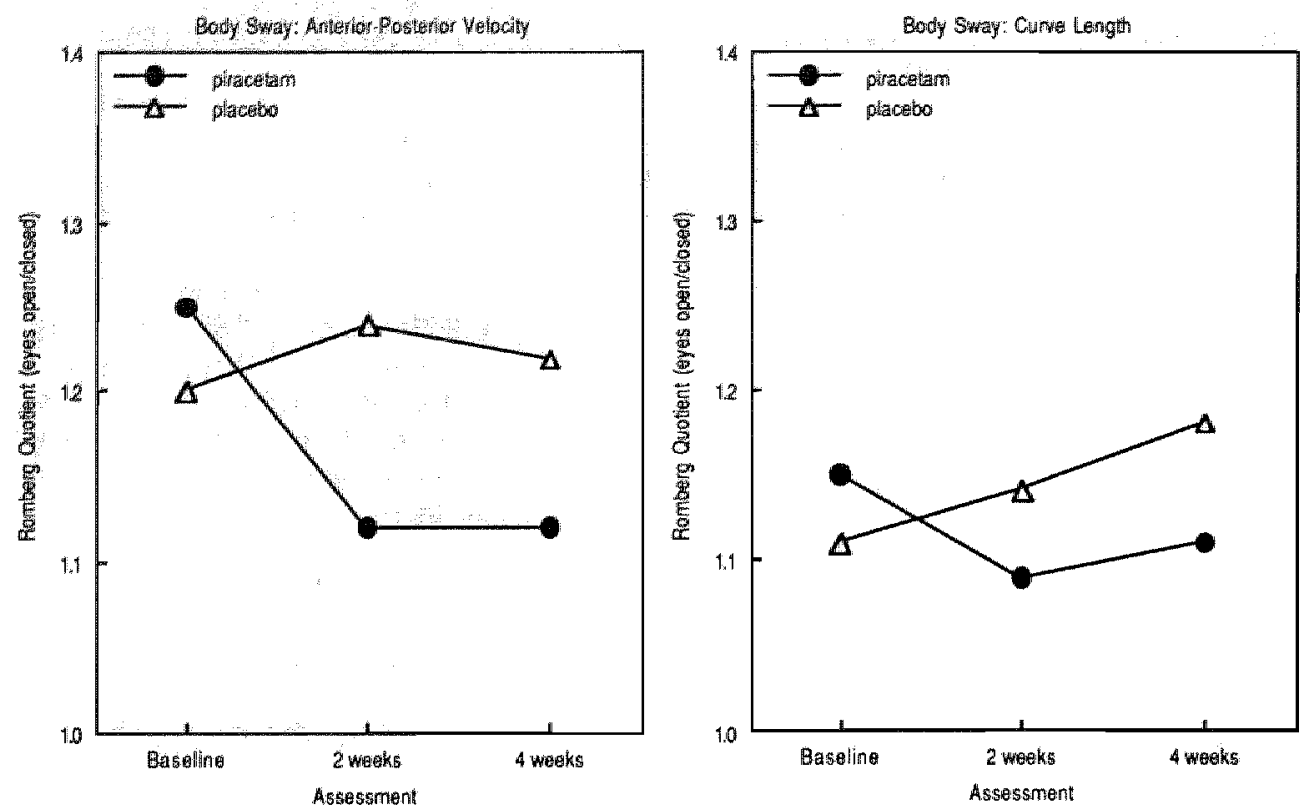

Figure 4 The effect of 4 weeks of treatment with piracetam and placebo on measures of body sway, taken at baseline, alter 2 and 4 weeks of treatment. Left: Romberg Ouotient of Anterior-Posterior Velocity. Plight: Romberg Quolient of curve length.

placebo. Overall, the hypothesis could not be confirmed. For the car-following test, standard deviation of headway distance data showed a decreasing trend during piracetam treatment, but the walues obtained did not differ significantly from those in the placebo condition. Response delay showed a decreasing trend during both medication periods, possibly due to a practice effect. The improvement was not significantly different for the placebo and the piracetam period. In short, for the car-following test, there were no clear indications for a beneficial piraceram effect. The main performance indicator from the highway test was the standard deviation of lateral position. Overall, the decrease in SDLP during piracetam condition did not differ significantly from that in the placebo condition. However, we found a very slight indication of improvement after 4 weeks of treatment with piracetam. The absolure magnitude of this effect was negligible, particularly when viewed in the context of the high SDLP scores of the treatment group as a whole. "Therefore, this 'effect' could serve as a typical example of a marginal statistical significant but dinically irrelevant one. However, it must be noted that in comparison with the recent state-ofthe-att in clinical trials investigating the effect of similar substances in similar populations, i.e. cognition entancers in age-related cognitive decline, the duration of our study was short. Usually, a minimum of 12 weeks is recommended as the minimum duration of the treatment period. So, it could very well be that the above described 'marginal piracetam effect' was signifying the beginning of its developing into a clinicall significant effect, which would take another 8 weeks. The clinical response to piracetam, i.e. the incidence of subjects responding positively to the treatment, has been estimated to lie in the $10-30 \%$ range 1181 . Thus, piracetam might not lead to an improvement of road tracking performance in all subjects, but it might do so for some. This was reported in previous findings $[28\}$. For the one parameter for which a significant piracetam effect was found (orientation towards and observation of traffic signs), the results were more pronounced for the subjects who had the worst scores on the baseline test. If it can be conclusively demonstra- 
ted that piraceram can have a beneficial effect on driving performance of even a small proportion of elderly drivers, this would have major implications. Accident statistics show that older drivers (from age 60 onward) are at greater risk of getring involved in traffic accidents when the distance travelled is taken into account: Moreover, the total number of older drivers increases rapidly, and they will also be travelling larger distances per person 49. . At present no drug is known to improve driving performance of elderly people. If piracetam would be able to do so for a proportion of elderly drivers, especially for the most deficient drivers, this would be very promising. However, our method of selecring the subjects apparently did have no beneficial effect on increasing the dinical response rate. In general, if no predictor of this "dinical response" to piracetam can be found and successfully applied, research into piracetam"s effect on behaviour will only be of academic interest and hence will have no future in treatment of age-related cognitive decline.

An important finding of the present study was that piracetam improved postural stability of elderly subjects as indicated by the Romberg Quotient for anterior-posterior velocity, velocity of sway in both direcrions and total sway-curve surface. The Romberg Quotient indicates the degree to which stability can be maintained after the elimination of visual compensation. With piracetam, the deterionation in stability with eyes closed was significanty less than with placebo. The only other study in which piracetam was shown to reduce postural instability, was a study in healthy young volunteers on piracetam's protection against the balance impairment seen after alcohol intake which led to an estimated blood alcohol concentration (BAC) of 0.8 1371. Stability with eyes closed was measured by means of the same balance platform. Alcohal intake followed the intake of a single dose of either placebo or piraceram. A reliable increase in body sway with alcohol was only seen when a placebo had been taken. The combination of alcohol and piracetam led to a significantly lesser impairment of balance. These results seem to present evidence that piracetam is violating its own definition of being a nootropic drug, i.c. one that has no influence on other than cortical functions of the brain and hence would neither be a cognition enthancer in the strict sense. However, if drugs improve postural stability, there is evidence that the central availability of cognitive processing resources is suppleted 131-331, and hence psychomotor and cognition enhancement could be the result. Such a hypothesis seems prominent in the case of the piracetamlike drugs and could very simply be tested by having the subjects' cognitive performance tested in standing position while simultaneously measuring their postural stability. Yer, this has, to our current knowledge, never been done.

\section{REFERENCES}

1. Barr RA. Recent changes in driving among older adults. Spxcial Issue: Safory and mobility of clderly drivers: Part 1. Human Dactors $1991 ; 33: 597 \cdot 600$.

2. Branconnier RJ. The efficacy of the cercobral metabolic enhancers in the treatment of senile dementia. Psychopharmacol Bull 1983; 19:212-9.

3. De Gier J]. Geneesniddelen en Verkeersweilighuid. Utrecht: Elinkwijk, 1980 .

4. Deberd W. Interaction between psychological and pharmacological treatinent in cognitive impaiment. Life Set 1994; $55: 2057-66$.

5. Deberdr W, Boucher A. Piraceram in vertigo: a pharmacological owerview. UCB. 1992. MRCE92E2701

6. Fioravanti $M$, Bergamasco $B_{\Perp}$ Bocola $V$, et al. A multicentre, double-blind, controlled study of pirtucetam vs placebo in geriatric paticnes with nonvascular mild-moderate impairment in cognition. New Trends in Clinical Neuropharmacology 1921 , V: $27-34$

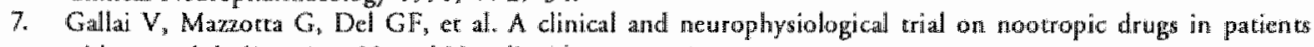
with mental decline. Acta Neurol Napoli 1991;13:1-12.

8. Giurgea $C E$. Vers une pharmacologie de l'activité integranive dui cerveau. Actual Pharmacologie 1972; 25: 115157.

9. Godrhelp ]. The limits of path error-neglecring in straight lane driving. Ergonomics $1968 ; 31: 609$.

10. Gortfies CG. Dementia. In: Hippius H. Winokur G, ed. Psychopharmacology: Clinical Psychopharmacology. Amsterdam: Excerpta Medica, 1983:

11. Gouliaev AH, Senting A. Piracetam and other structurally related nootropics. Brain Rews Brain Res Rew 1994 ; 19: $180-222$ 


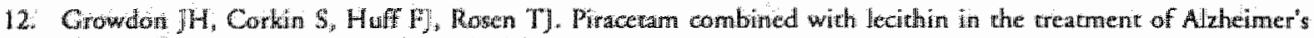

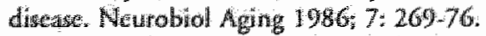

13. Wret $L$, Melac M, Milineviteh $D$, Dubos $G$. Drug therapy and memory traning programst A double-blind

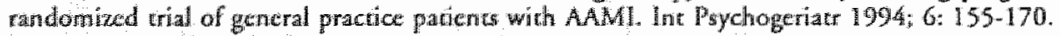

14. Kapteyn TS, Bles W, Njokikgein CJ, Rodde L, Massen CH, Mol JMF. Saandardization in platorm

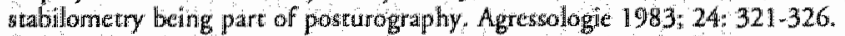

15. Maki BL, Holliday B. Fernie GR. Aging and postural control A comparson of spontancous- and induced-sway

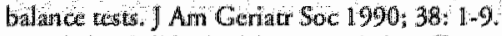

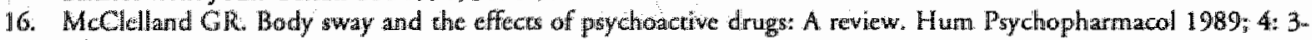
14.

17. McDonidid R. Drigg Trement of Senile Dementia. In: Wheatley D, ed. Psychopharmacology of old age. Oxford Unversity Press, 1982:113-139.

18. Mondadori $\mathrm{C}$. In search of the mechanism of action of the nootropics: new insights and potential clinical implications. Life Se 1994; $55: 2171-78$.

19. Mondadori C, Ducret T, Petschke F. Blockade of the nootropic action of piracetam-like nootropics by adrenalectomy: an effect of dosage" Bethaw Brain Res 1989; 34: 155-8.

20. OHarilon $\mathrm{JF}$. Driving performance under the influence of drugs" rationale for and application of a new test. Br. Clin Pharmacol 1984, 18:121-129.

21. O'Hanlon JF, Brookhuis KA, Louwerens JW, Volkerts IER. Performance testing as part of arug registracion. In: QHanlon JF, De Giler JJ, ed. Drugs \& Drining. London: Taylor \& Francis, 1986: 311-330.

22. O'Hanlon JF, Vermeenen A, Uicerwijk MMC, Van Veggel LMA, Swijgman HF. Anxiolytics' Effects on the Actual Driving Pefromathec of Patients and Healthy Volunteers in a Standardized Testa. Ar Integration of Three Sudites. Neuropsychobiology $1995 ; 31: 81-88$.

23. Orgogowo JM, Spiegel R. Critical review of clinical trials in senile dementia-1. Postgrad Med J 1987; 63: 237.40 .

24. Orgogozo JM, Spicgul R. Critical review of clinical trials in serile dementia-1I. Postgrad Mied J 1987; 63; $337-43$.

25. Ramaekers JG, O' Hanlon JP. Acrivastine, terfenadine and dipherihydramine effects on driving performance as a function of dose and time after dosing. Eur. J. Clin. Pharmacol. 1994; 47: 261-266.

26. Robbe HW]. Influence of marijuana on driving. Maastriche: Dacawyse, 1994.

27. Schaffer $K$, Klausnirzer W. Randomized placebo-controlled double-blind cross-over study on antihypoxidotic effects of piraceram using psychophysiological measures in healthy volunteers. Arzr. Forsch. 1988; 38: 288.91 .

28. Schmidt U, Brendemuhl D, Engels $K$, Schenk $N$, Ludemann E. Piracecam in elderly motoriscs. Pharmacopsychiany $1991 ; 24: 121-126$.

29. Spiegel R. Psychopharmacology: an introduction. (2nd ed) Chichester: John Wiley and Sons, 1989.

30. Stelmach GE, Nahom A. Cognitive-motor abilities of the elderly driver. Special Issue: Safety and mobility of elderly drivets: II. Human Pactors 1992; 34: 53-65.

31. Stemach GE, Zelawnik. HN, Lowe D. The influence of aging and atcentional demands on recovery from postural instability. Aging 1990; 2: 155-161.

32. Teadale $N$, Bard $C_{*}$ LaRlue J. Fleury M. On the cognitwe penetrability of posture control. Exp Aging Res 1993 ; 19: $1-13$.

33. "Teasdate $\mathbb{N}$, Stelmadh Ge Breunig. A. Postural sway chameteristics of the elderly under normal and altered wisual and support surface conditions. J Gerontol 1991:46: 13238 -13244.

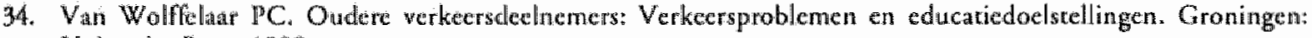
Uniwersity Press, 1988 .

35. Wan Wolfelat PC, Brouwer WH, Rochengater $\mathrm{T}$. Compensation Strategies of Elderly Car Drivers. In: Megaw ED, ed. Contemporary Ergonomics. London: Taylor \& Francis, 1987:

36. Vemon MW, Sorkin EM. Piracetam. An overview of its pharmacological properties and a review of its therapeutic use in senile cognitive disorders. Drugs Aging 1991; 1: 17-35.

37. Vurman EFPM. Piracetam acten uates alcohol-4nduced postural instability. in preparation.

38. Waller JA. Research and ocher issues concerning effects of medical condicions on ellderly drivers. Special Issue: Safery and mobility of elderly drivers: Part ll. Human fiactors $1992 ; 34: 3$; 15 .

39. Wallew PE. The older driver, Special lissue: Safety and mobility of elderly drivers: Part 1. Human Factors 1991; 33: 499.505 .

40. Wesnes KA, Anand R, Simpson PM, Christras L. The use of a scopolamine model to study the potential nootropic effects of aniracetam and piracetam in healthy volunteers. Journal of Psychopharmacology $1990 ; 4$ : 219.232.

41. Zyhlar G, Saletu B. Hitzenberger $G$, et al. Double-Blind, Placebo-Controlled, Pharmacokinetic and. Dynamic Studies with "Two New Formulations of Piracetam (Infusion and Syrup) Under Hypoxia in Man. Neuropsychopharmacology $1994 ; 10: 1175$. 


\section{Chapter 6}

\section{Caffeine Attenuates Scopolamine-Induced Memory Impairment in Humans*}

Abstract. Caffeine consumption can be beneficial for cognitive functioning. Although caffeine is widely recognized as a mild CNS stimulant drug, the most important consequence of its adenosine antagonism is cholinergic stimulation, which might lead to improvement of higher cognitive functions, particularly memory.

In this study, the scopolamine model of amnesia was used to test the cholinergic effects of caffeine, administered as three cups of coffec. Subjects were 16 healthy volunteers who received $250 \mathrm{mg}$ caffeine and $2 \mathrm{mg}$ nicotine separately, in a placebocontrolled double-blind cross-over design.

Compared to placebo, nicotine attenuated the scopolamine-induced impairment of storage in short-term memory and atcenuated the scopolamine-induced slowing of speed of short-term memory scanning. Nicotine also attenuated the scopolamineinduced slowing of reaction time in a response competition task. Caffeine attenuated the scopolamine-induced impairment of free recall from short- and long-term memory, quality and speed of retrieval from long-term memory in a word learning task, and other cognitive and non-cognirive measures, such as perceptual sensitivity in visual search, reading speed, and rate of finger-tapping.

On the basis of these results it was concluded that caffeine possesses cholinergic cognition enhancing properties. Caffeine could be used as a control drug in studics using the scopolamine paradigm and possibly also in other experimental studies of cognitive enhancers, as the effects of a newly developed cognition enthancing drug should at least be superior to the effects of three cups of coffee.

"Riedel WJ, Hogervorst E, Leboux R. Verlicy FIRJ, Van Prag HM, Jollles I. Psychopharmacology; ith press. 


\subsection{INTRODUGTION}

In recent years, much effort has been put into the development of cognition enhancing drugs to combat syndromes seen in the age-associated cognitive decline and in dementia 151 . This has probably also stimulated interest in the cognitive effects of caffeine and nicotine. These substances have long since penetrated the consumer markets and, possibly as a result of this, knowledge about their acute and long-term effects on cognitive performance in humans by far exceeds what is known about any novel, putarive cognitive enhancer.

The effects of nicotine on cognitive functions have been extensively studied in healthy persons, smokers, non-smokers, subjecrs with scopolamine-induced cholinergic blockade, and in patients with Alzheimer"s Discase (AD) $10,21,28)$. The mechanism by which nicotine exerts its effects on cognition is by agonism of nicotinic acetylcholine receptors. Nicorine might play a role in the prewention of $\mathrm{AD}$ by maintaining cholinergic function better in old age [az).

Improved performance on psychological tasks has also been reported frequently after caffeine intake in normal subjects, even with dosages as low as $32 \mathrm{mg}$ "13n, in well-controlled double-blind studies, whereas only a few studies report detrimental effects on psychological task performance [1\%, 23. The observed effects are described in terms of increased vigilance, arousal, activation. alertness, psychomotor sped, and nood. Learning and memory were improved by caffeine in one study 144] but impaired in a nother [27]. An interesting study describing a positive effect of caffeine on cognitive function, including memory, involved 741.4 people distributed over age groups of about $20,30,40,50$, and 60 years 19. A positive linear relationship existed berween the daily coffee consumption and cognitive performance. Older people appeared to be more susceptible to the performance-improving effects of caffeine than were younger people.

Adenosine antagonism is assumed to be the most important mechanism for explaining the stimulating effects of caffeine on behaviour 17,23 . Potential cognition enhancers include adenosine $A_{1}$-antagonists since inhibitory adenosine $A_{1}$-receptors have been found on cholinergic terminals in the hippocampus and the contex [4]. If this mechanism is involved in caffeine's mode of action, then the cognition enhancing rather than merely the activating properties of caffeine would underlie the beneficial effect of caffeine on learning and memory performance.

In this study we investigated whether caffeine consumption improves memory performance. Despite its known limitations, the scopolamine model of cholinergic dysfunction is a recognized. screening paradigm to assess the memory and cognition enhancing properties of substances proposed to combat the age-associated decline in cognitive performance or dementia of the Axheimer type $11.15,22,29$. We used the scopolamine model to induce cognitive deficits in healthy volunteers. Despire the vast amount of literature describing the psychological effects of caffeine, such a study has, to the best of our knowledge, never been carried out until now. We hyporhesized that the consumption of coffee would reverse or arrenuate the impairing effects of scopolamine, particularly upon memory performance, as compared to the effect of decaffeinated coffee. We also compared the effects of affeine with the known effects of nicotine upon scopolamine-induced cognitive dysfunction 211 , and for this reason double-blind administration of chewing gum with or without nicotine was included as an "acrive drug control".

\subsection{MATERTAL AND METHODS}

\subsubsection{Subjects}

Eighteen healthy wolunteers, balanced for sex, between 25 and 35 years of age were recruited. During the study, wo subjects dropped out, one for reasons unrelated to the study, and the other 
because of adverse effects of scopolamine. All subjects agreed to refrain from taking any form of medication, except orall contraceptives, during the study. All were moderate smokers (11-10 cigarertes / day) and had normal binocular acuity. The female wolunters were ascertained not to be pregnant. Exclusion criteria included any cardiac, hepatic, renal, pulmonary, neurological, gastrointestinal, haematological, or psychiatric conditions, as determined from the history, physical examination, ECG, and rourine labotatory blood sereens, a body weight $10 \%$ outside of population norms, a history of alcohol or drug abuse, excessive drinking ( $>28$ units/week; 1 unir $=$ $12.5 \mathrm{ml}$ pure ethanol), caffeine intolerance, rare or extreme use of caffeine (i.e. $<7$ cups per week or $>10$ cups each day), glaucoma, allergic reactions to cholinergic drugs, and sensory or motor impairments which could reasonably be expected to affect psychomotor performance. The study was approved by the standing Medical Ethics Review Commitree of the Uniwersity and written informed consent was given by all subjects. The subjects were paid for their participation.

\subsubsection{Study Design}

The study was conducted according to a $3 \times 3$ repeated measurements model. The first factor, Drug Treatment, had three levels: placebo, caffeine, and nicotine. This factor was studied according to a 3-period placebo-controlled, double-blind, double dummy, cross -0 ver design. Trearment order was ballanced according to three Latin squares which were randomly assigned wo blocks of six subjects. The second factor, Time after scopolamine administration, consisted of effect measures starting at 2,4 , and 6 hours after scopolamine administration $\left(T_{2}, T_{4}\right.$, and $T_{6}$, respectively). The baseline measure taken one hour before drug creatment was used as a covariate in order to correct for baseline differences.

A few days before the first experimental session, all subjects had individual training sessions in which they were shown and required to practice and to complete all the assessments and tasks used in the study. Then, the subjects participated in three study days which were spaced at least one week apart. The subjects were not allowed alcohol or other CNS drugs from 24 h before the testing sessions began. They were allowed a light caffeine-free (except for one cup of tea) breakfast and were provided lunch on the testing days. No beverages or food containing caffeine, theophylline, or theobromine (coffee; rea, cacao) were allowed during this time until the end of resting:

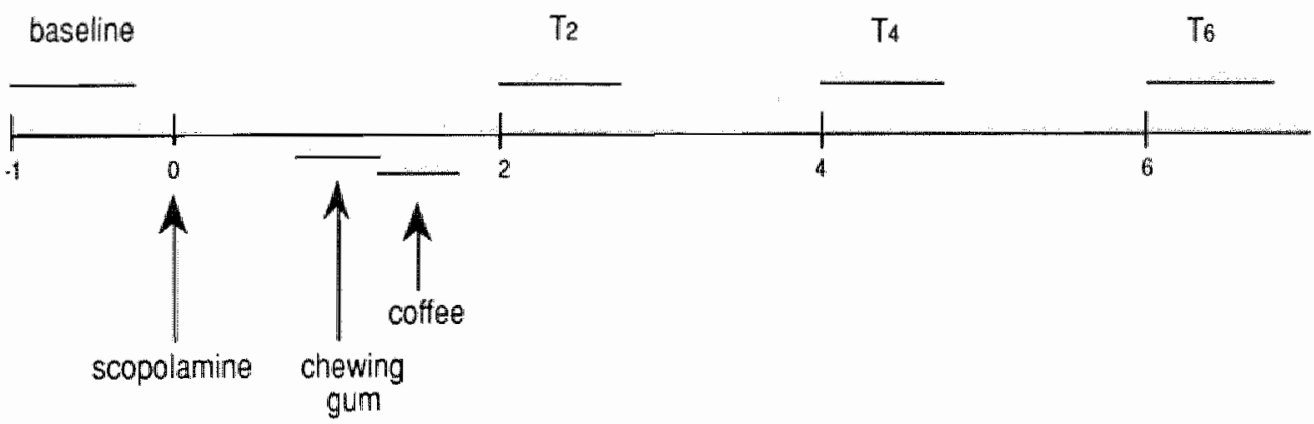

Figure 1 Time course of an experimental session. Assessments (above) and Treatments (below). Numbers refer to hours alter scopolamine administration.

\footnotetext{
These consisted of blurred wision and problems with balance. The scopolamine dose was weight callbrated $0.5 \mathrm{mg}$ $175 \mathrm{~kg}$, and as this subject weighed $90 \mathrm{Kg}$ the actual dose was $0.6 \mathrm{mg}$. Siruce no other subjects over 75 . $\mathrm{Kg} \mathrm{had} \mathrm{scarted}$ the scudy, it was decided to maintain the dose reginen. except that $0.5 \mathrm{mg}$ would be the maximum doset.
} 
On each occasion, scopolamine was imjected subcutaneously in the back of the upper arm. The dose was $0.5 \mathrm{mg} / 75 \mathrm{Kg}$ body weight. On three occasions the subjects received chewing gum containing $2 \mathrm{mg}$ nicotine (Nicoreted) or an identical looking placebo chewing gum and a coffee beverage containing $250 \mathrm{mg}$ caffeine or an identical looking decaffeinated beverage. Chewing gum was given 49 minutes after scopolamine. The subjects were instructed to chew the gum for 30 minures. Immediarely thereafrer they received a thermos flask containing $390 \mathrm{ml}$ of freshly brewed filter coffee. They were asked to drink the coffee within 30 minutes.

Table 1 Treament Conditions

$$
\begin{aligned}
& \text { PLA (scopollamine + placebo chewing gum + decaf) } \\
& \text { NIC (scopolamine + nicotine chewing gum + decaf) } \\
& \text { CAF (scopolamine + placebo chewing gum + coffec) }
\end{aligned}
$$

\subsubsection{Assessments}

The cognitive test battery consisted of several tests that have been shown to be sensitive to the effects of aging [i]. The battery took approximately 45 minutes to complete. All cognitive assessments and the dependent variables are listed in table 2 . We made a distincrion between primary and secondary cognitive outcome measures, because our hypothesis primarily aimed at testing memory effects. The primary outcome variables were measures of memory functions. The secondary outcome variables were measures of perceptual, attentional, psychomotor and executive functions. The following tests were used.

Primary Cognitive Measures: Memory Tasks. Word Learning Test (WLT). One of rwelve parallel lists of 15 monosyllabic meaningful nouns matched for word frequency was presented at a rate of 2 seconds per word. The subjects were asked to read the words aloud as they appeared on a computer screen and to recall verbally as many words as possible as soon as the presentation stopped. This first immediate recall trial was followed by four more trials in which the same words were repeated in the same order. When the fifth trial was completed, the subjects performed the subsequent tasks and after 20 minutes were asked to recall as many of the previously learned words without prompting (delayed recall). The number of correctly recalled words was noted after each trial. The trial yielding the maximum number of recalled words was taken as the dependent wariable (immediate recall). The delayed recall score was the number of words correctly recalled after 20 minutes. A 30-word list containing the initial 15 -word list was presented after 20 minutes and after presentation of each word the subject had to respond "YES / $\mathrm{NO}^{\prime \prime}$ as fast as possible to indicate recognition of the word (delayed recognition). The reaction times were recorded. According to the theory of signal detection 119, the proportion of correctly

2 Coffee was brewed using a Bran Aromaster 22 Compack Filter machine. Distilled water was used to prewent scaling in the coffee machine and to maintain a conswane brew during the 3-month study. The brew was made using $40 \mathrm{~g}$ filter ground coffec (Douwe Lgberts Zilvermerk) per liter of water, yidding $910 \mathrm{ml}$ of coffee. According ro the manufacturer this strength of coffee would yield $643 \mathrm{mg}$ caffeine per liter coffee. In order to calibrate the procedure, samples were sent to the manufacturer to determine the amount of caffeine. The results showed that fiwe different samples contained on awerage $636.5 \mathrm{mg}$ ( $\mathrm{sd}=4.5$ ) of caffeine per liter coffee. Hence, each subject had to drink $390 \mathrm{ml}$ colfee (about three cups) in order to ingest $250 \mathrm{mg}$ caffeine. The decafeinated coffee was brewed the same way using $40 \mathrm{~g}$ of decaffeinated ground coffee (Douwe Egbers Decaf). The ingested amount of decaffeimated coffee would contain about $10 \mathrm{mg}$ caffeine. 
recognized words (cr) and the proportion of falsely recognized (fr) constitute the nomparametric sensitivity measure: $A^{\prime}=1-1 / 4[\mathrm{fr} / \mathrm{cr}+[1-\mathrm{cr}] /[1-\mathrm{fr}]]$. $A^{\prime}$ is in fact the proportion of corredly recognized words, corrected for the subject's response tendency. Because the distribution of $A^{*}$ is skewed due to a ceiling effect. $A^{\prime}$ was aresin transformed before it was tused for statistical analysis.

Memory Scanning. The subjects were briefly shown a set of letters and told to memorize them, This is called the "memory set" [24]. The subjects then saw a series of 144 letrers cqually spaced in a matrix of 12 lines and 12 positions on a sheet of paper. Their task was to decide and respond, as rapidly as possible by marking the letter with a pencil, whether or nor each successive letter was one of those contained in the memory set. This task was performed with memory sets consisting of $1,2,3$, and 4 letters, respectively. Each test sheet contained 24 targets and 120 distractors. The total time needed by the subject to complete each sheet was rimed with a stopwatch. Individual total time $\mathrm{x}$ set size functions were calculated. This funcrion is defined by the equation $\mathrm{T}$ $t=A^{*} S s+B$, in which $T t=$ total time, $A=$ slope of the function (i.e, the amount of extra time needed per item in the memory ser), $S s=$ size of the memory set, and $B=$ intercept with the $Y$-axis. The slope is a measure of the speed of scanning short term memory whereas the intercept measures sensorimotor speed.

Secondary Cognitive Measures: Perception, Psychomotor and Executive Function. Visual Search Task. Dots were presented on a computer screen in a random fashion. Every second two dots changed position. When four dots formed a square, the subject had to push a button as quickly as possible (within 2 seconds). Efficient and rapid wisual search is required to obtain a high signaldetection performance on this task. The perceptual sensitivity measure $A^{\prime}$ was taken as the dependent variable.

Motor Choice Reaction Time Task. The subject held one butron and was asked to press one of five other buttons located equidistantly from the hold button when lit. This yiclded reaction times consisting of an initiation phase (time from stimulus onset until release of the hold button) and a movement phase (time from release of the hold button until the response button is pushed). The response set consisted of pressing the one button that lit up (simple RT), pressing one of three buttons which lit up ( 3 -choice RT), or pressing the button to the right of the lit button (incompatible 3-choice RT) as quickly as possible. Initiation times and movement times thus comprised the dependent variables obtained for each of the three reaction time tasks. This task measures sensorimotor speed, choice-reaccion speed, and choice-reaction speed with response comperition.

Stroop Colour-Word Interference. In subtest $\mathbb{1}, 10$ rows by 10 columns of colour names (red, blue, green, and yellow) were printed in black on white cardboard. In subtest II, the same number of correspondingly coloured patches were printed, and in subtest 111 a number of colour names were printed in incongruously coloured ink. For instance, the word "green" could be printed in red. For card I, the subject was requested to "read the colour names row by row, as fast as possible, without making mistakes'. The time needed to complete the whole card was recorded with a stopwarch. In the second subrest (card II) the instruction was "to name the coloured patches". The third trial (card III) involved naming the collour of the ink the colour words were printed in, without paying attention to the word itself. For each subtest the time taken to finsh the card and the number and type of errors were recorded. Outcome parameters wete: Reading $\left(t_{t}\right)$, Colour $\mathbb{N a m i n g}\left(\mathrm{t}_{1}-\mathrm{t}_{\mathrm{l}}\right)$, and Interference $\left(c_{11}-t_{11}\right)$. The Stroop Colour-Word test is a well-known test for the ease of shifting perceptual sers to conform to changing task requirements, which is indicative of executive function. It also yields measures of reading speed and speed of naming colours.

Tapping. The subject was required to finger-tap a response button as fast as possible during a short period of time ( 30 seconds). The number of taps per second is a measure of psychomotor speed. The test was carried out with the preferred hand.

Physiological Measures. Pulse Rate and Blood Pressure were neasured while the subject was in a relaxed sitring position before the start of each test battery, using an automated vital signs monitor (Dinamap 1800 BP; Critikon Inc. Tampa FL). 


\begin{tabular}{|c|c|c|c|}
\hline Test & Corncept & Dependent Variable & Units \\
\hline \multicolumn{4}{|c|}{ Primany Cognitiut Asseasments (Leaning and Mentar) } \\
\hline \multirow[t]{4}{*}{ Word Learning } & Primary Memory & Immediate Recall & \# of words \\
\hline & Secondary Memory & Dellayed Recall & \# of words \\
\hline & Retrieval & Recognition Sensitivity & proportion \\
\hline & Speed of Rerieval & Recognition RT & msec \\
\hline Memory Scanning & Speed of Scanning in $5 T M$ & Slope of Scanning Function & $\sec$ \\
\hline \multicolumn{4}{|c|}{ Secandary Cognitive Assessments (Infarmation Processing and Psychomotor Speed) } \\
\hline Memory Scanning & Sensorimator Speed & lintercept of Scanning & $\sec$ \\
\hline \multirow{4}{*}{$\begin{array}{l}\text { Signal Detection } \\
\text { Motor Choice RT }\end{array}$} & Virual Search & Perceptual Sensitivity & proportion \\
\hline & Motor Speed & Mowement $\mathbb{R T}$ & insec \\
\hline & Sensorimotor $S_{\text {peed }}$ & Simple RT & msec \\
\hline & Psychomoror Speed & 3-choice RT & msec \\
\hline \multirow{4}{*}{ Stroop } & Response Comperition & Incompatible Choice RT & msec \\
\hline & Vocal Motor Speed & Reading "Time & $\sec$ \\
\hline & Symbol Encoding & Color-Naming Time & $\sec$ \\
\hline & Executive Functio & Incongruent Color-Naming & $\sec$ \\
\hline Tapping & Manual Motor Speed & Number of Taps per Second & $\# / \sec$ \\
\hline
\end{tabular}

Blood Samples were taken by venous puncture to assess concentrations of nicotine, cotinine (an acrive metabolite of nicotine), and caffeine. These were taken 2 hours after scopolamine administration, i.e., 75 and 45 minutes after the start of nicorine and caffeine ingestion, respectively. The determinations of caffeine, nicotine and cotinine concentrations were performed by the Dept. of Clinical Pharmacy of the University Hospital of Maastricht. The method employed was that of high resolution gaschromatography (H.R.G.C.). Detection limits were $<5 \mu \mathrm{g} / 1$ for both nicotine and cotinine. Quantification limits were $<10 \mu \mathrm{g} / \mathrm{l}$ for both nicotine and cotinine and $<200 \mu \mathrm{g} / \mathrm{l}$ for caffeine. Two independent dererminations were made for each sample. Accuracy in series was $96.6 \%, 97 \%$ and $94.3 \%(\mathrm{df}=6)$ for nicorine, cotinine and caffeine, respectively.

Subjective Assessments. Mood was assessed by using the Bond and Lader (3) Mood Rating Scale, which consists of 16 bipolar analogue scales with two opposed mood related adjectives at the ends of the scales. These have been shown to yield three mood factors, alerness, contentedness, and calmness. These factor scores were used as dependent variables, higher values representing greater amounts of each assessment. Subjectively experienced peripheral cholinergic side effects; dry mouth, blurred vision, and nausea were assessed the same way. The Blindness of the subjects towards nicotine and caffeine was checked by means of a Yes/No response to the questions: 'Do you think your chewing gum contained nicotine?' and 'Do you think your coffee contained caffeine?'.

\subsubsection{Statistical Analysis}

Dependent variables were analyzed separately in a repeated measures multivariate and univariate (MANOVA using SPSS 4.0 on Macintosh) analysis of (co)variance, according to a 3 (treatment) $\mathrm{x} 3$ (time) factorial model to test the main effect of treatment and the treatment $\mathrm{x}$ time interaction, using baseline scores as covariates. Besides the multivariate tests, univariate a priori contrast comparisons were carried out between nicotine and placebo, and between caffeine and 
placebo, respectively. The latter were performed overall and separately $T_{2}, T_{4}$ and $T_{6}$. These comparisons were made regardless of the outcome of the corresponding overall $\mathbb{F}$ test. This is a legitimate procedure if the comparisons are buiti into the design or suggested by the theoretical basis of the experiment [3u. Correction for multiple testing was accomplished by using the sequential Bonferron "procedure for adjusting the $\alpha$-probability criterion $4 \cdot 8$,

\subsection{RESULTS}

The subjects could not tell whether they had ingested nicotine or caffeine. The Yes/No distribution was $9 / 7$ for nicotine and $8 / 8$ for caffeine.

Scopolamine adversely affected the performance of the subjects on nearly all tests, particularly the primary outcome measures recognition RT, immediate and delayed recall of word learning and slope of memory scanning, ar $T_{2}$ and $T_{4}$. At $T_{6}$, there were still detrimental effects of scopolamine.
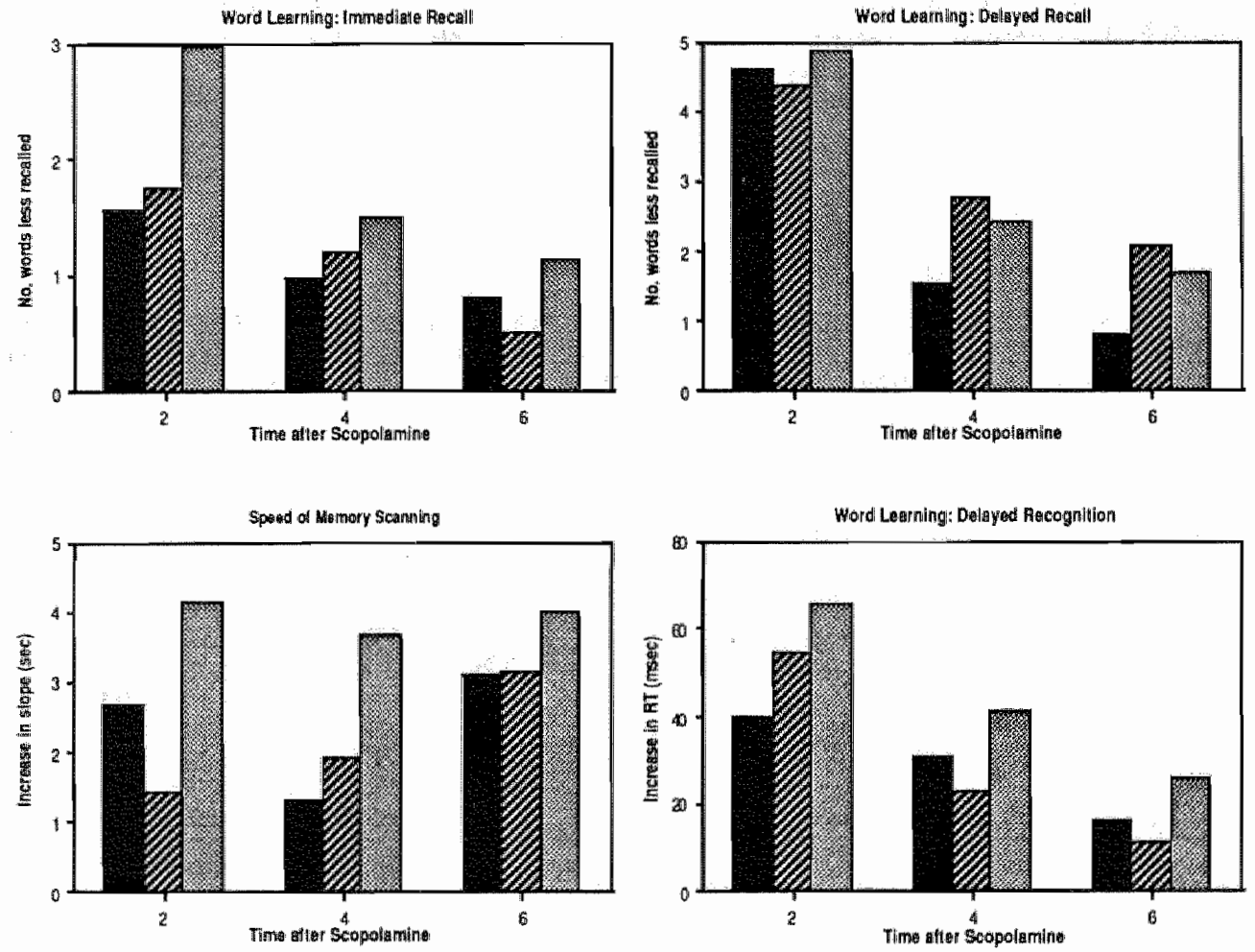

Figure 2 Memory effects of scopolamine+caffeine (biack bars), scopolamine+nicoline (diagonally striped bars), and scopolamine + placebo (grey bars) at $T_{2}, T_{4}$ and $T_{6}$ expressed as deviations from baseline scores. Height of bars worrespond with degree of impairment. 


\subsubsection{Primary Cogntive Measures}

Word Learning. The multivariate treatment effect on Immediate Recall was significant $\left(\mathrm{F}_{3,9}=3.9\right.$, pe.05). Both nicotine and caffeine significandy attenuated the effects of scopolamine on immediate recall $\left(\mathrm{F}_{1,15}=5.4, \mathrm{p}<.05, \mathrm{~F}_{1,15}=6.2, \mathrm{p}<.05\right)$. Mean paired comparisons revealed that this effect was mainly due to a significant decrease in the effect of 5 copolamine at $T_{2}$ elicited by nicotine $\left(\mathrm{F}_{1,15}=5.0, \mathrm{p}<.05\right)$ and by caffeine $\left(\mathrm{F}_{1,15}=6.5, \mathrm{p} \times .05\right)$. There was no multivariate effect of treatment on Delayed Recall. Nicotine had no effect on the scopolamine-induced impairment of delayed recall, whereas caffeine artenuated the scopolamine-induced impairment of delayed free recall at $T_{6}\left(\mathrm{~F}_{1,15}=9.8, \mathrm{p} c .01\right.$; see also figure 2$)$. The multivariate treatment effect on recognition $\mathrm{RT}$ was not significaint. Nicotine had no effect on recognition parameters. Overall, caffeine significantly attenuated the scopolamine-induced decrease in the speed of delayed recognition $\left(F_{1,15}=4.5\right.$. p<.05). This was mainly due to its significant attenuation of the scopolamine-induced slowing of word recognition $\mathrm{RT}\left(\mathrm{F}_{1,15}=9.4, \mathrm{p}<.01\right)$ and its reversal of the scopolaminc-impaired delayed recognition sensitivity at $\mathrm{T}_{2}\left(\mathrm{~F}_{1,15}=7.8, \mathrm{p}<.05\right)$.

Memory Scanning. There was no multivariate treatment effect on speed of memory scanning. Nicotine significantly attenuated the scopolamine-induced slowing of memory scanning $\left(\mathrm{F}_{1,15}=6.1, p<_{i} 05\right)$. This was mainly due to its significant reduction of the scopolamine-induced increased slope of memory scaning at $\mathrm{T}_{2}\left(\mathrm{~F}_{1,15}=13.2, \mathrm{p}<.005\right)$. Caffeine did not affect this parameter.

Table 3 The means and standard errors of the primary outcome measures: Learning and Memory Functions, broken down by 'Treatment (placebo, nicotinc, caffeine)' and 'Time after scopolamine administration (baseline, $T_{2}, T_{4}$, and $\left.T_{6}\right)^{3}$.

\begin{tabular}{|c|c|c|c|c|c|c|}
\hline \multicolumn{3}{|c|}{ Time after Scopolamine Administration } & \multirow{2}{*}{$\frac{\text { baseline }}{\text { mean(sc) }}$} & \multirow{2}{*}{$\frac{\mathrm{T}_{2}}{\operatorname{mean}(\mathrm{se})}$} & \multirow{2}{*}{$\frac{T_{1}}{\operatorname{mean}(s c)}$} & \multirow{2}{*}{$\frac{\mathrm{T}_{6}}{\operatorname{mean}(\mathrm{se})}$} \\
\hline Task & Measure & $\begin{array}{l}\text { sopolamine } \\
+ \text { treatment }\end{array}$ & & & & \\
\hline \multirow[t]{12}{*}{ Word Learning } & Immediare Recall & scopolamine & $14.5(.3)$ & $11.6(.7)$ & $13.0(.6)$ & $13.4(.5)$ \\
\hline & H of Words correct & + nicotine & $14.4(2)$ & $12.6(.7)$ & $13.2(5)$ & $13.9(.5)$ \\
\hline & & + caffeine & $14.6(2)$ & $13.1(.5)$ & $13.7(4)$ & $13.9(.4)$ \\
\hline & Delayed Recall & scopolamine & $13.1(6)$ & $8.2(1.0)$ & $10.6(9)$ & $11.4(.8)$ \\
\hline & \# of Words correct & + nicotine & $13.4(.5)$ & $9.0(.9)$ & $10.6(.9)$ & $11.3(.8)$ \\
\hline & & + caffeine & $13.3(4)$ & $8.7(.8)$ & $11.8(.7)$ & $125(.7)$ \\
\hline & Delayed Recogn. & scopolamine & $88(, 02)$ & $.82(.04)$ & $.82(.04)$ & $91(.02)$ \\
\hline & Sensitivity & + nicotine & $.88(.03)$ & $.86(.05)$ & $.84(.04)$ & $.88(.04)$ \\
\hline & (proportion) & + caffeine & $.91(.02)$ & $.91(.02)$ & $.86(.02)$ & $.92(.02)$ \\
\hline & Recognition speed & scopolamine & $578(13)$ & $644(12)$ & $619(14)$ & $604(12)$ \\
\hline & $\mathrm{RT}^{\top}$ (msec) & + nicotine & $580(15)$ & $635(22)$ & $603(16)$ & $591(13)$ \\
\hline & & + caffeine & $575(15)$ & $615(12)$ & $606(11)$ & $591(11)$ \\
\hline \multirow[t]{6}{*}{ Memory Scanning } & Slope & scopolamine & $10.2(1.2)$ & $14.4(1.3)$ & $13.7(1.4)$ & $14.0(1.5)$ \\
\hline & time (sec) & + nicotine & $10.2(0.8)$ & $12.0(1.1)$ & $12.6(1.3)$ & $13.4(1.0)$ \\
\hline & & + caffeine & $10.3(1.2)$ & $13.6(1.5)$ & $12.0(1.3)$ & $13.6(1.0)$ \\
\hline & Intercept & scopolarnine & $19.8(0.9)$ & $20.8(1.2)$ & $22.1(1.0)$ & $20.2(1.0)$ \\
\hline & time (sec) & + nicotine & $18.8(0.9)$ & $21.1(1.3)$ & $22.5(1.0)$ & $19.6(1.0)$ \\
\hline & & + caffeine & $19.4(0.8)$ & $19.2(1.1)$ & $23.3(1.3)$ & $19.3(1.1)$ \\
\hline
\end{tabular}




\subsection{Secondary Cognitive Measures}

Visual Search. Nicotine did not affect this parameter. Overall, calfeine attenuted the scopolamine-induced decrement in perceptual sensitivity of visual search $\left(F_{1,15}=6,5, p<.05\right)$. This was probably due to its attenuation of the scopolamine-induced impairment at $T_{\$}$ and $T_{6}$ respectively. This effect was not statistically significant:

Motor Choice Reaction Time. Nicotine significantly attenuated the scopolamine-induced slowing of the initiation time in the incompatible 3-choice $R T$ task at $T_{2}\left(F_{1,5}=13.7, p<.005\right)$. Nicotine had no effect on either the initiation time or the movement time which was slowed by scopolamine in the simple RT and choice RT tasks. Caffeine had no effect on any of the scopolamine-induced decrements in simple RT, choice RT, and incompatible choice RT.

Stroop. Nicotine significantly reversed the slowing effect of scopolamine on colour-naming time at $T_{2}\left(F_{1,15}=6.7, p<, 05\right)$. Nicotine had no effect on reading time and interference. Caffeine attenuated the scopolamine-induced slowing of reading time at $T_{2}\left(F_{1,15}=12.2, p<.005\right)$, but had no effect on colour-naming time and interference.

Tapping. Nicotine did not affect the finger-tapping rate. The scopolamine-induced decrease in the number of taps per second was significantly attenuated by caffeine at $T_{4}\left(F_{i, 15}=6.4, p<.05\right)$.

Table 4

The means and scandard errors of the secondary outcome measures: Perceptual "Psychomotor and Executive Functions, broken down by "Treatment" and "Time after scopolamine administration",

\begin{tabular}{|c|c|c|c|c|c|c|}
\hline \multicolumn{2}{|c|}{ Time after Scopolamine Adminustration. } & \multirow{2}{*}{$\begin{array}{l}\text { scopolamine } \\
+ \text { treacment }\end{array}$} & \multirow{2}{*}{$\begin{array}{l}\text { baseline } \\
\text { mean(se) }\end{array}$} & \multirow{2}{*}{$\frac{T_{2}}{\text { meaud (se) }}$} & \multirow{2}{*}{$\frac{\mathrm{T}}{\operatorname{menn}(\mathrm{xe})}$} & \multirow{2}{*}{$-\frac{\mathrm{T}_{6}}{\operatorname{mean}(\mathrm{se})}$} \\
\hline Task & Measure & & & & & \\
\hline \multirow[t]{3}{*}{ Wistual Search } & Perceptual & scopolamine & $.89(.02)$ & $82(.04)$ & $.83(.03)$ & $.85(.03)$ \\
\hline & Sensitivity & + nicotine & $88(.03)$ & $83(.03)$ & $.82(0,04)$ & $.85(.04)$ \\
\hline & (proportion) & + calffeine & $.90(.02)$ & $86(.02)$ & $.87(.03)$ & $.89(.02)$ \\
\hline \multirow[t]{12}{*}{ Choice Reaction } & Simple RT (msec) & scopolamine & $281(4)$ & $297(6)$ & $288(7)$ & $276(6)$ \\
\hline & & + nicotine & $278(5)$ & $295(7)$ & $284(6)$ & $273(6)$ \\
\hline & & * caffeine & $275(4)$ & $293(7)$ & $282(6)$ & $276(6)$ \\
\hline & 3-Choice RT (msec) & scopolamine & $324(6)$ & $352(9)$ & $350(10)$ & $333(10)$ \\
\hline & & + nicotine & $329(8)$ & $351(12)$ & $341(8)$ & $329(6)$ \\
\hline & & + caffeine & $316(6)$ & $333(9)$ & $340(8)$ & $333(9)$ \\
\hline & Response Compering & scopolaminc & $396(12)$ & $423(15)$ & $421(16)$ & $405(15)$ \\
\hline & 3. Coice RT (nisec) & + nilleotine & $394(15)$ & $409(15)$ & $411(15)$ & $398(14)$ \\
\hline & & + caffene & $386(10)$ & $426(16)$ & $412(14)$ & $396(14)$ \\
\hline & Movement time & scopolamine & $102(3)$ & $122(5)$ & $118(5)$ & $118(5)$ \\
\hline & (mised) & + ruicotine & $106(3)$ & $123(5)$ & $122(6)$ & $113(5)$ \\
\hline & & + caffeine & $102(3)$ & $116(4)$ & $115(4)$ & $114(4)$ \\
\hline \multirow[t]{9}{*}{ Stroop } & Reading & scopolamine & $34.3(1.2)$ & $36.5(1.3)$ & $35.4(1.4)$ & $35.3(1.3)$ \\
\hline & rime (sec) & + nicotine & $34.7(1.0)$ & $36.0(1.3)$ & $35.0(1,1)$ & $34.3(1.2)$ \\
\hline & & * caffeine & $3 \times 4.5(0.8)$ & $35.0(1.2)$ & $34.6(1.2)$ & $34,0(0.9)$ \\
\hline & Color Naming & scopolamine & $11.4(1.4)$ & $12.8(1.5)$ & $9.6(1.3)$ & $10.2(0.8)$ \\
\hline & extra time (sec) & + nicotine & $11.0(1.4)$ & $10.2(1.4)$ & $11.1(1.7)$ & $10.6(1.2)$ \\
\hline & & + caffeine & $9.9(1.4)$ & $11.6(1.6)$ & $9.5(1.3)$ & $9.1(1.5)$ \\
\hline & Interference & scopolamine & $20.2(1.5)$ & $23.7(25)$ & $23.1(1.8)$ & $22.8(2.6)$ \\
\hline & excra cime (sec) & + nicotine & $15.4(1.5)$ & $23.9(1.5)$ & $21.6(1.9)$ & $19.4(1.6)$ \\
\hline & & + calfeime & $19.6(2.2)$ & $23.8(2.2)$ & $25.0(3.4)$ & $23.1(2.5)$ \\
\hline \multirow[t]{3}{*}{ Tapping } & Preferred Hand & scapolamine & $6.85(.08)$ & $6.25(.08)$ & $6.35(.09)$ & $6.64(.08)$ \\
\hline & of taps/sec & + nicotine & $6.78(05)$ & $6.24(.08)$ & $6.36(11)$ & $6.66(006)$ \\
\hline & & + caffeine & $6.92(.09)$ & $6.37(.10)$ & $6.57(.09)$ & $6.71(0.9)$ \\
\hline
\end{tabular}




\subsubsection{Vital Signs}

Blood Presure and Heart Rute. There was a multivariate effect of treatment on systolic blood pressure $\left(\mathrm{F}_{3.2 \mathrm{~g}}=6,4, \mathrm{p}<.05\right)$. Nicotine did not significantly affect any of the scopolamine-induced alterations of cardiowascular parameters. Caffeine significantly atrenuated the scopolamineinduced decrease in systolic blood pressure $\left(\mathrm{F}_{1,15}-14,3, \mathrm{pc}, 005\right)$, at $\mathrm{T}_{4}\left(\mathrm{~F}_{1,15}=8.9, \mathrm{p}<.01\right)$ and $\mathrm{T}_{6}$ $\left(\mathrm{F}_{1,15}=18.9, \mathrm{p}<.001\right)$, but had no eftect on the scopolamine-induced decrease in diastolic blood pressure and heart rate.

finties 5

"The means and standard crors of the Plusiological Measures, broken down by "Ireatment" and "lime after sopolamine administration".

\begin{tabular}{|c|c|c|c|c|c|c|}
\hline \multicolumn{3}{|c|}{ Time after Scopolamine Administraton } & basuline & $\mathrm{T}_{2}$ & $\mathbb{T}_{4}$ & $\mathrm{~T}_{6}$ \\
\hline Task & Measure & * treament & meart(se) & $\operatorname{mean}(s \mathrm{~s})$ & $\operatorname{mean}(\mathrm{se})$ & mean (se) \\
\hline \multirow[t]{6}{*}{ Blood Pressure } & Sysitolic & scopolanine & $126.3(2.5)$ & 113.62 .6 & $113.2(2.4)$ & $111.4(3.1)$ \\
\hline & $\left(\mathrm{mm} \mathrm{H}_{\mathrm{g}}\right)$ & + micotine & $120.9(2.2)$ & $115.9(2.8$ & $116.8(2.1)$ & $112.3(2.5)$ \\
\hline & & + caffeine & $123.7(2.2)$ & $118.3(2.9)$ & $120.2(2.7)$ & $118.6(2.5)$ \\
\hline & Diastolic & scopolamine & $61.1(2.0)$ & $57.7(3.2)$ & $50.7(2.0)$ & $52.3(2.2)$ \\
\hline & $(\mathrm{mm} \mathrm{Hg})$ & + nicotine & $60.8(2.0)$ & $57.3(2.4)$ & $52.4(2.0)$ & $52.9(2.3)$ \\
\hline & & * caffeine & $60.9(2.3)$ & $60.6(2.3)$ & $53.4(2.2)$ & $54.6(1.9)$ \\
\hline \multirow[t]{3}{*}{ Heart Rare } & Beats / min. & scopolamine & $68.2(2.5)$ & $523(2.0)$ & $57.8(2.2)$ & $57.6(2.0)$ \\
\hline & & + nicotine & $67.7(2.9)$ & $56.4(3.0)$ & $60.4(3.1)$ & $60.3(2.9)$ \\
\hline & & * caffeine & $66.6(3.3)$ & $51.1(2.0)$ & $55.4(1.8)$ & $55.9(1.8)$ \\
\hline
\end{tabular}

\subsubsection{Subjective Measures and Blood Levels}

Peripheral Side effects and Mood Scales. Scopolamine-induced side-effect and mood ratings were not significandy affected by nicotine or caffeine.

Blood levels. The mean blood level of caffeine was $5339 \mu \mathrm{g} /$ in the caffeine condition, but 775 and $737 \mu \mathrm{g} / \mathrm{l}$ in the nicotine and placebo conditions, respectively. The difference was highly significant $\left(\mathrm{F}_{2,1}=68.2, \mathrm{p}<.0001\right)$. Cotinine blood levels were not significantly difterent (129, 126, and $113 \mu \mathrm{g} / \mathrm{l}$ in the nicotine, placebo, and caffeine conditions, respectively). Nicotine was detected in only 6 of the 16 subjects who received nicotine chewing gum and was detected 4 of the 32 times that placebo chewing gum was administered.

The nicotine and cotinine blood levels over the various conditions did not seem very clearly to confirm the presence of nicotine administered via chewing gum. However, the low incidence of detection of nicotine in the blood after the administration of nicotine $2 \mathrm{mg}$ in chewing gum, can be explained to a great deal. Benowitz et al. $|x|$ showed that the administration of nicotine $4 \mathrm{mg}$ chewing gum yielded a curve with nicotine concentrations varying between 7 and $11 \mu \mathrm{g} / /$ from 30 to 90 minutes after the end of the administration period. In our study, blood was taken 45 minutes after the end of the chewing period. Since we administered only $2 \mathrm{mg}$ of nicotine, we might expect, roughly, blood nicotine concentrations between 3.5 and $5.5 \mu \mathrm{g} / \mathrm{l}$ if we divide those reported by Benowitz et al. by two. However, our detection limit of nicotine in the blood was 5 $\mu \mathrm{g} / \mathrm{l}$ and the quantification limit was $10 \mu \mathrm{g} / \mathrm{l}$. Of the 6 correct nicotine detections only one was > $10 \mu \mathrm{g} / \|(12.7 \mu \mathrm{g} / \mathrm{l})$ and of the 4 false nicotine detections none were $>10 \mu \mathrm{g} / \mathrm{l}$. So, with respect to the detection of nicotine, the results do not seem to deny the absorption of nicotine. The nicotine dose administered was a very small one and therefore difficult to detect with the merhod used. 
The means and siandard criors of the Subjecrive Assesments broken down by "Treatment" and "Time afer scopolarnine administration".

\begin{tabular}{|c|c|c|c|c|c|c|}
\hline \multicolumn{2}{|c|}{ Time after Scopolamine Administration } & \multirow{2}{*}{$\begin{array}{l}\text { scopolamine } \\
\text { * treatment }\end{array}$} & \multirow{2}{*}{$\frac{\text { baseline }}{\text { mean(se) }}$} & \multirow{2}{*}{$\frac{r_{2}}{\operatorname{mean}(\mathrm{se})}$} & \multirow{2}{*}{$\frac{T_{4}}{\operatorname{mena}(s e)}$} & \multirow{2}{*}{$\frac{\mathrm{T}_{6}}{\operatorname{mean}(\mathrm{se})}$} \\
\hline Task & Measure & & & & & \\
\hline \multirow[t]{8}{*}{ Peripheral Effects } & Dry Mouth & scopolamine & $35.7(5.7)$ & $80.8(5.7)$ & $56.9(4.7)$ & $44.3(5.7)$ \\
\hline & $\begin{array}{l}(0-100) \\
(r=70)\end{array}$ & + nicotine & $32.3(4.9)$ & $78.2(5.7)$ & $\begin{array}{l}58.2(5.5) \\
58.475\end{array}$ & $45.3(6.1)$ \\
\hline & $\begin{array}{l}(r=70) \\
\text { Blurred Vision }\end{array}$ & $\begin{array}{l}\text { + caffeine } \\
\text { scopolamine }\end{array}$ & $\begin{array}{l}32.5(5.9) \\
16.9(4.4)\end{array}$ & $\begin{array}{l}84.8(3.6) \\
51.4(7.2)\end{array}$ & $\begin{array}{l}58.4(7.5) \\
44.5(2.8)\end{array}$ & $\begin{array}{l}43.6(5.7) \\
38.0(8.4)\end{array}$ \\
\hline & $(0-100)$ & + nicotine & $24.7(5.5)$ & $54.4(6.7)$ & $50.17 .9)$ & $44.7(7.2)$ \\
\hline & $(r=85)$ & * caffeine & $19.1(4.9)$ & $47.0(8.0)$ & $46.1(8.5)$ & $43.0(8.5)$ \\
\hline & Nausea & scopolamine & $15.7(4.4)$ & $49.0(5.4)$ & $41.6(6.9)$ & $34.4(5.5)$ \\
\hline & $(0-100)$ & + nicotine & $19.0(4.4)$ & $44.3(7.5)$ & $44.3(5.7)$ & $43.7(8.2)$ \\
\hline & $(r=.59)$ & + caffeine & $23.0(5.0)$ & $63.9(7.2)$ & $39.1(6.4)$ & $44.1(7,9)$ \\
\hline \multirow[t]{9}{*}{ Mood Scales } & Alertness & scopolamime & $65.2(4.4)$ & $40.7(2.7)$ & $47.1(3.8)$ & $47.9(3.6)$ \\
\hline & $(0-100)$ & + gicotine & $67.4(3.5)$ & $35.5(4.1)$ & $43.5(4.1)$ & $49.6(3.9)$ \\
\hline & $(r=.56)$ & + caffeine & $73.5(3.0)$ & $41.4(3.5)$ & $49.5(4.2)$ & $527(3.5)$ \\
\hline & Contentment & scopolamine & $69.0(3.3)$ & $63.4(3.3)$ & $64.6(3.8)$ & $67.9(3.5)$ \\
\hline & $(0-100)$ & + nicotine & $74.7(3.5)$ & $60.7(3.3)$ & $64.0(3.7)$ & $65.1(3.5)$ \\
\hline & $(\pi=.53)$ & + caffeine & $75.3(3.1)$ & $65.4(3.6)$ & $68.2(3.5)$ & $68.8(4,1)$ \\
\hline & Calmness & scopolamine & $72.4(4.8)$ & $64.2(4.8)$ & $67.3(3.0)$ & $69.3(3.2)$ \\
\hline & $(0.100)$ & + nicotine & $71.8(4.0)$ & $68.3(3.8)$ & $65.4(3.5)$ & $60.8(4.2)$ \\
\hline & $(r=.57)$ & + caffeine & $72.5(3.1)$ & $64: 8(3.8)$ & $69.8(3.7)$ & $65.2(4.3)$ \\
\hline
\end{tabular}

On the other hand, in order to explain the 4 faulty detections of nicotine, we have to ask ourselves the question whether this could have been caused by high nicotine levels obtained during the previous day, or whether we can prove with reasonable certainty that this was caused by a protocol violation: i.e. smoking before the experiment began. With regards to the latter: there was continuous supervision of the subjects starting three hours before the blood sample was taken, i.e. one hour before scopolamine and two hours before the active treatment was administered. The possibility of smoking before that time, can not be excluded however. Neither can it be excluded that smoking during the previous day led to the detection of nicotine in the blood. Nicotine which has a half-life of 2 hours, accumulates over the first $6.8 \mathrm{hr}$ of regular smoking, and persists at significant levels for $6.8 \mathrm{hr}$ after cessation, which is overnight if a smoker conrinues to smoke until bedtime [231. Smoking 10 cigarettes in the evening may in this manner lead ro a (faulty) detection of nicotine the next day. Cotinine has a half-life of 19 hours and hence, its levels may reflect smoking habits much more than they may reflect absorption of the treatment administered. In fact, the correlations of cotinine blood levels with the reported number of cigarettes smoked daily (varying from 2 to 10$)$, appeared to be .75 ( $\mathrm{p}<001), .71$ ( $<<.005)$, and .68 ( $\mathrm{p}<, 005)$ in the placebo, affeine, and nicotine conditions, respectively.

\subsubsection{The effect of Treatment Order}

The possibility that learning effects over the sessions influenced the results needs to be considered because the intended complete order balancing of the design was compromised by the two subjects that dropped out. If learning had taken place, it could possibly explain some of the drug effects, particularly the effect of caffeine upon delayed recall, in which performance after caffeine appeared to return to baseline sooner than after nicotine and placebo. Did the learning effect increase the baseline? We studied this possibility as follows: the distriburion of treatment order 
over sessions $1 / 2 / 3$ yielded $n=5 / 5 / 6$ for both caffene and nicotine and $n=6 / 6 / 4$ for placebo. When caffeine was administered at the first or second session, the baseline score one week later was taken as a "reversall to baseline score". The same procedure was applied to construct the nicotine and placebo "reversal to baseline scores". It transpired that baseline scores of delayed recall had increased over one week for placebo (1.0), nicotine (0.9), and caffeine (1.2). This means that a learning effect ower one week had indeed occurred but the difference between drug conditions was only minimal, indicating that not only the caffene baseline but also the placebo baseline increased.

We also analyzed the "reversal to baseline scores" for immediate recall (placebo: 0.3; nicotine: 0.6 ; caffeine: 0.1 ) and slope of memory scanning (placebo: 0.8 ; nicotine: -0.5 ; caffeine: 0.9 ). The difference between placebo and nicotine in the latter would amplify racher than diminish the offect of nicotine observed at $\mathbb{T}_{2}$ for this parameter. Therefore we concluded that very small learning effects might have occurred, but that they did not influence the results pertaining to the caffeine and nicotine placebo comparisons.

Table 7

Comparison of the magnitude of effects of different cogruition entancing substances on the scopolamine-induced memory deficit on immediate and delayed recall of word lists.

\begin{tabular}{|c|c|c|c|c|c|c|c|c|c|}
\hline \multirow{2}{*}{$\begin{array}{l}\text { Study substance } \\
\text { and dosgae } \\
\text { aniracetam } 1500 \mathrm{mg}\end{array}$} & \multicolumn{2}{|c|}{$\begin{array}{l}\text { Scop dose Time } \\
\text { formulationafter Scop }\end{array}$} & $\begin{array}{l}\text { Memory Test } \\
\text { (words/trials) }\end{array}$ & \multicolumn{2}{|c|}{$\begin{array}{r}\text { Baseline } \\
\text { Recallscore }\end{array}$} & $\begin{array}{l}\text { Scop. } \\
\text { deficit }\end{array}$ & \multicolumn{2}{|c|}{ attenuation } & Reference \\
\hline & $0.7 \mathrm{migs}$ s.c. & $3 \mathrm{~h} 20^{\prime \prime}$ & Buschke $(1 / 4 / \mathrm{n})$ & $\mathrm{LTR}$ & 353 & 20.9 & 2.7 & $13 \%$ & [30 \\
\hline TRH $0.5 \mathrm{mg} / \mathrm{kg}$ i.v. & $0.50 .75 \mathrm{mg} \mathrm{i.v}$ & $\ln 30^{\circ}$ & Buschke $(12 / 8)$ & $\mathrm{IR}_{\mathrm{R}}$ & 9.3 & 3.4 & 1.1 & $32 \%$ & $\mid \omega 6\}$ \\
\hline micotine $1.5 \mathrm{mg} \mathrm{p} \mathrm{p}_{*} \mathrm{c}$ & $1.2 \mathrm{mg}$ p.o. & $\ln 30^{3}$ & $\operatorname{Rey}(10 / 4)$ & $\mathrm{IR}$ & 8.3 & 0.7 & 0.2 & $29 \%$ & {$[21]$} \\
\hline * & - & $1 \mathrm{~h} 3 \mathrm{O}^{\circ}$ & $\operatorname{Rey}(30 / 4)$ & $M R$ & $16 n 1$ & 2.1 & -0.1 & $-5 \%$ & \\
\hline oxiracetam $800 \mathrm{mg}$ & $0.5 \mathrm{mg} 5.0$. & 3h & Rey $(20 / 3)$ & $\mathbb{R}$ & $31: 2$ & 13.5 & 1.8 & $13 \%$ & $\{20\}$ \\
\hline 4 & & $3 \mathrm{n}$ & & DR & 13.5 & 7.8 & 2.5 & $32 \%$ & \\
\hline oxirnacetam $1600 \mathrm{mg}$ & $"$ & $3 \mathrm{~h}$ & .6 & $\mathrm{IR}$ & 31.2 & 13.5 & 2.7 & $20 \%$ & \\
\hline " & $*$ & $3 \mathrm{~h}$ & " & $D \mathbb{R}$ & 13.5 & 7.8 & 4.8 & $* 62 \%$ & \\
\hline nicotine $2 \mathrm{mg}$ & $0.5 \mathrm{mg} / 75 \mathrm{~kg} \mathrm{s.c.}$ & $2 \mathrm{~h}$ & $\operatorname{Rey}(15 / 5)$ & $\mathbb{I R}$ & 14.5 & 2.9 & 1.1 & $38 \%$ & [this arodty] \\
\hline a & & $2 h$ & & DR & 13.1 & 4.9 & 0.5 & $10 \%$ & \\
\hline caffeine $250 \mathrm{mg}$ & " & $2 \mathrm{~h}$ & "is & $I R$ & 14.5 & 29 & 1.4 & $48 \%$ & \\
\hline$"$ & is & $2 \mathrm{~h}$ & " & $\mathrm{DR}$ & 13.1 & 49 & 0.3 & $6 \%$ & \\
\hline
\end{tabular}

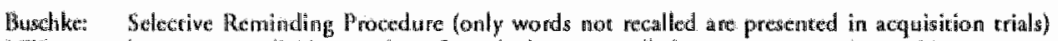

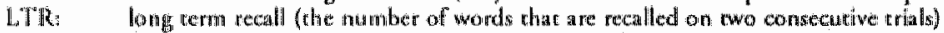

in The swective reminding procedure was done until the whole list was remembered on 6 consecutive occastons

Rey: Repeatud acquisition vrials (immedire recall: IR) followed by aldayed recall trial (DR) withoux presentation

*- This atcentuation was significant

\subsubsection{Effect sizes}

The treatment effects of caffeine and nicotine were significant on several parameters, but the size of these effects was generally small. Because the treatment effects of caffeine and nicotine were both significant for the immediate recall of the 15 word list, and because most studies investigating cognition entancers with the scopolamine model have used word lists, we set out to compare the magnitudes of these results with those obtained in similar scopolamine studies. The result of this corraparison is listed in rable 7. We calculated the absolute difference scores and percentages of change obtaned after the administrarion of a putative cognirive enhancer to combat the effects of scopolamine. Since different studies use different word lists with different lengths and different amounts of presentation rrials, some difficulties may arise as to the comparison of 
absolute values of treatment effects. As can be concluded from the results shown in table 7 , the absolute attenuation scores of the scopolamine-induced deficits in word recall obtained in our study after caffeine and nicotine are indeed small, but do not deviate drastically from (significant) results obtained in other studies wich putative cognitive enhancers such as the neuropeptide TRH $[16$, and the nootropic substances aniracetan $[30]$, and oxiracetam [20].

\subsection{DISCUSSION}

To the best of our knowledge, this is the first study demonstrating the effects of caffeine on memory in humans, as assessed with the scopolamine model of cholinergic blockade.

Before further interpreting the effects, several issues need to be addressed. First, the size of the treatment effect. As was shown in table 7 , the effect sizes of caffeine and nicotine in immediate recall memory were rather small, but there have been several other similar studies reporting effect sizes that were within the same range. Several factors influence the size of the treatment effect. The size of the scopolamine effect is probably determined by the dosage given and also by its route of administration. It is likely that the fairly large scopolamine effect in the study by Wesnes et al. 1301 was associated with the relatively high dose of scopolamine. The larger the scopolamine effect, the more room for improvement to be induced by a cognitive enhancing substance. The other major factor that determines the size of treatment effects is the presence of ceiling effects in the tests used. It is fairly obvious that the immediate recall score obtained in the baseline condition of our study could hardly be improved further. Rusted and Eaton-Williams ${ }^{211}$ showed that longer word lists of 30 , rather than 10 words, permit greater sensitivity for measuring improving effects of nicotine. However, we did not intend to measure cognition enhancing effects of nicotine and caffeine per $s e_{x}$ but only those apparent as an atrenuation of the scopolamine effect and hence the sensitivity of our method wholly depended on the presence, and size, of scopolamine effects. For that reason a true ceiling effect was perhaps only apparent in the measure of recognition sensitivity, with which the scopolamine effect was small and hence did not leave much room for atrenuation. Surprisingly, on this measure, a statistically significant effect of caffeine was found. So, eventual ceiling effects apparently did nor render the design insensitive. However, it is difficult to generalize from small significant effects, to any clinically relevant ones. For that reason, the most important finding among the results presented here is the novelty of the finding of caffeine's effect on memory in the scopolamine paradigm. In future studies on the memory enhancing effects of caffeine, we should take factors associated with effect size, such as the possibility of ceiling effects and word list length, into account. Another important point concerning the impact of even a small significant effect of caffeime on memory performance, is that caffeine is consumed daily, through the consumption of coffee and tea, by millions of people all over the world in!.

The question whether we had a real nicotine condition is an actual one, because of the difficulty in discriminating nicotine from placebo on the basis of nicotine and cotinine blood concentrations. Since it can not be excluded that subjects did actually smoke on the morning before the experiment, perhaps measures ought to be taken in future experiments to prevent this problem. We tried to do this by selecting irregular smokers. The reason was threefold. Firsty, it was considered unethical to administer nicotine to people who never used it. Secondly, subjects had to be familiar with the effects of nicotine, to a certain extent, to avoid adverse effects. Thirdly, subjects had to be used to abstaining from nicotine for a relatively long period. We thought this would only be possible in subjects who have a very low frequency of habitual use. It was difficult to find enough subjects who would fullul the criterion of smoking no more than 5 cigarettes per day and therefore we decided to include subjects with reported smoking frequencies of up to 10 cigarettes per day. To prevent the nicotine detection problem in furure experiments of this kind, it might be better to pursue the subject inclusion criterion of a maximum reported smoking frequency of no more than 5 cigarettes per day. The question whether we had a real nicotine condition is in the end 
answerced by the performance data. There was evidenty an active nicotine condition, but it could have been berter.

It appeared that the effects of nicotine were present at $T_{2}$ only while those of caffeine were distribured wet $T_{2}, T_{4}$ and $T_{6}$. The lack of effect of nicotine at $T_{4}$ and $T_{6}$ is probably due to its shorter half-life 17 . Furthermore; it is possible that the effects of caffeine last longer than those of scopolamine and hence some effects of caffeine emerge at $T_{4}$ and $T_{6}$. This is most clearly seen with the caffeine-induced reversal of the scopolamine-induced decrease in systolic blood pressure at $T_{4}$ and $T_{5}$ and with the caffeine-induced attenuation of the scopolamine-induced delayed recall deficit in word learning;

The memory enhancing effects of caffeine wrere of a different nature than those of nicotine. Gaffeine had a more pronounced effect on parameters reflecting speed and quality of delayed recognition of learned words, whereas nicotine seemed to facilitate working memory capacity, as seen by its artenuation of scopolamine-induced slowing of rate of memory scanning and incompatible choice reaction time. Most behavioral studies on the effects of caffeine in humans have suggested that caffeine acts as a CNS stimulant. However, the specificity, in terms of amnesic relative to its sedative effects, of the scopolamine model has been queried [21]. Despite this, the most pronounced effects of scopolamine on behaviour are consistently reported to be on memory function. Although we found scopolamine to have marked effects on non-memory parameters, such as tapping rate and movement time in choice reaction, the rather pronounced effects of scopolamine on immediate and delayed recall and recognition as well as on the rate of memory scanning seem to confirm the effects of scopolamine on memory processes as reported in the literature.

If caffeine were to act primarily as a CNS stimulant, one would have anticipated a different pattern of results, i.e., a more pronounced attenuation of the scopolamine-induced slowing of the finger-tapping rate, because caffeine alone is reported specifically to increase the tate of finger tapping ${ }^{6}, 29$, and also an attenuation of the scopolamine-induced increase in movement time in the reaction time tasks. Caffeine would have been expected to increase speed in cognition tests rather than improve qualitative scores of cognitive performance, such as free recall of words and perceptual sensitivity of word recognition and signal detection. The effects of caffeine on these latter parameters therefore seem to confirm our hypothesis that, at least when there is cholinergic dysfunction, caffeine acts as a cognition enhancer rather than a CNS stimulant.

In conclusion, our data indicate that caffeine has specific memory-enhancing properties and acts, at least partly, through cholinergic pathways. This raises the possibility that caffeine might be a protective factor against age-associated cognitive decline or even dementia. Another implication of our results is that many reports of the cholinergic effects of putative cognition enhancers, as asessed with the scopolamine model, should be read with caution. After all, we found that most of these effects could also be obtained by drinking three cups of coffee. We suggest therefore that caffeine should be used as a control drug in future scopolamine trials of putative cognition. entuncers.

\section{REFERENCES}

1. Barcus RT, Dean RL, Pontecorvo MJ, Flicker C. The cholinergic hypothesis: A historical overwiew, current perspective, and future direcrions. Annills of the New York Academy of Sciences 1985; 444.

2. Benowitz NL. Porcher H, Shiener L. Peyton JI. Nicoxine absorption and cardiovascular effects with smokeless tobacco use: Comparison with cigaretes and nicotime gum. Clin Pharmacol Ther 1988; 44: $23-38$.

3. Bond $A_{n}$ lader $M$. The use of aralogue wcales in rating subjective feelings. British Journal of Medical Psychology 1974; 80: 1.46;

4. Briley M. Biochemical strategies in the search for cognirion enhancers. Pharmacopsychiatry $1990 ; 2: 75-80$.

5. Cacabelos $R_{n}$ Nondberg $A$, Gamano J, er al. Molecular strategies for the firse generations of antidementia drugs (1). Tacrine and relared compounds. Drags of Today 1994:30:295-337. 


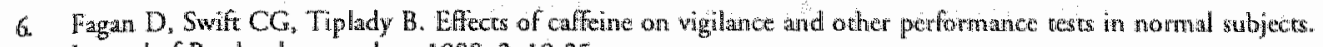
Journal of $\mathbb{P}$ sychopharmacology $1988 ; 2$ : 19-25.

7. Gilman AG, Rall TW, Nies AS, Taylor P, ed. Goodman and Gitman's The pharmalogical Basis of Therapeutics. 8th ed. Mew York: Pergamon Press, 1990 .

8. Houx PJ. Cognitive aging and health-relaced factors. Maarrichr: Durawyse, 1991.

9. Jarwis M. Does caffeine intake enhance absoluce levels of cognitive pertomance Psychopharmacology 199 ; $110: 45-52$.

10. Jones $\mathrm{GMM}$, Sahakian BJ, Warburton DM, Grry JA. Effects of acute subcutancous nicotine on atkention, information processing and short-werm memory in Alzheimer's disease. Psychopharmncology 1992; 108: 485494.

11. Klatsky Al, Armstrong MA, Friedman GD. Coffec, Tea, and Mortalizy. Annals of Epidemiology 1993; $3: 375$ 381.

12. Levin ED. Nicosinie systems and cognitive function. Psychophatnacology Berl 1992; 108:417-31.

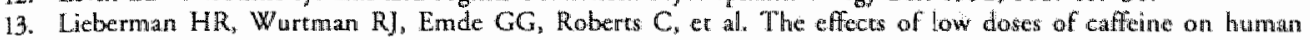
performance and mood. Psychopharmacology 1987; $92: 308-312$.

14. Loke WH. Effect of caffeine on mood and memory. Physiology and Behawior 1988; 44: $367-372$.

15. Molchan SE, Martinez RA, Hill JL, al. Increased cognitive semsitivity to scopolamine wich age and a perspecive on the scopolamine model. Brain Research Reviews 1992; 17: $215-226$.

16. Molchan SE, Mellow AM, Lawlor BA, er ä. TRH attenuates scopolamine-induced memory impaitment in humans. Psychopharmacology Berl 1990; 100: 84-9.

17. Nehlig A, Daval J-L, Debry $G$. Caffeine and the central nervous system: mechanisms of action, biochemical, metabolic and psychosimulant effects. Brain Research Rewiews 1992; 17: 1139-170.

18. Overall JE, Rhoades HM. Adjusting $p$ values for multiple tests of significance. In: Melczer HY $\mathrm{Y}_{n}$ ed. Psychopharmacology. The dhird Generarion of Progress. New York: Raven Press, 1987: 1013-1018.

19. Pollack 1, Norman DA. A non-parametric analysis of recognition experiments. Psychonomic Sciences $1964:$ 125-126.

20. Preda $L$, Alberoni $M$, Bressi S, Cattaneo $C$, et al. Effects of acute doses of oxiracetam in the scopolamine model of human amnesia. Psychopharmacology $1993 ; 110 ; 421-426$.

21. Rusted J, Eaton-Williams P. Distringushing between attentional and ammestic effects in information processing: The separate and combined ffects of scopolamine and nicotine on verbal free recall. Psychopharmacology 1991; 104: 363-366.

22. Rusted JM, Warburton DM. The effects of scopolamine on working memory in healthy young wolunteers. Psychopharmacology Berl 1988; 96: 145-52.

23. Stavric B. An update on research with coffee/caffeine (1989-1990). Food Chem Toxicol 1992; 30:533-55.

24. Sternberg $\mathrm{S}$. Memory seanning: mental processes revealed by reaction time experiments. American Scientist 1969; 57: 421-457.

25. Surgeon General. Nicotine addiction: The health consequencess of smoking. A report of the Sturgeon General. U.S. Department of Health and Human Services, Rockwille: 1988.

26. Swift CG, Tiplady B. The effects of age on the response to caffeine. Psychopharmacology 1988; 94: 29-31.

27. Terry WS, Phifer B. Caffeune and memory perfomance on the AVLT. Journal of Clinieal Psychology 1986 . 42: $860-863$

28. Wesnes $K$, Partot A. Smoking, Nicotine and Humar Perfornance. In: Handbook of Huntan Performance. Academic Press Let. 1992: $127 \% 167$.

29. Wesnes $\mathrm{K}$, Simpson P. Kidd A. An investigation of the range of cognitive impairments induced by seopolamine $0.6 \mathrm{mg}$ s.c. Hum Psychopharmacol $1288 ; 3: 27-41$.

30. Wesnes KA. Anand R, Simpson PM. Christmas L. The use of a scopolamine model so study the potential noorropic effects of aniracetam and piracetam in thealtiy woluntecrs. Jounal of Psychopharmacology 1990; 4 : 219-232.

31. Winer BJ. Statistical principles in experimemtal desigrn. New York: MeGraw-Hill, 1971. 


\section{Part III: ANTIDEPRESSANTS AND COGNITION}

\section{Chapter 7}

\section{Avoiding and Managing Anticholinergic Effects of Antidepressants*}

Abstract. The anticholinergic actions of antidepressants can have undesirable effects that affect patients' well-being. These effects can be peripheral or central in origin. The most frequently occurring anticholinergic effects are sedation, psychomotor and memory impairment, $d r y$ mouth and blurred vision.

One of the most prominent central anticholinergic effects is that on cognitive function. Effects that occur after a single dose consist of sedation (lowering of activation and arousal), psychomotor impairment [slowed sensorimotor processes that can adversely affect operational manual control (as in car driving)] and memory disturbances (forgetfulness, inability to store and retrieve information and recall events). After long term adminustration, tolerance to sedation and psychomotor impairment is likely to develop, but not to memory disturbances.

Elderly parients can be assumed to be particularly sensitive to anticholinergic effects on cognitive functioning and also to peripheral anticholinergic effects such as dryness of the mouth and loss of accomodation in the eye. It is argued that for this reason, prescription of the classical tricyclic antidepressants should be avoided in elderly depressed patients. The second generation, or arypical antidepressants, and the newer selective serotonine (5-hydroxytryptamine; 5-UT) reuptake inhibitors (SSRIs) are considered to be useful alternatives to tricyclics in elderly patients. These drugs posess greatly diminished anticholinergic activity, although the atypical antidepressants are very sedative and the effects of long term administration of SSRIs on cognition have rarely been studied. Another approach to avoiding anticholinergic effects is to use reversible inhibitors of monoamine oxidase (MAO)-A. (RIMAs), such as moclobemide. These agents can attenuate scopolamine-induced cognitive dysfunction.

An important point in managing and avoiding anticholinergic effects of antidepressants is to realise that not all so-called "anticholinergic effects" are actually cholinergically determined. Many orher pharmacological effects of antidepressants such as antihistaminergic and anti- $\alpha_{1}$-adrenergic effects can induce sedation, cognitive and psychomotor impairment, blurred wision and dry mouth.

*Riedel WJ, Van Praag HM. CNS Drugs 1995: 3: 245-259. 
Cholinergic receptors can be divided into 2 types: nicotinic and muscarinic. The vast majority of cholinergic receptors in the brain are of the muscarinic subtype, and these receptors appear to be involwed in memory and attentional functions. Outside the brain, muscarinic recptors are located in various organ systems such as the gastrointestinal tract, where they are involved in smooth muscle contraction. The term 'anticholinergic' refers to the blockade of acetylcholine receptors in general, while the term 'antimuscarinic' refers speciffally to blockade of muscarinic cholinergic receptors 1002 :

Antidepressant drugs have dinically important interactions with muscarinic receptors, while nicotinic receptors ate not affected by these drugs. For example, confusional states (induced by antimuscarinic actions) occur in as many as $13 \%$ of psychiatric parients receiving tricyclic antidepressants (TCAs) and other anticholinergic dngs $138,128,13: 1$.

\subsection{PHARMACOLOGICAL EFFECTS OF ANTIDEPRESSANTS}

The assumed conmon mechanism of action of all antidepressants is the increased availability of monoamines, particularly noradrenaline (norepinephrine) and/or seroronin (5-hydroxytryptamine; 5-HT), in the synaptic cleft. It is uncertain wether this process eventualy leads to increased or decreased neuronal activity in these monoaminergic systems. The effects of antidepressant drugs on mood are the basis for hyporheses relating depressive disorders to dysfunctions of serotonergic and/or noradrenergic neurotransmission.

\subsubsection{Tricyclic Antidepressants}

The TCAs typically affect multiple transmitter systems in the brain: they inthibit the reuptake of noradrenaline, serotonin and dopamine and block postsynaptic muscarinic, histaminergic, and $\alpha_{1}-$ adrenergic receptors. All TCAs possess anticholinergic activity, although to different degrees.

Of the TCAs amitriptyline, protrypuline, dothiepin, clomipramine, trimipramine, doxepin and imipramine have the strongest anticholinergic effects (see table 1). Nortriptyline and desipramine are modest anticholinergic drugs 4102,403$\}$ "

\subsubsection{Second Generation Antidepressants}

Antidepressants of the socalled 'second generation' group putarively affect mainly 1 neurotransmitter system, and hence induce fewer adverse effects than TCA and, notably, lack anticholinergic effects. These agents include the selective seroconin reuptake inhibitors (SSRIs): fluoxetine, fluvoxamine, paroxetine, sertraline. Pharmacological data show that, in general, SSRI"s have a very low affinity for muscarininc receptors $4103.126 \%$

Sertaline, fluoxetine and fluwoxamine do not display any significant affinity for muscarinic receptors, while paroxetine is considered to be only a weak antagonist of these receptors.

Other second generation antidepressants include mianserin (an antagonist of presynaptic $\alpha_{2}$ - and 5 $\mathrm{HT}_{2}$-receptors that acts through disinhibition of noradrenaline release) and trazodone (a serotonomimetic drug that also posesses $\alpha_{1}$-receptor blocking properties). Mianserin has a weak affinity for muscarinic receptors and hence causes few anticholincrgic effects [tom. Furthermore, antagonism of $\alpha_{2}$-receptors may even lead to increased release of acetylcholine via heteroreceptors [25]. Increased cholinergic activity (using measures of salivary flow and pupillary response to light) found in parients receiving mianserin $[165]$ seem to confirm this possibility. Mianserin has strong affinity for histamine $H_{y}$-receprors where it acts as an antagonist and consequently is a very sedaring substance. Trazodone has no affinity for muscarinic receptors [102], but is also very sedating [35.115.144!. 
Table 1

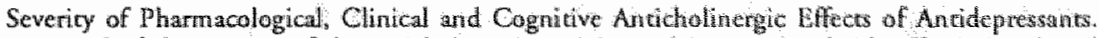

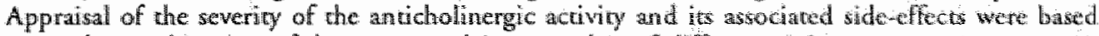

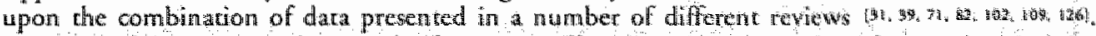
Appratsal of the nature and strength of cognituve effecs were bast upon the veferences listed in the rightmost column, which all consise of reports of empirical studies unduding dinal trads as well as experiments using wolunteer subject. Additionally, reviews were checked comcemimg

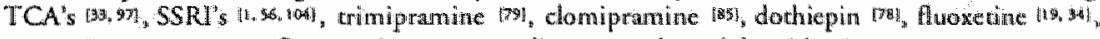

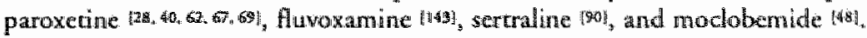

Affnity for Likelihood of
muscarinic anticholinergic Effect on Pychological functioning
aceryleholine adverse events vigilance psychomotor cognition References
receptors

Classinc ri/tetra-cyclics

Tertiaty amines.

Amitripicyline

$\sqrt{ } \sqrt{ }$

impaired impained impaired

Clomipramine

Dothicpin

Serandary aminer

Desipramine +

Nortriptyline *

Promiptyline $\quad++$ t

2nd generation

atypical

mianserine

trazodone 0

SSRT's

furoxerine 0

parroxerine

furoxamine

sertraline

reversuble MAO-A inhibitor

moclobemide 0 $\checkmark W$

$\sqrt{ } \sqrt{ }$

$\sqrt{ } \sqrt{ }$

$\sqrt{ } \sqrt{ }$

$\sqrt{ }$

$\begin{array}{ll}++ & \sqrt{ } \sqrt{ } \\ ++ & \sqrt{ } \\ ++ & \sqrt{ } \sqrt{ } \\ ++ & \sqrt{ } \\ ++ & \sqrt{ } \\ + & \sqrt{ } \\ + & \sqrt{ }\end{array}$

0

$\sqrt{2}$

0

$\sqrt{ }$

$\sqrt{2}$

1)

a

\begin{tabular}{|c|c|c|c|}
\hline & & & 80 \\
\hline & impaired & impaired & {$[7,32,45,490,35,59,26,306,194)$} \\
\hline & & impaired & 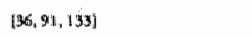 \\
\hline up + down & impaired & imparired & 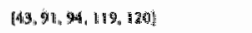 \\
\hline & somictimes & impaired & {$[3,74$, , $3,92,8,9 ; 120\}$} \\
\hline impared & impraired & impaired & {$[16,64\}$} \\
\hline 0 & 0 & Some & \\
\hline & 0 & & $951,52,1098,4199$ \\
\hline & 0 & 0 & $\{30,35,58,123 y$ \\
\hline
\end{tabular}

impaired impatred

impaired some impair up + down

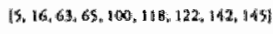

$35,9,16,20,27,39,50,115,340:$

\begin{tabular}{|c|c|c|c|}
\hline \multicolumn{2}{|c|}{ sone drownone } & improved & {$[6,44,50,58,84,72]$} \\
\hline $\mathrm{up}$ & some impair & no effects & $438,49,45,63$, c8, 79, 49, 107$]$ \\
\hline none & nonce & none & $17,87,549$ \\
\hline none & none & mone & 165.1041 \\
\hline updowoti & improved & imptoved & 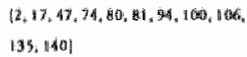 \\
\hline
\end{tabular}

a Agenes are devoid of affinity for muscarinic recptors but can cause pseatudo-andiclnolincrgic effects via interaction with hisitamine $\mathrm{H}_{1}$ and $\mathrm{O}_{1}$-adrencergic receptors.

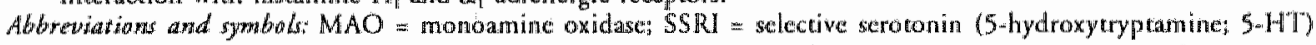

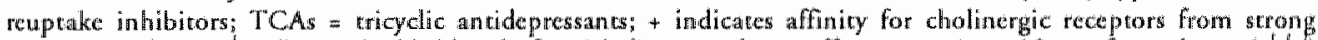

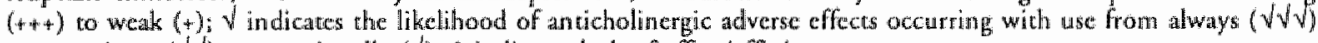
to sometimes $(\sqrt{ })$ to occasionally $(\sqrt{ }) ; 0$ indicates lack of effect/affinity

\subsubsection{Monoamine Oxidase Inhibitors.}

The monoamineoxidase (MAO) inhibitors are another class of antidepressants. Reversible inhibitors of the A isoenzyme of MAO (also known as RIMAs) have recently been developed. Unlike older, nonselecrive, irreversible $M A O$ inhibitors, these agents do not potentiate the pressor response to tyramine that leads to the so-called cheese-effect. This has revitalised the interest in this particular group of antidepressants [09y. Moclobemide, the first antidepressant in this class, increases noradrenaline and serotonin turnover and is devoided of anticholinergic activity [26, 37 . 


\subsection{OVERVIEW OF ANTICHOLINERGIC EFFECTS}

Clinical amticholinergic effects are mediated by a competitive antagonism of muscarinic acetylctholine receptors in the central and pertpheral nerwous system ill. 601. The most potent anticholinergic drugs are the belladonna alkaloids atropine and scopolamine. The antidepressants that have the most potet anticholinergic effects are the TCAs amitryptiline and protriptyline. Alhough these drugs possess about one-tenth of the antimuscarinic receptor binding affinity of atropine, the clinical antimuscarinic effect of them can be more prominent than that of atropine. This is because the therapeutic dose range exceds that of atropine 25- to 100-fold, for amitriptyline and 10 - to 20 -fold for protriptyline 11021 . Moreover, because the concentrations of anticholunergic drugs are dependent on dose regimen and phamacokinetic parameters (such as distribution time and elimination half-life) anticholinergic effects can emerge as a consequence of slow accumulation after repeated dosing.

Table 2 lists the dinically relewant anticholinergic effects induced by antidepressants. Unfortunately, none of the various anticholinergic symptoms listed in the table are specific and sensitive indicators of cholinergic dys function, although when drowsiness, dry mouth and blurred vision oceur together, the likelihood of a true anticholinergic effect is increased. These symptoms also occur after blockade of postsynaptic of $\alpha_{1}$-receptors, a pharmacological effect of many antidepressants. For example, depression of CNS activity, clinically manifested as sedation, is a very general effect that is also seen after blockade of histamine receptors and/or, $\alpha_{1}$-adrenoceptors with a number of agents including benzodiazepines and antipsychorics. Amnesia in combination with drowsiness may also occur after administration of benzodiazepines.

\subsection{PERIPHERAL ANTICHOLINERGIC EFFECTS}

The peripheral anticholinergic effects of antidepressants are mediated by a decreased functioning of parasympathetic nerves. This effect occurs due to a postsynapric blockade of the acetylcholinereceptors in parasymparhetically innervated organs.

In this way, antidepressants bring about the diminuition of virtually all secretions (except lactation). A common example of this effect is the so-called 'dry mouth' symptom (xerostomia), which is a result of decreased saliwation. This is by far the most prevalent expression of peripheral anticholinergic effects. Apart from subjectively experienced discomfort, it can lead to difficulty in swallowing and talking. In the longer term it can lead to dental caries and oral candidiasis.

Another example of the diminished secretion induced by antidepressants is the inhibition of sweating. While a sympathetically controlled mechanism, sweating is cholinergically mediated. Intibition of sweating can, in extreme situations, lead to hyperthermia (e.g. during exposure to high temperatures or in combination with exercise). However, paradoxically, excessive swearing is a fairly common complaint in paticnts receiving tricyclic (anticholinergic) antidepressants.

Two typical anticholinergic effects occur in the eye are an increased risk of acute glaucoma [due to relaxation of the musculus sphincter pupillae (mydriasis)] and blurred vision [due to relaxation of the musculas ciliaris (cycloplegia)]. Blurred vision is the expression of disturbed accomadation function and has a high probability of occurrence in parients receiving antidepressants that have anticholinergic effects.

A reduction of the cholinergically mediated tone and peristalsis in the gastrointestinal tract can lead to constiparion. Another anticholinergic effect, slowed micturition, is seldom noticed by the patient, but can lead to urinary retention. A reduction of peripheral vagal tone as a consequence of an anticholinergic effect, can induce an increase in heart rate. However, this effect is not always obvious since it can be overridden by a blockade of muscarinic $\left(M_{1}\right)$ receptors on postganglionic parasympathetic neurons, producing a decrease in heart rate [60]. 
Table 2 Clinically relevane antcholinergic etfects induced by antidepressants, their poremtial clinical dangers and the probability of occurrence of anticholinergic signis and symptoms

Signs 1 symptoms

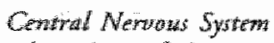

- drowsiness, fatigute.

- ammesia

- diffrculty in concemerating

- slowness of thought

- slowed or impaired

psychomotor coordination.

- loss of interest and initiatixe

- confusïon, delirium

- reducrion of REM* sleep

Peripheral Norwows Syotem

- reduced suliva/dry mozath (xerostamia)

- pupil dilacacion (mydriasis)

- Loss al accomodation (cycloplegia)

- redwced gastroincestinal movilig

- slowed micturition, urinary rerention

- reduced sweat secretion

- blushing; flushing
Clinicil dargers

brobobiling

risk of falling in elderly people, hip fracture disruption of daly life activitices

diffeculty in atending and mantaning attention dificulty in comprehending information inability to operare dangerous machinery. driwe a car or participate in traffic safely dimimished qualizy of life psychiaric sequel ate reduction of slcep qualicy

high moderare

high

moderate

highti modorate

low

high

difficulty in swallowing and talking; dental caries and orall candidiasts increased intraocular pressure

high

high

blurred viston, dizzyness, unsteady gait; risk of falling

constipation

low abdominal pain

increased body temperature (especially

at lugh environmental temperatures ) high

moderate

low

low

moderate

$\overline{\mathrm{REM}}=$ rapid eye novement

\subsection{CENTRAL ANTICHOLINERGIC EFFECTS}

\subsubsection{Cognitive Function}

\subsubsection{The Scopolamine Model of Cholinergic Blockade}

The anticholinergic drug scopolamine, which acts by blocking muscarinic receptors, has been used to study the role of acetylcholine in attention and memory, and to model aspects of memory and

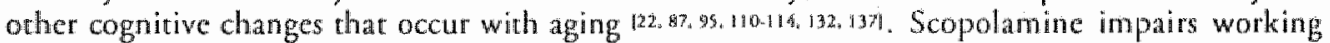
memory 1122, and the selection and evaluation of environmentall information $129 \%$ and reduces the likelihood of information presented being subsequently recalled or recognised :114. Scopolamine causes sedarion which may interfere with alerness, atrention and vigilance and contribute ro apparent memory impairment 67,137 . However, the disruptive effects of scopolamine on memory have been shown to be independent of sedative effects 175.76 .37 . In general, the scopolamine induced cognitive dysfunction can be reversed when drugs that stimullate the cholinergic system are administered concomitantly $170,89,917,936,138,1411$. However, this offect is not always found with CNS stimulants 1:2.877, another indication that anticholinergic effects are specifically related to impained memory functions.

Detrioration of the functioning of the cholinergic system has been postulated to contribute to the memory impaiment obserwed in normal aging and Alylheimer"s Disease [12.13!. Increased cognitive sensitivity of elderly persons to experimentally induced cholinergic blockade 187 is consistent with the impression of clinicians that older persons are more sensitwe than younger ones to anticholinergic adverse effects of drugs such as TCAs, including cognivive impaiment 138, 54). 


\subsubsection{Effects of Antidepressants on Cognitive and Psychomotor Function}

In numerous studies with antidepressants, the abiliry of these agents to induce sedation and drowsiness and to affect vigilance, psychomotor performance, artention and memory are reponed (see table 1). Unfortunately, only very few studies explicitly describe the relationship between

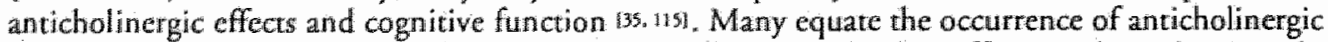
effects with the presence of sedation, memory problems and other effects such as dry motht without analysing whether these effects are actually related to cholinergic dysfunction. For example, sedation can be induced by blockade of cholinergic, histaminergic, $\alpha_{1}$-adrenergic and $\gamma$-aminobutyric acid (GABA) teceptors, and impaired performance on psychomotor- and cognitive performance can occur as a consequence of sedarion. For this reason, drugs with very different pharmacological actions may lead to apparendy the same net effect on behavior.

Psychomotor imparment can lead to an inability to or difficulty in manually controlling or steering objects, apparatus or machines. The most practical example of this is impaired car driving ability, In laboratory experiments, psychomotor impairment is expressed in terms of impaired tracking ability or slowed motor choice reaction time. Cognitive impairment refers to a patient's inability to concentrate, think, calculate, make decisions or judgements, comprehend language and remember information or events. In laboratory experiments, cognitive impairment is expressed in terms of decreased capacity to store and retrieve information in short- and/or long-term memory, increased attentional distractability, and decreased capacity to focus or divide artention.

The use of antidepressants, alcohol (ethanol), hypnotics, analgesics, antihistamines may all render a patient unfit to drive a car, less able to remember what he/she was doing when performing simple tasks requiring working memory (such as calculating, shopping and reading the newspaper) or unable to make proper judgements or decisions. However, sedating antidepressants differentially affect cognitive functioning $120,27,35,1151$.

In experimental studies of cognitive effects of psychotropic drugs, many different tests are used. For practical reasons, in reviewing the literature we have interpreted the awailable results in terms of three of the most studied components of psychological functioning. These include vigilance (which can be considered as the experimental psychological operationalisation of the clinically used term "sedation'), psychomotor function (which refers to the many resuls that are reported in terms of choice reaction time, tracking and car driwing) and cognition (which refers to attentional factors and tests of memory functioning). There are many other tests (e.g. Digit-SymbolSubstitution) that measure all the above parameters, and hence are non-specific, bur usually very sensitive indicators of the quality of cognitive functioning. In rable 1 an overview of studies assessing the anticholinergic and cognitive effects of antidepressants is presented.

TCAs. Many of the TCAs cause moderate to severe effects on cognitive functioning, inducing symptoms such as forgetfulness, slowness of thought and diffeuly in concentrating (more specifically, difficulty in focussing attention on one source of information while ignoring others). These effects are attributed to anticholinergic activity, but could also be caused by blockade of histaminergic and a-adrenergic receptors. Curran and colleagues [35. 115] showed that both strongly (amitriptyline) and weakly (rrazodone) anticholinergic antidepressants induced a high degree of sedacion that was associated with many different types of psychomoror and cognitive impair ments, but that memory was more impaired by anticholinergic antidepressants. Thus, forgetfulness qualifies as the most prominent cognitive effect differentiating antidepressants with and without anticholinergic activity.

Second Generation Antidepressants. As mentioned in secrion 7.1.2., trazodone and mianserin are considered to lack anticholinergic activity, but are highly sedating 1102. For example, Sakulsripong et al. "11s! demonstrated that tolerance to the sedative effects of trazodone did not 
develop ower the course of 2 weeks administration. The phamacological profte of mianserin's may appear to offer an advantage over other agents (ice procholinergic activity combined with very weak anticholinergic activity); however, this is nullified by the severely impaining effects that the drug has on psychomotor functions, such as tracking accuracy, brake reaction time and prolonged car-driving $165,66,1001$. These effects are most probably caused by antagonism of histamine $\mathrm{H}_{1}, \alpha_{1}$-adrenergic and possibly $5-\mathrm{HT}_{2}$-receptors, to which tolerance dows not readily devellop [100].

The SSRI"s are devoid of anticholinergic as well as anthistaminergic and $\alpha$-blocking effects, and hence do not induce sedation after single or repeated administration. Most studies investigating the adverse effects of SSRIs reveal no sedation (or psychomotor impairment or coginitive impairment) associated with treatment. However, a review of 6 -week, double-blind, placebocontrolled clinical trials assessing the adverse effects of fixed dosages of fluoxetine 20,40 or 60 $\mathrm{mg} / \mathrm{day}$ [3a demonstrated that, although the gastrointestinal complaints are predominant the incidence of drowsiness was increased after administration of dosages of $40 \mathrm{mg}$ and $60 \mathrm{mg} / \mathrm{day}$ relative to placebo. Also, the incidence of dry mouth was found to be increased after fluoxetine $40 \mathrm{mg} / \mathrm{day}$ relative to placebo, although the reported difference was very small.

A placebo-controlled study of 3 weeks' administrtation of fluoxerine $20 \mathrm{mg} / \mathrm{day}$ to healthy volunteers demonstated that the drug has the potential to impair vigilance by reducing critical Alicker/fusion frequency (CFF) and sustained attention $\$ \$ 9)$. However, other studies suggest that SSRls may result in an improvement in memory in depressed patients over the course of thetapy 1721. It is not known whether this is a pharmacological effect or a consequence of the alleviation of depression.

RMAs. Moclobemide 200 to $400 \mathrm{mg}$ in a single dose did not have any effects on cognitive and psychomotor function in young healthy volunteers [6fl. Elderly volunteers receiving moclobemide 100 to $300 \mathrm{mg}$ displayed only a slight impairment in vigilance, while at the same time their verbal recognition memory and memory scanning was found to be improved 1109. Moclobemide $200 \mathrm{mg}$ rwice daily had no effect on measures of psychomotor skills, vigilance (prolonged automobile driving) and attention in volunteers after 8 days of treatment 1000 , whereas the same individuals were found to be severely impaired after mianserin $10 \mathrm{mg} 3$ times daily.

In healthy volunteers, a single dose of moclobemide $400 \mathrm{mg}$ antagonised the cognitive dysfunction induced by scopolamine 11351 . Furthermore, studies of moclobemide in young depressed patients and in elderly depressed patients who were cognitively impaired $\left[4 R_{1}\right.$ showed that cognitive functions were improved after 6 weeks of treatment. Again it is not clear wherher the memory improvement is a pharmacological effect or a result of the alleviation of depression. However, the finding that modobemide reverses scopolamine-induced deficits 113s? suggests that this is a pharmacological effect. Of course this does not exclude the beneficial effects of alleviation of depression on cognitive functioning.

\subsubsection{The Development of Tolerance: Acute wersus Chronic Effects of Antidepressants}

The initial pharmacological effects of antidepressants, most notably the anticholinergic effects, emerge within minutes or hours after administration. This means that often, as is in the case of TCAs and second generation antidepressants, the performance-impairing effects of the drugs become manifest long before the therapeutic effects. This is of crucial impact for the vast majority of depressed patients who are ambulant and who receive their treatment from general practitioners.

Although conflicring results have been reported, a number of studies in young healthy volunteers have shown that sedating antidepressants (i.e. TCAs) impair cognitive and psychomotor test performance after a single dose, but that the effect can diminish with repeated administration $13_{*} 4$. $77.107 .115 .118 .11 \% 1211$. For example, the sedating effects of amitriptyline $(50 \mathrm{mg}$ ar night plus $25 \mathrm{mg} 3$ 
hour prior to testingy led to increased fatigue, drowsiness, loss of concentration and markedly impared performance in healthy wolunteers performing a real life car-driving task and other psychomotor tasks on the first crearnent day, but no inpaired performance was recorded on the eighth treament day. Furthermore, increased drowsiness dissipated over the 8 days of treatment and was not different to that associated with placebo 100$]$.

With respect to memory impairments induced by amitriptyline $(37.5 \mathrm{mg}$ at 2 hours prior to testing), tolerance developed over a period of 2 weeks to the effects on immediate memory, but not to the effects on long term memory task (uss. In patients receiving amitriptyline, memory impaiment was still present after 4 weeks 1231 . It is not known wherher tolerance is related to pharmacologically induced changes in receptor sensitiwity and, if so, in which receptors. Also, it is important to note that sedation caused by anticholinergic, antihistaminergic and anti- $a_{1}$-adrenergic activity can distupt all psychological performance, from basic sensorimotor to the very complex cognitive processes. Be this as it may, the data available on amitriptyline suggest that tolerance develops to the global sedative effecrs of the drug, and to a lesser extent to its effects on memory functions. The latter effect is believed to be selectively related to anticholinergic activity [35]. Tolerance to the sedative and psychomotor impairing effects of mianserin $10 \mathrm{mg} 3$ times daily, as measured in terms of very marked impairment in a reall-life car-driving task, did not develop over the course of 8 days nool. Lack of tolerance to the sedative effects of trazodone was observed in terms of subjective drowsiness, impairment of psychomotor performance (digit-symbol substitution and symbol copying and tapping) and immediate memory [1s?. Also, no tolerance was obscrved in healthy wolunteers to subjectively reported drowsiness (significantly increased relative to placebo) after 8 days of treatment with paroxetine $40 \mathrm{mg}$ |107, Little is known about the differences between short and long term effects of other antidepressants, particularly the newer agents.

\subsubsection{Other Effects}

Other consequences of CNS anticholinergic effects that sometimes occur during treatment with antidepressants include disturbance of judgement [131, and delirium and confusion 138]. These effects are primarily thought to be associated with accumulated or almost toxic concentrations of agents with anticholinergic properties. The symptoms may also be the emergent signs of a more severe distuption of memory and information processing funcrions. They rarely occur as a consequence of antidepressant therapy, but the syndrome is known from anaesthesia where it us described as the 'Central Anticholinergic Syndrome'. The prevalence of the syndrome after anaesthesia is thought to be augmented by antidepressant use [s/7.

Anticholinergic drugs are effective in preventing motion sickness. This acrion is probably mediated either in the cortex or more peripherally in the vestibular apparatus. Nevertheless, anticholinergic antidepressants can cause dizziness and unsteady gait, an effect probably explained by the actions of the drugs on the sye which indirectly disturb the maintenance of posture and sense of balance lit 6 in.

Another anticholinergic effect of antidepressants is their hypnotic or sedative property. They decrease the number of awakenings, increase slow-wave-sleep (SWS) and increase the latency and decrease the total time spent in rapid-eye-mowement (REM) sleep [n]. Allthough it is believed that this REM suppression is beneficial for the alleviation of depression, it is argued by some investigators that sleep improvement in non-REM stages is more important for an antidepressants effect (15). 


\subsection{ANTIDEPRESSANT TREATMENT STRATEGIES WITH PARTICULAR REFERENCE TO ANTICHOLINERGIC EFFECTS}

\subsubsection{Anticholinergic effects and the elderly}

Depression is a common problem in old age and the use of antidepressant drugs is particularly prevalent among elderly patients. Limited data suggest that dose requirements may be lowered in the elderly because of age-related changes in pharmacokinerics [31. Elderly parients receiving psychotropic drug therapy must be monitored carefully because treatment failure due to undermedication and drug toxicity due to overmedication may have more severe consequences in older than in younger adults. For example dizziness can increas the risk of falls and resultant hip fracture $[42,116]$.

Because the number of medications prescribed increases with age, and as mentioned in section 7.4.1.1. sensitivity to anticholinergic effects also increases with age, the chance of observing memory problems, confusion or delirium after administration of antidepressants also increases with age. The administration of an antidepressant, even one with only weak anticholinergic properties, may represent the trigger rather than the main cause of memory problems, confusion or delirium in the elderly. Therefore, the risk of fallsely diagnosing age-associated cognitive decline or dementia increases with age. Alchough in general, differential diagnosis of depression and dementia is not affected by antidepressant medication [53,831, Verhey and colleagues 112\%, 13\%] showed that in patients in whom depressive symptoms coexist with symptoms of dementia, the differential diagnosis of depression and dementia was more often in error.

Age-dependent and depresion-induced impairments of cognitive performance may be additive, resulting in elderly depressived patients experiencing more pronounced cognitive deficits than a younger patient group " 1 *a]. Therefore, antidepressants that have the least anticholinergic effects are the most useful compounds for geriatric patients. These include the secondary amines, desipramine and nortriptyline $[\because 4,14]$ and the SSRIs. The latter group of agents have been shown to be effective in the elderly. Importantly, they lack anticholinergic properties, and sedation, psychomotor impairment and cognitive dysfunction are rarely observed. While the second-generation drug trazodone has the advantage of lacking anticholinergic effects, it is very sedaring and so may not be very useful in elderly patients [awil.,

RIMAs such as moclobemide may prove to be the best tolerated alternative in older patients [24], because they not only lack anticholinergic properties, but antagonise them without acting as a stimulant thit.

\subsubsection{Managing Anticholinergic Effects}

\subsubsection{1: Central Anticholinergic Effects}

In general, there is litte or no resiearch or clinical experience concerning the use of drugs: to combat the central anticholinergic effects of antidepressants. However, theoretically interesting possibilities do exist, such as combining anticholinergic antidepressants with nootropic drugs or so-called cognition enhancers. The latter category of drugs is suggested to combat cognitive impairment induced by cholinergic dysfunction 17\%, 88, 98, 117, 136, 398. 141. Several analogues of piracetam (e.g. tenilsetam, aniracetam and oxiracetam 196. 138, 139) have been shown to attenuate anticholinergic-induced cognitive deficits. The piracetam-like nootropic compounds are relatively well tolerated, and for this reason this would be interesting possibilites. However, the bencficial effects of these agents on antidepressant-induced cognitive dysfunction have yet to be demonstrated in controlled clinical trials. It is also worthwile mentioning that many depressed patiencs who are receiving antidepressant therapy are probably already attenuating antidepressant-induced effects to some extent by self-medication with nicotine and caffeine, i.e. 
smoking wobacco and drinking coffee. Niconine, a nicotinic cholinergic agonist, has been demonstrated repeatedly to antagonise anticholinergic effects 110,30 . High doses of caffeine $(>2$ cups of coffee) have tecenty shown to posess the same cognitive enhancing property as nicotine llosi. In parients receiving anticholinergic antidepressans that induced sedarion, the dosage can be taken at nightrime to prevent daytine slecpiness. Conwersely, the sedative properties of antidepressants can also be used to good effect. When a depressed patient experiences problems slleeping and nightly sedation is desired, the whole or part of the dally dose can be taken at night. The clinician can choose from anticholinergic sedative antidepressants such as amitriptyline or imipramine, but can also achicve sedation without anticholnergic effects by prescribing trazodone or mianserin.

\subsubsection{Peripheral Anricholinergic Effects}

The only peripheral anticholinergic adverse effect of antidepressants that can be reasonably successfully treated is glaucoma. The risk of glaucoma is probably highest in elderly patients who already have narrow-angle glaucoma. Tricyclic antidepressants can be used in parients with glaucoma provided that pilocarpine eyedrops, or an equivalent lacally applied procholinergic medication, is administered. However, it is obvious that in such a case a tricyclic antidepressant posessing the least anticholinergic effects (such as desipramine) would be the most appropriate choice of antidepressant medication [11. An annidepressant with no or very low anticholinergic effects such as trazodone, fluoxerine, fluwoxamine, sertraline or moclobemide would be an even more appropriate choice.

\subsubsection{Anticholinergic Effects after Overdosage}

A deliberately taken overdose is a risk that is particularly prewalent in depressive patients taking antidepressants 1391 . In the case of an overdosewith an anticholinergic antidepressant, a central anticholinergic syndrome might occur. At this crucial stage the patient must be treated in an intensive care unit. Application of physostigmine, a cholinesterase inhibitor which prowides acute relief in the case of an anticholinergic overdose, can confirm thils diagnosis 111 . The treatment of antidepressant overdosage has recently been reviewed in this Joumal (ati).

\subsubsection{Awoiding Anticholinergic Effects}

High blood concentrations of anticholinergic drugs are associated with an increased risk of delirium [2\%. Therefore, decreasing the number and/or the dosages of concurrently prescribed drugs that have potential anticholinergic effects before beginning antidepressant therapy can avoid addivive anticholinergic effects. Obviously, a high degree of blockade of cholinergic receptors can occur during the administration of large doses of agents with anticholinergic properties. However, this effect can also be caused by drugs with entirely different different mechanisms of action and is less likely to be foreseen. Tune et al. ${ }^{2} 27$ published a list of drugs frequently prescribed to elderly patients and their associated degree of anticholinergic blockade. Such a list can assist in ensuring that combinations of agents with anticholinergic properties are nor prescribed. Thus, the risk of invoking anticholinergic effects through antidepressant prescription can be decreased by knowledge of a patient's concurrent medications.

It is common practice to use dose escalation procedures at the stant of antidepressant therapy. This serves mulciple purposes, but in the case of an anticholinergic substance it is also meant to prevent the occurrence of severe acute anticholinergic effects that would occur if the full dosage was administered from day 1.

Atremprs to totally avoid ancicholinergic effects will result in a very limired choice of drug, i.e. only those absolutely devoid of anticholinergic effects would be considered. Using such a criterion, no tricyclic antidepressant would qualify. Of the second generation antidepressants 
trazodone is without affinity for muscarinic receptors (102. 403. 1091. However, trazodone has an adverse effect profile that looks very like that of an agent with anticholinergic efects, lie. sedation and, to a lesser extent, blurred vision and dry mouth. These effects are a result of $\alpha_{1}$-adtenergic receptor blockade. The SSRIs fluoxetine, fluwoxamine and sertraline have no affinity for muscarinic receptors [103] and, consequently dinical anticholinergic effects do not emerge with use. Moclobemide antagonises the anticholinergic effects induced by scopolamine ussi. Because of this, moclobemide has been suggested to be a cognitive enhancer that may be used to combat agerelated cognitive decline and dementia ${ }^{1400}$. Finally, high potency benzodiazepines like alprazolam could possibly be used. Although sedative, they are devoid of anticholinergic effects, and according to some authors, are therapeutically active in depression [23, 10\%. 134.

\subsection{DISCUSSION AND CONCLUSION}

The core problem in managing anticholinergic effects is the fact that these effects can not easily be discriminated from pseudo-anticholinergic effects, such as antihistaminergic and anti- $\alpha_{1-}$ adrenergic effects. For this reason, in table 1 the rank orders of affinty of antidepressants for muscarinic receptors is listed along with rankings of anticholinergic signs associated with the drugs. As can be seen, drugs that are devoid of affinity for cholinergic receptors can still cause effects, such as drowsiness, sedation, blurred vision and dry mouth that in the literature are often described as 'anticholinergic effects'.

Sedation and blurred vision are associated with TCAs and atypical antidepressants (trazodone and mianserin), whereas memory impairment and reduced salivary flow (dry mouth) are more prevalent with TCAs, hence discriminating TCAs from atypical antidepressants. On the other hand, reduced salivary flow can occur after treatment with an SSRI, bur sedation and blurred vision are much less likely to occur, and hence can discriminate SSRIs from TCAs.

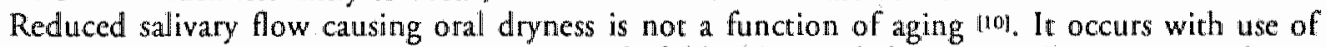
anticholinergic antidepressants, but also with B-blocking and diuretic antihypertensive drugs. Therefore, the key to diagnosing the presence of anticholinergic effects consists of two elements: (i) assessing what is likely to be anticholinergic (e.g. dry mouth, preferrably also measuring salivary flow rate, blurred vision and memory disturbances, preferrably using standard neuropsychological tests) and (ii) knowledge of all of the patient's mediactions.

Cognitive dysfunction often occurs in patients with depression $\left.{ }^{21,} .29\right]$ and for that reason additional drug-induced cognitive dysfunction is particularly badly tolerated by these patients. Furthermore, cognitive dysfunction that is present before the start of the rreatment prevents the clinician from detecting drug-induced cognitive dysfunction. Therefore antidepressants that possess cognition-enhancing properties are preferable in depressed patients. The incroduction of nonsedating, non-cognition impairing and even cognition-enhancing, antidepressants, such as the SSRIs and RIMAs, respectively, have shown that an improvement of cognitive function can often be observed during farmacotherapy. This implies that anticholinergic effects are unwanted and preventable adverse effects of antidepressant treatment.

\section{REFERENCES}

1. Aberg WA. The andidepressant effect of 5-HT uptake inhibitors. Br I Psychiatry 1989; 5uppl 8: 32-40.

2. Allain $H$, Lieury $A$, Bruner BF, et al. Antidepressancs and cognition: comparative effects of moclobemides, wiloxazine and maprociline. Psychopharmacology Berl Suppl 1992; 106: 56-61.

3. Allen $D$, Curran $\mathrm{HW}$, Lader $M$. The cffects of repeated doses of clomipramine and alpranolam on physiclogi* cal, psychomotor and cognirive functions. European Joumal of Clinical Phamacology 1991; 40:355-362. 


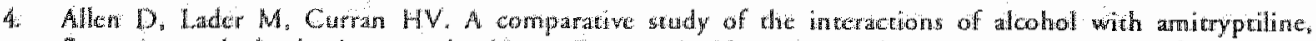

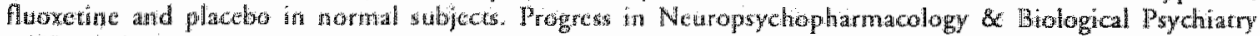
$198.8 ; 12 * 63-80$ :

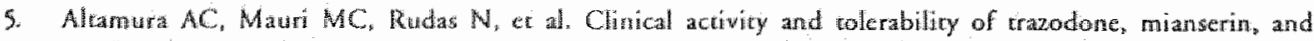

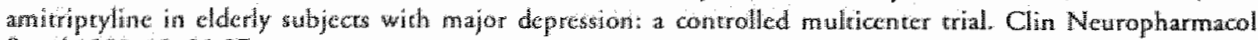
Suppl 1989; $12+2537$

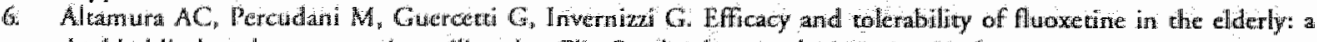
double-blind suidy versus aminypuline: Ine Clin Psyehophamacol 1989, 1. 103-6.

7. Anore $M$, Bellini $M$, Berardi $D$, Berlinzani $L$, et al, Double blind comparison of fuvoxaminc and

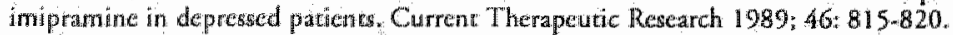

8. Hascum, Mrenekell Rv, Mertems $C$, er al. Controlled comparison of rwo doses of milnacipran (F 2207) and amitriptyline in a ajor depressive inpatients. Psychopharmacology 1sert 1989: 98: 163-8.

9. Ather SA, Ankier SI, Middeton RSW. A Double-Blind Evaluation of Tiaxodone in the Treatment of Depression in the Elderly. The British Josunal of Chimical Practice 1985: 39: 192-199.

10. Atkinson $\backslash \mathrm{C}_{\mathrm{s}}$ Fox PC. Salivary gand dysfunction. Clin Coriat Med 1992; 8: 499-511.

11. Baldessarini R. Drugs and the Treatment of Psychiatric Disordcrs. In Cilman AG, Rall TW, Nies AS, Taylor P. ed. Goodman and Cilman's T"he pharmalogical Basis of Therapeutics. 8th ed. New York: Pergamon Press, $1990: 383-435$.

12. Bartus RT", Dean RL. Bew B. Lippa AS. "The cholinergic bypothesis of geriatric memory dysfunction. Science $1982 ; 217: 408-417$

13. Bartus RT, Dean Ri, Pontecorvo MJ, Flicken $C$. The cholinergic hypothesis: A historical overview, current perspective, and farure directions. Annals of the Now York Acadeny of Sciences 1985; 444: 332-358.

14. Beasley GJ, Saylen ME, Pawin JH. Fhaxetine versus amioriptyline in the treatment of major depression: a multicenter trial. Int Clin Psychopharmacol 1993; 8: 143-9.

15. Bemme $A L v$, Havermans $R_{6}$, Diest Rw, Rfects of trazodone on $\mathbb{E}$ EG sleep and clinical scate in major depression. Psychopharmacology Benl 1992;107:569-74.

16. Blacker $R$, shanks N], Chapman $\mathbb{N}$, Drway A. The drug tracment of depression in general practice: a comparison of mocre administation of tramodone with mianserin dothiepin and amirripryline. Psychopharmacology 1988; $25: 18-24 \mathrm{~S}$.

17. Bougeral T, Uchida $C$, Gachoud JP, Kohler $M$, Mikkelsen H. Efficacy and colerability of moclobemide compared with fuwoxaminc in depressive disorder (DSM MI:). A French/Swiss double-blind trial. Psychopharmacology Berl Suppl 1992; 106:102\%108.

19. Bourne M, Szabiadi E. Bradshaw CM. A comparison of the effects of single doses of amoxapine and amitriptyline on autonomic funcrions in healthy volunteers. Eur J Clin Pharmacol 1993: 44: 57-62.

19. Boyer WF, Felghner JP. An overview of fluoxecine, a new serotonin-specific antidepressane. Mr Sinai $J$ Med $1989 ; 56: 136-40$.

20. Branconnice R. Cole JO. Effects of acure administration of trazodone and amitriptyline on cognition, cardiovascular function, and salivation in the normal geriatric subject. Journal of Clinical INychoptharmacology $1981: 1: 82-885$.

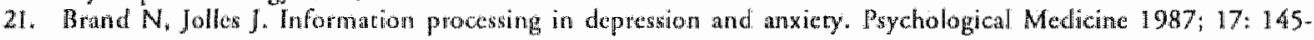
1153 .

22. Brtndeis D. Naylor H, Halliday R, Callaway L, Yano L Scopolaminie effects on visual information processing"

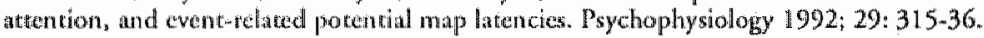

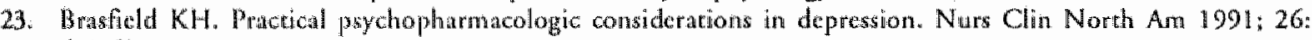
$651-63$.

24. Bressler R, Kald MD. Drug therapy for geriatric depression. Drugs Aging 1993; 3: 195-219;

25. Briley M. Biochemical strategites in the search for cognition enhancers. Mharmacopsychiary 1990; $2: 75-80$.

26. Burkard WP, Honcti EP, DaPrada M, at al. Tharmacological profile of moclobemide, a shore-acting and reversible intibito of monomine oxidase ype A I Phamacol Exp Ther 1989; 248: $391-9$.

27. Burns $M$, Moskowirz $H$, Jafe $J$. A Comparison of the Efects of Trazodone and Amitriptytine on Skulls Performance by Geriatric Subjects. J Clin Psychiary 1986:47:252-254.

28. Caley CI: Weber S5. Paroxctine: a selective serotonin reuptake inhibiting antidepressant. Ann Pharmacother 1993:27:1212-22.

29. Callaway $\mathrm{L}$, Halliday $\mathrm{R}$, Naylor $\mathrm{H}$. Cholinergic activicy and comstaints on information processing. Biological Psychology 1992;33: 1-22.

30. Camoll N, Parker RA, Branthwate MA. The use of protriptyline for respiratory failure in patients with chronic atflow limitation. Eur Respir J 1990; 3: 746.51.

31. Coccaro EF Siever 1.j. Second Generation Antidepressants: A Comparative Rewiew. Journal of Clinical Phanmacology 1985; 25:241-260. 


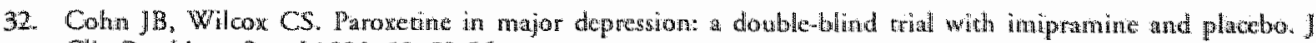
Cin Psychatry Suppl $1992 ; 53: 52,56$.

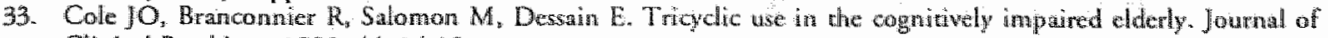
Clinical Psychiary 1983, 44: 140.19.

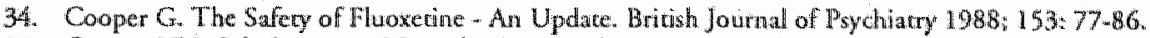

35. Curran HW, Sakulsriprong M, Lader M. Antidepressints and human memory: an wivestigation of four drugs wich different sedase and anticholinergic profiles. Psychopharmacol $1988 ; 95: 520-527$.

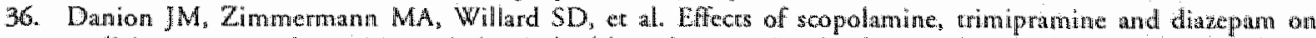
explicit memory and repetition priming in heal hy wolunteers. Pophopharmacology Berl 1990; 102: 422 4 .

37. DaPrada M, Kenter R. Keller HH, Burkard WP, Haefely WL. Preclinical profiles of the mowel reversible MAO-A inhibitors, moclobemide and brofaromine, in comparison with irreversible MAO inbibitars. J Neural Transm Suppl 1989; 28: 5-20.

38. Davies RK, Tucker GI, Harrow Mea. Confusional episodes and ancidepressne medication. Am I Psychatr $1971 ; 128: 95-99$.

39. De Jonghe $\mathbb{E}$, Swinkels $\ A$. The safery of antidepressants. Drugs 1992: $2: 40-475$.

40. Dechant KL. Clissold SP. Paroxetine. A review of ites pharmacodymamic and pharnacokinetic properties, and therapeutic potential in depressive illness. Drug: 1991; $41: 225-53$.

41. Del Zompo M, Bernardi F, Burrai $C$, Bocchecta A. A doubleblind study af minaprine versus amieriptyline in major depression. Neuropsychobiology 1990; $24: 7948$.

42. Dewan MI, Huszonck J, Koss M. Hardoby W, Ispahani A. The use of antidepressants in the elderly: 1986 and 1989.) Gerian Psychiatry Neurol 1992; 5: 40-4.

43. Dunner $\mathrm{DL}_{\mathrm{y}}$ Cohn $\mathrm{JB}$, Walsthe $\mathrm{Td}$, er al. "Two combined, nulcicenter double-blind studies of paroxetine and doxepin in geriatric patients widn major depression. J Clin Psychiatry Suppl 1992; 53:57-60.

44. Dewikas L, Cameron P. Management of ancidepressants in overdose. CNS Drugs 1994: 2:367-380.

45. Fabre LF. A 6-week, double-blind trial of paroxetine, inuipramine, and placebo in depressed outpartents. J Clin Psychiacry Suppl 1992; 53:40-43.

46. Fairweather DB, Kerr JS, Hilton S, Hindmach I. A placebo conrolled double-blind evaluation of the pharmacodymamics of fengabine vs amitriptyline following single and muleiple doses in elderly volunters. $\mathrm{Bu}^{2}$ J Clin Pharmacol $1993 ; 35: 278 \times 83$.

47. Fairweather DB, Kerr IS, Hindmarch I. The effeces of moclobemide on psychomoton performance and cognitive function. Int Clin Psychopharmacol 1993; 8: $43-7$.

48. Firton A, Faulds D, Goa KL. Moclobemide. A review of tes pharmacological properties and cherapeutic use in depressive illness lpublished erratum appears in Drugs 1992 \$ep; 44(3):374). Drugs 1992; 43:561-96.

49. Frewer L], Lader M. The effecs of nefazodone, impramine and placebo, alone and combined with alcohol, in mormal subjects. Int Clin Psychopharmacol 1993; 8: 13.20.

50. Fudge JL, Perry P], Garwey MJ, Kelly MW. A comparison of che effect of fluoxetine and trazodone on the cognitive functioning of depressed outpaticnts. ] Affect Disord 1990; 18:275-80.

51. Geller B, Cooper TB, Graham DL, Fetner HH, Marsteller PA, Wells JM. Pharmacokinetically destgned double-blind placebo-controlled study of nortriptyline in 6- to 12-year-olds with major depressive disorder. I Am Acad Child Adolese Psychianr 1992; $31: 34-44$.

52. Geller $B$, Cooper TB. Graham DL, Marsteller FA, Bryant DM. Doublemblind placebo-controlled andy of nortriptyline in depressed adolescents using "fixed plasma level" design. Pyychopharmacol Bull 1990 " 26.85 90.

53. Germer RH. Geriatric depression and reatment with trazodone. Sympositum: Fulfilling the promise: Desyreh: A five-year review" (1986, Montreal "Canada). Psychopathology Suppl 1987; 20; 82.91.

54. Gershon $\$$. Comparative side effect profiles of trazodone and imipramine: Special reference to the geriatric population. Psychopathology Suppl 1984; 17: 39-50.

55. Gonella $G$, Baignoli $G$, Ecari $U$. Fluwoxamine and imipramine in the treatment of depressive paticnts: a dewble-blind controlled study. Curr Med Res. Opin 1990; 12:177-84.

56. Grimsley SR, Jann MW. Paroxerne sertaline, and fluwoxamine: new selective semotonin reuptake inhibitors. Clin Pharm 1992; 11:930-57.

57. Hansen D, Fohring U, liyych $K$. Long-term antidepressive medication- an increased ancegtheric risk? Anaesthesist 1990; $39: 205-10$.

58. Hanzel DA, Proia NG, Hudgel DW. Response of obstuctive slecp apnea to luoxentine and protriptyline. Chest 199 : 100: $416-21$

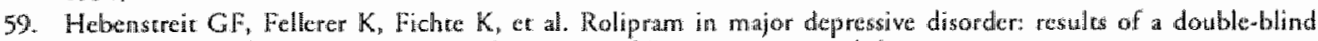
comparatiwe study with imipramine. Pharmacopsychiatry 1989;22: 156-60.

60. Heller Brown J. Aropine, Scopolamine and Related Antimuscarinic Drugs. In: Gilman AG, Rall TW, Nics AS, Taylor P, ed. Goodman and Gilman's "The pharmalogical Basis of "Therapeurics. 8th we. Wew York" Pergamon Press, 1900: 150-166. 
61. Hindmard 1. Three antideprexisan (aminiptyn, dothiepun, fluoxetine), with and without alcohol, compared whith placebo on test of psychomotor ability related to car driving. Hum Psychopharmacol $1987,2: 177-183$.

62. Hindmarch 1. A review of the psychomotor effecs of paroxerine. Int Clin Pychopharmacoll 1992; 4: 65-7.

63. Hindmarh 1, Harrison C. The Effect of Paroxetine and other Aneidepressants in Combination with Aloohol in Psychomotor Activery Related to Car Driving. Hunan Psychopharmacology 1988; 3: 13-20.

64. Hindmarch I, Kerr J. Behavioumal toxicicy of antidepressancs with particular referemice no moclobemide. Psychopthamacology Bert suppl 1992:106:49-55.

65. Hindmarch 1, shilingford J Shllingford C. The effects of sertraline on psychomotor performance in elderly volunteers. J Clin Psychiatry Suppl 1990; $51: 34-36$.

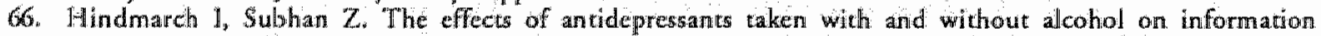
processing, psychomotor purformance and car handling dbility. In: $\mathrm{O}^{*} \mathrm{Hanlon} J \mathrm{~F}$, Giver JJd, ed. Drugs $x$ Driving. London: Taylor \& Francis 1986: 231-240.

67. Holliday" SM, Plogker GL. Paroxetine. A review of its phamacology, therapeutic use in depression and therapeutic potentiflil in diabetic neuropathy. Drugs Aging 1993: 3: 278-99.

68. Hutchinson DR, Tong $S_{3}$ Mown CA, Vunce M, Clarke A. Paroxetine in the treatment of elderly depressed patientio in general practice: a double-blind comparison with amirriptyline. Int Clin Pychopharmacol 1992; 4 43.51 .

69. Jenner PN. Paroxetine: an overwicw of dosage, rolerability, and safety. Int Clim Psychoplramacol 1992; 4: 69-80.

70. Jones RW, W/esnes KA, Kirby J. Effects of NMDA modulatom in scopolamine dementia. Ann N Y Acad Sü $1991 ; 640: 241.4$.

71. Kasper $\mathrm{S}$, Fuger J, Moller H]. Comparative efficacy of annidepressants. Drugs 1992; $2: 11-22$.

72. Keegan D, Bowen RC, Blackshaw $S_{*}$ et al. A comparison of fluoxerine and amitriptyline in the treatment of major depression. Int Clin Psychopharmacol 1991; 6: 117-24.

73. Kerr 15, Fairweather $D B$, Mahendran $\mathrm{R}$, Hindmarch 1 . The effeces of paroxerine, allone and in combinarion with aldichol on psychomocor performance and cognitive function in the elderly. Int Clin Psychopharmacoli $1992: 7: 101-8$.

74. Kocikas $C$, Holm P, Karlsson $A$, et al. Moclobemide and clomipramine in endogenous depression. $A$ randomized clinical trial. Acca Psychiatr Scand 1989; 79:523-9.

75. Kopelman MD. The cholinergic neurotransmiter system in human memory and dementia: $A$ review. Specilal Is ue: Human memory. Quarterly Joumal of Experimental Psychology Human Experimental Psychology 1986 38. 535.73 .

76. Kopelman MD, Corn TH. Cholinergic blockade' as a model for cholinergic depletion. A comparison of the memory deficits with those of Altheimer-type dementia and the alcoholic Korsakoff syrndrome. Brain 1988: $111: 1079-1110$.

77. Laden M, Melhuish A, Freka $G$, Fredricson-Overo K, Christersen V. The effects of citalopram in single and repeated doses and with alcohol on physiological and psychological measures in healthy subjects. European Journal of Clinical Psychopharmacology 1986:31: 183-190.

78. Lancaster $S G_{1}$ Gonzalez JP. Dothiepin. A review of its pharmacodynamic and phamacokinetic properties, and therapeutic efficacy in depressive illness. Drugs 1989; 38: 123-47.

79. Lapiere Y D. A review of trimipramine. 30 years of dinical ase. Drugs 1989: 1: 17-24.

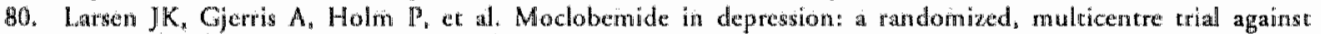
isocartoxuzide and clomipramine emplasizing atypical depression. Acta Psychiatr Seand 1991; 84: 564.70 .

81. Latan JKR, Holm P. Hoyer E, al. Moclobemide and domipramine in reactive depression. A placebocontrolled randomized clinical trial. Acta Isychiatr Scand 1989; 79:530-6.

82. Leonard BE. Phamacological differences of serotonin reuptake inhibitors and posstble dinical relewance. Drugs 1992; $2 ; 3-9$.

83. Matcopulos BA, Graves RE. Antidepressant effect on memory in depressed older persons. J Clin Exp Neuropsychol 1900; 12:655-63.

84. MoCue RE. Using tricyclic ancidepressants in the elderly. Clin Geriatr Med 1992: 8; $323-34$.

85. Mclavisti D, Benficld P. Clomipramine. An overview of its pharmacological properties and a rewiew of its therapentic use in obsessive compulsive disorder and panic disorder. Drugs, 1990; 39: 136-53.

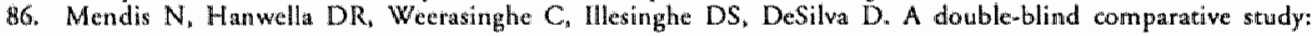
anineptine (Sutvector 100) versus imipramine. Clin Neuropharmacol Suppl 1989: 12:58-65.

87. Molchan SE, Matine. RA. Hill JL, et al. Increased cognitive sensitivity to scopolamine with age and a perspective on the scopolamine model. Brain Research Reviews 1992; 17:215-226.

88. Molchan SE. Mellow AM, Lawtor BA, et al. TRH atrenuates scopolamine-induced memory impairment in humatns. Psychopharmacology Berl 1990; 100: 84-\%.

89. Moller H]. Berzewsi H, Lickmann F, et al. Double-blind multicenter study of paroxetine and amitriptyline in depressed inparients: Pharmacopsychiatry 1993; 26:75-8. 
90. Murdoch $D_{3}$ McTavish D. Sertraline. A review of its pharmacodynamic and pharmacokinetic properties, and therapeutic potential in depression and obsessive-compulsive disorder. Drugs 1992; 44: 604-24.

91. Nair NP, Amin $M$, Schwart $G$, er al. A comparison of the cardiac safery and therapeutic efficacy of trimipramine versus doxepin in geriatric depressed patients. I Am Geriatr Soc 1993; 41: 863-7.

92. Nielsen NP, Cesana B, Zizolfi S, Ascalone V, Priore P, Morselli PL. Therapeutic effects of fengabine, a new GABAergic agent, in depressed outpatienes: a double-blind study verstus clomipramine. Acta Psychiatr Scand 1.990; 82: 366-71.

93. Nolan $\mathrm{L}_{n}$ O"Malley K. Adverse effects of antidepressants in the elderly. Drugs Aging 1992; 2 : 450-8.

94. Philipp $M$, Kohnen $R$, Benkert $O$. A comparison study of modobemide and doxepin in major depression with special reference to effects on sexual dysfunction. Int Clin Psychopharmacol 1993; 7:149-53.

95. Potter DD, Pickles CD, Roberts RC, Rugg MD. The effects of scopolamine on event-related potentials in a continuous recognition memory task. Psychophysiology 1992; 29: 29437.

96. Preda $L_{3}$ Alberoni M, Bressi S, Catcaneo $C$, et al. Effects of acute doses of oxiracetam in the scopolamine model of human amnesia. Psychopharmacology 1993; 110: $421-426$.

97. Preskorn SH, Jerkowich GS. Central nervous system toxicity of tricyclic antidepressants; Phenomenology, course, risk factors and role of therapeutic drug monitoring. J Clin Psychopharmacol 1990; 10: 88-95.

98. Preston GC, Ward C, Lines CR, Popplecon P, Haigh JR, Traub M. Scopolamine and benzodiazepine models of dementia: cross-reversals by Ro $15-1788$ and physoscigmine. Psychopharmacology Berl 1989: $98: 487.94$.

99. Ramackers JG, Muntjewerff ND, O'Hanlon JF, A comparative study of acuce and subchronic effects of dorhiepin, fluoxetine and placebo on psychomotor and actual driving performance. British Journal of Clinical Pharmacology 1995; 39: 397-404.

100. Ramaekers JG, Swijgman $\mathrm{HF}$, OHanlon JF. Effects of moclobemide and manserin on highway driwing, psychometric perforraance and subjectiwe parameters, relative to placebo. Psychopharmacology Berl Suppl 1992; 106: 62-67.

101. Reimherr FW, Chouinard $G$, Cohn $C K_{n}$ er al. Aneidepressanc efficacy of serrealine: an double-blind, placebo- and amitriptyline-controlled, multicenter comparison study in outpatients with major depression [see comments]. ] Clin Psychiatry Suppl 1990; 51: 18-27.

102. Richelson E. Pharmacology of antidepressants. Psychopathology 1987; 1:1-12.

103. Richelson E, Nelson A. Antagonism by antidepressants of neurotransmitter receptors of nornal thuman brain in vitro. J Pharmacol Exp Ther 1984; 230: 94-102.

104. Rickels K, Schweizer E. Clinical overview of serotonin reuptake inhibitors. J Clin Psychiatry Suppl 1990: 51 : 9-12.

105. Riedel WJ, Leboux RLAM, Hogervorst E, et al. Caffeine enhances Memory Function after Cholinergic Blockade. Neurobiology of Aging 1994: 15: 100-101.

106. Rimon $\mathbb{R}$, Jaaskelainen J, Kaartinen $P_{r}$ et al. Moclobemide versus imipramine in depressed out-patients: a double-blind multi-centre study. Int Clin Psychopharmacol 1993; 7: 1411-7.

107. Robbe HWJ, OHanlon JF. Acute and subchronic effects of paroxetine 20 and $40 \mathrm{mg}$ on actual driving, psychomotor performance and subjecrive assessments in healthy volunteers. European Neuropsychopharmacology $1995 ;$ s: 35-42.

108. Rosen J. Pollock BG, Alrieri LP, Jonas EA. Treatenene of nortriptyline's side effects in elderly patients: a double-blind study of bethanechol. An I Psychiatry 1993; 150: 1249-51.

109. Rudorfer MV, Potter WZ. Antidepressants. A comparative review of the dinical pharmatology and therapeutic use of the 'newer' versus the 'older' drugs. Drugs 1989; 37: 713-38.

110. Rusted J, Eaton-Williams P. Distinguishing between attentional and amnestic effects in information processing: The separate and combined effects of scopolamine and nicotine on vertsal frec recall. Psychopharmacology 1991: 104: 363-366.

11. Rusted JM, Eaton WP, Watburton DM. A comparison of the effects of scopolamine and diazepan on working memary. Psychopharmacology Bcrl 1921; 105: 442-5.

112. Rusted $J M$, Warburton DM. The effects of scopolamine on working memory in healthy young volunteers. Psychopharmacology Berl 1988; 96: 145-52.

113. Rusred JM, Warburton DM. Cognitive models and cholinergic drugs. Neuropsychobiology 1989; 21:31-36.

114. Rusted JM, Warburton DM. Effects of scopolamine on werbal memory: A recrieval or acquisition deficie? Neuropsychobiology $1989 ; 21: 76-83$.

115. Sakulisripong $M_{n}$ Curran HV, Lader $M$. Does tolerance develop to the sedative and amnesic effects of antidepressants? A comparison of amitripryline, orazodone and placebo. Eur J Clin Pharmacol 1991: 40:43.8.

116. Salzman C. Pharmacologic treatment of depression in the elderly. J Clin Psychiatry Suppl 1993; 54:23-28.

117. Sarter $M$, Bodewitz $G$, Srephens DN. Artentation of scopolamine-induced imparment of spontaneous alternation behaviour by antagonist but not inverse agonist and agonist b-carbolines. Psychopharmacalogy 1988; 94: 491-495. 


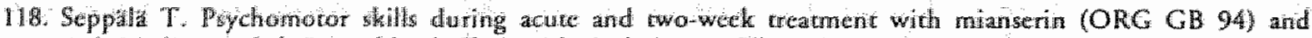

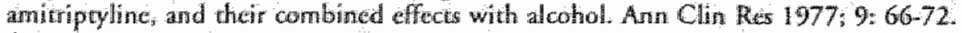

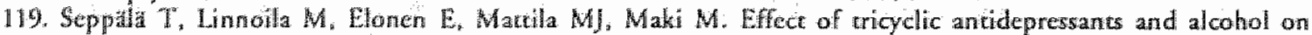
prychomotor sills related to diving. Clinicial Pharmacology and Therapeuke 1975: 17:515-522.

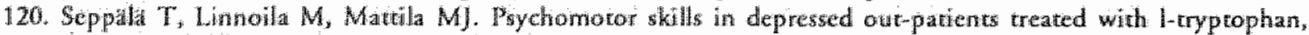
doxepin, or chlorimiprame, Arn Clin Res 1970: $10 \times 214221$.

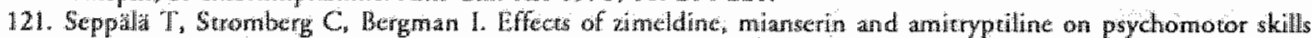

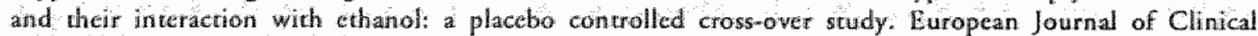
Mharmacology 1984,27:181-18\%.

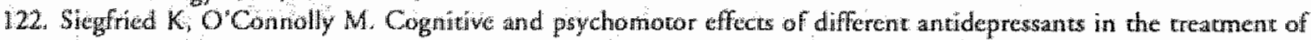
old age depueston. International Climical Psychopharmacology 1:986; 1, 231-243.

123. Smith PE, Edwards RH, calverley PM. Protripryline treament of stlep hypoxamia in Duchenne muscular dystroptiy. Thorax 1989; $44,1002-5$.

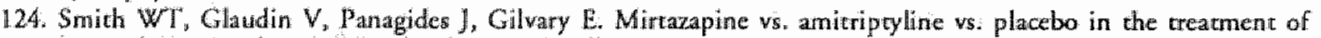
major depressive disorder. Psychopharmacol Bull 1990; 26:191-6,

125. Spring B, Gelenberg $\mathrm{A}$, Gavwn R, Thompson S. Amitriptyline, dovoxamime and cognirive function: a placebo*comtrolsed comparison in depressed outpatients. Psychopharmacology Berl 1992; 108: 327-32.

126. Stanton T, Boldikn WC, Cusack $B$, Richelson G. Antagonism of the five doned human muscarinic cholinergic receprors, expressed in CHO-K1 cells by ancidepressants and ancihistaminics. Biochem Pharmacol 1993; 45 ; 23524 .

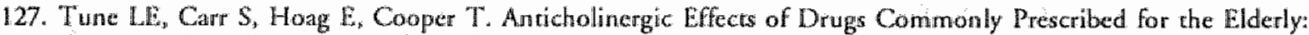
Potential Mears for Assessing the Risk of Deliniam. Am J Psychiatr 1992; 149: 1393-1394.

128. Tune LE Strass MF, Lew MF, Breidinger E, Coyle JT. Serum levels of anticholinergic drugs and impaired recent memory in chronic schizophrenic patienes. An J Psychiatr 1982; 139: 1460-1462.

129. Werhey $\mathbb{1 4}$ ]. Dementia, depression and forgetfuness [dissertation]. Maastrichar, University of Limburg, 1993.

130. Werhey $\mathbb{N} \mathbb{R}$, Jolles J Ponds RWHM, ex al. Diagnosing dementia: comparison between a monodisciplimary and a multidisciplinary approach. Journal of Neurapsychiatry and Clinical Wetrosciences 1993; 5: 78-85.

131. Walkup J. Increased ancicholinergic lewels, memory and judgement. Human Psychopharmacology Clinical and Experimental 1991:6:189-196.

132. Warburion DM, Wesnes K. Drugs as researcly tools in psychology: Cholinergic drugs and information processing. Neuropsychobiology $1984 ; 11: 121-132$.

133. Ware JC, Pirard JT. Increased deep slecp after trazodone use: a double-blind placebo-controlled study in healthy young adults. I Clin Psychiatry Suppl 1990; 51: 1:8-22.

134. Weissman MM, Prusoff B, Sholonnsas AJ. Greenwald S. A double-blind clinical trial of alprazolam, imipramine, or placebo in the depressed alderly. J Clin Psychopharmacol 1992; 12: 175-82.

135. Wesnes $K$. Anand $\mathrm{R}$, Lorscheid T. Potential of moclobemide to improwe cerebral insufficiency idencified using a scopolamine nodel of aging and dementia. Acta Psychiatr Scand Suppl 1990; 360; 71-2.

136. Wesnes: $K$, Revell A. The separate and combined effects of scopolamine and nicotine on human information processing. I'sychopharmacology 1984; 84: 5-11.

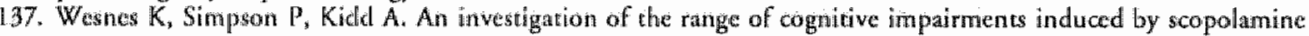
0.6 mg s.c. Heman Psychopharmacology Clinical and Experimental 1988; 3: 27.41 .

138. Wesnes K, Simpson PM. Kidd A. The use of a scopolamine model to study the nootropic effects of enilsetam (CAS 997) in man. Medical Science Rescarch Psychology and Pychiacry 1987; 15: 1063-1064.

139. Wesnes KA. Anand R Simpson PM, Christmas L. The use of a scopolamine model to sudy the potential nowtropic effects of aniracetum and piracetam in healthy volunecers. Journall of Psychopharmacology 1990; 4: $219-232$

140. Wesnes KA, Simpson PM, Christmas L, Anard R, McClelland GR. The effects of moclobemide on cognirion. J Neural Transur Suppl 1989;28:91-102.

141. Wesnes KA, Sinpison PM, White L et al. Cholinesterase inhibition in the scopolamine model of dementia. Ann N Y Acad Si 1 $991 ; 640: 268-71$.

142. Wheatley $\mathrm{D}$. Minaprine: an anticholinergie-free antidepressane? Results of a controlled trial of mianserin. Br J Psychurry $1989 ; 155: 106-7$.

143. Whitehead AM, Ashford J]. Huvoxamine in the treatment of depressive ulliness. A series of double-blind hosphital basted comparative studies carried owt in the UK. Br J Chin Pract 1992; 46:21-3.

144. Williams GO. Mamagement of depression in the elderly. Prim Care 1989; 16:451.74.

145. Wiltson WH, Pertic WM, Bant A. Possible lack of anticholinergic effece widh mianserin: a pilot study. Journal of Clinical Psychiatry 1980; $41: 63-65$. 


\section{Chapter 8}

\section{The Influence of Trazodone Treatment on Cognitive Functions in Outpatients with Major Depressive Disorder ${ }^{*}$}

Abstract. Eight patients suffering from major depression were treated with trazodone $150 \mathrm{mg}$ bid or $200 \mathrm{mg}$ bid (non-responders) during five weeks, preceded and followed by a placebo week. Cognitive functioning was tested in the rnorning at the end of each treatment week. Before trazodone treatment commenced, patients" cognitive performance was compared with non-depressed controls. The depressed. group showed significantly slower reaction rimes on the memory-scanning test, but did not differ from the control group on five other tests including word-learning, critical flicker-fusion frequency (CFF), wigilance, tracking and divided attention. CFF threshold decreased significantly during trazodone treatment CFF returned to its initial baseline-devel at the end of the placebo withdrawal. During the trazodone treatment period, recall from long-term memory of a previously learn word-list significanty improved, but at the end of the placebo withdrawal period memory performance recurned to its initial baseline-level. "These results indicated that the subchronic influence of trazodone on cognitive functions is at least of a two-dimensional nature: decreased CFF threshold can be interpreted in terms of lowered CNS arousal, whereas a higher cognitive funcrion, memory, improved, possibly related to the relief of depressive symptoms.

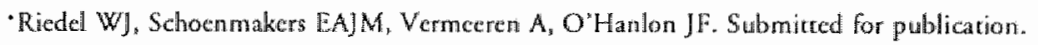




\subsection{INTRODUCTION}

Antidepressant treament can produce cogninive dysfunction for a variety of reasons. The best known mechanism that of muscarinic receptor antagonism. Yet $\alpha_{1}$-adrenergic, and $H_{1}$ histaminergic receptor antagonism is also associated with cognitive dysfunction [26]. Memory impairments are particularly associared with the use of anticholinergic drugs $130,32,351$, Depression itself is associated with impaired cognicive functioning, particularly memory processes [6: $8,19.28]$. For that reason, it has been argued that antidepressants should be devoid of anticholinergic action to awoid exacerbating memory deficits 1381, An improvement in patients' abilities to perform cognitive tests might be achieved through the relief of depressive symptoms. In fact, improwed psychomotor and cognitive performance of depressed patients under the influence of antidepressants has often been reported $[1,13,29,3 n$.

Trazodone is among antidepressants possessing the least anticholinergic affinity [25]. Newertheless, sedation or drowsiness is the most frequently reported side-effect during trazodone therapy [10, 151. Single dose studies involving young healthy volunteers have established an acute impairing eftect of trazodone upon critical flicker fusion (CFF) and other psychomotor functions measured in laboratory tests [11, 18, 36, 38. The same holds for elderly wolunteers 15.91. One study confirmed trazodone"s acute effects on cognitive functions but failed to show any after repeated doses over 2 weeks 1271, Patient studies have, in general, confirmed that trazodone is free of adverse effects on memory in depressed outpatients $[1,9 ;$; that it is efficacious in elderly depressed patients $|2,3.15|$; and also, that nocte administration is efficacious $[4]$.

Sedation would pose hazards for patients who engage in potentially dangerous tasks such as car driving. Because $40 \%$ of antidepressant prescriptions (in the U.S.A.) are renewed over periods longer than a year 1211, it seems important to derermine whether impairing effects continue in patients treated for longer periods.

The primary aim of this study was to determine, in outpatients suffering from major depression, whether psychomotor-and cognitive functions, and depressive symptoms, would change during the course of a five-week antidepressant drug treatment with trazodone.

In order to be able to interpret the predicted changes in psychomotor-and/or cognitive performance after antidepressant treatment, the baseline cognitive performance patients before the treatment, was compared with that of a matched control group. This comparison comprised the secondary aim of this study. The hypothesis was that depressed patients would perform worse on memory tasks.

\subsection{METHOD}

Subjects. Eight outparients, six women and two men, completed the study. They were independenty diagnosed as suffering from single or recurrent major depression and insomnia (DSM IILR), by two psychiatists. The 17-item version of the Hamilcon Depression Rating Scale, HDRS [14, was used for measuring the severity of the depression. A HDRS score of 17 or higher was required for entry. The mean HDRS ( \pm s.e.m.) for the eight patients at intake was $27.5 \pm 1.2$. Their mean ( \pm s.e.m.) age was $43.5 \pm 2.6$ years and their average years of education was $( \pm$ s.e.m.) $10.4 \pm 1.2$ years.

Exclusion criteria were history of drug dependence, pregnancy and severe organic disorders. Results of physical examination, ECG, blood chemistry and haematology were within normal limits. All subjects gave written informed consent. The protocol of this study was approved by the Medical Ethics Committee of the University Hospital Maastricht. The study was conducted in accordance with the Declaration of Helsinki as modified in Tokyo (1975), Venice (1983) and HongKong (1989).

Control Group. A sex-and age-matched control group were drawn from 30 volunteers participat- 
ing in a parallel study 34 . These wolunteers were trained and then tested under baseline conditions in the same manner as the patients.

The six female and two male volunteers had a mean ( \pm sem) age of $40.2 \pm 1.5$ years and their awerage years of education was $( \pm$ sem) $11.5 \pm 1.2$ years. The volunceers had no history of depression or any other psychiatric disorder.

Study Design. Every patient's participation lasted seven wecks. Their use of all psychoactive medication was suspended two weeks prior to participation and no co-medication was administered during antidepressant therapy. Patients received placebo the first week (1), trazodone for the next five weeks (2-6) and placebo again during the last week (7). Placebo and drug were selfadministered single blind, at 13:00 hours and 22:00 hours daily in identically appearing gelatine capsules. Trazodone was administered in ascending doses (Table 1). A daily dose of $300 \mathrm{mg}$ was achieved by the beginning of week 4 . The dose remained constant or was increased to $400 \mathrm{mg} / \mathrm{day}$ at the beginning of the week 5 for, respectively, patients showing more and less than a $50 \%$ reduction in HDRS scores.

Table 1. Situdy design with dosage regimert and assessments

\begin{tabular}{|c|c|c|c|c|}
\hline Weak & $\begin{array}{l}\text { Dossge re } \\
1: 00 \text { p.m. }\end{array}$ & $10: 00$ p.m & $\begin{array}{l}\text { Trazodone } \\
\text { daily dose (mg) }\end{array}$ & $\begin{array}{l}\text { Cognitive } \\
\text { Assersmernt }\end{array}$ \\
\hline 0 & PLA & PLA & 0 & Placebo Baseline \\
\hline 1 & $\mathbb{P} L A$ & 100 & 100 & \\
\hline 1 & PLA & 1.50 & 150 & T1 \\
\hline 2 & 50 & 150 & 200 & \\
\hline 2 & 50 & 200 & 250 & $T 2$ \\
\hline $3-5$ & 100 & 200 & 300 & $\mathrm{T3}, \mathrm{T} 4, \mathrm{~T} 5$ \\
\hline$(45$ & 200 & 200 & 400 & $74,75$ mon-resp $)$ \\
\hline 6 & PLA & $P L A$ & 0 & Placebo Withdrawal \\
\hline
\end{tabular}

Test Procedure. All parameters were recorded at the end of each weck. Thus, during trazodone treatment, the patients' cognitive functions were assessed after dosage had been stable for at least four days. Weekly test sessions occurred in the morning, two hours after the patients arose from sleeping in a polysomnographic laboratory. Their depressive symptoms had been recorded the night before in a psychiatric interview. The results of clinical assessments and polysomnographic sleep recording have been reported elsewhere inj.

\section{Cagnituve assessments}

The battery comprised six different tests lasting about one hour. The general idea of employing a test battery is that each test measures a different cognitive, psychomotor, or CNS function and hence results can be evaluared independently. Also, hypotheses concerning memory are not expected to influence non-memory measures. It cannot be excluded however, that for the proper performance of a full test battery, subjects draw on common pools of cognitive resources that may be assumed to influence performance on all tests.

Before the beginning of the study, subjects were trained to perform the tests during fou 1 -hour sessions. They performed while seated behind a computer screen and a variable-function response panel located in a sound-attenuated test cabin. The equipment for controlling the rest and recording tesponses was located outside the test cabin. 
Word Learning Test (WLT). One of twelve lists of 15 monosyllabic nouns matched across word frequency, was presented at a rate of one per 2 seconds 7 . Subjects were asked to read the worts alloud as they appeared on the computer screen, and verbally recall as many words as possible when the presentation stopped. This first trial was followed by four more in which the same words were repeated in the same order. After the fifth trial was completed, the subjects performed other tasks for 20 min. They were then required to recall as many of the previously learned words as possible without prompting. The numbers of correct recalled words were noted after every trial. The total number of words recalled on the first 5 trials was taken as the Immediate Recall Score. The Delayed Recall Score wast the number of words correctly recalled after twenty minutes.

Memory Scanning Test. This test was based on Sternberg's memory search paradigm inl. Subjects were briefly ( $3 \mathrm{sec}$ ) shown a set of letters and cold to memorize them (memory set). Subjects then saw a series of 90 letrers, each presenced with a one second duration and two seconds inter-stimulus-interval. Their task was to decide and respond as rapidly as possible by pressing respective push-buttons to indicate wherher or not each successive lletter was one of those contained in the memory set. This task was performed wirh memory-sets of 1,2 and 4 letters, respecrively. This task places demands on short-term memory retrieval functions. Mean reaction times of the correct positive (' Yes") and negative ("No') responses were the dependent variables.

Critical Flicker/Fusion Frequency (CFF) measures the thresthold in the frequency domain which separates the perception of Alicker or discontinuity from that of fusion or light constancy. The threshold is fundamentally determined by the rate of information processing of the visual system. It can vary up and down under the influence of stimulating or sedarive drugs. Subjects discriminated flicker from fusion of an intermirtent stimulus provided by four light emitting diodes held in foveal fixation at $0.75 \mathrm{~m}$. Individual thresholds were determined by the psychophysical Method of Limits as an average of three ascending and three descending frequency trials. As the CFF measure is very sensitive to changes in CNS arousal within subjects, it is usually taken as an index of CNS arousal $[16$.

Critical Tracking Task (CTT). This test ${ }^{201}$ measured the subject's ability to control a displayed error signal using a joystick in a first-order compensatory tracking task. Error was shown as horizontal deviation of a cursor from the midpoint of a horizontal scale. As the task progressed the welocity of the cursor's deviation increased requiring compensatory movements at a progressively higher frequency. Eventually the response frequency lagged the error signal by $180^{\circ}$. At that point, the subject's response added to rather than subtracted from the error and control was llost. The frequency at which control loss occurred was defined as the "critical frequency" or $\lambda_{c}$. The subject performed this test in five trials on each occasion, and median $\lambda_{e}$ was recorded as the final score.

Divided Attention Test. This test man measured the ability to divide attention berween tracking and monitoring tasks performed simultancously. The former subtask was similar to that described above, except that the error signal velocity was fixed at a constant level $50 \%$ of the particular subject's $\lambda_{c}$. Tracking error was measured as the average absolute distance (mm) between the cursor's position and display centre over the entire 12 min rest. The latter subtask was that of monitoring 24 peripheral LED displays fixed to botth sides of the main display. These displays presented numerals, $0-9$, which changed asynchronously every $5 \mathrm{sec}$. The subject removed his foot from a pedal-switch as quickly as possible after detecting the target numeral, "2". Average correct reacrion time to targets was the second response measure.

Visual Vigilance Test. This test $\{23,21\}$ was used to measure sustained visual discrimination. Digits appeared on a video display for $34 \mathrm{msec}$ each, at a rate of one per second. One $(0)$ was defined as "target" and six others $(2,3,5,6,8$ and 9$)$ as 'non-targers'. Srimulus images were oprically degraded by a glass diffusion screen interposed between the display and the subject. Reaction times and percentage of correc detecrions were measured. 


\section{Siavistical Analysis}

Patients vs Controls. The differences between test scores of patients and controls were compared using uniwariate and multivariare analysis of variance. One between groups factor (patients vs: controls) was prominent in each analysis. Tasks with one dependent variable were analyzed with a univariate analysis of variance. Tasks with multiple dependent parameters were analyzed with a multivariate analysis of variance. One task, the memory scanning task, permits simultaneous testing of the main effects of two task variables, the memory load ( 3 levels: 1,2 and 4 items in memory) and response type (2 levells: Yes-answers and No-answers). The evaluation of interactioneffects of these task wariables with the between-groups factor (patients us. controls) permit eventual conclusions as to differences in mernory scanning processes between the two groups.

Trazodone Treament. Subjects' average test scores from the five assessments over the tratodone treatment period $(\mathrm{T}=\{\mathrm{T} 1+\mathrm{T} 2+\mathrm{T} 3+\mathrm{T} 4+\mathrm{T} 5\} / 5)$ were analyzed in comparison to scores obtaincd at the end of the placebo-baseline (PB) and -washout periods (PW) using repeated measures multiwariate analysis of wariance, MANOVA 127 . Univariate mean-pair comparisons (T ws. PB and $T$ vs. $P W D$ were performed in order to detect where significant changes occurred. The sequential Bonferroni-Hölm $\alpha$-probabiliry criterion adjustment was applied with these pairwise mean comparisons.

\subsection{RESULTS}

Patients' cognitive performance compared with the control group.

In table 2 the baseline test scores of paticnts compared with that of the control group are listed. Although the depressed patients performed worse than normal controls on nearly all tests, these differences were not significant, except for the depressed patients' performance on the memory scanning task. In this task, patients displayed significantly slower RT's than normal controls irrespective of memory load and response rype (multivariate main effect of group: $F_{1,4}=5.49$, p<.05).

"able 2 Cognitive performance of depressed and nomal control groups

\begin{tabular}{|c|c|c|c|c|c|}
\hline \multicolumn{2}{|l|}{ Group: } & \multicolumn{2}{|c|}{ Controls } & \multicolumn{2}{|c|}{ Patients } \\
\hline $\mathrm{CH} \|^{*}$ & Hiderefusion frequency $(\mathrm{Hz})$ & 25.4 & (.8) & 24.5 & $(.7)$ \\
\hline WLT & $\begin{array}{l}\text { Immediate Recall } \\
\text { Delayed Recall }\end{array}$ & $\begin{array}{r}45.9 \\
8.0\end{array}$ & $\begin{array}{l}(3.3) \\
(1.5)\end{array}$ & $\begin{array}{r}42.5 \\
6.8\end{array}$ & $\begin{array}{l}(2.7) \\
(9)\end{array}$ \\
\hline VIG & $\begin{array}{l}\text { Correct Detections }(\%) \\
\text { RT (msec) }\end{array}$ & $\begin{array}{l}79.1 \\
487\end{array}$ & $\begin{array}{l}(3.5) \\
(10)\end{array}$ & $\begin{array}{l}81.9 \\
495\end{array}$ & $\begin{array}{l}(5.1) \\
(19)\end{array}$ \\
\hline $\mathrm{CTT}$ & $\lambda_{i}(\mathrm{rad} / \mathrm{sec})$ & 4.0 & $(.2)$ & 3.8 & (3) \\
\hline DAT & Error $(\mathrm{mm})$ & 17.7 & (1.3) & 20.3 & (1.9) \\
\hline & $\mathbb{R T}($ msec) & 237 & $(372)$ & 2517 & (367) \\
\hline$C R T_{Y e u}$ & $\begin{array}{l}\text { load I RT(msec) } \\
\text { load } 2 \text { RT (msec) }\end{array}$ & $\begin{array}{l}463 \\
506\end{array}$ & $\begin{array}{l}(21) \\
(22)\end{array}$ & $\begin{array}{l}536 \\
553\end{array}$ & $\begin{array}{l}(18) \\
(18)\end{array}$ \\
\hline CRT ${ }_{N}$ & $\begin{array}{l}\text { load A RT (msec) } \\
\text { load I RT (msec) } \\
\text { load } 2 \text { RT (msec) } \\
\text { load \& RT (msec) }\end{array}$ & $\begin{array}{l}564 \\
479 \\
540 \\
600\end{array}$ & $\begin{array}{l}(22) \\
(15) \\
(18) \\
(22)\end{array}$ & $\begin{array}{l}629 \\
546 \\
597 \\
649\end{array}$ & $\begin{array}{l}(29) \\
(26) \\
(26) \\
(21)\end{array}$ \\
\hline
\end{tabular}


RT is plotted as a function of memory load in figure 2 . The main effects of memory load $\left(F_{2,13}=26.46, p<.0001\right)$ and response type $\left(F_{1,4}=6.85 * p<.05\right)$ and their interaction $\left(F_{2,13}=6.52\right.$, $\mathrm{p}=01 \mathrm{1})$ showed significant effects of these task factors over the two groups. These effects were not significandy different in the two groups, indicating that the patients and controls did not employ different memory search strategies and that the slower RT's found in the patient group were unrelated to the speed of seatch in shont-term memory ("intercept-effect).
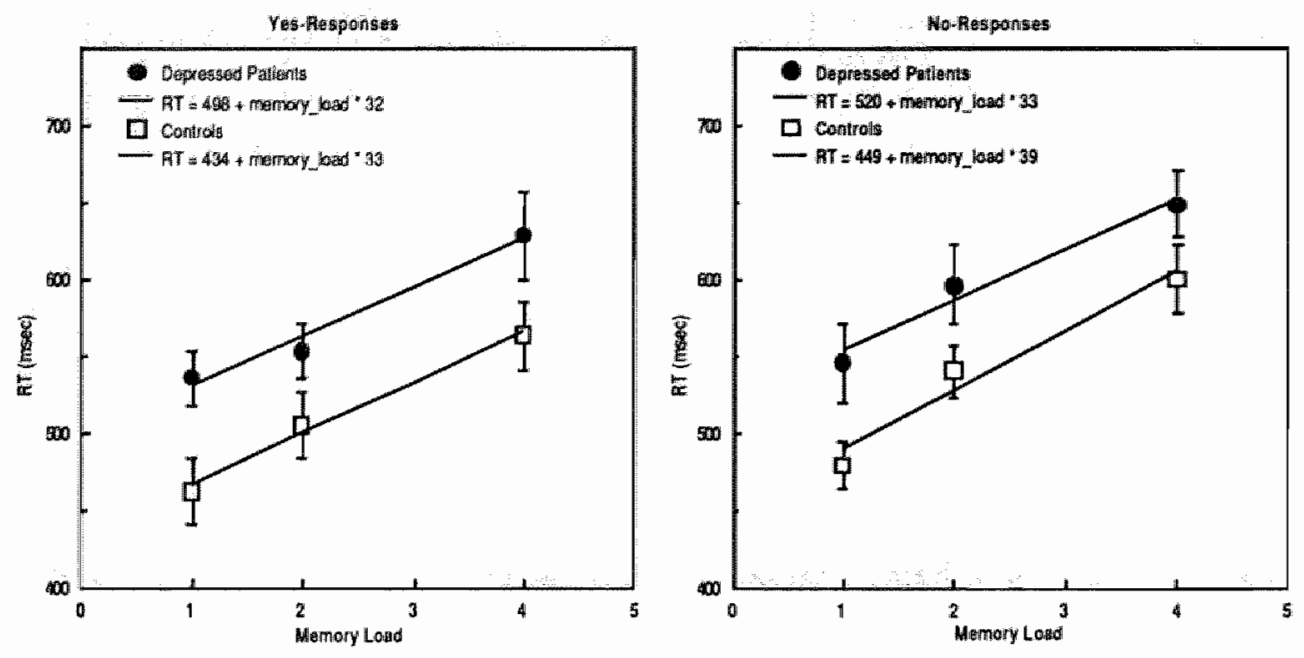

Figure 1 Reaclion lime (RT) as a lunction ol increasing memory load and response lype, assessed during baseline in depressed and non-depressed subjects

Table 3 Clinical and cognitive measures of patients with major depressive disorder ( $\mathrm{PB}=$ placebo baseline; T1-TS = trazodone treatment weeks; $\mathrm{PW}=$ placetro withdrawal).

\begin{tabular}{|c|c|c|c|c|c|c|c|c|c|c|c|c|c|c|}
\hline & & $\mathrm{PB}$ & & TI & $\mathrm{T} 2$ & & T3 & & $\mathrm{T} 4$ & & $T 5$ & & $P W$ & \\
\hline \multicolumn{2}{|l|}{ HRSD } & 26.3 & $(1.1)$ & $20.8(2.3)$ & 14.5 & $(3.0)$ & 16.4 & $(3.5)$ & 15.5 & $(3,0)$ & 11.6 & (3.3) & 16.5 & $(3.0)$ \\
\hline $\mathrm{CHF}$ & Frequency $\left(H_{2}\right)$ & 24.6 & $(.7)$ & $23.5 \quad(9)$ & 23.7 & (9) & 23.7 & (.8) & 23.3 & (.7) & 23.6 & $(.7)$ & 25.0 & $(.8)$ \\
\hline \multirow[t]{2}{*}{ WLT } & Immediatc Recall & 42.5 & $(2,7)$ & $44.8 \quad(2.5)$ & 46.1 & $(2.2)$ & 48.6 & (3.3) & 50.9 & (2.3) & 44.1 & (3.3) & 43.1 & (3.0) \\
\hline & Dellayed Recall & 68 & $(9)$ & $90 \quad(8)$ & 10.2 & (.9) & 8.8 & $(1.2)$ & 10.3 & (6) & 8.0 & $(1.2)$ & 6.6 & (1.5) \\
\hline \multirow[t]{2}{*}{ VIG } & Corr Detect $(\%)$ & 81.9 & $(5.1)$ & $83.0(4.4)$ & 80.4 & $(5.9)$ & 78.9 & $(5.8)$ & 77.0 & (6.1) & 79.1 & $(5.7)$ & 77.0 & (4.9) \\
\hline & $\mathrm{RT}^{\prime}$ (msec) & 495 & (19) & $509 \quad(19)$ & 495 & (23) & 499 & (26) & 485 & $(22)$ & 496 & (17) & 494 & (15) \\
\hline $\operatorname{CTT}$ & $\lambda_{\mathrm{c}}(\mathrm{rad} / \mathrm{sec})$ & 3.8 & (.3) & $3.7 \quad(.2)$ & 3.81 & (.39) & 3.5 & (3) & 4.1 & (3) & 4.0 & (.3) & 3.8 & (3) \\
\hline \multirow[t]{2}{*}{$\mathrm{DAT}^{\circ}$} & Brror $(\mathrm{mm})$ & 20.3 & (1.9) & $21.6(1.4)$ & 21.0 & (2.1) & 21.6 & (2.1) & 19.9 & $(1.5)$ & 20.5 & (2.2) & 19.0 & $(2.3)$ \\
\hline & $\mathrm{RT}($ msec) & 2517 & $(367)$ & $2488(340)$ & 2597 & $(414)$ & 2466 & (357) & 2424 & $(322)$ & 2351 & (338) & 2306 & (369) \\
\hline \multirow[t]{3}{*}{$\mathrm{CR}^{\prime} \mathrm{T}_{\mathrm{\gamma}}$} & load I RT (ms) & 536 & (18) & $534 \quad(25)$ & 568 & $(46)$ & 550 & (36) & 541 & (26) & 536 & $(45)$ & $\$ 12$ & (11) \\
\hline & load 2 RT (ms) & 553 & (18) & 577 & 554 & (15) & 599 & (34) & 582 & (23) & 607 & (46) & 553 & (21) \\
\hline & load 4 RT (ms) & 629 & (29) & 618 & 615 & (22) & 651 & $(48)$ & 619 & (30) & 623 & (22) & 633 & (33) \\
\hline \multirow[t]{3}{*}{$\mathrm{CRT}_{\mathrm{NO}}$} & load I RT (ms) & 546 & $(26)$ & (26) & 575 & (40) & 561 & (3I) & 557 & (28) & 568 & (41) & 524 & (10) \\
\hline & load 2 RT (ms) & 597 & (26) & (26) & 575 & (23) & 625 & (24) & 596 & (118) & 627 & (32) & 593 & $(23)$ \\
\hline & load 4 RT (ms) & 649 & (21) & (41) & 635 & (27) & 695 & (23) & 684 & (41) & 658 & (28) & 675 & (30) \\
\hline
\end{tabular}




\section{Treatment effect.}

In Table 3 the scores on HDRS and all cognitive tests are listed per week of the treatment period. There was a significant change in HDRS during the treatment period $\left(F_{2,6}=11.86, p<.01\right)$. Mean pair comparisons between trazodone and placebo-baseline and -withdrawal respectively, revealled that HRSD score was significantly decreased during the trazodone treatment period $\left(\mathrm{F}_{1,7}=26.91\right.$, $\mathrm{p}<.001$ ) in comparison with placebo baseline and was still lower during the withdrawal period $\left(\mathrm{F}_{1,7}=14.65, \mathrm{p}<.01\right)$.

CFF changed significantly during the treatment period $\left(F_{2,8}=6.17, p<.05\right)$. Mean-pair comparisons revealed that CFF during the trazodone treatment period was significantly lower than during the placebo-baseline and -withdrawal periods $\left(F_{1,7}=8.26, p<.025\right)$ whereas $C F F$ during the placebo withdrawal period did not differ from $C F F$ during the placebo baselline period $\left(\mathrm{F}_{1,} \mathrm{~F} \mathrm{0.87}, \mathrm{n} .5.\right)$.

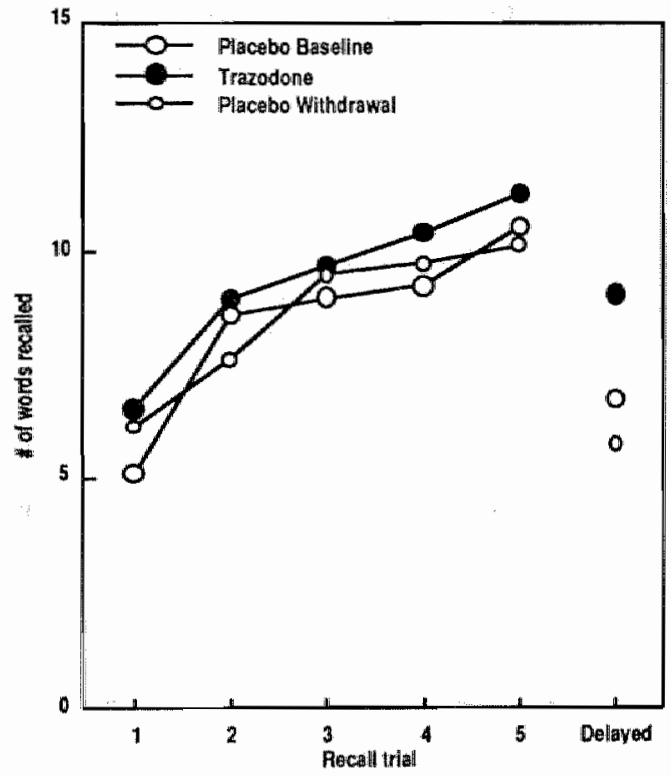

Figura 2 Immediate $(-5)$ and delayed recall trials of learned words in depressed patienls during placebo baseline trazodone treatment and placebo withdrawal periods.
Word learning changed significandy during the trearment period (see Figure 2). This concerned both immediate recall $\left(F_{2,6}=5.95, p<.05\right)$ and delayed recall $\left(F_{2,6}=12.36, p<.01\right)$. Mean-pair comparisons revealed that immediate recall was not significantly better during the trazodone treatment period than during placebo baseline $\left(F_{1.7}=6.61, n_{.} .5\right)$. Neither was immediate recall significantly better during trazodone treatment than at the end of the placebo withdrawal period $\left(F_{1, j}=0.14\right.$, n.s. $)$. However, delayed recall improved during the trazodone treatment period in comparison with placebo baseline $\left(F_{1,7}=25.54, p<.001\right)$ but delayed recall during the placebo withdrawal period was not significantly different when compared with delayed recall during placebo baseline $\left(\mathrm{F}_{1.7}=1.27\right.$, n.s.). The patients" performance on the tests of memory scanning, vigilance, tracking and divided attention did not differ significantly between the baseline, treatment and withdrawal periods.

\subsection{DISCUSSION}

The results can be summarized as follows. Depressed patients were slower in a memory search task than normal controls. During trazodone treatment CFF was decreased and returned to baseline level in the placebo withdrawal period. During trazodone treatment Delayed Recall Memory improved and returned to bascline level in the placebo withdrawal period. 
Comparison of cognitive performance of depressed patients with normal controls.

The comparison of depressed with nomal controls revealed that memory scanning, the task with which Brand \& Jolles 191 could differentiate unipolar and bipolar depressives and anxious parients, was the most sensitive among a battery of six cognitive tests, to discriminate depressed patients from nondepressed controls. One could argue against this statement that a battery of multiple tests was assessed in order to test the same hypothesis 6 times. Howewer, there was a priori expectation and hence an explicit hypothesis, that the difference between the rwo groups primarily would pertain to memory. This hypothesis has partly been confimed. One of the two memory tests showed a significant difference between the two groups. This may be an interesting result, but no more than that. The only firm conclusion about it could be that two groups of 8 subjects is too small to compare and does certainly not permit any conclusion in the direction of generalization of "no difference". The point to be taken from the comparison between the depressed patients and controls is that it at least seems to confirm that even our small patient group is representative of what is now thought to be a characteristic of major depression, namely the prevalence of cognitive dysfunction. And this is a relevant item in the subsequent evaluation of antidepressant treatment effects on cognitive functions.

\section{The effect of trazodone on cognitive functions in depressed patients}

The treatment effect on performance that was most consistent and most probably drug-related was that on CFF. This explanation would be in line with the effects of trazodone on CFF consistently seen in acute dose studies $[11,17,08,36\}$ and also after 14 days of trazodone administration in healthy volunteers $[27$. The meaning of a CFF effect is that of a drug-induced lowered CNS arousal level, which may very well explain the occurrence of sedation that was noted after trazodone treatment previously.

On the other hand, long-term memory, improved during trazodone treatment. This result seems at first sight not to be in line with the finding of lowered CNS arousal. Earlier results had shown that healthy volunteers treated with single doses of trazodone and amitriptyline showed little memory impairment after trazodone but much following amitriptyline nu. At the same time, these drugs' impairing effects in other types of cognitive impairment were closely comparable. The memory impairing effect of trazodone was ascribed to strong acute sedation and the more severe memory impairing effect of amitryptiline was explained by pronounced cholinergic receptor blockade which is absent in trazodone. Sakulsripong et al. ${ }^{[27]}$ administered trazodone over two weeks (100 mg and $200 \mathrm{mg} \mathrm{dd}$. respectively), amitryptiline (37.5 and $75 \mathrm{mg}$ ) and placebo to healthy wolunteers. They assessed the effects before and two hours after the daily dosage on the firs, the eighth and fourteenth treatment day. The assessments before the daily dosages are comparable to the ones in our study, that is, our assessments at placebo baseline and after the first two weeks. Sakulsripong et al, 127 did not find a change in CFF after one and two weeks of tratodone treatment and neither did they find an effect on Word Learning, when assessed before the next daily dose. However, their assessments at two hours after the daily dosage at the first, the eighth and the fourteenth day did show impairing effects of trazodone on both tests. The difference between their findings and ours can be explained in two ways. The higher dose that our patients received, could have overcome tolerance leading to the longer persistence of the effect of trazodone on CFF. The second is that memory improvement due to trazodone treatment would not be expected in healthy wolunteers. The findings of Sakulsripong er al. suggest thar, if we had tested the depressed patients at 2 hours after their daily dosage, we would have found impairments of memory and bigger decrements of CFF and perhaps of other cognitive functions as well. Furthermore, if an antidepressant is administered for its hypnotic action it should improve sleep and no residual sedation should be measurable the next morning. Therefore, the observation that, in our study. CFF remained low throughour the trazodone treatment period, is disturbing, particularly in wiew of the fact that sleep continuity was not improved by trazodone [331. But it must be noted that the impact of this lowered CNS arousal on memory was not negative. 
The conclusions of this study is that trazodone is an antidepressant that lowers CNS arousal permanently during treatment, but in spite of this, improvenent of learning and memory can occur during trazodone treament. It is not dear if the observed improvement in learning and memory is related to trazodone treatment via a pharmacological mechanism or is mediated vila the relief of depressive symptoms.

\section{REFERENCES}

1. Allain H, Lieury A, Brunet BF, et al. Antidepressants and cognition: comparative effects of modobemide, viloxazine and maprotiline. Psychopharmacology Berl Suppl 1992; 106: 56-61.

2. Alcamura $\mathrm{AC}_{3}$ Mauri $\mathrm{MC}_{\mathrm{n}}$ Rudas $\mathrm{N}$, et al. Clinical activity and toletability of trazodone, mianserin, and amitriptyline in elderly subjects with major depression: a controlled multicenter trial. Clin Neutopharmacol Suppl 1989; 12:25-37.

3. Ather SA, Ankier SI, Middleton RSW. A Double-Blind Evaluation of Trazodone in the Treatment of Depression in the Elderly. The British Journal of Clinical Practice 1985; 39: 192-199.

4. Blacker R, Shanks NI, Chapman N, Davey A. The drug treatment of depression in general practice: a comparison of nocre administration of krazodone with mianserin, dochiepin and amitripcyline. Psychopharmacology 1988; 95: 18-24S.

5. Branconnier RJ, Cole JO. Effects of acure administration of trazodone and amitriptyline on cognition, cardiovascular funcrion, and saliyation in the normal geruatric subject. Journal of Clinical Psychopharmacology 1981;1:82-88S.

6. Brand AN, Jolles J, Gispen-de Wied C. Recall and recognition memory deficits in depression. Journal of Affective Disorders $1992 ; 25: 77-86$.

7. Brand $N$, Jolles j. Learning and retrieval rate of words presented auditorily and visually. Journal of Gencral Psychology 1985; 112: 201-210.

8. Brand N, Jolles J. Information processing in depression and anxiety. Psychological Medicine 1987; 17: 145. 153.

9. Burns $\mathrm{M}$, Moskowitz $\mathrm{H}$, Jaffe J. A Comparison of the Effects of Trazodone and Amitriptyline on Skills Performance by Geriatric Subjects. J Clin Psychiatry 1986; 47: 252-254.

10. Coccaro EF, Siever L.J. Second Generation Antidepressants: A Comparative Review. Journal of Clinical Pharmacology $1985 ; 25: 241-260$.

11. Curran HV, Sakulsriprong $M_{*}$ Lader $M$. Ancidepressants and human memory: an investigation of four drugs with different sedacive and anticholinergic profiles. Psychopharmacoll 1988; 95: 520-527.

12. Finn JD, Mattson J. Multivariate analysis in educational research Applications of the MULTIVARIANCE program. Chicago: International Educational Resources, 1978.

13. Fudge JL. Perry P], Garvey MJ, Kelly MW. A comparison of the effect of fluoxetine and trazodone on the cognitive functioning of depressed outpatients. J Affect Disord 1990; 18: 275-80.

14. Hamilton M. Development of at rating scale for primary depressive illness $1 \mathrm{r} r$ Soc Clin Psychiatry 1967; 16: 278-296.

15. Haria M, Fition A, McTawish D. Trazodone. A revicw of its pharmatology, therapeutic use in depression and therapeutic porential in orher disorders. Drugs Aging 1994; $4: 331-55$.

16. Hindmarch I. Psychomotor funcrion and psychoactive drugs. Br J Clin Pharmacol 1980; 10: 189-209.

17. Hindmarch 1, Harrison C. The Effects of Parometine and other Antidepressants in Combination with Alcohol in Psychomoror Activiry Related to Car Driving. Hum Psychopharmacol 1988; 3: 13-20.

18. Hindmarch 1, Subhan $Z$. The effecrs of antidepressants taken with and without alcohol on information processing, psychomotor performance and car handling ability. In: $\mathrm{O}^{\prime} \mathrm{Hanl}$ lon Jl, Gier JJd, ed. Drugs \&\& Driving. London: Taylor \& Francis, 1986: 231-240.

19. Hobi V, Gastpar M, Gastpar G, Gilsdorf U, Kielholy P, Schwarz E. Driving ability of depressive patients under ancidepressants. J Int Med Res 1982; 10: 65-81.

20. Jex HR, McDonnel JD, Pharak AV. A 'critical" tracking cask for manual control research. MEE Transactions Hum Fac Electronics 1966: 7: 138-145.

21. Linnoila M, Seppala T. Ancidepressants and Driving. Accident Analysis \& Prevention 1985; 17: 297-301.

22. Moskowitz $\mathrm{H}$. Laboratory studies of the effects of alcohol on some variables related to driving Journal of Snfecy Research 1973; 5: 1.85-199.

23. Nuechrerlein $\mathrm{KH}$, Parasuraman $\mathrm{R}$, Jiang $\mathrm{Q}$. Viswal sustained attention: image degradation produces rapid sensirivity decrement over time. Science $1983 ; 220: 327-9$.

24. O'Hanlon JF, Vermeeren A. Effects of Ro $15-1788$ on the vigilance performance of sleep-deprived men. Hum Psychopharmacol 1988; 3: 267-274. 
25. Richelson E. Phamacology of andepressants. Pychopathology $1987 ; 1: 1.12$.

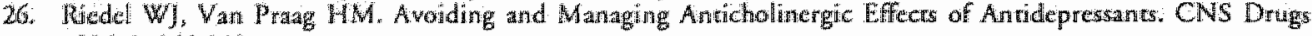
$1995: 3: 245-259$.

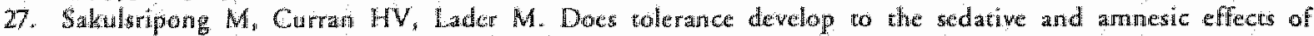

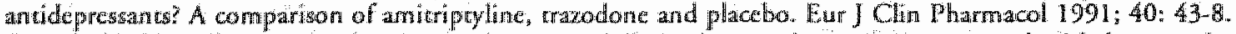

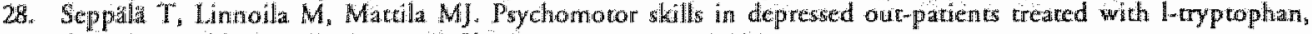
doxepin, or chlormipramine. Ant Chn Resi 1978; 10:214-221.

29. Siegried $K_{\text {. }} \mathrm{O}^{\prime} \mathrm{Connolly} \mathrm{M}$. Cognitive and psychonotor effect of different antidepressants in the treatment of old age depression. International Clinical Psychopharmacology 1986; 1: 231-243.

30. Spring B, Crelchberg, A, Carvin R, Thompson S. Amitripryline, clovoxamine and cognitive function: a placebo-controlled comparison in depressed outpatiencs. Psychopharmacology Berl 1992; 108: $327-32$.

31. Sumberg S. Memory scanring mentail processes rewealed by reaction time experiments. American Scientist $1969 ; 57: 421-457$.

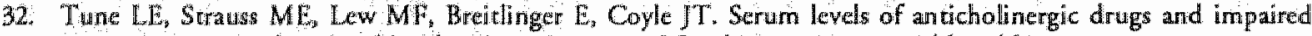
recenc memory in chronic schiophenic parients. Am J Psychiat 1982; 139:1460-1462.

33. Van Bemmel $A L$, Haverinans $R G$, Van Diest $R$ Effects of trazodone on EEG sleep and clinical state in major depression. Psychopharmacology Berl 1992; 107: 569-74.

34. Vermeeren A, OHanton JP. "Trainsdermal nicotine system (TNS) Effects on slep and performance of chronic smokers during 48 hours of abstinence. Institute for Drugs Safery and Behavior U of Limburg The Netherlands. 1990. ICVG 90-13

35. Walkup J. Incedsed anticholnerpic levels, memory and judgemene. Hum Psychopharmaco 1991; 6: 189-196.

36. Wartington SJ, Ankier SI, Turner P. An cvalustion of possible interactons between ethanol and trazodone or amitriptyline. Br I Clin Pharmacol 1984; $18: 549-557$.

37. Wesnes K, Anand R, Lorstheid T. Porential of moclobenide to improve cerebral insufficiency identified using a scopolaminc model of aging and dententia. Acta Psychiatr Scand Suppl 1990; 360: 71-2.

38. Wesnes KA, Simpson PM, Chriscmas L. Aruand R, McClelland GR. The effects of modobemide on cognition. J Neural Transm Suppl 1989; 28: $91-102$. 


\section{EPILOGUE}

\section{General Discussion}

\section{Memory Complaints, Memory Deficits, and Cognitrve Deceleration in Age-Related Cogmitine Dedine}

As was pointed out in the first chapter there is much more to cogntrive aging than becoming forgetful. Many cognitive and psychomotor functions other than menory slow down as a function of age, and also as a function of many age-extrinsic factors. Hence it comes as no surprise that elderly people with memory complaints do show declined speed of information processing in addition to the effects of aging. Memory complaints may not refer to memory function per se, but may reflect cognitive dysfunction or a decline of cognitive functioning in general. In addition, psychosocial factors and personality play a role in the expression of age-related cognitive dedine. The principle question whether age-related cognitive decline is a dinical entity and whether it can be pharmacologically treated can not be evaluated by a single answer. Age-extrinsic factors can be diagnosed and perhaps treated more easily than the effects of aging per se. Diagnosis can be based on signs and symproms, using the new class of cognitive impairment disorders in DSM IV. Despite a vast amount of research with cognirion enhancers, no accepted pharmacological treatment exists, howewer.

The comparison between the effects of scopolamine on cognition with those of age, showed that the nature and the magnitude of scopolamine's effects on memory are comparable to those of age. However, the magnicude of the effects of scopolamine on the speed of other cognitive functions, which were highly consistent and statistically significant, did not at all tesemble the magnitude of the effects of age on cognitive speed: the effects of age on speed were far more outspoken than those of scopolamine. Experimentally induced cholinergic dysfunction therefore seems to be a model of memory dysfunction more than a model of age-related cognitive decline. When more pharmacological dimensions of cognition, i.e. serotonergic, dopaminergic, noradrenergic and glutamatergic neurotransmission function, are manipulated in a comparable manner as to induce temporary cognitive dysfunction, eventually the dimensions underlying cognitive function in humans, their interactions, and their relation with aging will be unravelled. As far as we can conclude now, the cholinergic hypothesis may contribute only in part to age-related cognitive decline, probably most of all to the memory dysfunctions associated with it. The most typical expression of age-related cognitive decline, namely a general slowing of cognitive functions, presumably resembling reduced availabilicy of resources for information processing, is not mimiced by scopolamine.

\section{Statistically Significant wersus Clinically Relewant Effects of Cognition Enhancers}

The pharmacological treatment of cognitive dysfunction in normal aging remains a topic of research rather than of clinical application. By and large, the review on cognition enhancers in chapter 4 showed that statistically significant drug-induced cognitive enhancements were observed in many clinical trials, particularly in experiments in which models of age-related cognitive decline were employed. In general, the cognition enhancers studied very frequently seem to be effective a lictle, irrespective of the mode of action that may be involved. This state of the art was more or less confirmed by the results of the studies described in chapters 5 and 6 which yicled statistically significant effects, the magnirudes of which were questioned as to their clinical relevance. The results obtained with piracetam were on the edge of statistical significance, but 
were judged to be clinically irrelevant. The results obtained with caffeine and nicotine were statistically significant, but their magnitudes were not very big. Howewer, a fair milestone was set by the conclusion that the effects of new cognitive enhancing drugs should at least be superior to the effecis of three cups of caffeinated coffee. On the other hand, the caffeine finding can be judged to be of tremendous importance: Caffeine is already the world's most widely used psychoactive substance. In chaper 6 , the conclusion was drawn that caffeine is a cognitive enhancer. rather than an aspecific CNS stimulant. This would mean that the world's most widely used psychoactive substance is a cognitive enhancer. In our department"s survey, conducted over 2043 people distributed over 5year age categories ranging from 25 to 85 years, we found that more than $90 \%$ of all people over 35 years of age report to consume coffee daily [15]. The subjects" reported ayerage daily coffee consumption is low in the youngest age group ( 3 cups/day), gradually increases with age and peaks at $50 \mathrm{yrs}$ ( 5 cups/day), remains constant until 75 yrs (4 cups/day) and diminishes in the two highest age groups ( 3 cups/day). We further analyzed whether this trend was associated with the same number of consumers drinking different amounts, or whether the number of coffee consumers also varied with age. It appeared that the lower consumption of young people could be explained by a lower percentage of coffee consumers ( $81 \%$ and $88 \%$ in the 25 and 30 yr groups; all orther groups over $90 \%$ ), whereas the drop in reported consumption in old age appeared to be due to a diminished consumption and not a diminished percentage of consumers 115 . These data again make cleat that even when the cognition enhancing effect of caffeine, which was observed in the scopolamine-model experiment, is small, its implication is tremendous. Daily caffeine intake has been shown to be associated with better cognitive functioning [11]. Hence, life-long consumption of caffeine may have an impact on cognitive aging. Caffeine consumption may even affect the prevalence of dementia and cognitive complaints. Furthermore, a better estimate of daily caffeine intake has to be determined. The growing number of consumers of decaffeinated coffee has to be taken into account. They are probably more prevalent among the elderly. These are questions that our research group will be dealing with in the near future. We have already set out al research program in which the cognitive effects of caffeine are evaluated as a function of aging and reported daily caffeine intake. Furthermore, the cognitive effects of caffeine are currently being studied in a diversity of models of cognitive dysfunction, such as experimentally induced hypoxia and hypercapnia in healthy volunteer subjects.

An implication of the caffeine finding is that the cognitive enhancing effects of new substances targeted for the indication of Alzheimer's Disease, must also be superior to the effects of caffeine. Furthermore, given the high incidence of caffeine intake, it would be desirable to study the interaction of cognitive effects of new cognition enlancing substances with those of caffeine.

\section{Antidepressants and cognition enhancement}

There is much more consensus abour the possibility of improvement of cognitive funcrions as a cofactor in antidepressant drug treatment $[1,9,17,22]$, than there is about the efficacy of cognition enhancers in age-related decline. Reasonable agreement exists as to the prevalence of cognitive dysfunction in depression $[4,5,8,201$, leaving aside the questions concerning cause and effect. However, assuming that the proper function of serotonergic-and (nor)adrenergic neurotransmission play a vital role in optimal cognitive functioning, the monoaminergic hypothes 1191, i.e. a dysregulation of serotonergic and noradrenergic neurotransmission, may explain cognitive dysfunction [12,13) and also its improvement after antidepressant drug trearment [18].

\section{The cholinergic bypothesis}

The cholinergic hypothesis of geriatric dysfunction [2] has been a leading principle for the research described in this thesis. In part I the cholinergic hypothesis was applied to study the cognivive 
effects of cholinergic blockade in the CNS, by means of the administration of the anticholinergic

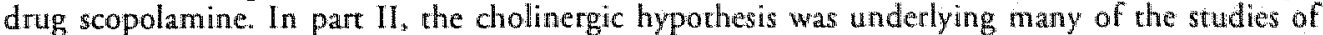
cognition enhancers which were reviewed in chapter 4 . In chapter 6 , a study was described in which the scopolamine-model was applied as a model of cognitive dysfunction, in which the cognition enhancing effects of substances, nicotine and caffeine, can be evaluated. In part 11I, the cholinergic hypothesis played a major role in rewiewing the adverse, anticholinergic effects of antidepressants. The cholinergic hypothesis has originated from research into the etiology of cognitive aging and dementia [3]. These were defined as a pathology of memory. Subsequently it was shown that cholinergic denervation played a role in the aging of the CNS and had a high prevalence in AD victims at autopsy. It was observed afrer the administration of anticholinergic anaesthetic and antidepressant agents, signs of dementia, i.e. forgetfulness and in high doses confusion occurred las 7. 16]. The memory dysfunction induced experimentally in healthy individuals by the anticholinergic agent scopolamine thas since than been demonstrated many times [14]. By now, it is time to conclude that experimentally induced cholinergic dysfunction is an adequate model of memory dysfunction in healthy individuals and that it allows the testing of substances to counteract the anticholinergic effects. However, it was shown in chapter 3 that the cognitive effects of cholinergic dysfunction do only partially resemble those of cognitive aging. Cholinergic dysfunction does not at all seem to resemble what is so often observed in aging subjects, namely a global diminuition of the availability of cognitive resources, or mental effort. This is particularly evident as to its relatively minor effects on cognitive speed, which is most affected by aging. "The apparent confusion raised by these findings can be explained by the relatively global and omnipresent, but faulty assumption, that dysfunction and complaints of memory are the most typical expression of aging and dementia. This is precisely the reason why the cholinergic hypothesis of geriatric dysfunction fails. The cholinergic hypothesis probably accounts for only a minor percentage of the cases in cognitive aging and dementia. One of the more practical consequences of the cholinergic hypothesis is that anticholinergic antidepressant drugs should not be preseribed to elderly parients suffering from depression. The finding that caffeine attenuates anticholinergic effects on cognition may also have relevance for (depressed) patients taking anticholinergic medication.

Despite all these limitations, and despite the fact that expectations used to be much higher as to the development of cognition enhancing drugs, the cholinergic hypothesis has survived in the search for anti-dementia drugs [10], and the first drug that has been registered in many countries is a cholinergic drug, tacrine [21]. This situation resembles the time-delay which exists between first discovery and clinical application. So, the first drug against dementia is based on the cholinergic hypothesis that most researches have abandoned, years ago. Current hypotheses concern the degeneration of amylould proteins, the glutamate hypothesis and oxidative stress mechanisms. However, due to the anti-dementia registration of tacrine, the interest in the cholinergic hypothesis has reviwed and pharmaceutical industries have been stimulated to search for more selective cholinergic drugs, particularly anticholinesterase inhibitors. As was already pointed out in chapter 4, human models of cognitive dysfunction are of importance in testing the efficacy in humans of a certain mode of action of a new substance. For example, cholinergic agents ought to reverse the scopolamine-induced cognitive dysfunction. This is parricularly important in light of the expectation of a host of "me-too" drugs developed after tacrine and claiming cholinergic enhancement. It takes only a single dose study to investigate such a claim, using the scopolamine model.

\section{Condusion}

In the quest for cognition enhancers in the treatment of age-related cognitive decline, we have found that both the existence of the disease and the cure are, despite ongoing promising developments, a subject of debate. However, we may have discovered a factor which influences both, namely the memory effects of caffeine. 


\section{REFERENCES}

1. Allain $\mathrm{H}$, Lieury $A_{\text {; }}$ Brunet $B F$, et al. Antidepressants and cognition: comparative effects of maclobemide, wiloxazine and maprotiline. Psychopharmacology Berl Suppl 1992; 106: 56-61.

2. Bartus RT, Dean RL, Beer B, Lippa AS. The cholinergic hypothesis of geriarric memory dysfunction. Science $1982 ; 217: 408-417$

3. Bartus $\mathrm{RT}_{\text {, Dean }} \mathrm{KL}_{n}$ Pontecorvo $\mathrm{MJ}$, Flicker $\mathrm{C}$. The cholinergic hypothesis: $\mathrm{A}$ historical overview current perspective, and future directions. Annals of the New York Academy of Sciences 1985; 444:.

4. Brand $A N$, Jolles J, Gispen-de Wied C. Recall and recognition memory deficits in depression. Journal of Affective Disorders 1992; 25: 77-86.

5. Brand $\mathbb{N}_{3}$ Jolles j. Information processing in depression and anxiety. Psychological Medicine 1987; 17; 145153.

6. Cole $\mathrm{JO}_{i}$ Brancomnier $\mathrm{R}$, Salomon $\mathrm{M}$, Dessain E. Tricyclic use in the cognitively impaired elderly. Journal of Clinical Psychiatry 1983; 44: 14-19.

7. Dawies RK, Tucker GJ, Harrow M, et.al. Confusional episodes and antidepressant medication. Am J Psychiatr $1971 ; 128: 95-99$.

8. Deijen $J B_{3}$ Orlebeke JF, Rijsdijk FV. Effeet of depression on psychomotor skills, eye movements and recogrition-mernory. J Affect Disord 1993; 29: 33440.

9. Fudge JL, Perry PJ, Garvey MJ, Kelly MW. A comparison of the effect of fluoxetine and trazodone on the cognitive functioning of depressed outpatients. J Affect Disord 1990; 18: 275-80.

10. Giacobini E, Becker R. Dewclopment of Drugs for Alyheimer Therapy: A Decade of Progress. In: Giacobini E, Becker RE, ed. Alzheimer's Disease:" Therapeutic Sitrategies. Basel: Birkhäuser Verlag AG, 1994: 1-7.

11. Jarwis $M$. Does caffeine intake enhance absolute levels of cognitive performance? Psychopharmacology 1993; $110: 45-52$.

12. McEnttee WJ, Crook TH. Agge-associated memory impairment: a role for cattecholamines. Neurology 1990; 40: 526.530.

13. MeEnte W], Crook TH. Serotonin, memory, and the aging brain. Psychopharmacology Berl 1991; 103: 143-9.

14. Parrott A, Deary L. Scopolamine, cognition and dementia. J of Psychopharmacology 1992; 6: 541-542.

15. Riedel WJ, Hogervorst Ex Jolles J. Cognition Enhancers and Aging. In: Jolles J, Houx PJ, Van Boxtel MPJ, Ponds RWWHM, ed. Maastricht Aging Study: Determinants of Cognitive Aging. Maastricht, The Netherlands: Neuropsych Publishers, 1995:

16. Ruprehit $\rfloor$, Dworacek B. Central anticholinergic syndrome during postoperative period. Ann Fr Anesth Reanim $1990 ; 9: 295-304$.

17. Siegfried $\mathrm{K}, \mathrm{O}^{\prime}$ Connolly $\mathrm{M}$. Cognitive and psychomotor effects of different antidepressants in the treatment of old age depression. International Clinical Psychopharmacology 1986; 1:231-243.

18. Thompson PJ. Anridepressants and memory: A rewiew. Hum Psychopharmacol 1991; 6: 79-90.

19. Van Praag HM, Asnis GM, Kahn RS, et all. Monoamines and abnormal behaviour. A multi-aminergic perspective. Br J Psychiatry 1990; 157: 723 34.

20. Verhey FRJ. Dementia, depression and forgecfulness. Maastricht: Datawyse, 1993.

21. Wagstaff AJ, McTavish D. Tacrine. A review of its pharmacodynamic and pharmacokinetic properties, and therapeutic efficacy in Alzheimer's disease. Drugs Aging 1994: 4: 510-40.

22. Wesnes $K A$, Simpson P'M, Christmas $L$, Anand R, McClelland GR The effects of moclobemide on cogmition. J Neural T'Tansm Suppl 1982; 28:91-102. 


\section{SAMENVATTING}

Dit proefschrift gaat over cognitief dysfunctioneren, zoals traagheid van warnemen beslissen, reageren, handelen, onthouden en herinneren, welke veel voorkomen bij veroudering en depressie; en mogelijkheden om deze verschijnselen met psychofarmaca te behandelen. De stoffen waar het om gaat worden in de angelsaksische literatuur "Cognition Enhancers", oftewel "cognirieverbeterende stoffen' genoemd. De cholinerge hypothese van cognitieve veroudering en dementie impliceert dat de achreruitgang van cognitieve functies, met name geheugen, samenhangt met een verminderd functioneren van de zenuwen welke voor hun impulsoverdracht (neurotransmissie) afhankelijk zijn van acetylcholine. Veel potentiële cognitie-verbeterende stoffen beogen verbetering van de acetylcholine neurouransmissie. Verslechtering van acetylcholine neurotransmissie is een veelal storende bijwerking van veel geneesmiddelen tegen depressie (antidepressiva), maar is tevens een interessant model voor geheugen- en andere cognitieve problemen. Als zodanig kunnen hierdoor experimenteel toegebrachte cognitie- en geheugenstoornissen fungeren als proefopzet om effecten te testen van potentiële cognitie-verbeterende stoffen. De functic van acetylcholine met betrekking tot cognitie en geheugen is de rode draad in dit proefschrift, dat overigens uit 3 delen mer een verschillend accent bestaat. Her eerste deel (hoofdstuk $1 \mathrm{~d} / \mathrm{m}$ 3) gaat over de cognitieve veranderingen welke gepaard gaam met veroudering. Her tweede ded (hoofdstuk $4 \mathrm{t} / \mathrm{m}$ 6) gaat over onderzoek naar mogelijke nieuwe geneesmiddelen tegen cognitieve veroudering: cognitieverbeterende stoffen. Het derde deel (hoofdstuk 7 en 8) gaat over positiewe en negatieve bijwerkingen, op cognitieve funcries, van geneesmiddelen tegen depressie. Eilk deel begint mer een overzichtsartikel van het betreffende gebied en wordt gevolgd door artikelen waarin gerapporteerd wordt over onderzoek uitgevoerd op dit gebied.

\section{Deel I}

In hoofdstuk 1 wordt een overzicht gegeven van de effecten van normale veroudering op het cognirief functioneren. Tevens wordt uitgebreid ingegaan op de afgrenzing van normale cognitiewe veroudering, en cognitieve dysfuncties zoals vergeetachtigheid, welke ook worden aangetroffen bij depressie en in sterkere mate bij dementie. Her blijkt dat vrijwel alle cognitiewe functies, wanmeer objectief getest, achteruitgaan met het klimmen der jaren. Ook subjectieve klachten over geheugen-achteruitgang, verminderde concentratie, traagheid van denken, of onvermogen meerdere dingen tegelijk te doen, nemen toe in antal met de leefrijd. De snelheid warmee cogniticwe achteruitgang als gevolg wan veroudering optreedt verschilt tussien mensen en hangt wellicht mede samen met een aantal gezondheids-gerelatecrde factoren die in verband gebracht kunnen worden met gestoorde hersenfuncties (biological 'life events'; BLE). Het gaat hier om gebeurtenissen, zoals geboortecomplicaties, hersentrauma's, meerdere langdurige narcosen, overmatig alcoholen/of medicijngebruik, blootstelling aan neuroroxische stoffen, neurologische en/of psychiarrische ziektes, wellke geruime tijd voor her bereiken van de ouderdom gebeurd kunnen zijn en toch pas op latere leefrijd hun inwloed doen gelden. Het grijze gebied tussen normalle en pathologische veroudering is minder duidelijk omschreven dan de gebieden waar het tussenin ligt. Verschillende, maar verwante diagnose-georiënteerde beschrijwingen van leeftijdsgebonden cognitiewe achteruitgang bestaan naast elkaar. Goedaardige en kwaadaardige ouderdomswergectachtigheid (Benign Senescent Forgetfulness; BSF en Malignant Senescent Forgetfulness; MSF), leefrijdsgeas- 
socieerde gcheugenachteruitgang (Age-Associated Memory Impaiment; AAMH), leeftijdsconsistente geheugenachteruigang (Age-Consistent Memory Impairment: ACMI), vergeetachtigheid op latere leefrijd (Latc-Life Forgerfulness; LLF) en cognitieve stoomissen (Mild cognitive changes [subthreshold] and Cognitiwe impairment disorders; DSM IV) volgens de meest recente psychiatrische diagnostiek (DSM IV) zifn slechts enkele voorbeelden van de varièteit aan experimentele diagnostische categoricen die het onderzoek naar cognitieve veroudering en dementie de latate jaren heeft voortgebrachit. Teneinde tot deze diagnostische uitspraken te kunnen kwmen bestaan er bovendien diverse instrumenten of schalen. Bijvoorbeeld de "Global Deterioration Scale' (GDS), de 'Clinical Dementia Rating scale' (CDR) en de 'Cambridge Mental Disorders of the Euderly Examinarion' (CAMDEX). Een diagnose van cognitieve stoornissen kan van belang aijn voor het vroegtijdig onderkennen van de diagnose Dementie. Medicamenteuze behandeling van leefrijdsgebonden cognirieve achteruitgang bevindt zich in een experimented stadium. Er is veel onderzoek gedaan naar mogelijke cognitieve verbetering na behandeling met experimentele "cognitie-verbeterende stoffen", zowel bij patiënten met de ziekte van Alzlieimer als bij ouderen met klachten over geheugen en/of cognitieve functies. Dit onderzoek heeft tot nu toe weinig opgeleverd. Enerzijds ligt dat aan de experimentele stoffen, maar anderzijds ligt dat aan de heterogeniteit van de onderzochre groepen patiënten. Toekomstige strategieèn zouden meer georiënteerd moeten zijn op een nog scherpere beschrijving van de symptomen welke men wil behandelen. Tevens zal bij de samenstelling van patièntengroepen voor dit type onderzoek meer gelet moeten worden op gezondheids-gerelateerde factoren (BLE).

In hoofdstuk 2 worden de resultaten beschreven van cen wergelijkend onderzoek natar de samenhang tuissen geheugenklachten en cognitieve functies bij oudere mensen. Twee groepen van 36 personen (47-81 jaar) werden onderzocht met behulp van twee aandachtstesten uit de neuropsychologische praktijk. De ene groep voldeed aan de criteria voor leeftijds-geassocieerde geheugenachteruitgang (AAMI). De andere groep had geen klachten over het geheugen. Voor het overige waren beide groepen gezond en bevatten evenveel mannen als vrouwen. Bovendien waren de groepen gelijk samengesteld voor wat betreft de verdeling van opleidingsniveau en gezondheids-gerelateerde factoren. Metingen van de geheugenzoektijd, informatiecoderingssnelheid, en van leessnelheid, kleurbenoemingssnelheid en de mate van automatische leesresponsonderdrukking bij het kleurwoord conflict werden respectievelijk verkregen met de papier-en-potbood-versie van de 'Sternberg-Tak' en de 'Stroop-Taak'. Het resultaat was dat de onderzochten met geheugenklachten gemiddeld trager waren in informatiecoderingssnelheid: zij hadden meer tijd nodigg om de opgedragen tekentjes op een vel papier aan te kruisen, vooral als dat letters waren. Hun geheugenzoektijd was echter geenszins vertraagd. De lecsnelheid van de onderzochten met geheugenklachten was gemiddeld langzamer dan die van de controlegroep, maar de snelheid van her benoemen van kleuren en wan gekleurde woorden met ecn conflictueuze inhoud (bijw. het woord rood, maar dan groen gekleurd, verschilde niet tussen de groepen. De conclusie was dat de onderzochte groepen wooral verschilden met betrekking tor de snelheid van het codeten wan letters, hetgeen ook de selectief vertraagde leestijd zou kunnen verklaren. Er werd derhalve een objectieve basis gevonden voor subjectieve geheugenklachten. De resultaten waren eens te meer aanleiding om te conduderen dat subjecrieve geheugenklachten niet alleen maar duiden op objectieve geheugenstoornissen maar veeleer op cognitieve of informatieverwerkingstoornissen in het algemeen.

Een van de belangrijkste onderdelen van de cholinerge hypothese is een proefopzer waarin bij gezonde vrijwill ligers gedurende korte tijd stoornissen van geheugen en cognitieve functies worden opgewekt door het roedienen van scopolamine, een stof die de acetylcholine neurotransmissie tijdelijk blokkeert. Onderzock naar de wraag of deze experimentele blokkade van de acetylcholinehuishouding in her central zenuwstelsel (CZS) de toestand weerspiegelt zoals van het normaal-en/of pathologisch verouderde CZS, is na 30 jaar onderzoek nog altijd niet afdoende beancwoord. In hoofdstuk 3 worden de resultaten gerapporteerd van een onderzoek naar het effect van deze proefopzet met scopolamine bij 16 gezonde wrijwilligers bij wie dezelfde geheugen- en 
cognitieve functies werden gemeten als in het grootschalige verouderingsondertock, moals destijds door Houx eveneens in Mastricht uitgevoerd. De effecten van scopolamine werden gemeten 2; 4 en 6 uur na toediening en werden vergeleken mer de metingen verkregen voor de toediening van scopolamine. De resultaten lieren zien dat scopolamine de prestatie op geheugentests tijdelijk drastisch verslechterde. Cognitieve en psychomotorische snelheid waren ook vertraagd, maar sommige hogere cognitieve functies, met name die waarbij geen sterk beroep op geheugen werd gedaan, zoals het vermogen om een dominante maar onjuiste reactie te onderdrukken (responsonderdrukking), waren onaangedaan. Vergelijkingen wan de sterkte en het patroon van de effecten van scopolamine mer die van leefrijd op geheugen- en cognitieve functies lieten zien dat met aame de geheugeneffecten van scopolamine lijken op die van leeftijd en in de zelfde orde van grootte waren, maar dit gold absoluut niet voor psychomotorische en cognitieve snelheid op andere taken. De leeftijdsgebonden vertraging wan psychomotorische- en cognitieve functies was vele malen groter dan het effect van scopolamine. Scopolamine tast blijkbaar vooral de hersenfuncties aan welke nodig zijn voor het uitoefenen van geheugen-gerelareerde processen, rerwijl bij weroudering waarschijnlijker veel meer hersenfuncties vertraagd zijn.

\section{Deel II}

In hoofdstuk 4 wordt een uitgebreid overzicht gegeven van onderzoeken welke de afgelopen 5 jaar (vanaf 1990) zijn uitgevoerd naar de invloed wan 'cognirie-verbeterende stoffen" op het cognitief functioneren bij niet demente jonge en oude mensen. De resultaten van 67 onderzoeken mer eenmalige doseringen en 42 herhaalde doseringen van 'cognitie-verbeterende stoffen' zijn samengevat in twee tabellen en worden besproken. Alle eenmalige dosering studies en 14 herhaalde doseringsstudies werden uitgevoerd bij jonge of oude vrijwillige proefpersonen. In 45 van deze 81 studies bij vrijwilligers werden experimentele proefopzetten van cognitieve stoornissen toegepast. De scopolamine-proefopzet was het meest gebruikt (21). Bij de overige onderzoeken werden benzodiazepinen (8), hypoxische lucht (7), alcohol (5), en slaap-deprivatie (4) gebruikt als proefopzet voor het bestuderen van tijdelijk opgewekte cognitieve stoornissen. De overige 28 herhaalde doseringsstudies waren klinische onderzoeken welke gemiddeld 14 weken duurden (minimaal 2 weken en maximaal 1 jaar). In 21 klinische onderzoeken, werd her effect van 'cognitie-verbeterende stoffen' onderzocht in pariënten welke voldeden aan de criteria voor AAMI of een andere vorm van leeftijdsgebonden cognitieve achteruitgang (Age-Associated Cognitive Decline; AACD). De overige klinische onderzoeken verschilden alleen met betrekking tot de patiëntengroepen: verschillende diagnosen uit de neuropsychologische praktijk (epilepsie, alcholisme, hersentrauma) met cognitieve stoornissen als gemeenschappelijk kenmerk.

In veel van deze onderzoeken konden keine 'cognitie-verbeterende' effecten van de onderzochte stoffen ondubbelzinnig worden aangetoond. De wrag nat de klinische effecriviteit in de behandeling van leeftijdsgebonden cognitieve achteruitgang is echter mowilijker te beantwoorden op grond van de besproken onderzoeksresultaten. Onder de onderzochte stoffen bevinden zich ook de reeds zeer veel gebruikte stoffen cafeine en nicotine alsmede verschillende vitaminen. Nisuw ontwikkelde stoffen welke inwerken op de neutotransmissie van subtypen van serotonine (receptorantagonisten van 5-hydroxytryptamine; $5 \mathrm{HT}_{3}$ ) en glutamaat (partiele receptor-antagonisten van $\mathrm{N}$-methyl-d-aspartaat; NMDA), lieten echter teleurstellende resultaten zien in klinisch onderzoek bij ouderen met AAMI. Er is eigenlijk geen enkele stof waarvan de klinische effectiviteit bij leeftijdsgebonden cognitieve achteruitgang afdoende bewezen is. Geneesmiddelenontwikkeling op het gebied van de ziekte wan Alzheimer welke tot steeds grotere selectiviteit en specificiteit van de nieuw ontwikkelde stoffen leidt, alsmede tot verbetering van hun bijwerkingsprofielen, kan mogelijk ook bujdragen, in de nabije toekomst, aan de ontwikkeling van klinisch effectieve 'cognitie-verbeterende stoffen' woor leeftijdsgebonden cognitiewe achteruitgang.

In hoofdstuk 5 wordt een onderzoek beschreven, naar de invloed van piracetam, de eerst ontwik- 
Welde potentide 'cognitic werbeterende stof, op het rijgedrag wan cen groep van 38 oudere (60-80 jar) automobilisten. Deze groep was geselecteerd uit een groep van 134 vrijwilligers in dezelfde leeftijdsklasse. De sclectiecriteria waren naase medische geschiktheid om aan het onderzoek mee te doen, bet overschrijden van twee onafhankelijke criteria van rijgedrag. Een score voor het rijgedrag in het stadsverkeer was gebascerd op de "ANWB rijtest voor ervaren automobilisten". Het slaag/faal criterium (niet leeftijdsgebonden) was $80 \%$. Een score voor het koershouden op de rechte (snel) weg werd verkregen door de statistische index voor het slingergedrag te meten en te berekenten over een traject op de autosnelweg van ca. $90 \mathrm{~km}$. Het criterium werd zodanig gekozen (gemiddelde score op de slingerindex van jongeren +1 standaarddeviatie) dat ongeveer de helft wan de ouderen deze zou overschrijden. De aldus geselecteerde proefpersonen kregen gedurende twee perioden wan 4 weken dagelijkse doseringen van 4.8 gram piracetam en placebo, respectievelijk. Het onderzoek was uitgevoerd volgens een dubbel-blinde, placebo-gecontroleerde, 'cross-over' onderzoeksopzet. Vlak voor het begin van de behandelingsperioden en na 2 , en na 4 weken behandeling, werden metingen van het rijgedrag verricht. De slingerindex werd gemeten alsmede een index voor het adequaat reageren op een voorliggende auto ten aanzien waarvan een veilige afstand gehouden diende te worden. Omdat piracetam in Nederland (en vele andere landen) geindiceerd is als geneesmiddel tegen evenwichtsstoornissen, werd op de testdagen ook de stabiliteit van de lichaamshouding bij het rechtop staan met ogen open en ogen dicht gemeten, mbv. een zgn. evenwichtsplatform. Op het rijgedrag werd gemiddeld geen verschil gezien tussen de piracetam- en placebo behandelde testritten. Echter, na 4 weken behandeling met piracetam werd een iets betere slingerindex gevonden dan na 4 weken placebo. Wellicht zou dit na een langere behandelingsperiode tot een groter verschil kunnen leiden, maar gezien de rigoureuze selectic van slecht presterende proefpersonen kan niet geconcludeerd worden dat hier sprake was van een relevante verbetering. Zoals al in hoofdstuk 4 werd opgemerkt, laten veel onderzoekers van 'cognitie-verbeterende stoffen' achteraf zien dat de proefpersonen die bij binnenkomst het slechtst presteerden, het meest wan de behandeling profiteren. Bij dit onderzoek met piracetam werd de selectie van te voren gedaan en de goed scorende oudere automobilisten werden niet behandeld. Deze methode om het behandelingseffect te vergroten heeft echter gefaald, getuige de afwerigheid van een betekenisvolle verbetering van het rijgedrag. Bovendien leek de geconstateerde significante verbetering van de stabiliteit van lichaamshouding na behandeling met piracetam, uit te wijzen dat de indicatic van piracetam, evenwichtsstoornissen van centrale aard, waarschijnlijk beter op z"n plaats is dan 'cognitie-verbetering'.

Andere stoffen waarvan 'cognitie-verbeterende' eigenschappen worden vermoed zijn cafeïne en nicotine. Alhoewel tot nu roe cafeïne vooral als een milde CZS stimulant wordt gezien, is pas vrij recent vastgesteld dat cafeine in mensen meer specifiek cognitieverbeterende eigenschappen wou kunnen hebben, met name op hogere leeftijd. Van nicotine waren de cognitie- en aandachtsverbeterende eigenschappen al iets langer bekend en de toediening van nicotine aan patiënten met de ziekte van Alzheimer, middels nicotine-pleisters, wordt al geruime tijd onderzocht. In hoofdstuk 6 worden de resultaten gerapporteerd van een onderzoek naar de geheugen- en cognitie-verbeterende werking van cafeüne en nicotine, waarbij gebruik gemaakt werd van de scopolamine proefophet om eerst tijdelijk cognitieve stoornissen bij 16 gezonde vrijwilligers (25-33 jaar) op te wekken. De proefpersonen kregen na voorbehandeling met scopolamine, $250 \mathrm{mg}$ cafeine (in 3 kopjes koffie), 2 mig nicotine (in kauwgum), en/of placebo ( 3 kopjes decafé en placebo-kauwgum) roegediend tijdens 3 verschillende testdagen. De studie werd uitgevoerd volgens een placebo-gecontroleerde, dubbel-blinde, "cross-over' onderzoeksopzer. Nicotine verbeterde de door scopolamine opgewekte stoornissen van het onmiddellijk geheugen, de door scopolamine opgewekte vertraging wan de geheugenzoektijd en eveneens de door scopolamine opgewekte vertraging van reactietijd in een responsonderdrukkingstaak. Cafeïne verbeterde de door scopolamine opgewekte stoornissen van het onmiddellijk en lange termijn geheugen alsmede de kwaliteit en snellieid wan herkenning van geleerde woorden. Ook de door scopolamine opgewekte vertragingen in de visuele informaticcoderingstijd, leessnelheid, en motorische snelheid werden 
door cafeine in enige mate verbeterd. De conclusie van het onderzoek was dat nicotine en cafeine kwalificeren als 'cognitie-verbeterende stoffen', al moet gezegd worden dat hun effect niet groo: was, maar daar staat tegenover dat de onderzochte doseringen berrekkelijk gering waren. Van nicotine was de "cognitie-verbeterende" eigenschap al bekend en her behalde resultatat is dan ook vooral een ijking van de gevoeligheid van de neuropsychologische testbatterij voor her meten van dit type effecten. Echter, de "cognitie-verbeterende" effecten van cafeïne $250 \mathrm{mg}$, een hoeveclheid welke normaal wordt ingenomen wanneer men 3 kopjes koffe van een gemiddelde sterkte consumeert, waren verrassend. Aangezien zo"n hoevelheid cafeine door een zeer aanzienlijk deel $(90 \%)$ van de bevolking dagelijks geconsumeerd wordt, kan zo'n resultaat verstrekkende implicaties hebben voor het onderzoek naar cognirieve veroudering. Mogelijk is cafeinegebruik zelfs een beschermende factor tegen cognitieve veroudering, een hypothese welke thans binnen de Maastrichtse verouderingsstudie onderzocht wordt.

\section{Deel III}

Bijwerkingen van antidepressiva wellke worden veroorzakt door blokkering van de acetylcholine neurotransmissie in het CZS, herzelfde mechanisme als de door scopolamine opgewekte geheugen- en cognitieve stoomissen, dragen over her algemeen niet bij tor verlichting van de depressie en zijn dus ongewenst, in het bijzonder bij oudere patiënten. Bowendien beginnen dezc zgn. anticholinerge bijwerkingen vaak op de eerste dag van medicamenteuze behandeling met antidepressiva, terwijl de therapeutische werking pas na 2 tot 6 weken merkbaar wordt. Verlichting van de depressieve klachten worden over het algemeen toegeschreven aan verbetering van de neurotransmissie van serotonine (5.HT) en/of noradrenaline (NA). In hoofdstuk 7 wordt cen overzicht gegeven van de cognitieve effecten van antidepressiva, met name voor zover deze in verband kunnen worden gebrache met de mate van anticholinerge werking van de middelen. De tricyclische antidepressiva vertonen over het algemeen de meeste anticholinerge bijwerkingen. Deze uiten zich vooral door vergectachtigheid, droge mond en onscherp zien. Er is een ruime keus uit antidepressiva zonder anticholinerge bijwetkingen, maar dat betekent niet dat deze geen cognitieve stoomissen kunnen veroorzaken. Voorbeelden hiervan zijn de middelen trazodone en mianserine: stoffen zonder acetylcholine blokkering, maar met een grote kans op sufheid als bijwerking waardoor de prestatie op veel cognirieve tests eveneens kan verminderen. De nieuwere selective 5-HT heropname remmers (SSRI's) vertonen over het algemeen geen ernstige bijwerkingen op cognitief functioneren. Waak wordt verberering van geheugenfunctie na behandeling van enkele weken met deze middelen gevonden. Een andere categorie nieuwe antidepressiva zijn de reversibele remmers van monoamine-oxidase- $A$ (RIMA's), het enzym dat de afbralk van 5 H $\mathrm{H}$ en NA regell. Van dexe categorie werden zowel in experimenteel onderzock, middels de scopolamine-proefopzet als in klinisch onderzock bij depressieve patiënten . geheugenverbeterende effecten gevonden.

In hoofdstuk 8 worden de resultaten beschreven van een onderzoek naar het effect van een trazodone, een antidepressivum zonder enige anticholinerge werking, bij ambulante pariënten met een diagnose depressie (major depression). Acht patiënten (34-56 jaar) werden (na een geleidelijk werhoogde dosering) behandeld gedurende 5 weken met trazodone $150 \mathrm{mg}$ twee maal daags of $200 \mathrm{mg}$ tweemaal daags (voor 3 patiènten die anvankelijk niet gunstig op de behandeling reageerden; non-responders). Voor en na deze periode werden zij een week met placebo behandeld. De onderzoeksopzet was enkel-blind. Aan het eind van elke week werden cognitieve functies getest. Een vergelijking wan de cognitieve functies van de patièntengroep met cen vergelijkbare niet-depressieve controlegroep liet zien dat de depressieve pattënten veel trager waren op de geheugenwergelijkingstest (Sternberg taak), maar dat deze vertraging niet verklaard werd door een vertraagde geheugenzoektijd, maar waarschinlijk door vertraagde informariecoderingssnelheid. Tijdens de behandelingsperiode was de index van visuele beeldfusic (critical flicker frequency treshold; CFF), significant verlaagd in wergelijking met de metingen voor en na de behandeling 
met trawodone. En verlaging wan deze index wijst in het algemeen op een lagere verwerkingssnelheid in het CZS en kan her gevolg zijn wan de sederende werking van trazodone. Dit is watschijnlijk omdat van trazodone bekend is dat her en sterke blokkering van $\alpha_{1}$-adrenerge receptoren teweeg brengr. Tijdens de behandelingsperiode werd in vergelijking met de periodes darvoor en daarna echter een verbetering van de lange termijn geheugenscore gevonden. Deze resultaten leidden tot de conlusie dat trazodone, ook al is het warschijnlijk een sederend antidepressiwum, geheugenwerbetering toelaat bij depressieve patiènten. Of deze geheugenwerbetering farmacologisch gemedieerd was, dan wel cen indirect gevolg was van stemmingswerbetering, kon op grond van dit onderzock niet worden uitgemaalkt. Het belang van deze gegevens is gelegen in de klimische relevantie van geheugenverbetering bij depressie.

\section{Conclusie}

Onderzoek naar de cognitieve effecten van antidepressiva, mits het tenminste niet gaat om anticholinerge middelen, laat over het algemeen zien dat geheugenverbetering na medicamenteuze behandeling tor de mogelijkheden behoort. Zo'n resultaat wordt helaas (nog) niet gevonden na experimentele medicamenteuze behandelingen van leeftijdsgebonden cognitieve achreruitgang en dementie. In de speurtocht naar 'cognirie-verbeterende scoffen' zijn we echter gestuit op de geheugenverbeterende effecten van caferne, een bevinding die mogelijk wan belang is voor zowel het onstaan wan leeftijdsgebonden cognitieve achteruitgang, als voor de behandeling erwan. 


\section{Dankwoord}

Tijdens het schrijven van dit proefschrif, of liever gezegd vooral tijdens de periode dat het had moeten worden geschreven, werden vele kilometers te land, ter zee en in de lucht afgelegd en moesten wele pillen worden geslikt. Dit ging nier zonder de morele ondersteuning, assistentie en medewerking wan veel mensen. Een aantal wil ik met name noemen. Ik doe dit aan de hand van de hoofdstukken uit dit proefschrift; een geheugensteuntje, want voor sommigen geldt de dank voor de pretrige samenwerking uit een wat langer geleden periode.

De hooflstukken 1, 4 en 7 kwamen tot stand onder leiding van de mensen die misschien wel het moeilijkste werk moesten verrichten: mij leiding geven.

Hooggeleerde Jolles, hooggeachte promotor, beste Jelle. De gouden tip die je me al vrij snel na mijn indiensttreding gaf, luidde dat onderzoek, hoe goed ook uitgevoerd, dat niet gepubliceerd is, in wezen niet is gedaan. Meer dan wie ook heb je me er bovendien van weten te overtuigen dat ik "het alleen nog maar ewen moest opschrijven". Uiteindelijk bleken deze uitspraken belangrijke drijfveren woor de totstandkoming van dit proefschrift en hopelijk nog voor veel toekomstig werk. Mijn dank voor het gestelde wertrouwen.

Hooggeleerde Van Praag, beste Herman. Mijn dank voor de deskundige en uiterst snelle respons op mijn protocollen en artikelen. Met name voor het geschonken vertrouwen, wat leidde tot het artikel waaruit hoofdstuk 7 bestaat, ben ik je in het bijzonder zeer erkentelijk.

Zeergeleerde O'Hanlon, beste Jim. Her IGVG was een zeer enerverende en leerzame periode. Dat gold des te meer voor zaken die ik niet verwacht had te zullen leren en daarvan is het leren drinken van whisky nog wel één van de onschuldigste.

Promovendi die mij voorgingen: Zeergeleerde Houx en Verhey; beste Peter en Frans. Bedankt voor jullie bijdrage aan hoofdstuk 1 . Bedankt ook voor jullie welhaast alomtegenwoordige scherpzinnigheid en humor. Peter, bedankt voor de controlegroepen (hooffdstuk 2 en 3). Frans, bedankt voor de plezierige en collegiale wijze van samenwerking in het vele onderzock dat we deden, slechts een deel daarvan heeft betrekking op dit proefschrift (hoofdstuk 6).

Zeergeleerde Peters; beste Madelon. Bedlankt dat je het karwei afmakke dat ik op het toenmalige IGVG achterliet, en wat uiteindelipk tor hoofdstuk 5 heef geleid.

Geleerde Hogerworst, beste Eef, bedankt voor je bijdrage aan thoofdstukken 3 en 6 , voor het paranimf zijn, voor het begeleiden van stagiaires, de vele discussies over cognicion enhancers, modellen voor cognitieve dysfunctie, smart drugs, caffeïne, nicotine, uitputting, resources, effort, en ga zo maar door. Jouw proefschrift zal een waardevol vervolg zijn op het mijne.

Verder wil ik de collega"s Martin van Boxtel, Els Schoenmakers en Annemiek Vermeeren bedanken die een bijdrage aan de diverse onderzoeken, waaruit dit proefschrift bestaat (hoofdstukken 5 en 8), hebben geleverd. Speciale dank gaat uit naar Huub Hamers voor de rechnische ondersteuning, zowel op het IGVG als bij NNP. Henk Brauers, bedankt voor de supervisie over de rijvaardigheid van de oudere proefpersonen. Zonder jouw oplettendheid, was dit proefschrift misschien wel niet geschreven. Ingrid Baaijens, Bas Bekkers, Mircille van Bree, Rogier van Drumpt, Marthijs Hesselink, Geraline Leusink, Wim Linders, Astrid Quist, Arno Rademaker, Marc Rademaker, Anton van der Vusse en Jeldican Visser, zeg ik dank voor hun hulp bij het verzamelen wan gegevens voor dit proefschrift. 
De beste bass voor discipline-owerschrijdende wetensichappelike samenwerking is een goede onderlinge verstandhouding. Moofe woorden, maar breng te maar eens in de praktik. Dar lukte heel aardig mer de FC Brainwawe: Rudolf, Jos; Martin, Pieter-Jelle, John en Robby weten net als ik watr de echte integratie tussen de B- en de $\mathrm{H}$-sectie het best kan beginnen.

Alle collega's van P\&N enlof NNP, die ervoor zorgden dar her pretrig is on te werken in UNS50, de geneugenpoli, de Y-factoren, B1, en de 4e verdieping: Bedankt!

Ploeggenoten van TWC "De Specht": ik zit weer in de bus en ga van woren uitstappen.

Alle owerige vrienden en wriendirnen, bedankt dat ik bij jullie zoveel afleiding wond dar mij gelukkig niet te vaak de vraag is gesteld: "Hoe gaat het met je proefschrift?". Eén uitzondering hierbij moet gemaalkt worden voor paranimf Peter van Niekerk. Peter, bedankt voor je enorm stimulerende medeleven en nimmer aflatende belangstelling woor mijn werk.

Tenslonte, Vader en Moeder, bedankt dat jullie me lieten studeren en altijd respecteerden in mijn vele onmavolgbare keuzes. 


\section{Curriculum Vitae}

Wim Riedel werd op 22 maart 1956 geboren te Groningen. $\mathrm{Na}$ het Atheneum-B in 1975 studeerde hij psychologie aan de Rijksuniversiteit Groningen. Tijdens deze studie had hij in de periode '77-'84 diverse berrekkingen als student-assistent ten behoeve wan onderwijs en onderzock. De stageperiode vervulde hij bij de afdeling medische psychologie an de Rijksuniversiteit Limburg te Maastricht. Na het afstuderen in de psychologische functieleer (1984) was hij werkzaam bij het Verkeerskundig Studiecentrum aan de Rijksuniversiteit Groningen waar hij onderzoek verrichtre naar de beïnloeding van snelheidsgedrag van automobilisten. Vanaf medio 1986 gaf hij mede gestalte aan de verrijzenis van het Instituut voor Geneesmiddelen Veiligheid en Gedrag (thans Instituut voor Humane Psychofarmacologie) aan de Rijksuniversiteit Limburg en verrichte daar toegepast onderzoek naar de invloed van psychofarmaca op psychologische functies, slaap en het besturen van auto's en wiegtuigen. Vanaf 1992 is hij werkzaam bij de vakgroep Psychiatrie, sectie Neuro-psychologic, Neuropsychiatrie en Psychobiologie, waar hij onderzoek verricht naar de invloed van psychofarmaca op geheugen en andere cognirieve functies bij gezonde vrijwilligers, ouderen met geheugenstoomissen en depressie- en dementicpatiënten. De auteur is in zijn vrije tijd enthousiast toerfietser en is voorzitter van de ToerWiderClub "De Specht" te Maastricht. Verder behaalde hij in 1994 het international brever voor het besturen van énmotorige vliegtuigen. 



\section{Publications}

Articles:

Riedel WJ, \& Van Praag HM (1995). Avoiding and Managing Anticholinergic Effects of Antidepressants. CNS Drugs, 3(4), 245-259.

Riedel WJ, Hogervorst E, Leboux RLAM, Verhey FRJ, Van Praag HM, \& Jolles I (1995). Caffeine attenuates scopolamine-induced memory impairment in humans. Psychopharmacology, in press.

Riedel WJ (1995). Book Review: Intellectual Functions and the Brain. An Historical Perspective. Journal of Chemical Neuroanatomy, $9(3)$, in press.

Jolles J, Verhey FRJ, Riedel WI, \& Houx PJ (1995). Cognirive lmpairment in Elderly People* Predisposing Factors and Implications for Experimental Drug Studies. Drugs \& Aging; in press.

Riedel WJ, \& Jolles J (1995), Cognition Enhancers in Age-Related Cognitive Decline. Drugs \& Aging; Invited submission.

Riedel WJ, Hogervorst, EFM, \& Jolles J The Scopolamine Model of Cholinergic Depletion: Model of Memory Dysfunction? Submitted for publication.

Riedel WJ, Houx, PJ, \& Jolles J Memory Scanning, Automatic Processing and Focussed Attention in AAMI. Submitted for publication.

Riedel WJ, Peters ML, Van Boxtel MPJ, \& O'Hanlon JF The Influence of Piracetam on Actual Driving Behaviour and Postural Stability of Elderly Subjects. Submitted for publication.

Riedel WJ, Schoenmakers EAJM, Jolles J, \& O'Hanlon JF Treatment of transient insomnia in rotating shiftworkers with short acting benzodiazepines. Submitted for publication.

Riedel W], Schoenmakers EAJM, Vermeeren AE, \& O'Hanlon JF The Influence of Trazodone Treatment on Cognitive Functions in Outpatients with Major Depressive Disorder. Submitted for publication.

Riedel WJ, Schoenmakers EAJM, Jolles J, \& O'Hanlon JF Instrument Flight Performance after Desynchronized Sleep Treated with Lormetazepam. Submitted for publication.

Hogervorst $E$, Riedel WJ. Jeukendrup A, \& Jolles J. Lack of cognitive deficiencies due to strenuous exercise in fatigued athletes. Submitted for publication.

\section{Book sections.}

Michon JA, Bruinsma A \& Riedel WJ (1984). Concatenation of short time intervals. In: Limits of Perception. Lisse: Swets \& Zeitlinger.

Riedel WJ \& Lulofs R (1986). Vigilance performance and psychophysiologic reactions of type A and vitally exhausted persons. In $\mathrm{T}$ Schmidt, TM Dembroski \& G Bluemchen (Eds.), Biological and Psychological Factors in Cardiovascular Disease, (pp. 302-314). Heidelberg: Springer Verlag.

Riedel W, Rothengatter T, \& De Bruin RA (1988). Selective enforcement of speeding behaviour. In T Rothengatter \& RA De Bruin (Eds.), Road user behaviour: Theory and research., (pp. 578-583). Assen, Netherlands: Van Gorcum \& Co B.V.

Riedel WJ, Schoenmakers EAIM \& $\mathrm{O}^{\prime}$ Hanlon JF (1989). Sedation and performance impaiment with antihistamines. In M Kaliner (Ed.), Management of Allergy in the 1990's, (pp. 38-49). Toronto: Hans Huber.

Riedel WJ, Schoenmakers EAJM, \& O'Hanlon JF (1990). Driving while under the influence of alcohol: An attempt to explain behavioural variability. In T Benjamin (Ed.), Proceedings of the International Symposium on Driving behaviour in a Social Context, (pp. 733-737). Cean, France: Paradigme. 
Riedd W] (1991). Eye movements, expert ratings, weaving and time-to-line-crossing as measures of driving performance and driving performance impaiment. In $\mathrm{AG}$ Gale, ID Brown, HM Hasslegrave \& SP Taylor (Eds.), Vision in wehicles, (Vol. III, pp. 299-306). Amsterdam, the Netherlands: North Holland Publishing Company.

Riedel W], Hamers HMW, Robbe HW], Vermeeren A \& O'Hanlon JF (1991). Automated behavioral testing in psychotropic drug research. In LJM Mulder, FJ Maarse, WPB Sjouw \& AE Akkerman (Eds.), Computers in psychology". Applications in education, research and psychodiagnostics (pp. 166-170), Amsterdam, Netherlands: Swets \& Zeitlinger.

Riedel WJ, Hogerworst $\mathrm{E}$, \& Jolles J (1995). Cognition Enhancers and Aging. In J Jolles, PJ Houx, MPJ Van Boxtel, \& RWHM Ponds (Eds.), Maastricht Aging Study: Determinants of Cognitive Aging. Maastricht, The Netherlands: Neuropsych Publishers.

Hogervorst E, Riede: WJ, Rozendaal N, Van Boxtel MPJ, \& Jolles J (1995). Smoking and cognitive complaints, In J Jolles, PJ Houx, MPJ Van Boxtel, \& RWHM Ponds (Eds.), Maastricht Aging Study: Determinants of Cognitive Aging. Maastricht, The Netherlands: Neuropsych Publishers.

Riedel WJ, \& Lulofs R (1995). Differences in Vigilance Behavior and Cardiovascular Reactivity berween male Type-A and Type-B subjects. In G. Orter \& F. Palmero (Eds.), Type A Behavior Partern and Cardiovascular Disease. Valencia: Promolibro; in press.

\section{Published Abstracts:}

Riedel WJ, Quasten, R, \& O'Hanlon JF (1988). Effects of midazolam triazolam and temazepam on shifworkers' day-sleep and subsequent driving performance. Psychopharmacology, 96(232), 1565 .

Quasten, R., Riedel WJ, \& O'Hanlon JF (1988). Residual effects of midazolam, triazolam and temazepam on shiftworker' visual efficiency during city-driving using eye-movements measurements. Psychopharmacology, 96(232), 358S.

Van LeeuwenCJ, Riedel WJ, \& O'Hanlon JF (1988). A novel experimental approach for assessing anti-aggresstve drugs: pilot study with CGP $361 \mathrm{~A}$ and diazepam. Psychopharmacology, $96(232), 3585$.

Riedel WJ, Van Veggel L, \& O'Hamlon JF (1990). Ceririzine 10 and $20 \mathrm{mg}$ impair psychomotor performance. Clin Exp Allergy, 20(S1), 97.

Riedel WJ, \& Jolles J (1993). Decteased blood level of xinc: Does it explan Age-AssociatedMemory Impairment? Neuropsychopharmacology, 9(2S), 57.

Riedel WJ, Leboux RLAM, Hogervorst $E_{*}$ Quist $A$, Van der Vusse A, Verhey FRJ, \& Jolles J (1994). Cafleine enthances Memary Function after Cholinergic Blockade. Neutobiology of Aging, $15(1), 100-101$.

Leboux RLAM, Ried WJ, Verhey FRJ, \& Jolles J (1994). Assessment of Cognitive Speed in Patients with Mild Alzheimer"s Disease. Neurobiology of Aging, 15(1), 92.

\section{Registered Research Reports:}

Riedel WJ, De Bruin RA, Rothengatter JA (1985) De invloed wan intensiteit van verkeerstoezicht en variabele snetheidsbebording op het snelheidsgedrag op $80 \mathrm{~km}$ wegen (with english summary). "Traffic Research Centre, Groningen. The Netherlands. ISBN 90-6807-038-X

Rothengatter JA, Riedel WJ, Vogel RW (1985) De invloed wan gericht verkeers toezicht op het snelheidsgedrag op $80 \mathrm{~km}$ wegen (with english summary). Traffic Research Centre, Groningen, The Netherlands. ISBN 90-6807-019-3 
Riedel WJ, De Bruin RA, Rothengatter JA (1986) De invloed wan voorlichting en verkeerstoezicht op het snelheidsgedrag op $80 \mathrm{~km}$ wegen (with english summary). Traffic Research Centre, Groningen, The Netherlands. ISBN $90-6807-049-5$

Riedel WJ 8t De Bruin RA (1986). Demonstratieproject Gericht Verkeerstoezicht Snelheidsgedrag op $80 \mathrm{~km}$-wegen. Den Haag: Centrale Politie Verkeers Commissie. ISBN 90 $6807-055-X$

Riedel WJ, Schoenmakers EAJM, O"Hanlon JF (1987) The effects of loratadine alone and in combination with alcohol on acrual driving performance. Institute for drugs, safery and behavior "Maastricht, "The Netherlands. ISBN 90-5147-002-9

Schoenmakers EAJM, Riedel WJ, De Gier J], Van Dijke CPH, Beuman GH, O'Hanlon JF (1987) The effect of terfenadine on the driving proficiency of selected patients. Institute for drugs, safery and behavior, Maastriche, The Netherlands. ISBN 90-5147-001-0

Riedel WI, Quasten R, Hausen C, O'Hanlon JF (1988) A study comparing the hypnotic efficacies and residual effects on actual driving performance of midazolam $15 \mathrm{mg}$, rriazolam $0.5 \mathrm{mg}$, temazepam $20 \mathrm{mg}$ and placebo in shiftworkers on night dury. Institute for drugs, safery and behavior, Maastricht, The Netherlands. ISBN 90-5147-006-1

Riedel WJ, Schoenmakers EAJM, Van Eekelen J, Ostertag J, Wolfs R, O'Hanlon JF (1989) Lormetazepam and Jer-lag. Residual effects upon Flight Performance in a Fokker Friendship Simulator. Institute for drugs, safery and behavior, Mastricht, The Netherlands. ISBN 90 5147-011-8

Riedel WJ, Ramaekers JG, Uiterwijk M, O'Hanlon JF (1990) Higher Doses of Terfenadine and Loratadine Acute and Subchronic Effects on Psychomotor and Actual Driving Performance. Institute for drugs, safety and behawior, Maastricht, The Netherlands. ISBN 90-5147-009-6 